\title{
Handbook T-XIII
}

CIERMMII Women in Science

Medicine and Health Sciences

MaRroQuíN-DE JESÚS, Ángel OLIVARES-RAMIREE, Juan Manuel CRUZ-RAMÍREz, Marisela CRUZ-CARPIO, Luis Eduardo Coordinators 


\section{ECORFAN®}

\section{Coordinators}

MARROQUÍN-DE JESÚS, Ángel. PhD

OLIVARES-RAMÍREZ, Juan Manuel. PhD

CRUZ-RAMÍREZ, Marisela. PhD

CRUZ-CARPIO, Luis Eduardo. BsC

\section{Editor in Chief}

VARGAS-DELGADO, Oscar. PhD

\section{Executive Director}

RAMOS-ESCAMILLA, María. PhD

\section{Editorial Director}

PERALTA-CASTRO, Enrique. MsC

\section{Web Designer}

ESCAMILLA-BOUCHAN, Imelda. PhD

\section{Web Diagrammer}

LUNA-SOTO, Vladimir. PhD

\section{Editorial Assistant}

TREJO-RAMOS, Iván. BsC

\section{Translator}

DÍAZ-OCAMPO, Javier. BsC

\section{Philologist}

RAMOS-ARANCIBIA, Alejandra. BsC

ISBN: 978-607-8695-56-0

ECORFAN Publishing Label: 607-8695

HSW Control Number: 2021-13

HSW Classification (2021): 251021-1301

\section{OECORFAN-México, S.C.}

No part of this writing protected by the Federal Copyright Law may be reproduced, transmitted or used in any form or by any means, graphic, electronic or mechanical, including, but not limited to, the following: Quotations in radio or electronic journalistic data compilation articles and bibliographic commentaries. For the purposes of articles 13, 162,163 fraction I, 164 fraction I, 168, 169,209 fraction III and other relative articles of the Federal Copyright Law. Infringements: Being compelled to prosecute under Mexican copyright law. The use of general descriptive names, registered names, trademarks, or trade names in this publication does not imply, even in the absence of a specific statement, that such names are exempt from the relevant protection in laws and regulations of Mexico and therefore free for general use by the international scientific community. HCE is part of ECORFAN Media (www.ecorfan.org) 


\section{Handbooks}

\section{Definition of Handbooks}

\section{Scientific Objectives}

To support the International Scientific Community in its written production of Science, Technology and Innovation in the CONACYT and PRODEP research areas.

ECORFAN-Mexico, S.C. is a Scientific and Technological Company in contribution to the formation of Human Resources focused on the continuity in the critical analysis of International Research and is attached to the RENIECYT of CONACYT with number 1702902, its commitment is to disseminate research and contributions of the International Scientific Community, academic institutions, agencies and entities of the public and private sectors and contribute to the linkage of researchers who perform scientific activities, technological developments and training of specialized human resources with governments, businesses and social organizations.

To encourage the interlocution of the International Scientific Community with other study centres in Mexico and abroad and to promote a wide incorporation of academics, specialists and researchers to the serial publication in Science Niches of Autonomous Universities - State Public Universities - Federal IES - Polytechnic Universities - Technological Universities - Federal Technological Institutes - Teacher Training Colleges - Decentralised Technological Institutes - Intercultural Universities - S\&T Councils CONACYT Research Centres.

\section{Scope, Coverage and Audience}

Handbooks is a product edited by ECORFAN-Mexico S.C. in its Holding with repository in Mexico, it is a refereed and indexed scientific publication. It admits a wide range of contents that are evaluated by academic peers by the double-blind method, on topics related to the theory and practice of the CONACYT and PRODEP research areas respectively with diverse approaches and perspectives, which contribute to the dissemination of the development of Science, Technology and Innovation that allow arguments related to decision-making and influence the formulation of international policies in the field of Science. The editorial horizon of ECORFAN-Mexico ${ }^{\circledR}$ extends beyond academia and integrates other segments of research and analysis outside that field, as long as they meet the requirements of argumentative and scientific rigour, in addition to addressing issues of general and current interest of the International Scientific Society. 


\section{Editorial Board}

PÉREZ - NERI, Iván. PhD

Universidad Nacional Autónoma de México

SERRA - DAMASCENO, Lisandra. PhD

Fundação Oswaldo Cruz

CANTEROS, Cristina Elena. $\mathrm{PhD}$

ANLIS - Argentina

LERMA - GONZÁLEZ, Claudia. PhD

McGill University

DE LA FUENTE - SALCIDO, Norma Margarita. PhD

Universidad de Guanajuato

MARTINEZ - RIVERA, María Ángeles. PhD

Instituto Politécnico Nacional

SOLORZANO - MATA, Carlos Josué. PhD

Université des Sciencies et Technologies de Lille

TREVIÑO - TIJERINA, María Concepción. PhD

Centro de Estudios Interdisciplinarios

DIAZ - OVIEDO, Aracely. PhD

University of Nueva York

GARCÍA - REZA, Cleotilde. PhD

Universidad Federal de Rio de Janeiro 


\section{Arbitration Committee}

BLANCO - BORJAS, Dolly Marlene. PhD

Instituto Nacional de Salud Pública

NOGUEZ - MÉNDEZ, Norma Angélica. PhD

Universidad Nacional Autónoma de México

MORENO - AGUIRRE, Alma Janeth. PhD

Universidad Autónoma del Estado de Morelos

CARRETO - BINAGHI, Laura Elena. PhD

Universidad Nacional Autónoma de México

TERRAZAS - MERAZ, María Alejandra. PhD

Universidad Autónoma del Estado de Morelos

SÁNCHEZ - PALACIO, José Luis. PhD

Universidad Autónoma de Baja California

RAMÍREZ - RODRÍGUEZ, Ana Alejandra. PhD Instituto Politécnico Nacional

CRUZ, Norma. PhD

Universidad Autónoma de Nuevo León

CARRILLO - CERVANTES, Ana Laura. PhD

Universidad Autónoma de Coahuila

ALEMÓN - MEDINA, Francisco Radamés. PhD

Instituto Politécnico Nacional

BOBADILLA - DEL VALLE, Judith Miriam. PhD

Universidad Nacional Autónoma de México 


\section{Assignment of Rights}

By submitting a Scientific Work to ECORFAN Handbooks, the author undertakes not to submit it simultaneously to other scientific publications for consideration. To do so, the author must complete the Originality Form for his or her Scientific Work.

The authors sign the Authorisation Form for their Scientific Work to be disseminated by the means that ECORFAN-Mexico, S.C. in its Holding Mexico considers pertinent for the dissemination and diffusion of their Scientific Work, ceding their Scientific Work Rights.

\section{Declaration of Authorship}

Indicate the name of 1 Author and a maximum of 3 Co-authors in the participation of the Scientific Work and indicate in full the Institutional Affiliation indicating the Unit.

Identify the name of 1 author and a maximum of 3 co-authors with the CVU number -PNPC or SNICONACYT- indicating the level of researcher and their Google Scholar profile to verify their citation level and $\mathrm{H}$ index.

Identify the Name of 1 Author and 3 Co-authors maximum in the Science and Technology Profiles widely accepted by the International Scientific Community ORC ID - Researcher ID Thomson - arXiv Author ID - PubMed Author ID - Open ID respectively.

Indicate the contact for correspondence to the Author (Mail and Telephone) and indicate the Contributing Researcher as the first Author of the Scientific Work.

\section{Plagiarism Detection}

All Scientific Works will be tested by the PLAGSCAN plagiarism software. If a Positive plagiarism level is detected, the Scientific Work will not be sent to arbitration and the receipt of the Scientific Work will be rescinded, notifying the responsible Authors, claiming that academic plagiarism is typified as a crime in the Penal Code.

\section{Refereeing Process}

All Scientific Works will be evaluated by academic peers using the Double Blind method. Approved refereeing is a requirement for the Editorial Board to make a final decision which will be final in all cases. MARVID® is a spin-off brand of ECORFAN ${ }^{\circledR}$ specialised in providing expert reviewers all of them with PhD degree and distinction of International Researchers in the respective Councils of Science and Technology and the counterpart of CONACYT for the chapters of America-Europe-Asia-Africa and Oceania. The identification of authorship should only appear on a first page, which can be removed, in order to ensure that the refereeing process is anonymous and covers the following stages: Identification of ECORFAN Handbooks with their author occupancy rate - Identification of Authors and Co-authors PLAGSCAN Plagiarism Detection - Review of Authorisation and Originality Forms-Assignment to the Editorial Board - Assignment of the pair of Expert Referees - Notification of Opinion - Statement of Observations to the Author - Modified Scientific Work Package for Editing - Publication. 
The Handbook will offer volumes of selected contributions from researchers who contribute to the scientific dissemination activity of the Colegio de Ingenieros en Energías Renovables de Querétaro A.C. in their areas of research in Medicine and Health Sciences. In addition to having a total evaluation, in the hands of the directors of the Colegio de Ingenieros en Energías Renovables de Querétaro A.C., the quality and timeliness of its chapters, each individual contribution was refereed to international standards (RESEARCH GATE, MENDELEY, GOOGLE SCHOLAR and REDIB), the Handbook thus proposes to the academic community, recent reports on new developments in the most interesting and promising areas of research in the Medicine and Health Sciences.

For future volumes:

http://www.ecorfan.org/handbooks/ 
MARROQUÍN-DE JESÚS, Ángel. PhD

OLIVARES-RAMÍREZ, Juan Manuel. PhD

CRUZ-RAMÍREZ, Marisela. PhD

CRUZ-CARPIO, Luis Eduardo. BsC

Coordinators

\section{CIERMMI Women in Science T-XIII Medicine and Health Sciences Handbooks}




\section{Prologue}

Women in health and medical science It is important to recognize and respect the impact that women have had on scientific evolution. This space provides generous information on recent scientific findings of women in medical and health sciences. It is gratifying to be a participant in the interdisciplinary goal of CIERMMI, which surely intends to consolidate in the future as a transdisciplinary space, the main objective of science. As researchers, our hobby, not our job, is to solve doubts, the "heart of the matter", to give the core answer to a problem by checking and re-checking and reaffirming and demonstrating to the scientific community again and again, if necessary, the veracity of our results. This manual presents a space for discussion and reflection on topics of interest developed by women in science. Owners of a prodigious and exhaustive pen, they take us by the hand explaining molecular and behavioral topics. And so, they take us into the importance of screening tests for human papillomavirus, a common sexually transmitted infection. Three research groups offer us data derived from studies on young university students. In two of them the population is of medical students and they analyze health risk behaviors, emotional state and in another one specifically anxiety during the covid 19 pandemic. Let us remember that doctors look after the health of their patients, but who looks after them? they themselves, hence the importance of emotional well-being for their health and that of others, even in the face of a pandemic. The third study in young university students provides us with data on proinflammatory cytokines: leptin and visfatin associated with obesity. It is worth mentioning that sedentary lifestyles and lifestyle changes lead us to chronic inflammatory states such as obesity, a pathological process that in Mexico presents higher figures than the world average. Another group of innovators discusses how early trauma is a conditioning factor of psychopathologies in adult women; a current argument in vogue that affects the individual and harms not only the family, but also society.

Continuing with the wealth of findings present in the manual, we find the evaluation of physical activity and fitness and sedentary behaviors in perimenopausal women; analysis that addresses different points of the present day, for example, in Mexico there is a greater proportion of women than men and menopausal problems are increasing because the population is aging in a technological era linked to sedentary lifestyles. So much so that aging is also accompanied by an increase in the incidence of neurodegenerative processes such as Parkinson's disease. According to the analysis of our research group, neuroglobin is a promising molecule that protects dopaminergic neurons of the substantia nigra, the main brain area damaged in this pathology and the one in charge of controlling body movement, from death. Thanks to the above, we were able to contribute a grain of sand for the development of research on new adjuvant treatments for this disease. And speaking of processes that occur in the skull, experts explain to us how the growth and development of the craniofacial region and the stomatognathic apparatus (mouth and jaws), which in short helps us to speak, eat, socialize and breathe and therefore a deficit in its development can be catastrophic. As well as ectopic eruption and intercanine distance in children, which is the subject of study by another research team. Finally, and to strengthen this manual, a group of scientists examined the uses and adverse effects of general plant toxicology, transdisciplinary information of great utility, for example, to help justify the use of homeopathy in animals, including the self-styled human hominid primate. After appreciating the wealth of results exposed thanks to the sustained effort of the knowledge makers present, I am certain that it will be of your interest to read the cautious information in this manual. Let's get to work. 


\section{Introduction}

The Colegio de Ingenieros en Energías Renovables de Querétaro A.C., A.C. (CIER-QUERÉTARO), and its chapters of Renewable Energy, Industrial Maintenance, Mechatronics and Computer Science, technical sponsors of the International Interdisciplinary Congress on Renewable Energy, Maintenance, Mechatronics and Computer Science, CIERMMI 2021 has as general objective to establish a space for discussion and reflection on issues related to the areas of: renewable energy, industrial maintenance, mechatronics and computer science with the participation of students, professors, researchers and national and international speakers, promoting the formation and consolidation of research networks. Contributing to provide a space for dissemination and discussion of the presentations of students, graduates, academics and researchers, representatives of various higher education institutions, research centers in our country, as well as educational institutions beyond our borders. Promoting the formation of research networks between different institutions. Offering a space for undergraduate, master's, doctoral and postdoctoral students, in which they can present the progress of the research they carry out in their different educational centers. Providing a space in which study groups and members of academic bodies, linked to the curricular program of renewable energy, industrial maintenance, mechatronics and computer science careers, can present the research work developed within their institution and in collaboration with other national or international educational institutions. Establishing a training space for the attendees, through the development of specific lectures and conferences.

This volume, Women in Science T-XIII-2021 contains 10 refereed chapters dealing with these issues, chosen from among the contributions, we gathered some researchers and graduate students from the 32 states of our country. We thank the reviewers for their feedback that contributed greatly in improving the book chapters for publication in these proceedings by reviewing the manuscripts that were submitted. 
As the first chapter, Terán, Cisneros and Gutiérrez present Knowledge of health personnel about HPV screening tests: a systematic review, as second chapter, González, Meraz, Chávez and González will discuss Health Risk Behaviors and Emotional State of Medical Students as third chapter, Aguilar, Morado, Villada and Tovar present Early trauma as conditioning of psychopathology in adult women, as fourth chapter, Torre, Therio, Carrillo and Mendoza propose Growth and development of the craniofacial region and the stomatognathic apparatus, as the fifth chapter, Villarreal, Enriquez, Hernández and Medina, perform Assessment of physical activity, sedentary behaviors and physical fitness in perimenopausal women, as the sixth chapter, Díaz, González, Uvalle and Mederos develop Pro-Inflammatory cytokines: Leptin and visfatin associated to obesity in young university students, as seventh chapter, Enríquez, Vieyra, Ramos and Trujillo, will discuss Presence of neuroglobin in the substantia nigra in a murine model of parkinson's disease: an immunohistochemical study, in eighth chapter, Martínez, Tavizon, Carlos and Mauricio present Prevalence of ectopic eruption and intercanine distance in children aged 6 to 12 years. Cycle 2019-2020, as the ninth chapter, Caceres, Zárate, Flores and Bustillos, performed Anxiety in medical students, during a COVID-19 pandemic and as the last chapter, González, Hernández, Martínez and González, focus on Overwiev of general plant toxicology uses and adverse effects. 
1 Knowledge of health personnel about HPV screening tests: a systematic review TERÁN-FIGUEROA, Yolanda, CISNEROS-RODRÍGUEZ, Jessica and GUTIÉRREZ-ENRÍQUEZ, Sandra Olimpia

2 Health risk behaviors and emotional state of medical students GONZÁLEZ-RAMÍREZ, Leivy Patricia，MERAZ-MEDINA，Tzintli，CHÁVEZTOSTADO, Mariana Guadalupe and GONZÁLEZ-HEREDIA, Tonatiuh

3 Early trauma as conditioning of psychopathology in adult women AGUILAR-ZAVALA, Herlinda, MORADO-CRESPO, Lisette, VILLADA, Carolina and TOVAR-VEGA, Alma Rosa

4 Growth and development of the craneofacial region and the stomatognátic apparatus TORRE-MARTÍNEZ, Hilda, THERIOT-GIRÓN, María de Carmen, CARRILLOGONZÁLEZ, Roberto and MENDOZA-TIJERINA, Adrian

5 Assessment of physical activity, sedentary behaviors and physical fitness in perimenopausal women

VILLARREAL-SALAZAR, Angelly del Carmen, ENRIQUEZ-REYNA, María Cristina, HERNÁNDEZ-CORTÉS, Perla Lizeth and MEDINA-RODRÍGUEZ, Rosa Elena

6 Pro-inflammatory cytokines: leptin and visfatin associated to obesity in young university students

DÍAZ-BURKE, Yolanda, GONZÁLEZ-SANDOVAL, Claudia Elena, UVALLENAVARRO, Rosario Lizette and MEDEROS-TORRES, Claudia Verónica

7 Presence of neuroglobin in the substantia nigra in a murine model of parkinson's disease: an immunohistochemical study

ENRÍQUEZ-MEJIA, María Guadalupe, VIEYRA-REYES, Patricia, RAMOSBERUMEN, Diana Carolina and TRUJILLO-CONDES, Virgilio Eduardo

8 Prevalence of ectopic eruption and intercanine distance in children aged 6 to 12 100-106 years. Cycle 2019-2020

MARTÍNEZ-ORTIZ, Rosa María, TAVIZON-GARCÍA, Jesús Andrés, CARLOSSÁNCHEZ, María Dolores and CORDERO-CELIBEE, Monserrat

9 Anxiety in medical students, during a COVID-19 pandemic

CACERES-MATTA, Sandra V., ZÁRATE-DEPRAECT, Nikell E., FLORESFLORES, Paula and BUSTILLOS-TERRAZAS, Nora A.

10 Overwiev of general plant toxicology uses and adverse effects GONZÁLEZ-GARCÍA, Arcelia, HERNÁNDEZ-SALAS, Claudia, MARTíNEZORTIZ, Rosa María and GONZÁLEZ.MARTÍNEZ, Lilia 
Chapter 1 Knowledge of health personnel about HPV screening tests: a systematic review

Capítulo 1 Conocimiento del personal de salud sobre pruebas de detección de VPH: una revisión sistemática

TERÁN-FIGUEROA, Yolanda†*, CISNEROS-RODRÍGUEZ, Jessica and GUTIÉRREZ-ENRÍQUEZ, Sandra Olimpia

Universidad Autónoma de San Luis Potosí, School of Nursing and Nutrition, Mexico.

ID $1^{\text {st }}$ Author: Yolanda, Terán-Figueroa / ORC ID: 0000-0002-6118-6393, CVU CONACYT ID: 78254

ID $1^{\text {at }}$ Co-author: Jessica, Cisneros-Rodríguez / ORC ID: 0000-0002-1300-270, CVU CONACYT ID: 864967

ID $2^{\text {nd }}$ Co-author: Sandra Olimpia, Gutiérrez-Enríquez / ORC ID: 0000-0003-2719-766X, CVU CONACYT ID: 215601

DOI: $10.35429 / \mathrm{H} .2021 .13 .1 .10$

*yolandat@uaslp.mx

A. Marroquín, J. Olivares, M. Cruz, L. Cruz. (Coord.) CIERMMI Women in Science TXIII Medicine and Health Sciences. Handbooks-@ECORFAN-México, Querétaro, 2021. 


\begin{abstract}
Objective: to describe the scientific production published between 2009-2019, on the knowledge of health personnel about HPV detection tests.

Methodology: A systematic review based on the PRISMA methodology was developed using three databases selecting studies in inglish and spanish that were published in indexed journals. Out of a total of 2,611 articles, 1,711 written in inglish and 6 in spanish were included in the research. After the analysis of the articles, it was observed that they reflect little knowledge about HPV detection tests by the health personnel involved in the Cervical Cancer Timely Detection Program.

Contribution: The development of molecular tests for HPV detection represents a valuable tool, therefore, it is essential to investigate what knowledge the health personnel in charge of the Cervical Cancer Timely Detection program have in relation to these. This work reaffirms the need for continuous educational programs for health personnel so that they can provide correct information on the prevention of HPV infection and cervical cancer to their patients.
\end{abstract}

\title{
Systematic review, Evidence-based medicine, Knowledge
}

\section{Resumen}

Objetivo: describir la producción científica publicada entre 2009- 2019, referente al conocimiento del personal de salud sobre pruebas de detección de VPH.

Metodología: Se desarrolló una revisión sistemática basada en la metodología PRISMA utilizando tres bases de datos seleccionando estudios en idioma inglés y español que estuvieran publicados en revistas indexadas. De un total de 2,611 artículos, se incluyeron a la investigación 1,711 escritos en inglés y 6 en español. Después del análisis de los artículos se observó que reflejan poco conocimiento sobre pruebas de detección de VPH por parte del personal de salud involucrado en el Programa de Detección Oportuna de Cáncer Cervicouterino.

Contribución: El desarrollo de pruebas moleculares para la detección del VPH representa una herramienta de gran valor, por lo que es esencial investigar qué conocimiento tiene el personal de salud a cargo del programa de Detección Oportuna de Cáncer Cervicouterino en relación con estas. Con este trabajo se reafirma la necesidad de programas educativos continuos para el personal de salud con el fin de que puedan proporcionar información correcta sobre la prevención de la infección por VPH y cáncer cervicouterino a sus pacientes.

\section{Revisión sistemática, Medicina basada en la evidencia, Conocimiento}

\subsection{Introduction}

Cervical cancer (CC) it is the fourth most prevalent in women worldwide, with an estimated 570 thousand new cases in 2018 (Antoni et al., 2016). The International Agency for Research on Cancer (IARC) reports that the global incidence was 13.1 per 100,000 women of all ages (Antoni et al., 2016; Almonte et al., 2019). CC is associated with Human Papillomavirus infection, especially subtypes 16 and 18, and becoming today a major public health problem (Pinho Silveira et al., 2016), it is one of the main causes of death among women in Latin America, a region where most countries have not been successful in implementing cytology-based screening programs at the population level (Health Secretary, 2018).

In recent years, from the development of DNA-based screening tests for Human Papillomavirus (VPH) renewed enthusiasm arose in the scientific community about the possibility of having a technology that overcomes the limitations of cervical cytology and that, in conjunction with HPV vaccination, make something that always seemed like a utopia come true: eliminate CC (Castle, 2012). The development of molecular tests therefore represents a tool of great value, since its contribution to primary screening has been proven, reason why its incorporation is part of the current international guidelines (World Health Organization, 2015; Herrera y Sánchez, 2015). 
The Pan American Health Organization (PAHO) in its guide to incorporating human papillomavirus testing into $\mathrm{CC}$ prevention programs mentions that one of the critical elements in cancer screening programs is the knowledge of health personnel about the technical and operational characteristics of the available tests (Pan American Health Organization / World Health Organization, 2016). Previous work has pointed out the importance of promoting continuing education among health personnel, so that they increase their knowledge and skills regarding CC screening (Gutiérrez-Enríquez et al., 2017; Gutiérrez-Enríquez et al., 2014) and become enablers of it.

Thus, the present work aims to know what the current status is related to the knowledge that health personnel have about the currently available HPV tests through a systematic review. (SR), with the understanding that these are scientific investigations in which the unit of analysis is the original primary studies, in addition to being an essential tool to synthesize the information proven by serious studies, available on a specific topic, increase the validity of the conclusions of individual studies and allow the identification of areas of uncertainty where research is necessary (Ferreira González, 2011).

The guiding research question for conducting this systematic review was: Based on the reported evidence What knowledge does the health personnel who implement the Cervical Cancer Early Detection Program (CCEDP) have in relation to HPV detection tests?

\subsection{Methodology}

The systematic review process was based on the PRISMA methodology (Shamseer et al., 2015), Three databases were selected to search for original articles: PubMed, SCOPUS and Scielo. The period for obtaining the articles was from December 2018 to February 2019. Keywords were used in inglish and spanish: Human Papilloma Virus Detection Tests, Human Papillomavirus Infection, Hybrid Capture, Polymerase Chain Reaction, Early Detection of Cancer, Knowledge of Health Personnel and Health Assessment.

Supported by the Boolean operators "and" and "or", the following algorithms were used for the search: (Human Papilloma Virus Detection Tests) or (Human Papilloma Virus Infection [MeSH Terms]) or (Hybrid Capture) or (Polymerase Chain Reaction) or (Early Detection of Cancer [MeSH Terms]) and (Knowledge of Health Personnel [MeSH Terms]) or Health Assessment). In addition to searching the previous databases, the authors' personal files were reviewed to ensure the capture of all relevant material. Duplicate references were removed before the abstracts of the articles were reviewed.

The inclusion criteria considered were articles published in two languages: inglish and spanish, publications corresponding to the period from January 2009 to December 2019, studies that in their content address the prevention of infection and detection of Human Papillomavirus through the implementation of HPV detection tests, original and/or theoretical research; those publications that describe the knowledge of health personnel about HPV testing. Articles that did not meet the following criteria were excluded: full text access, mention of other methods of prevention of HPV infection such as vaccines, and dissemination on non-scientific internet sites.

The search was carried out by two research analysts, who reviewed the titles and abstracts found, one of them marked papers for recovery, the second analyst audited the search results to verify quality. All marked articles were retrieved in full text, then compliance with the established inclusion criteria was determined. A total of 17 articles were selected in full agreement between the two analysts. The methods and results of each included study were summarized in evidence tables by the first research analyst, who identified and classified potential sources of bias or uncertainty in the studies, writing them in a comment column. The second analyst checked the summary data and assessment of bias for all included studies.

\subsection{Results}

The initial search gave 2,761 documents in the databases, after the elimination of duplicate references, 2,611 remained. By review of titles and abstracts, 69 references were discarded, of which, when applying the eligibility criteria, 4 articles were excluded, to finally include 17 papers in the systematic review. The PRISMA diagram shown in Figure 1.1 shows the number of items that are being considered at each step of the process. 
Figure 1.1 PRISMA flow chart for systematic reviews. Compilation process of the articles included in the systematic review

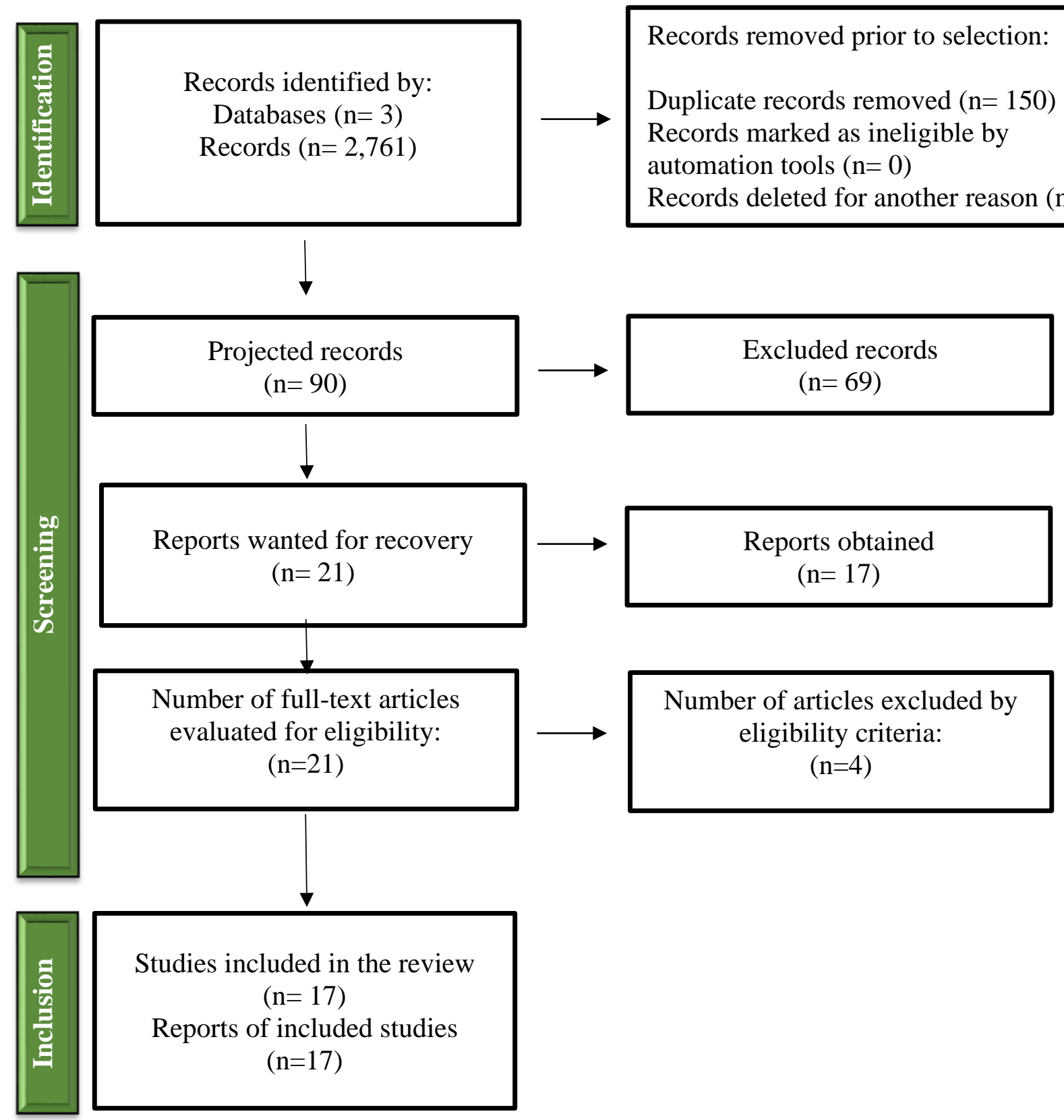

Source: The PRISMA 2020 statement: an updated guideline for reporting systematic reviews

Twelve articles with a quantitative approach, three with a qualitative approach, and two review articles were included in the research, 59\% of the documents were obtained from the PubMed search platform, the year in which the greatest scientific production was obtained was 2017 with $23 \%$, the American Continent was where most of the primary investigations were carried out. These bibliometric data can be seen in Table 1.1.

Table 1.1 Distribution of publications by database, year of publication, origin and journal

\begin{tabular}{|l|rr|r|}
\hline \multicolumn{1}{|c|}{ Papers } & \multicolumn{2}{c|}{$\mathbf{\%}$} & \multicolumn{2}{c|}{ References } \\
& $\mathbf{2 1}$ & $\mathbf{1 0 0}$ & \\
\hline Database & & & \\
\hline Scielo & 6 & 35 & $13,14,15,16,17,29$ \\
\hline Scopus & 1 & 6 & 18 \\
\hline Pubmed & 10 & 59 & $19,20,21,22,23,24,25,26,27,28$ \\
\hline Years of publication & & & $19,20,21$ \\
\hline 2011 & 3 & 18 & 24 \\
\hline 2013 & 1 & 6 & $13,16,28$ \\
\hline 2014 & 3 & 18 & 27 \\
\hline 2015 & 1 & 6 & 22,29 \\
\hline 2016 & 2 & 11 & $14,17,18,23$ \\
\hline 2017 & 4 & 23 & 14 \\
\hline
\end{tabular}




\begin{tabular}{|c|c|c|c|}
\hline 2018 & 3 & 18 & $15,25,26$ \\
\hline \multicolumn{4}{|l|}{ Country of origin of the study } \\
\hline Mexico & 2 & 11 & 13,17 \\
\hline USA & 2 & 11 & 24,28 \\
\hline Chile & 2 & 11 & 15,16 \\
\hline Argentina & 1 & 6 & 18 \\
\hline Brazil & 1 & 6 & 21 \\
\hline Colombia & 1 & 6 & 29 \\
\hline Cameroon & 1 & 6 & 19 \\
\hline Tanzania & 1 & 6 & 20 \\
\hline Greece & 1 & 6 & 22 \\
\hline Ireland & 1 & 6 & 26 \\
\hline Italy & 1 & 6 & 23 \\
\hline New Zealand & 1 & 6 & 25 \\
\hline Australia & 1 & 6 & 27 \\
\hline South America & 1 & 6 & 14 \\
\hline \multicolumn{4}{|l|}{ Journal } \\
\hline Salud pública de México & 2 & 11 & 13,15 \\
\hline Salud colectiva & 1 & 6 & 17 \\
\hline Revista Médica Chile & 1 & 6 & 16 \\
\hline Cadernos de saúde pública & 1 & 6 & 18 \\
\hline Revista Salud Pública & 1 & 6 & 29 \\
\hline Colombiana de obstetricia y ginecología & 1 & 6 & 14 \\
\hline BMC Women's Health & 1 & 6 & 19 \\
\hline African Health Sciences & 1 & 6 & 20 \\
\hline Aust Fam PHISYCIAN & 1 & 6 & 27 \\
\hline Prenvention Medicine & 1 & 6 & 24 \\
\hline PLOS One & 2 & 11 & 25,26 \\
\hline European Journal of Cancer Prevention & 2 & 11 & 22,23 \\
\hline Asian Pacific Journal Cancer Prevent & 1 & 6 & 21 \\
\hline The Oncologist & 1 & 6 & 28 \\
\hline
\end{tabular}

Source: Own elaboration

Scientific evidence shows an area of opportunity in the training of personnel who implement the CCEDP, due to the need to increase knowledge in: HPV counseling, testing, HPV infection, its link to $\mathrm{CC}$, the usefulness of the HPV test in screening, as well as the new guidelines of the program. A summary of these needs is found in Table 1.2.

Table 1.2 Articles referring to the knowledge of the health personnel that implement the CCEDP

\section{Reference}

León Maldonado L, Allen Leigh B, Lazcano Ponce E. Counseling in the detection of HPV as a cervical cancer screening test: a qualitative study on the needs of women in Michoacán, Mexico. 2014.

Maya-Salazar JJ, Rojas-Zumaran VA. Human papillomavirus research trends in Latin American compared to high income countries. 2017

Ferreccio C. New strategies for the prevention and control of cervical cancer in Chile. 2018

\section{Objective}

Explore the information and counseling needs of a group of Mexican women when using the human papillomavirus test.

Reflect on trends in Human Papillomavirus research in Latin America compared to high-income countries.

Discuss cervical cancer, HPV, the CC control program and propose alternatives for Chile

\section{Resulted}

The personnel that implement the program for the timely detection and control of CC urgently need training and support materials regarding HPV counseling and testing, on its etiology and link with the CC, as well as on the usefulness of the HPV test within the screening and the new guidelines of the program.

HPV prevention techniques and
strategies are changing over time, and health professionals involved in prevention programs for $\mathrm{CC}$ should increase their knowledge related to these new technologies and interventions. For educational objectives to be successful, a teaching character is required by health personnel.

The main challenge is resistance to innovation by those responsible for public health, who are called to lead this process. 

\begin{tabular}{|l|}
\hline Léniz Martelli J, Van de Wyngard \\
V, Lagos M, Barriga MI, Puschel \\
Illanes K, Ferreccio Readi C. Early \\
detection of cervical cancer in \\
Chile: time for change. 2014
\end{tabular}

Mendoza González Z. Screening program for cervical cancer: public policies and experiences of actors who implement the program in the state of Veracruz, Mexico. 2017
Review the situation of the $\mathrm{CC}$ in Chile considering new prevention strategies and national and international evidence, to propose innovations in the national prevention strategy.

Analyze how the Program for the Detection of Cervical Cancer in a dysplasia clinic and some health centers in the state of Veracruz, Mexico

Updating providers and the population regarding this disease are key aspects to achieve a modification of the program. To minimize adverse reactions, HPV testing should be accompanied by education on the natural history of the disease and the high prevalence of infection in the population.

In health centers, the program is run by nurses, and many are not trained, take shots outside the proper zone. It is essential to have sensitive personnel capable of carrying out their practice with cultural relevance, only by knowing the explanatory models of the different actors will it be possible to try to establish bridges between them.

Curotto M, Borletta P, Paolino M, Arrossi S. Health agents' perspective on the incorporation of self-collected samples in HPV screening programs. 2017

Analyze the perception that health agents have about offering the self-take of HPV test to women and the degree of agreement of the agents to incorporate it into their daily tasks.

McCarey C, Pirek D, Marie Tebeu P, Boulvain M, Sama Doh A, Petignat P. Awareness of HPV and cervical cancer prevention among Cameroonian healthcare workers. 2011

Urasana M, Darj E. Knowledge of cervical cancer and screening practices of nurses at a regional hospital in Tanzania. 2011

Determining nurses' awareness of cervical cancer and their own screening practices in a hospital in Tanzania. cervical cancer prevention among health workers in Cameroon.

Health workers who received special training to explain to women how to perform self-taking, less frequently indicated the existence of problems in the offer due to lack of training.

Knowledge about the etiology and detection of $\mathrm{CC}$ was lower among nurses/midwives. For successful screening programs, all healthcare workers should understand the causal relationship between HPV and CC, as well as the importance of detection as a preventive measure.

The need for additional education regarding the $\mathrm{CC}$ is reflected in the dissatisfaction of the nurses with its knowledge. The need for additional education regarding the $\mathrm{CC}$ is reflected in the dissatisfaction of the nurses with its knowledge.

Melo Villar L, Dutra Rabello A, To assess the knowledge about HPV Salete de Paula V. Evaluating among seventy-nine professionals who Knowledge about Human completed a questionnaire on diagnosis, Papillomavirus Infection among transmission, symptoms, prevention, Brazilian Health Professionals. 2011 and general information.

Farazi PA Hadji P, Roupa Z. Awareness of human papilloma virus and cervical cáncer prevention among Greek female healthcare workers Gynecologists and human papillomavirus DNA testing: exploring knowledge, attitudes, and practice in Italy. 2017

Caglioti C, Pileggi C, Nobile CGA, Pavia M. Gynecologists and human papillomavirus DNA testing: exploring knowledge, attitudes, and practice in Italy. 2017

Rolanda KB, Benard VB, Greek A, Hawkins NA, Manninen D, Saraiya M. Primary care provider practices and beliefs related to cervical cancer screening with the HPV test in Federally Qualified Health Centers. 2013
To assess the level of awareness and attitudes of Greek health workers on cervical cancer and HPV prevention.

To examine the knowledge, attitudes, and behavior of gynecologists in terms of human papillomavirus (HPV) DNA testing as a primary screening tool for cervical cancer.

Assess primary care provider practices, beliefs, enablers, and barriers to using pooled testing and extending screening intervals among low-income women.
General knowledge about HPV was high, as most of them recognized that it is sexually transmitted, the disease may be asymptomatic, or warts may be present on the genitals. However, many professionals did not know that there are variants of HPV and that not all are oncogenic. These data show that more educational programs are needed, especially on the prevention of HPV infection in Brazil.

The results show that there are gaps in women's knowledge on this topic, especially in terms of the latest information on $\mathrm{CC}$ prevention through HPV testing and vaccination. In fact, only $80 \%$ of the women surveyed knew about the existence of HPV tests.

Although the use of the HPV DNA test is widespread among Italian gynecologists who test for CC, there is a lack of standardization of practices according to current guidelines.

Most primary care providers believe that the joint test is good and beneficial, yet in practice, less than half routinely used the HPV test for screening. The literature has long reported barriers to the implementation of preventive health services evidence-based and cancer screening at the patient, provider, clinic, and health system level. 


\begin{tabular}{|c|c|c|}
\hline $\begin{array}{l}\text { Sherman SM, Bartholomew K, } \\
\text { Denison HJ, Patel H, Moss EL, } \\
\text { Douwes J, et al. Knowledge, } \\
\text { attitudes and awareness of the } \\
\text { human papillomavirus among health } \\
\text { professionals in New Zealand. } 2018\end{array}$ & $\begin{array}{l}\text { Compare what nurses and smear takers } \\
\text { understand about HPV, if they feel well- } \\
\text { informed and assess any training needs, } \\
\text { they may identify. }\end{array}$ & $\begin{array}{l}\text { The need for education indicated by } \\
\text { knowledge scores was reinforced by the } \\
\text { fact that more than a third of } \\
\text { respondents disagreed that they felt } \\
\text { adequately informed about HPV and } \\
\text { that being adequately informed and } \\
\text { feeling confident in answering patients' } \\
\text { questions were associated with } \\
\text { knowledge. Some of the respondents } \\
\text { made suggestions for training. }\end{array}$ \\
\hline $\begin{array}{l}\text { McSherry LA, O'Leary E, } \\
\text { Dombrowski SU, Francis JJ, Martin } \\
\text { CM, O'Leary JJ, et al. Which } \\
\text { primary care practitioners have por } \\
\text { human papillomavirus (HPV) } \\
\text { knowledge? A step towards } \\
\text { informing the development of } \\
\text { professional education initiatives. } \\
2018\end{array}$ & $\begin{array}{l}\text { Investigate knowledge of HPV and } \\
\text { associated factors, among general } \\
\text { practitioners and nurse practitioners. }\end{array}$ & $\begin{array}{l}\text { The percentage of correct answers to a } \\
\text { similar question in the current study was } \\
\text { higher, but a third of the professionals } \\
\text { did not answer correctly. The } \\
\text { similarities in the findings of these } \\
\text { studies suggest that the professionals in } \\
\text { many settings may be unclear about } \\
\text { these aspects of HPV. }\end{array}$ \\
\hline $\begin{array}{l}\text { Munro A, Codde J, Semmens J, } \\
\text { Leung Y, Spilsbury K, Williams V, } \\
\text { et al. Utilization of co-testing } \\
\text { (human papillomavirus DNA testing } \\
\text { and cervical cytology) after } \\
\text { treatment of CIN: a survey of -GPs' } \\
\text { awareness and knowledge. } 2015\end{array}$ & $\begin{array}{l}\text { Understand if the joint test (human } \\
\text { papillomavirus DNA test and cervical } \\
\text { cytology) is fully used by general } \\
\text { practitioners. }\end{array}$ & $\begin{array}{l}\text { Study results and qualitative comments } \\
\text { suggest that there is a clear need for } \\
\text { further education and promoting the use } \\
\text { of high-risk HPV DNA testing as a } \\
\text { management pathway for doctors. }\end{array}$ \\
\hline $\begin{array}{l}\text { Townsend JS, Stormo AR, Roland } \\
\text { KB, Buenconsejo Lum L, White S, } \\
\text { Saraiya M. Current Cervical Cancer } \\
\text { Screening Knowledge, Awareness, } \\
\text { and Practices Among U.S. Affiliated } \\
\text { Pacific Island Providers: } \\
\text { Opportunities and Challenges. } 2014\end{array}$ & $\begin{array}{l}\text { Assess knowledge, beliefs, practices, } \\
\text { and perceived barriers regarding routine } \\
\text { cervical cancer screening. }\end{array}$ & $\begin{array}{l}\text { Although screening for CC is a priority } \\
\text { in clinical practice, beliefs about annual } \\
\text { screening, associated costs and different } \\
\text { levels of support for alternative } \\
\text { screening tests raises barriers for } \\
\text { providers. Further exploration of the use } \\
\text { of sustainable, low-cost, and evidence- } \\
\text { based screening technologies is } \\
\text { warranted, as well as emphasizing } \\
\text { timely follow-up of all positive cases. }\end{array}$ \\
\hline $\begin{array}{l}\text { Rodríguez Feria P, Hernández } \\
\text { Flores LJ, Rodríguez Feria D. } \\
\text { Knowledge, attitudes and practices } \\
\text { of prevention for cervical cancer and } \\
\text { breast cancer among medical } \\
\text { students. } 2016\end{array}$ & $\begin{array}{l}\text { Evaluate the knowledge, attitudes, and } \\
\text { practices of medical students to } \\
\text { prevention of breast neoplasia and } \\
\text { cervical neoplasia, likewise, the study } \\
\text { will provide recommendations to } \\
\text { improve the curriculum of public health } \\
\text { classes. }\end{array}$ & $\begin{array}{l}\text { In order to perform early detection in } \\
\text { cancer, skills must be improved, } \\
\text { knowledge and training regarding } \\
\text { induced demand, active community and } \\
\text { institutional search and reduction of lost } \\
\text { opportunities related to public health. } \\
\text { Additionally, it is important to improve } \\
\text { clinical practice related to Pap smears } \\
\text { and training on clinical guidelines and } \\
\text { protocols for these types of cancer. }\end{array}$ \\
\hline
\end{tabular}

Source: Secondary

\subsection{Discussion}

Since its introduction, HPV detection tests have been the subject of multiple articles of scientific dissemination, currently most of this production is in developing countries because the incidence and mortality from CC continue to occupy the first places in women (World Health Organization, 2015). In Latin America, most countries have not been successful in implementing cytology-based screening programs at the population level (Jeronimo et al., 2016; Secretaría de Salud, 2018). In Mexico, most of the research is concentrated due to the increase in HPV infections in women, which impacts an incidence of CC of 23.3 for each 100000 inhabitants per year (Flores Miramontes et al., 2015; Martínez Portilla et al., 2016).

Despite the advantages of using molecular HPV detection tests, for example, that they are automated, have high reproducibility and allow handling of large volumes of samples at the same time (Torné Bladé et al., 2014), the success in reducing the cases of CC consists in the training that health personnel have around these. 
This systematic and integrative review of the literature synthesized the information and observed the need for training of the personnel that implements the CCEDP, as shown by a study carried out in 2013 by Mojahed and Karimi Zarchi, they found that the minority of nurses surveyed were aware of HPV infection and how it can cause abnormal Pap test results (Mojahed et al., 2013). Hernández and Salinas in 2018 in the same way, they mention as a conclusion in their study carried out on the perception of health personnel about the CCEDP, the felt need to reinforce career plans and programs in both nursing and doctors (Hernández y Salinas, 2018), in order to develop skills and competencies based on scientific knowledge for the use of medical terms, search for information and interest in the continuous updating of future workers in the health area.

In Mexico there is a legislature for this, as established by the Official Mexican Standard 014 for the prevention, detection, diagnosis, treatment, control and epidemiological surveillance of cervical cancer that indicates the training and updating of professional health personnel, to guarantee a quality service, with the periodicity that each institution determines, adapting the assignment of activities to the professional and technical characteristics, as well as to their level of responsibility (Official Journal of the Federation, 2007).

However, as the scientific literature shows, currently, the health personnel who implement the CCEDP is lacking in knowledge for the implementation of HPV testing. This is undoubtedly of the utmost importance because, the lack of preparation in health personnel is reflected in the level of knowledge about HPV in the population, This is shown by studies carried out in adolescents and young university students, who found low knowledge in general regarding HPV, which contributes to poor health (Contreras Gonzáles et al., 2017; Perrotte et-al., 2012) promoting in this way that the objectives of the CCEDP are not fulfilled.

\subsection{Conclusions}

What this systematic review as scientific evidence sign is that the personnel evaluated when measuring their knowledge about HPV prevention usually show low levels, despite being health professionals, where most passed subjects during their careers such as viral infections and malignancies. Given the above, the need for continuous educational programs is reaffirmed, in order to allow health personnel to be trained to provide correct information on HPV prevention to their patients.

\subsection{References}

Almonte, M., Murillo, R., Sánchez, G.I., Jerónimo, J, Salmerón, J., Ferrecio, C., Lazcano-Ponce, E., Herrero, R. (2010). New paradigms and challenges in cervical cancer prevention and control in Latin America. Salud Publica de México, 52(6), 544-59. doi: https://doi.org/10.1590/S003636342010000600010

Antoni, S., Soerjomataram, I., Møller, B., Bray, F., Ferlay, J. (2016). An assessment of GLOBOCAN methods for deriving national estimates of cancer incidence. Bull World Health Organ, 94(3),174-84. doi: https://doi.org/10.2471/BLT.15.164384

Castle, P.E., de Sanjosé, S., Qjao, Y., Belinsone, J.L., Lazcano-Ponce, E., Kinney, W. (2012). Introduction Human Papillomavirus DNA screening in the world: 15 years of experience. Vaccine. 30(suppl 5), F117-122. doi: https://doi.org/10.1016/j.vaccine.2012.05.071

Contreras Gonzáles, R., Magaly Santana, A., Jiménez Torres, E., Gallegos Torres, R., Xeque Morales, Á., Palomé Vega, G., García-Aldeco, A., Perea-Ortíz, G. (2017). Level of knowledge on the human papilloma virus among adolescents. Enfermería Universitaria. 14 (2). doi: https://doi.org/10.1016/j.reu.2017.01.002

Official Journal of the Federation (2007). Official Mexican Standard NOM014-SSA2-1994. For the prevention, detection, diagnosis, treatment, control and epidemiological surveillance of cervical cancer. Recovered from: http://www.salud.gob.mx/unidades/cdi/nom/m014ssa294.pdf. 
Ferreira González, I., Urrútia, G., Alonso-Coello, P. (2011). Systematic reviews and meta-analysis: conceptual bases and interpretation. Revista Española de Cardiología. 64(8),688-696. Recovered from: https://www.revespcardiol.org/es-revisiones-sistematicas-metaanalisis-bases-conceptuales-articuloS0300893211004507

Flores Miramontes, M., Torres Reyes, L., Aguilar Lemarroy, A., Vallejo Ruiz, V., Piña Sánchez, P., Cortés Gutiérrez, E., Reyes Leyva, J., Jave Suárez, L.F. (2015). HPV genotypes prevalence in México and worldwide detected by Linear Array. Revista Médica del Instituto Mexicano del Seguro Social. 53 (Suppl 2), 122-130. doi: https://www.medigraphic.com/cgibin/new/resumen.cgi?IDARTICULO=62978

Gutiérrez-Enríquez, S.O., Gaytán-Hernández, D, Zamarripa-Leyva, J.M, Terán-Figueroa, Y. (2014). Performance of health staff in Papanicolauo test: theoretical knowledge and practical implementation. Ginecología y Obstetricia de México. 82, 296-306. Recovered from: https://www.ncbi.nlm.nih.gov/pubmed/24701856

Gutiérrez-Enríquez, S.O., Mendoza-Donjuan, L.F., Terán-Figueroa, Y., Gaytán-Hernández, D., OrosOvalle, C., Díaz-Oviedo, A. (2017). Impact of Applying a Learning Strategy to Improve the Sample Quality in Cervical Screening in Nursing Staff in Social Service. Investigación y Educación en Enfermería. 35(3), 340-347. Recovered from: http://www.scielo.org.co/scielo.php?script=sci_arttext\&pid=S0120-53072017000300340

Hernández Márquez, C.I., Salinas Urbina, A.A. (2018). Health personnel perception of a cervical cancer early detection program. Enfermería Universitaria. 15 (2). doi: https://doi.org/10.22201/eneo.23958421e.2018.2.65170

Herrera, Y.A., Sánchez, P.P. (2015). History of the development of screening tests for cervical cancer. Revista Médica del Instituto Mexicano del Seguro Social. 53(6), 670-677. Recovered from: https://www.ncbi.nlm.nih.gov/pubmed/26506482

Jeronimo, J., Holme, F., Slavkovsky, R., Camel, C. (2016). Implementation of HPV testing in Latin America. Journal of Clinical Virology. 76, 69-73. doi: 10.1016/j.jcv.2015.11.035

León Maldonado, L., Allen Leigh, B., Lazcano Ponce, E. (2014). Counseling for HPV detection when used to screen for cervical cancer: a qualitative study on the needs of women from Michoacan, Mexico. $\begin{array}{llllll}\text { Salud Pública } & \text { de } & \text { México. } & \text { (5), } & 519-527 . & \text { doi: }\end{array}$ http://www.scielo.org.mx/scielo.php?script=sci_arttext\&pid=S0036-36342014000500019

Martínez Portilla, R.J., López Velázquez, J.L., Martínez Rojas, G.C., Aguilar Villagómez, M.I., Torre Rendón, F.E., Villafán Bernal, J.R. (2016). Prevalence of HPV high-risk serotypes detected by PCR in patients with normal cervical cytology at the Hospital Regional Adolfo López Mateos, ISSSTE. Ginecología y Obstetricia de México. 84 (9), 556-561. https://www.medigraphic.com/cgibin/new/resumen.cgi?IDARTICULO=73210

Mojahed S, Karimi Zarchi M, Bokaie M, Salimi T. (2013). Attitude and knowledge of Iranian famele nurses about Human Papilomavirus infection and cervical cáncer: a cross sectional survey. Journal of $\begin{array}{lllll}\text { Preventive } \quad \text { Medicine } & \text { Hygiene. } & \text { 187-190. }\end{array}$ https://www.ncbi.nlm.nih.gov/pmc/articles/PMC4718374/

Pan American Health Organization / World Health Organization. (2016). Incorporation of the human papillomavirus test in cervical cancer prevention programs. Handbook for managers of health programs.Washington D.C. Recovered from: http://iris.paho.org/xmlui/handle/123456789/31223

Perrotte, N., Gomez, A., Mason, G., Stroup, D. (2012). An Assessment of Knowledge, Attitudes and Behaviour Regarding Human Papillomavirus. West Indian Medical Journal. 61 (19), 58-63. doi: https://www.ncbi.nlm.nih.gov/m/pubmed/22808567/ 
Pinho Silveira, N.S., Moreira Vasconcelos, C.T., Oliveira Nicolau, A.I., Batista Oriá, M.O., Neyva da Costa Pinheiro, P., Bezerra Pinheiro, A.K. (2016). Knowledge, attitude and practice about the colpocytological test and its relationship with female age. Revista Latino-Americana de Enfermagem, 24, e2699. doi: http://dx.doi.org/10.1590/1518-8345.0700.2699.

Health Secretary. (2018). Prevention, detection, diagnosis and treatment of cervical cancer precursor lesions in the first and second level of care. Mexico. Recovered from: https://cenetec-difusion.com/gpcsns $/$ ? $=525$

Shamseer, L., Moher, D., Clarke, M., Ghersi, D., Liberati, A., Petticrew, M., Shekelle, P., Stewart, L.A., the PRISMA-P Group. (2015). Preferred reporting ítems for systematic review and meta-analysis protocols (PRISMA-P) 2015: elaboration and explanation. BMJ. 349, g7647 doi: https://doi.org/10.1136/bmj.g7647

Torné Bladé, A., Pino Saladrigues, M., Cusidó Gimferrer, M., Alamada Quitllet, F., Andia Ortiz, D., Castellsagué Piqué, X., Cortés Bordoy, J., Granados Carreño, R., Guarch Troyas, R.M., LLoveras Rubio, B., Lubrano Rosales, A., Martínez-Escoriza, J.C., Ordi Majà, J., Puig-Tintoré, L.M., Ramírez Mena, M., de Sanjosé Llongueras, S., Torrejón Cardoso, R., Bosch J., X., Piris Pinilla, M.A., Rodríguez Costa, J., Comino Delgado, R., Lailla Vicens, J.M., Ponce Sebastià, J. (2014). Cervical cancer screening guide in Spain, 2014. Revista española de patología. 47 (Supl 1), 1- 43. doi: http://www.elsevier.es/es-revistaprogresos-obstetricia-ginecologia-151-pdf-S0304501314730687

World Health Organization (WHO). (2015). Comprehensive control of cervical cancer. Essential practice guides. Second edition. Retrieved from: http://iris.paho.org/xmlui/bitstream/handle/123456789/28512/9789275318799_spa.pdf?ua=1 


\section{Chapter 2 Health risk behaviors and emotional state of medical students}

Capítulo 2 Conductas de riesgo para la salud y el estado emocional de los estudiantes de medicina

GONZÁLEZ-RAMÍREZ, Leivy Patricia'†*, MERAZ-MEDINA, Tzintli”, CHÁVEZ-TOSTADO, Mariana Guadalupe"" and GONZÁLEZ-HEREDIA, Tonatiuh"'"

'School of Medicine and Health Science, Campus Guadalajara, Tecnólogico de Monterrey.

"Department of Basic Science of Health, University Center of South, Universidad de Guadalajara.

"'Department of human reproduction, growth and child development, University Center of Health Science, Universidad de Guadalajara.

"'"Department of Biomedical Sciences, University Center of Tonalá, Universidad de Guadalajara.

ID $1^{\text {st }}$ Author: Leivy Patricia, Gonález-Ramírez / ORC ID: 0000-0002-2952-2836, CVU CONACYT ID: 426755

ID $1^{\text {st }}$ Co-author: Tzintli, Meraz-Medina / ORC ID: 0000-0002-2062-8618, CVU CONACYT ID: 131300

ID $2^{\text {nd }}$ Co-author: Mariana Guadalupe, Chávez-Tostado / ORC ID: 0000-0002-2308-6105, CVU CONACYT ID: 509855

ID $3^{\text {rd }}$ Co-author: Tonatiuh, González-Heredia / ORC ID: 0000-0003-4089-5462, CVU CONACYT ID: 386340

DOI: $10.35429 /$ H.2021.13.11.19

L. González, T. Meraz, M. Chávez and T. González

* tzintli.meraz@cusur.udg.mx

A. Marroquín, J. Olivares, M. Cruz, L. Cruz. (Coord.) CIERMMI Women in Science TXIII Medicine and Health Sciences. Handbooks-@ECORFAN-México, Querétaro, 2021. 


\begin{abstract}
The promotion of healthy lifestyles amongst medical students is important in reducing alterations in their emotional state and the creation of healthier habits which, when adopted at this stage, could influence the promotion of better lifestyles for their patients. This current study intends to evaluate health risk behaviors and their relationship with the emotional state in medical students. An analytical crosssectional study was carried out, evaluating 173 students of a public university between January and March of 2019, evaluating anxiety (Beck Anxiety Inventory, BAI), depression (Beck Depression Inventory, BDI-II), alcohol and nicotine dependence (Alcohol Use Disorders Identification Test, AUDIT, Fagerström Physical Nicotine Dependence), and Body mass index (BMI). sociodemographic and clinical data was collected through an interview. An association was found between anxiety and a sedentary $(\mathrm{p}$ $=0.01, \mathrm{OR}=0.446, \mathrm{CI}=0.24-0.83)$, and depression with alcohol consumption $(\mathrm{p}=0.005, \mathrm{OR}=2.972$, $\mathrm{CI}=1.36-6.49)$. During college students face various demands that can unleash alterations in their emotional and physical state, the results obtained in this study allow the development of intervention programs against risky behaviors and promote healthy lifestyles.
\end{abstract}

\title{
Lifestyles, Emotional state, Medical students
}

\section{Resumen}

La promoción de estilos de vida saludables entre estudiantes de medicina es importante para reducir riesgos de enfermedades y alteraciones del estado emocional. Este estudio pretende evaluar conductas de riesgo para la salud y su relación con el estado emocional en estudiantes de medicina. En un estudio analítico transversal, se evaluó 173 estudiantes de una Universidad pública en el periodo de enero - marzo del 2019, considerando ansiedad (Beck Anxiety Inventory, BAI), depresión (Beck Depression Inventory, BDI-II), dependencia al alcohol (Alcohol Use Disorders Identification Test, AUDIT), a nicotina (Fagerström Physical Nicotine Dependence) e índice de masa corporal (IMC). Mediante entrevista se recabaron datos clínicos y sociodemográficos. Los resultados del estudio mostraron asociación entre ansiedad y sedentarismo $(\mathrm{p}=0,01, \mathrm{OR}=0,446, \mathrm{CI}=0,24-0,83)$, y depresión con consumo de alcohol $(\mathrm{p}=0,005, \mathrm{OR}=2,972, \mathrm{CI}=1,36-6,49)$. Se observa una diferencia entre géneros al considerar el estado emocional, donde las mujeres tienen mayor prevalencia de ansiedad y depresión. Durante la universidad los estudiantes enfrentan diversas exigencias, que pueden desencadenan alteraciones del estado emocional y físico, los resultados obtenidos en este estudio permitirán elaborar programas de intervención contra conductas de riesgo y promover estilos de vida saludables.

\section{Estilos de vida, Estado emocional, Estudiantes de medicina}

\subsection{Introduction}

Inadequate lifestyles have been associated with the development of mental disorders such as stress and anxiety, which represent some of the main causes of death around the world (Alzahrani et al., 2019). Recent data demonstrates that these diseases have begun to affect younger and younger generations (Almutairi et al., 2018). Encouraging the inclusion of healthy behaviors within the lifestyle, such as physical activity, eating a healthy diet, avoiding the use of substances such as tobacco or drugs and having a restful sleep, can promote the health and well-being of these individuals (Lolokote, Hidru, \& Li, 2017; Pacheco, Santos-Silva, Gordia, de Quadros, \& Petroski, 2014). However, the manner in which an individual's lifestyle is practiced is very much influenced by the culture, beliefs and motivation of those individuals (Rodriguez-Gazquez, Chaparro-Hernandez, \& Gonzalez-Lopez, 2016).

Anxiety and depression are the psychological disorders with the greatest impact upon public health and which have also been associated with an unhealthy lifestyle (Sharma et al., 2016). For example, ample evidence has shown the benefits of physical activity for potentially avoiding or reducing the symptoms of anxiety and depression (Hyakutake et al., 2016, Velten, Bieda, Scholten, Wannemuller, \& Margraf, 2018). Sedentarism, smoking and alcohol consumption have also been associated with the development of depression and anxiety (Rao, Shah, Jawed, Inam, \& Shafique, 2015, Saneei et al., 2016). University students are at a stage in their lives which involve certain changes to their lifestyles, the development of new social networks and greater autonomy in their self-care (Almutairi et al., 2018). 
These changes are often influenced by social factors, such as income or interpersonal relationships. This may be the period in which many adolescents incorporate risk behaviors such as alcohol, tobacco, drugs, risk sexual behavior, sedentary lifestyle and poor eating and sleep habits, among others that could increase the amounts of stress (Almutairi et al., 2018; Cezaretto, Ferreira, Sharma, Sadeghirad, \& Kolahdooz, 2017; Nogueira et al., 2018). In addition, risk behaviors which are initiated at this stage can be perpetuated throughout adulthood (Kim, 2018, Lolokote et al., 2017). In a study conducted by Rao (2015) it was observed that adolescents who had four or more risk behaviors were also twice as likely to have associated mental disorders.

For these reasons, it is important to evaluate health behaviors in university students, to detect the main problems and be able to implement health promotion programs in this population (Lolokote et al., 2017), especially when we take into account that these individuals are at a stage where the acquisition and maintenance of healthy lifestyle habits is critical (Cezaretto et al., 2017). This is particularly important considering that these medical students will be responsible for promoting such healthy behaviors in the future (Zarrazquin et al., 2014). Studies have shown that the practice of healthy behaviors amongst physicians also has an impact upon the attitudes and motivations of their patients towards preventive actions and the adoption of healthy lifestyles (Yu et al., 2015). The objective of this study was to evaluate behaviors which pose a potential risk to health and to know if they are in any way related to the emotional state, particularly to the presence of anxiety and depression amongst medical students.

\subsection{Methods}

\subsubsection{Study design and participants}

An analytical cross-sectional study was carried out between January and March of 2019. A representative sample of 173 public university students was used out of a population of 1,000 students, with a margin of error of $10 \%$ and a confidence level of $99 \%$. Both men and women were included, from all grades of medical school, with ages between 18 and 30 years. Students with previous diagnosis of anxiety, depression or some other psychiatric disorder were not included, nor those who were receiving any medical treatment.

\subsubsection{Instruments}

The sociodemographic and clinical data of the patients was collected through an interview. In addition, the weight and height of the students were measured to calculate the Body Mass Index (BMI).

The "Beck Anxiety Inventory (BAI)" was used to measure anxiety. This tool consists of 21 items, with a score ranging between 0 and 63 . A score between 0 and 7 corresponds to a normal level of anxiety while scores of 8 to 15,16 to 25 and 26 to 63 correspond to mild, moderate and severe levels of anxiety, respectively. It has a reliability of $\alpha=0,83$ (Robles, Varela, Jurado, \& Páez, 2001).

The Beck Depression Inventory (BDI-II) was used to measure depression. This tool consists of 21 items with four response options each. It has been validated in the Mexican population, and has a satisfactory internal consistency, both for the general factor $(\alpha=0,9)$, and for each of the factors with 0,85 in the cognitive-affective dimension and 0,78 in the somatic-motivational dimension (AcostaRodríguez, Rivera-Martínez, \& Pulido-Rull, 2011, González, Reséndiz-Rodríguez, \& Reyes-Lagunes, 2015).

The "Alcohol Use Disorders Identification Test (AUDIT)" was used to measure behaviors which may have an impact on health. This tool contains 10 questions that identify the use of alcohol in the last 12 months. Questions 4-6 identify the symptoms of alcohol dependence while questions 7-10 explore the negative consequences associated with alcohol consumption. Each question has three to five possible answers that can give a maximum score of 40 points. Based on the scores, an abstemious or low risk person can be identified by obtaining a score between 0 to 7 , while 8 to 12 points indicates a person with risky use or alcohol abuse and 13 to 40 points indicates probable dependence. AUDIT has been tested in the Mexican population with a sensitivity of $90 \%$ and specificity of $94 \%$. Different studies have validated it in adolescent populations, which report it as the best instrument for the identification of consumption and problems or disorders related to alcohol use in this type of population (Medina-Mora, Castro, Campillo-Serrano, \& Gómez-Mont, 1981; Mora-Rios \& Natera, 2001). 
On the other hand, the Fagerström Physical Nicotine Dependence Scale was also used. This tool contains six questions which consider the number of cigarettes consumed, the compulsion to use and abstinence. The results are established on a scale of 0 to 10 points. The tool categorizes an individual into 1 of 3 groups according to the score obtained. The physical dependence upon nicotine is categorized into mild $0-3$ points, moderate $4-7$ points, and severe $8-10$ points. This tool has demonstrated an internal consistency between 0,55 and 0,74 , with a standard of 0,72 , and stability around 0,58 and 0,91 in different samples (Moreno-Coutiño \& Villalobos-Gallegos, 2017, Paz-Ballesteros, Zavala-Arciniega, GutiérrezTorres, Ponciano-Rodríguez, \& Reynales-Shigematsu, 2019).

Finally, physical activity was considered to be adequate when an individual reported at least 30 minutes of exercise a day.

\subsubsection{Ethical considerations}

Informed consent was obtained from all students who were evaluated for this study. This was considered a low risk study given the fact that only non-invasive evaluations were performed. A number was assigned to each participant to comply with the confidentiality criteria. In addition, all ethical principles put forth by the declaration of Helsinki were followed.

\subsubsection{Statistical analysis}

The qualitative variables included sociodemographic characteristics such as sex, current year of medical school and marital status; emotional state: anxiety and depression and health-risk behaviors such physical activity, nicotine dependence, risk alcohol consumption, overweight and obesity. These were analyzed using frequencies and percentages, as well as mean and standard deviation for quantitative variables (age). The chi square or the Fisher exact statistical test was used to know if there were any differences due to the presence of anxiety, depression or gender. Additionally, the Odds Ratio (OR) was estimated for the groups where there were significant differences. Statistical analyses were carried out using a SPSS software (version 19) and the values of $\mathrm{p}<0.05$ were considered significant

\subsection{Results}

A total of 173 medical students were evaluated, of which $125(72,3 \%)$ were women and $48(27,7 \%)$ were men. The average age was 20.9 years $(\mathrm{SD}=2,2) .63,3 \%$ studied the first or second year of their medical training, 23,7\% the third or fourth year and $12,7 \%$ the fifth year or sixth year. $86,1 \%$ dedicated their time exclusively to studying. Of the students who were evaluated, $114(65,9 \%)$ were single, $55(31,8 \%)$ were engaged and only $4(2,3 \%)$ were married.

Regarding mental health, 103 students (59,5\%) presented anxiety and 48 (27\%) showed depression. Regarding unhealthy lifestyle behaviors which could pose potential physical and mental risk factors, 97 students $(56,1 \%)$ were sedentary, $1(0,6 \%)$ had nicotine dependence, $34(19,7 \%)$ reported risk alcohol consumption, 38 (22\%) were overweight and $15(8,7 \%)$ were obese.

Analyzing the relationships within this data, statistically significant differences were observed between sedentary individuals and those who performed regular physical activity in relation to anxiety, with a $\mathrm{p}=0,01$ and an $\mathrm{OR}=0,446(\mathrm{CI}=0,24-0,83)$. Regarding depression, differences were found between those with risk alcohol consumption habits and those who did not have any problems with alcohol consumption, with a $\mathrm{p}=0,005$ and an OR of 2,972 ( $\mathrm{CI}=1,36-6,49)$. No differences were observed regarding the variables of psychological state and tobacco consumption, although it should be noted that only one individual of those evaluated had nicotine dependence. No statistically significant differences were observed regarding the classification of Body Mass Index (Table 2.1). 
Table 2.1 Anxiety, depression and health risk behavior

\begin{tabular}{|c|c|c|c|c|c|c|}
\hline \multicolumn{4}{|c|}{ Anxiety } & \multicolumn{3}{|c|}{$\begin{array}{c}\text { Depression } \\
\text { n }(\%)\end{array}$} \\
\hline Variable & Without & With & $\mathbf{P}$ & Without & With & $\mathbf{p}$ \\
\hline \multicolumn{7}{|l|}{ Sedentarism } \\
\hline Present & $31(44)$ & $66(64)$ & \multirow[t]{2}{*}{$0,01 * *$} & $67(54)$ & $30(62)$ & \multirow[t]{2}{*}{0,291} \\
\hline Absent & $39(56)$ & $37(36)$ & & $58(46)$ & $18(38)$ & \\
\hline \multicolumn{7}{|l|}{ Smoking } \\
\hline Present & $70(0)$ & $102(99)$ & \multirow[t]{2}{*}{0,595} & $125(100)$ & $47(99)$ & \multirow[t]{2}{*}{0,277} \\
\hline Absent & $0(0)$ & $1(1)$ & & $0(0)$ & $1(1)$ & \\
\hline \multicolumn{7}{|c|}{ Excessive Alcohol Consumption } \\
\hline Present & $10(14)$ & $24(23)$ & \multirow[t]{2}{*}{0,143} & $18(14)$ & $16(33)$ & \multirow[t]{2}{*}{$0,005 * *$} \\
\hline Absent & $60(86)$ & $79(77)$ & & $107(86)$ & $32(67)$ & \\
\hline \multicolumn{7}{|l|}{ BMI } \\
\hline Low Weight & $4(6)$ & $3(3)$ & \multirow[t]{3}{*}{0,586} & $5(4)$ & $2(4)$ & \multirow[t]{3}{*}{0,276} \\
\hline Normal Weight & $46(65)$ & $67(65)$ & & $86(69)$ & $27(56)$ & \\
\hline $\begin{array}{l}\text { Overweight or } \\
\text { Obesity }\end{array}$ & $20(29)$ & $33(32)$ & & $34(27)$ & $19(40)$ & \\
\hline
\end{tabular}

\section{Source: Own elaboration}

When analyzing emotional state in relation to the sociodemographic variables, particularly gender, $(\mathrm{p}=0,002)$ anxiety and depression were found to be more prevalent among women than men with (62\% vs. $46 \%)$ and (34\% vs. $10 \%)$, respectively (Table 2.2$)$.

Table 2.2 Anxiety, depression and gender

\begin{tabular}{|c|c|c|c|c|}
\hline & $\begin{array}{r}\text { Feminine } \\
n(\%)\end{array}$ & $\begin{array}{c}\text { Masculine } \\
\text { n (\%) }\end{array}$ & $\mathbf{p}$ & $\begin{array}{l}\text { OR } \\
\text { (CI) }\end{array}$ \\
\hline Anxiety & & & & \\
\hline Present & $77(62)$ & $22(46)$ & \multirow[t]{2}{*}{0,372} & \\
\hline Absent & $48(38)$ & $26(54)$ & & \\
\hline \multicolumn{5}{|l|}{ Depression } \\
\hline Present & $43(34)$ & $5(10)$ & \multirow[t]{2}{*}{$\mathbf{0 , 0 0 2} * *$} & 0,22 \\
\hline Absent & $82(66)$ & $43(90)$ & & $(0,82-60)$ \\
\hline
\end{tabular}

\section{Source: Own elaboration}

No significant differences were found in terms of risk-health behaviors between both sexes, except in eating habits, where men had a higher prevalence of obesity than women (52\% vs $22 \%$ ) (Table $3)$.

Table 2.3 Gender and health risk behaviors

\begin{tabular}{|c|c|c|c|}
\hline Variable & $\begin{array}{r}\text { Feminine } \\
n(\%)\end{array}$ & $\begin{array}{l}\text { Masculine } \\
\text { n (\%) }\end{array}$ & $\mathbf{p}$ \\
\hline \multicolumn{4}{|l|}{ Sedentarism } \\
\hline Present & $71(57)$ & $26(54)$ & \multirow[t]{2}{*}{0,755} \\
\hline Absent & $54(43)$ & $22(46)$ & \\
\hline \multicolumn{4}{|l|}{ Smoking } \\
\hline Present & $0(0)$ & $1(2)$ & \multirow[t]{2}{*}{0,277} \\
\hline Absent & $125(0)$ & $47(98)$ & \\
\hline \multicolumn{4}{|c|}{ Excessive Alcohol Consumption } \\
\hline Present & $21(17)$ & $13(27)$ & \multirow[t]{2}{*}{0,128} \\
\hline Absent & $104(83)$ & $35(73)$ & \\
\hline \multicolumn{4}{|l|}{ BMI } \\
\hline Low Weight & $7(6)$ & $0(0)$ & \multirow[t]{3}{*}{$<0,001 * * *$} \\
\hline Normal Weight & $90(72)$ & $23(48)$ & \\
\hline $\begin{array}{l}\text { Overweight or } \\
\text { Obesity }\end{array}$ & $28(22)$ & $25(52)$ & \\
\hline
\end{tabular}




\subsection{Discussion}

The findings of the current study reveal an association between patterns of multiple unhealthy behaviors and mental health outcomes among college students, even though these unhealthy behaviors often cooccur and overlap. The data indicates that around $60 \%$ of medical students with unhealthy behaviors also suffered from anxiety, of which, a sedentary lifestyle (56\%), being overweight or obese $(30,7 \%)$ and alcohol consumption $(19,7 \%)$, were found to be the most prevalent unhealthy behaviors. Previous studies have compared health behaviors in students from health sciences and compared them to other students from different areas; these studies have found statistical significant differences in favor of better habits found students studying health sciences (Almutairi et al., 2018; Zarrazquin et al., 2014). Given these results, university students should be considered a priority challenge.

In accordance with the results obtained in the current study, other studies have also found that those with healthy habits are less likely to experience anxiety and depression. For example, Saneei and colleagues (2016) showed that individuals with healthier lifestyles were less likely to suffer from anxiety and depression (>95\%). In the same sense, another study revealed that adolescents with four or more health-risk behavior-were twice as likely to suffer from psychological issues, specifically anxiety or depression (Rao et al., 2015).

One of the most consistent findings of the scientific literature is that physical activity provides an undeniable benefit upon the improvement of symptoms related to anxiety and depression, thus it can even be considered as an effective treatment for these mental health problems (Belair, Kohen, Kingsbury, \& Colman, 2018; Kandola et al., 2018; Legey et al., 2017; Velten et al., 2018). One study revealed that even those individuals who report physical activity at least once a week have less risk of suffering from anxiety and depression when compared to individuals with a sedentary lifestyle (Belair et al., 2018). It should be noted that our results only showed significant differences between sedentary lifestyle and anxiety; however, no significant difference was found in relation to depression.

In agreement with the reports in literature (Johannessen, Andersson, Bjorngaard, \& Pape, 2017; Kenney, Anderson, \& Stein, 2018), the results of this study also showed a relationship between depression and alcohol consumption. It has been observed that higher levels of depression have been associated with the use of alcohol at an early age, and that this affects the female population more than the male population (Johannessen et al., 2017). Also, current issues, such as cyberbullying, also increase the risk of experiencing mental health problems (Selkie, Kota, Chan, \& Moreno, 2015).

Additionally, differences in psychological state were observed between both genders. The prevalence of anxiety (62\% vs. $46 \%$ ) and depression (34\% vs. 10\%) is higher in women than in men. Other studies have already reported this finding (Pacheco et al., 2014; Rao et al., 2015), attributing this increased risk to both socio-cultural issues and to physical and psychological experiences which are associated with gender (Pacheco et al., 2014).

On the other hand, the percentage of obesity or overweight was higher in men $(52 \%)$ than in women (22\%) (Alzahrani et al., 2019; D'Souza, Walls, Rojas, Everett, \& Wentzien, 2015; Kanikowska et al., 2017). Similar findings have been seen in other studies, for example, Alzahrani and his collaborators (2019) reported statistically significant differences in mean BMI with $26,9 \pm 5,2 \mathrm{~kg} / \mathrm{m}^{2}$ in men vs. $22,8 \pm 4,1 \mathrm{~kg} / \mathrm{m}^{2}$ in women. It has been observed that men are generally more physically active than women, but tend to have worse eating habits (Pacheco et al., 2014). It should be noted that the proportion of overweight and obese individuals in the sample of students is below the national average, which reports that 7 out of 10 Mexican adults are overweight or obese $(72,5 \%)$, and contrary to the findings of the present study, women $(75,6 \%)$ tend to have higher rates than men $(69,4 \%)$ (UribeCarvajal, Jiménez-Aguilar, Morales-Ruan, Salazar-Coronel, \& Shamah-Levy, 2018).

As previously stated, current medical students will be the future responsible for the promotion of healthy habits among the general population, in addition, the good habits practiced by these professionals have shown to influence in the lifestyle choices of their patients (Yu et al., 2015; Zarrazquin et al., 2014). Given these observations, student education should emphasize the importance of promoting healthy habits regarding self-care and the care of others, to prevent the development of chronic diseases, which are currently one of the biggest public health concerns in the world. 
It is recommended that future studies be carried out comparing students from different scientific disciplines, to better detect the different issues which may exist between these groups.

\subsection{Acknowledgments}

We appreciate the valuable participation of medical students from the Tonalá University Center belonging to the University of Guadalajara.

\subsection{Conclusions}

Medical students carry a large academic load which could potentially contribute to present a variety of risk factors against health. At the top of the list of risk factors are anxiety followed by depression, both of them are linked to sedentary lifestyle and overweight problems. In the other hand the gender plays an important role over the emotional state, since women's present highest prevalence of anxiety and depression.

Nowadays, students mental health becomes an apprehensive issue within the universities. Anxiety is the most common mental health problems in students, followed by depression. Medical schools are known to be a stressful environment that leads to negative effect on the students physical and psychological health. Long term follow-up of such study cohorts will be useful to educators, administrators and practitioner to inform efforts to optimize the health, safety, and efficiency of our future medical practitioners

\subsection{References}

Acosta-Rodríguez, F., Rivera-Martínez, M., \& Pulido-Rull, M. A. (2011). Depression and anxiety in a sample of unemployed Mexican individuals. Journal of Behavior, Health \& Social, 3(1), 35-42.

Almutairi, K. M., Alonazi, W. B., Vinluan, J. M., Almigbal, T. H., Batais, M. A., Alodhayani, A. A., et al. (2018). Health promoting lifestyle of university students in Saudi Arabia: a cross-sectional assessment. BMC Public Health, 18(1), 1093.

Alzahrani, S. H., Malik, A. A., Bashawri, J., Shaheen, S. A., Shaheen, M. M., Alsaib, A. A., et al. (2019). Health-promoting lifestyle profile and associated factors among medical students in a Saudi university. SAGE Open Med, 7, 2050312119838426.

Belair, M. A., Kohen, D. E., Kingsbury, M., \& Colman, I. (2018). Relationship between leisure time physical activity, sedentary behaviour and symptoms of depression and anxiety: evidence from a population-based sample of Canadian adolescents. BMJ Open, 8(10), e021119.

Cezaretto, A., Ferreira, S. R., Sharma, S., Sadeghirad, B., \& Kolahdooz, F. (2017). Impact of lifestyle interventions on depressive symptoms in individuals at-risk of, or with, type 2 diabetes mellitus: A systematic review and meta-analysis of randomized controlled trials. Nutr Metab Cardiovasc Dis, 26(8), 649-662.

D'Souza, M. J., Walls, K. J., Rojas, C., Everett, L. M., \& Wentzien, D. E. (2015). Effect of Gender and Lifestyle Behaviors On BMI Trends In A Sample Of The First State's Undergraduate Population. Am J Health Sci, 6(1), 59-74.

González, D. A., Reséndiz-Rodríguez, A., \& Reyes-Lagunes, I. (2015). Adaptation of the BDI-II in Mexico. Salud Mental 38(4), 237-244.

Hyakutake, A., Kamijo, T., Misawa, Y., Washizuka, S., Inaba, Y., Tsukahara, T., et al. (2016). Crosssectional observation of the relationship of depressive symptoms with lifestyles and parents' status among Japanese junior high school students. Environ Health Prev Med, 21(4), 265-273.

Johannessen, E. L., Andersson, H. W., Bjorngaard, J. H., \& Pape, K. (2017). Anxiety and depression symptoms and alcohol use among adolescents - a cross sectional study of Norwegian secondary school students. BMC Public Health, 17(1), 494. 
Kandola, A., Vancampfort, D., Herring, M., Rebar, A., Hallgren, M., Firth, J., et al. (2018). Moving to Beat Anxiety: Epidemiology and Therapeutic Issues with Physical Activity for Anxiety. Curr Psychiatry Rep, 20(8), 63.

Kanikowska, D., Sikorska, D., Kuczynska, B., Grzymislawski, M., Breborowicz, A., \& Witowski, J. (2017). Do medical students adhere to advice regarding a healthy lifestyle? A pilot study of BMI and some aspects of lifestyle in medical students in Poland. Adv Clin Exp Med, 26(9), 1391-1398.

Kenney, S. R., Anderson, B. J., \& Stein, M. D. (2018). Drinking to cope mediates the relationship between depression and alcohol risk: Different pathways for college and non-college young adults. Addict Behav, 80, 116-123.

Kim, E. G. (2018). Multilevel Analysis of the Risk Factors in High-Risk Health Behavior among Korean Adolescents. Osong Public Health Res Perspect, 9(1), 3-8.

Legey, S., Aquino, F., Lamego, M. K., Paes, F., Nardi, A. E., Neto, G. M., et al. (2017). Relationship Among Physical Activity Level, Mood and Anxiety States and Quality of Life in Physical Education Students. Clin Pract Epidemiol Ment Health, 13, 82-91.

Lolokote, S., Hidru, T. H., \& Li, X. (2017). Do socio-cultural factors influence college students' selfrated health status and health-promoting lifestyles? A cross-sectional multicenter study in Dalian, China. BMC Public Health, 17(1), 478.

Medina-Mora, M. E., Castro, S., Campillo-Serrano, C., \& Gómez-Mont, F. A. (1981). Validity and reliability of a high school drug use questionnaire among Mexican students. Bull Narc, 33(4), 67-76.

Mora-Rios, J., \& Natera, G. (2001). Expectations of alcohol consumption and associated problems in university students in Mexico City. Public Health of Mexico, 43, 89-96.

Moreno-Coutiño, A., \& Villalobos-Gallegos, L. (2017). Psychometric Properties of the Fagerstro “m Test for Nicotine Dependence in a Sample of Mexican Smokers. J Addict Nurs, 28(1), 27-33.

Nogueira, P. S., Ferreira, M. G., Rodrigues, P. R. M., Muraro, A. P., Pereira, L. P., \& Pereira, R. A. (2018). Longitudinal Study on the Lifestyle and Health of University Students (ELESEU): design, methodological procedures, and preliminary results. Cad Saude Publica, 34(4), e00145917.

Pacheco, R. L., Santos-Silva, D. A., Gordia, A. P., de Quadros, T. M., \& Petroski, E. L. (2014). Sociodemographic determinants of university students' lifestyles. Rev Salud Publica (Bogota), 16(3), 382-393.

Paz-Ballesteros, W. C., Zavala-Arciniega, L., Gutiérrez-Torres, D. S., Ponciano-Rodríguez, G., \& Reynales-Shigematsu, L. M. (2019). Evaluation of the physical and psychological dependence on tobacco in adult Mexican smokers, Encodat. Public Health of Mexico, 61, 136-146.

Rao, S., Shah, N., Jawed, N., Inam, S., \& Shafique, K. (2015). Nutritional and lifestyle risk behaviors and their association with mental health and violence among Pakistani adolescents: results from the National Survey of 4583 individuals. BMC Public Health, 15, 431.

Robles, R., Varela, R., Jurado, S., \& Páez, F. (2001). Mexican version of Beck's Anxiety Inventory: Psychometric Properties. Mexican Journal of Psychology, 18(2), 211-218.

Rodriguez-Gazquez, M. L. A., Chaparro-Hernandez, S., \& Gonzalez-Lopez, J. R. (2016). Lifestyles of nursing students from a Colombian public university. Invest Educ Enferm, 34(1), 94-103.

Saneei, P., Esmaillzadeh, A., Keshteli, A. H., Reza Roohafza, H., Afshar, H., Feizi, A., et al. (2016). Combined Healthy Lifestyle Is Inversely Associated with Psychological Disorders among Adults. PLoS One, 11(1), e0146888. 
Selkie, E. M., Kota, R., Chan, Y. F., \& Moreno, M. (2015). Cyberbullying, depression, and problem alcohol use in female college students: a multisite study. Cyberpsychol Behav Soc Netw, 18(2), 79-86.

Sharma, B., Nam, E. W., Kim, D., Yoon, Y. M., Kim, Y., \& Kim, H. Y. (2016). Role of gender, family, lifestyle and psychological factors in self-rated health among urban adolescents in Peru: a school-based cross-sectional survey. BMJ Open, 6(2), e010149.

Uribe-Carvajal, R., Jiménez-Aguilar, A., Morales-Ruan, M. D. C., Salazar-Coronel, A. A., \& ShamahLevy, T. (2018). Perception of body weight and the probability of developing obesity in Mexican adults. Public Health of Mexico,60, 254-262.

Velten, J., Bieda, A., Scholten, S., Wannemuller, A., \& Margraf, J. (2018). Lifestyle choices and mental health: a longitudinal survey with German and Chinese students. BMC Public Health, 18(1), 632.

Yu, Y., Yang, Y., Li, Z., Zhou, B., Zhao, Y., Yuan, S., et al. (2015). The association between medical students' lifestyles and their attitudes towards preventive counseling in different countries. BMC Public Health, 15, 1124.

Zarrazquin, I., Torres-Unda, J., Ruiz, F., Irazusta, J., Kortajarena, M., Hoyos Cillero, I., et al. (2014). Longitudinal study: lifestyle and cardiovascular health in health science students. Nutr Hosp, 30(5), 1144-1151. 
Chapter 3 Early trauma as conditioning of psychopathology in adult women

Capítulo 3 Trauma temprano como condicionante de la psicopatología en mujeres adultas

AGUILAR-ZAVALA, Herlinda $\uparrow^{*}$, MORADO-CRESPO, Lisette, VILLADA, Carolina and TOVARVEGA, Alma Rosa

Universidad de Guanajuato, Health Sciences and Engineering Division, Campus Celaya-Salvatierra, Mexico.

Universidad de Guanajuato, Health Sciences Division, Leon Campus, Mexico.

Institute of Public Health of the State of Guanajuato, Mexico.

ID $1^{\text {st }}$ Author: Herlinda, Aguilar-Zavala / ORC ID: 0000-0003-1032-8192, CVU CONACYT ID: 45038

ID $1^{\text {st }}$ Co-author: Lisette, Morado-Crespo / ORC ID: 0000-0002-1754-8959, CVU CONACYT ID: 217688

ID $2^{\text {nd }}$ Co-author: Carolina, Villada / ORC ID: 0000-0003-1071-2362, CVU CONACYT ID: 898411

ID $3^{\text {rd }}$ Co-author: Alma Rosa, Tovar-Vega / ORC ID: 0002-6685-5285, CVU CONACYT ID: 406825

DOI: $10.35429 /$ H.2021.13.20.35 


\begin{abstract}
Violence is a public health problem, with severe negative consequences on the mental and physical health of people, female primarily; one of five women reports more child abuse or maltreatment than each one of 13 men; women who have suffered some form of child abuse, have up to four times the risk of developing symptoms of depression in adult life. According to the WHO, between 1990 and 2013, people with depression or anxiety increased by 50\%, from 416 million to 615 million. About $10 \%$ of the world's population is affected, and mental disorders account for $30 \%$ of the global burden of non-fatal disease. Humanitarian emergencies and conflict increase the need to expand therapeutic options. Major Depressive Disorder is characterized by severe mood alteration, displeasure and these affect the social, work, and personal areas; the persistence of the disorder could cause distress and physical and functional disability. The women are at twice the risk of suffering depression and suffer more severe depressive symptoms. In addition, women who have been victims of physical or sexual abuse have higher rates of mental health problems. Exposure to child abuse is associated with a markedly increased risk of psychiatric and medical disorders; The hypothalamic-pituitary-adrenal (HPA) axis is one of the main signaling pathways activated in response to stress and trauma. Alterations in the HPA axis or allostatic load are a psychophysiological condition due to the chronic persistence of child abuse, increasing the risk of suffering from mental disorders in adulthood. It is necessary to emphasize the importance of early trauma when psychiatric diagnosis, offer better treatment options, and stop the family chain of adverse events.
\end{abstract}

\title{
Early trauma, Allostatic load, Psychopathology, Women
}

\section{Resumen}

La violencia es un problema de salud pública, con graves consecuencias negativas en la salud mental y física de las personas, principalmente de las mujeres; una de cada cinco mujeres denuncia más abuso o maltrato infantil que cada uno de los 13 hombres; las mujeres que han sufrido alguna forma de abuso infantil, tienen hasta cuatro veces más riesgo de desarrollar síntomas de depresión en la vida adulta. Según la OMS, entre 1990 y 2013, las personas con depresión o ansiedad aumentaron un 50\%, pasando de 416 millones a 615 millones. Alrededor del 10\% de la población mundial está afectada, y los trastornos mentales representan el $30 \%$ de la carga mundial de enfermedades no mortales. Las emergencias humanitarias y los conflictos aumentan la necesidad de ampliar las opciones terapéuticas. El Trastorno Depresivo Mayor se caracteriza por una severa alteración del estado de ánimo, el malestar y estos afectan a las áreas social, laboral y personal; la persistencia del trastorno puede causar angustia y discapacidad física y funcional. Las mujeres tienen el doble de riesgo de padecer depresión y sufren síntomas depresivos más graves. Además, las mujeres que han sido víctimas de abusos físicos o sexuales presentan mayores tasas de problemas de salud mental. La exposición al maltrato infantil se asocia a un riesgo notablemente mayor de trastornos psiquiátricos y médicos; El eje hipotálamo-hipófisis-suprarrenal (HPA) es una de las principales vías de señalización que se activan en respuesta al estrés y al trauma. Las alteraciones del eje HPA o carga alostática son una condición psicofisiológica debida a la persistencia crónica del maltrato infantil, aumentando el riesgo de padecer trastornos mentales en la edad adulta. Es necesario enfatizar la importancia del trauma temprano a la hora del diagnóstico psiquiátrico, ofrecer mejores opciones de tratamiento y detener la cadena familiar de eventos adversos.

\section{Trauma temprano, Carga alostática, Psicopatología, Mujeres}

\subsection{Introduction}

In modern psychology, there is great interest in the relationship between early trauma due to adverse experiences in childhood and psychopathology in adult women; first, we will present in this chapter the definition of adverse experiences in childhood, their classification, the outcome, and how this could bring socio-emotional and physiological alterations. Second, we will define early trauma and its effects on physical and mental health; then, we will focus on trauma in women. We will explore the statistics; the studies focused on post-traumatic stress in women and the impact of life stress on psychosis and attenuated psychosis. We will address the impact of early trauma and neuronal affectations due to child abuse and the relationships with an inappropriate or prolonged activation function of the hypothalamicpituitary-adrenal axis (HPA). 
We will also address schizophrenia and the impact of stress and early trauma on the development of this disease; the allostatic load and psychosis will be related too. Finally, we will talk about the public policies that exist in México to prevent early trauma.

\subsection{Methodology}

One search in PubMed NCBI about "childhood trauma", "psychopathology" and "women" has deployed 145 articles and 90 of them have been included. The following topics were defined:

Adverse childhood Experiences, Early trauma, Early trauma in women, Impact of early trauma, Neuronal alterations' due to childhood maltreatment, Child maltreatment and the hypothalamic-pituitary-adrenal axis (HPA), Allostatic load and mental pathology, Schizophrenia, The impact of stress and early trauma on the development of schizophrenia and Public Policies in México for the prevention and care of early trauma

\subsection{Topics}

\subsubsection{Adverse childhood experiences}

Adverse Childhood Experiences (ACEs) act as stressors and risk factors that impact well-being during adulthood. Although these factors are commonly reported in Western countries, little data focuses on low- and middle-income countries. However, studies show that the prevalence of these experiences is frequently higher than those reported in studies from more developed nations. These data indicate social disparities between the world's communities. The greater the adverse experiences in childhood, the greater the risk of chronic diseases, the more significant the social and emotional impact in later years. There is an association between ACEs and the risk of diseases including diabetes, obesity, and heart diseases. Given that ACEs carry devastating impacts until adulthood, it is imperative to focus on the prevention of these experiences in vulnerable populations, developing programs of detection and prevention, as well as an early warning and contingency system (Chu and Chu, 2021).

Abuse, as well as emotional neglect, leads to an increased risk of mood and anxiety disorders, substance and alcohol abuse, and certain other medical disorders in adulthood. Negligence is defined as the failure of a parent or another caring person, to implement the responsibility or supervision and don't provide food, clothing, shelter, and necessary medical attention to minors (Lippard and Nemeroff, 2020).

Abuse and emotional neglect lead to an increased risk of mood and anxiety disorders, substance and alcohol abuse, and certain other medical disorders in adulthood. Negligence is defined as the failure of a parent or another caring person to implement responsibility or supervision and do not provide food, clothing, shelter, and necessary medical attention to minors (Amores-Villalba and Mateos-Mateos, 2017).

Recent studies have shown that exposure to childhood maltreatment, anywhere stage of development, could trigger disease that perdures all life. Childhood maltreatment is associated whit a higher risk of psychiatric and physical disorders. Alterations on the Hypothalamic-Pituitary-Adrenal axis (HPA) and inflammatory cytokines due to childhood maltreatment could contribute to the vulnerability of depression (Lippard and Nemeroff, 2020). Furthermore, there is evidence about a maltreatment history is associated with specific depressive symptoms in adulthood, more severe, more chronic, and a worse response to pharmacological therapy (Vitriol, et al., 2017).

\subsubsection{Early trauma}

According to World Health Organization, 66.2\% of adults report traumatic experiences before 18 years old and they have pointed multiplex traumas in an average of two or more (Dennis et al., 2009). Trauma is the effect on the human psyche caused by a traumatic event. We can consider a traumatic event as an event that is perceived as threatening or aversive, and that could damage self-security and self-integrity and cause fear and inability feelings, so this triggers physiologic arousal by stress reaction (DSM-5). Supposing this event occurs in early childhood when physical and psychological coping is lower, and resources for fighting or flying are low. In that case, the psychological impact will be more significant and chronic, and as a result, it will damage the physiological response on adolescence and adulthood front life stressors. 
Trauma can be classified as a) physical abuse, defined as physical violence, b) sexual abuse is a force to the child to do sexual activities, c) psychologic and emotional abuse which includes, threats, intimidation, discrimination, rejection and ridicule, and d) neglect about health, education, nutrition, and safe living of child (Martins et al., 2011; World Health Organization [WHO], 2006).

Early trauma is associated with a higher risk of many medical disorders such as ischemic cardiopathy, diabetes, irritable bowel syndrome, asthma, and others. Also, early trauma induces poor health, depression, anxiety, and sudden death in the adulthood (Brown et al., 2009; Danese and McEwen, 2012; Danese et al., 2009; Dennis et al., 2009; Dube et al., 2009; Openshaw et al., 2015). Hence, we can consider the ACEs as a powerful predictor of health state in adulthood. The impact of traumatic experience on psychological development depends on many factors, including age at the first event, frequency, and active rolling of care people (Antonopoulou et al., 2017). Family history of chronic illness is well related to the effects on the physical and mental health of the child; nevertheless, there are few studies about the effects of abuse and negligent infant on physical and mental childhood health. This highlights the complex interactions between environment, experience, and biological factors. To understand these complex biopsychosocial phenomenon, multidisciplinary efforts are mandatory (Nemerof, 2016).

\subsubsection{Early trauma in women}

In our society, the woman is the quintessential caretaker of children and adult patients, whether at home or in hospitals, family, friends, or professional work. Women's role as caregivers, both within the health system and at home, can put them at greater risk and may raise concerns about the disease. Approximately $70 \%$ of health workers and welfare worldwide are women (WHO, 2019), including frontline health workers. Women are also more likely to care for sick children or other relatives (Wenham et al. 2020).

Gender-based differences are related to the frequency of occurrence of child abuse experiences, while 1 of 5 adult women report having suffered some abuse in childhood, only 1 in 13 men report it; in the same way, women report a greater intensity of emotional abuse than men (Edwards et al., 2003; WHO, 2018). In addition, there is a higher prevalence of post-traumatic stress in women than in men, besides the discordance in the types of traumas experienced between women and men; to unravel the gender-related alteration in these phenotypes because of abuse, more research is needed (Seligowski et al., 2020).

On the other hand, ethnicity also influences the coping response to stress in women; in a recent study, it was found that Hispanic women and African American women had higher levels of hair cortisol than non-Hispanic white women, which could be evidenced by the participation of genetic mechanisms, lifestyles, and social differences (Schreier et al., 2015). Furthermore, ethnicity also influences the coping response to stress in women; in a recent study, it was found that Hispanic women and African American women had higher levels of hair cortisol than non-Hispanic white women, which could be evidenced by the participation of genetic mechanisms, lifestyles, and social differences (Schreier et al., 2015). These differences begin in early life for women, continue into adolescence, and persist into late adulthood; therefore, during women's reproductive and productive years, they present a greater risk of mental illness.

Other interesting aspect to consider is, that psychosocial and biological factors impact mental illness' course and in its treatment response. Recently, it has been revealed that biological processes involved in the predisposition of female depression, including genetically determined vulnerability, hormonal fluctuations, and excessive sensitivity to hormones in the brain system, are mediated by depressive states. The authors also found that psychosocial events such as stress, ACEs, victimization, socialization, cultural beliefs related to gender, coping styles including internalization of stress, and a disadvantaged social status increase women's vulnerability (Sassarini, 2016). In this line, recent studies show that women who had experienced trauma in early life perceive their social networks as less useful, conflictive, and more unpredictable; in general, they perceive less social support than those who did not experience early trauma (Anand et al., 2018; Light et al., 2019).

In addition, neuropsychological problems secondary to child abuse are related to the difficulties these girls encounter when adjusting to school or interacting with her classmate, either due to academic intellectual issues or socio-emotional problems (Amores-Villalba and Mateos-Mateos, 2017). 


\subsubsection{Impact of early trauma}

Recently, researchers have begun to examine the impact of life stressors on psychosis and attenuated psychosis. All psychosis patients who have experienced childhood trauma report increased negative emotions and psychotic symptoms in response to life stress than patients with psychosis, but without early trauma (Collip et al., 2011; Lardinois et al., 2011). Adolescents with Posttraumatic Stress Disorder (PTSD) also developed psychosis at a high rate of $21 \%$ in just 2.5 years. This group has also reported many stressful, independent, and undesirable life events than healthy adolescents, and they report more distress in response to daily complaints (Tessner et al., 2011). Additionally, the frequency of daily stressors predicted an increase in positive symptoms one year later.

On the whole, this confers Clinical High Risk (CHR); CHR is a measure used to evaluate the predisposition to develop psychopathologies in later ages (French and Morrison, 2004). It has been found that young people with CHR show an elevated dopaminergic response after stress exposure compared to healthy controls and patients with schizophrenia not treated with antipsychotics (Mizrahi et al., 2012). We can suggest that trauma-derived stress increases the reactivity of the HPA axis in adolescents with attenuated and complete psychosis, triggering fluctuations in dopamine transmission and the severity of psychotic symptoms; this could be influenced by genetic predisposing and environmental factors combined with ACEs.

It is well known that CHR patients report higher stress levels than first-episode psychosis patients (Pruessner et al., 2011). Hence, reducing stress and improving coping is a critical goal for developing preventive interventions for schizophrenia.

New research areas are beginning to focus on the natural plasticity of the HPA axis during adolescent development to implement effective interventions that promote resilience to stress during the prodromal phase. For example, cognitive-behavioral therapy approaches help people to re-evaluate the interpretation of stressful stimuli more adaptively. Behavioral stress reduction techniques teach people to take an active role in reducing their exposure to stressors. Family therapy reduces stressful interactions and increases family support. Cognitive training exercises improve the accuracy and rationality of processing cognitive and socio-affective stimuli and increase the brain's "cognitive resilience" to data in its environment.

\subsubsection{Neuronal alterations' due to childhood maltreatment}

Child sexual abuse at critical stages of the development carries with substantial alterations at neuronal function, and therefore structural, since abuse and neglect are, for the biological system, a stressful event chronic, these affect the current and subsequent operation of the central and peripheral nervous system and the individual (De Bellis, 2005; Mesa-Gresa and Moya-Albiol, 2011; Amores-Villalba and MateosMateos, 2017).

A previous study showed that exposure during sensitive child periods resulted in a steep doseresponse function. The severity of adversity experienced at age 10-11 contributed to larger right but not left amygdala volume in adulthood. These results provide preliminary evidence that the amygdala may have a developmentally sensitive period in preadolescence (Pechtel et al., 2014).

Early child abuse could be inhibiting neurogenic processes, causing a decrease in gray matter in the hippocampus, in ventral, rostral and dorsolateral areas of prefrontal, in the insular cortex, and in the pre-limbic area, as well as delays in myelination of the white matter, which affects neuronal connectivity and hypo functionality (Kirsch, 2021). Also, alterations in the normal process of neuronal pruning can be observed during critical periods (De Bellis, 2005; Mesa-Gresa and Moya-Albiol, 2011).

Neurobiological correlates on mental disorders in women with a history of child abuse or maltreatment is expected since the more significant the child abuse, the greater the increase in prodromal symptoms in adult life (Kirsch, 2021). Previous studies have reported a lower hippocampal volume in adult women with major depression, which was found exclusively in those women with a severe and prolonged history of sexual or physical abuse in childhood (Vythilingam et al., 2002). However, these deficits and neurobiological alterations may not be evidenced during childhood, but in adult life, there is a failure to develop the individual's neurocognitive potential (Capilla et al., 2007). 


\subsubsection{Child maltreatment and the hypothalamic-pituitary-adrenal axis (HPA)}

The hypothalamic-pituitary-adrenal axis (HPA) is the main signaling pathway activated in response to stress and trauma.

Suppose the cerebral cortex interprets environmental stimuli as dangerous. In that case, it communicates to the amygdala, which projects signals to the paraventricular nucleus of the hypothalamus, resulting in a Corticotropin-Releasing Hormone (CRH) and Arginine Vasopressin Protein (AVP). Already bound to their receptors (CRHR1 and AVPR1A, respectively), they activate the release of adrenocorticotropic hormone (ACTH) by the pituitary gland; this hormone acts on the adrenal cortex, releasing glucocorticoids such as cortisol, in humans, to the blood system (Lupien and McEwen, 1997; Rivier and Plotsky, 1986; Šimić et al., 2021).

Cortisol exerts adaptive functions to respond to adverse biological stimuli due to adverse experience, such as glucose mobilization, increased muscle activity, and cardiovascular tone, and gastric acid secretion. Once the dangerous situation has passed, cortisol itself exerts a negative feedback mechanism to return to the basal state and restore the body's homeostasis; however, the repetition of the event generates a sensitization of the CRH regulation system, and therefore, the feedback system is altered. The persistent sensitization of this system constitutes a biological substrate to develop a greater vulnerability to suffering alterations in response to subsequent stress, damage to the cognitive-emotional system, and consequently, acquire a long-term mental disorder (Cerda-Molina et al., 2017).

It is well-knowing that early violence and chronic stress induce an altered response of CRH secretion and other neurotransmitters involved in the reward system. Regarding the alteration of cortisol reactivity (CR) in cases of early violence, previous studies confirm that this persistent activation of the HPA axis during childhood leads to post-traumatic stress disorder (PTSD), depressive and anxiety episodes (Juruena 2014). Adult women who suffered from depression and had been victims of sexual abuse in childhood showed hyperreactivity of the HPA axis and, therefore, increased cortisol secretion in an acute stress test. In contrast, women who suffered abuse but did not present depressive symptoms had a moderate cortisol secretion pattern. In contrast, Juul et al. (2016) described those adult women with reports of sexual abuse and other trauma during childhood decreased their CR levels.

Improper or prolonged activation of the HPA axis is energetically costly and has been associated with numerous physiological and psychological states of illness (Danese and McEwen, 2012). Some results suggest that it is possible to consider alterations in cortisol secretion as a biomarker for designing interventions and pharmacological treatments for people suffering from PTSD and depression because of early violence (Cerda-Molina, 2017).

\subsubsection{Allostatic load and mental pathology}

Derived from the allostasis concept, McEween and Stellar (1993) developed the concept of Allostatic load. This concept links the cost-of-living chronic stress and the probability of developing certain diseases. The allostatic load (AL) can be defined as " The wear and tear of the body in the face of sustained resistance to chronic stressors, such as the presence of frequent adverse events." Hence, this concept reflects the impact of life experiences and a series of biopsychosocial factors of reference and response that generate patterns of behavior and physiological reactivity for life. The allostatic load causes physiological changes that eventually lead to biological or mental illnesses. This perspective offers many opportunities to handle affected people through medical approaches and psychosocial strategies, helping them restoring the baseline state (before physiological stress activation), emphasizing general health, fitness, and control of thoughts and perceptions.

Some research confirms that high levels of allostatic load in adulthood are related to adverse childhood experiences, including child abuse and maltreatment (Carroll et al., 2013). Studies focused on adults with PTSD after suffering early life traumas revealed a relationship between neuroendocrine biomarkers of allostatic load and early life stress and subsequent PTSD development (Thayer et al., 2017). 
The primary mediators of the allostatic load or overload are cortisol, dehydroepiandrosterone (DHEA), epinephrine, norepinephrine, because of their immediate correlation with adrenal function (Seeman et al., 1997;2001). Considering these biomarkers along with others such as body mass index, cholesterol, triglycerides, among others; authors can calculate the rate or index of allostatic load. This index has been positively associated with patients at first-episode psychosis and multiple-episode schizophrenia patients, and with more severe manic symptoms (Berger et al., 2018a, b); the former study also found that AL index predicted lower social and occupational functioning (Berger et al., 2018a).

A recent study showed that the rate of allostatic load was significantly higher in patients with psychosis. This association was greater linked in those with childhood trauma and sexual abuse (Piotrowski 2020). Authors also concluded that the greater belief of social support and social interactions following adverse events could alleviate the biological deregulations associated with trauma during childhood.

\subsubsection{Schizophrenia}

Schizophrenia is a highly heritable disorder (80\% to 85\%) (Brown 2011). Genetic factors interact with environmental injuries, which begin in the pre and perinatal period, increasing risk and vulnerability to several environmental stressors. Although the prevalence of this disease is equal between men and women, it is women the most affected by the burden of life stress, which could increase the risk of disease, especially in developing countries (Thara and Kamath, 2015).

This interaction between genes and the environment leads to aberrations in brain development and the origination of neural networks, which will become evident until adolescence or early adulthood, when brain maturation is almost complete (Andreasen 2010; Hoffman and McGlashan 1997). Cognitive models of positive and negative symptoms of schizophrenia could link genetic vulnerability, early experience, and environmental stressors later in life with schizophrenia upset (Batinic, 2019). In the beginning, the individual experiences a break in reality and psychotic symptoms, almost always $t$ in a mild or attenuated manner, but if they do not receive the treatment, it will progress to a psychotic episode. Schizophrenia can be considered a neurodevelopmental disorder characterized by decreased efficiency and regular connectivity in cortical and subcortical neural networks. This fact makes them particularly vulnerable to the harmful effects of stress. It leads us to understand how interventions aimed at an adaptive response to vitally stressful stimuli or how treating the abnormal processing of the nervous system can improve the early course of schizophrenia.

In normal and healthy neural development, peak synapse proliferation and peak synaptic density occur at approximately two years of age, followed by a decrease in this synaptic density during childhood and a decline in adolescence (Spear, 2003). This process has been defined as synaptic pruning, which is especially essential in the prefrontal cortex regions, to increase the efficiency of neural processes and neurocognitive functions (Spear 2003). Once the synaptic pruning in the prefrontal cortex has been carried out, a reestablishment of the functions happens, such as an increase in the ability to solve abstract and complex problems, increased reasoning, planning, flexible thinking, emotional control, among other executive functions (Giraldo-Chica et al., 2018; Spear 2003). Several studies suggest that excessive pruning or abnormalities in the pruning process are related to the establishment of psychosis in adolescence (Andreasen et al., 2011; McGlashan and Hoffman 2000); for example, individuals with schizophrenia exhibit decreased dendritic spine density, but the number of neurons is intact (Glantz and Lewis 2000; Selemon et al., 1995). Specific genes are known to contribute to abnormalities in synaptic pruning and synaptic functioning in schizophrenia. However, the primary effect is a reduction in the volume of gray matter in cortical and subcortical regions key to the development of the disease (frontal and temporal areas) (Fusar-Poli et al., 2012).

Another critical process is the increase in density in white matter. Beginning in adolescence and continuing into early adulthood, the hippocampus and frontal lobe undergo a substantial myelination process, mainly driven by brain mechanisms of experience-dependent plasticity (or simply, adaptive learning). Recent evidence suggests that this process is disrupted in schizophrenia; the net result is that decreased white matter density hinders the rapid and efficient integration of information processing within and across cortical zones and contributes to cognitive decline (Dwork et al., 2007). 
In a longitudinal study covering the changes in brain volume over time in a cohort of patients with schizophrenia, the results confirm a decrease in several regions of gray matter and white matter, which is more pronounced two years after the first episode of psychosis (Andreasen et al., 2011).

Cascade alterations in the functioning of neural networks in schizophrenia are evident, including a reduction in synaptic density and reducing neural integrity; all may result from one or more abnormalities in brain plasticity mechanisms, leading to maladaptive changes (Balu and Coyle, 2011). The reduced functional connectivity between crucial nervous systems and reduced efficiency in their socio-cognitive operations suggests that clinical attention must be focused on correcting this abnormal functioning. If possible, before the individual experiences maladaptive changes that can be irreversible to improve the picture of schizophrenia.

\subsubsection{The impact of stress and early trauma on the development of schizophrenia}

A stressful environment interacts with neurocognitive vulnerability, increasing the risk that triggers the establishment of psychosis (Walker and Diforio 1997; Nuechterlein and Dawson 1984). Many studies show an association between the magnitude of the stressor and psychosis in individuals with schizophrenia; evidence of the link between stress and attenuated psychosis during the prodromal phase continues increasing. The main proposed mechanism that outlines this relationship is the dysregulation of the hypothalamic-pituitary-adrenal (HPA) axis, which turns out to be the central stress response system in mammals.

In this line, recent research has found the interaction between mineralocorticoids (MR) and glucocorticoids receptors (GR) with genes implicated in neuroplasticity processes, therefore, in learning and memory. Moreover, some of these genes are also involved in mental disorders such as schizophrenia, among others (Mifsud et al., 2021).

Chronic stress and the elevation of glucocorticoids in response to stress can cause stress sensitization, resulting in a reduction of hippocampal neurons, glucocorticoid receptors in the hippocampus, and a suppression of long-term potentiation (LTP) (Pavlides et al., 1993; Sapolsky 1985; Sapolsky et al., 1990; Stein-Behrens et al., 1994), which impairs the consolidation of declarative memory. Chronic stress damages hippocampal functions and increases and conditions thoughts about threats that affect the amygdala, which persist after recovery from stress (Conrad et al., 2004; Vyas et al., 2004). In animal models, prolonged stress causes dysregulation in the negative biofeedback circuit, whereby the damaged hippocampus fails to properly modulate the activity of the HPA axis (Meaney et al. 1989; Sapolsky et al. 1990) and increases glutamate both in the prefrontal cortex as well as in the hippocampus, which can result in altered levels of dopamine (Moghaddam 2002).

Many studies have verified dysregulation of the stress response system in schizophrenia, primarily using cortisol assays to access the integrity of the HPA axis (Walder et al., 2000). Salivary cortisol is related to symptom severity in a sample of patients with schizophrenia, affective disorders, or no history of mental illness; for example, baseline cortisol and ACTH levels are higher in newly diagnosed chronic schizophrenia patients than in healthy subjects (Bradley and Dinan 2010). Some studies suggest that the stress response and the functioning of the HPA axis are dysregulated during the prodromal phase of schizophrenia, which is related to the level of symptoms and the transition to psychosis (Aiello et al., 2012; Holtzman et al. 2012). In a study with adolescents with schizotypal personality disorder, salivary cortisol levels were associated with the severity of schizotypal symptoms and transition to psychosis at a 12-24-month follow-up (Walker et al., 2001; Walker and Bollini 2002). Salvaging the concept of High clinical Risk (HCR), Yee et al. (2007) found that patients with High Clinical Risk (HCR) showed higher basal cortisol levels than healthy controls. They also found that, after a social stress test in the laboratory, the magnitude of the cortisol response of patients with schizotypal personality disorder was lower than in controls, but they showed a response to stress with a delayed recovery pattern of cortisol compared to controls (Yee et al., 2007). Other studies have also shown that over-activation of the HPA axis is more common during the prodromal phase (Büschlen et al., 2011; Garner et al., 2005; Pantelis et al., 2009). 
Interestingly growing evidence has documented higher rates of childhood trauma in patients with schizophrenia than controls, suggesting an environmental influence that increases the stress response in schizophrenia (Matheson et al., 2013; Sideli et al., 2012). The relationship between early adversity due to trauma and later psychiatric symptoms has been well investigated for depressive disorders and substance abuse (Cerda-Molina et al., 2017; Laucht et al., 2013).

\subsubsection{Public Policies in México for the prevention and care of early trauma}

Violence is a public health problem, with severe negative consequences and alterations in the mental and physical health of the population, especially of the female gender (Krug et al., 2002). Women who have suffered abuse in childhood are up to four times greater risk of developing symptoms of depression in adult life (Heim et al., 2000); furthermore, the magnitude of the trauma correlates significantly with the severity of depressive symptoms (Mullen, et al., 1996).

An agenda of attention to child abuse is urgently needed since spending on care and treatment of depression, and anxiety costs the world economy 1 trillion US\$ a year and, according to the WHO, common mental disorders are on the rise throughout the world. Between 1990 and 2013, the number of people with depression or anxiety has increased by 50\%, from 416 million to 615 million. About $10 \%$ of the world's population is affected, and mental disorders account for $30 \%$ of the global burden of nonfatal disease. Humanitarian emergencies and conflict increase the need to expand therapeutic options. The WHO estimates that 1 in 5 people is affected by depression and anxiety (WHO, 2016). It is a fact that countries should invest in rigorous national studies on the prevalence of child maltreatment and obtain detailed information on its nature (Mathews et al., 2020); this can help improve treatment and prevention strategies (Lippard and Nemeroff, 2020). Child sexual abuse continues to be a severe public health problem in all countries worldwide, as confirmed by the prevalence data. The terrible consequences that child sexual abuse tends to have outweighed the necessary efforts required in the changes and adjustments of public policies (Castro et al., 2019). The adjustments include the prevention of child abuse or neglect, early detection with the use of instruments with high sensitivity and specificity, and timely treatment. Mental health professionals need to recognize that childhood trauma is directly associated with the presence and severity of psychiatric symptoms, attempts, and ideation suicide, especially in women. Finally, optimal treatment of psychiatric patients must consider the history of child abuse and alterations in the stress response. The proposal implies that the Mexican health system invests in studies of the prevalence of early trauma and recognizes the crucial role in the presence and severity of mental disorders. This latest could help implement effective care strategies to compensate for the allostatic burden that already exists, mainly when it affects women, who become potential caretakers and abusers.

\subsection{Conclusions}

Early trauma carries severe adverse consequences for the mental health of individuals, especially for women, who have up to four times the risk of suffering from a mental disorder if they have a history of sexual or physical abuse in childhood. Allostatic load promotes inadequate responses to acute stressors. This condition would be a consequence of constant exposure to chronic stressors, mainly if the experiences occurred in childhood (before 15 years old). The younger the individual, the greater the neurological damage and the greater the risk of suffering from a psychiatric disorder. Some alterations are only visible until adulthood, when the individual presents misadjusted behaviors in the work, social, and family spheres; presenting, in addition, violent or negligent behaviors that perpetuate the chain of adverse events in the minors in their care. The research focused on the prevalence of child abuse in Mexico, its consequences, and regulatory factors are essential and influence public policies for prevention and offering optimal treatment to psychiatric patients who consider the history of childhood trauma, especially in women.

\subsection{References}

Aiello, G., Horowitz, M., Hepgul, N., Pariante, C.M. and Mondelli, V. (2012). Stress abnormalities in individuals at risk for psychosis: a review of studies in subjects with familial risk or with "at risk" mental state. Psychoneuroendocrinology, 37(10), 1600-1613. https://doi.org/10.1016/j.psyneuen.2012.05.003 
Amores-Villalba, A., and Mateos-Mateos R. (2017). Revisión de la neuropsicología del maltrato infantil: la neurobiología y el perfil neuropsicológico de las víctimas de abusos en la infancia. Psicología Educativa, 23:81-88

Anand, P., Esposito, L., and Villaseñor, A. (2018). Depression and economic status: evidence for nonlinear patterns in women from Mexico. Journal of mental health (Abingdon, England), 27(6), 529-551. https://doi.org/10.1080/09638237.2018.1521918

Andreasen N.C. (2010). The lifetime trajectory of schizophrenia and the concept of neurodevelopment. $\begin{array}{llll}\text { Dialogues in } \quad \text { neuroscience, } & \text { 409-415. }\end{array}$ https://doi.org/10.31887/DCNS.2010.12.3/nandreasen

Andreasen, N.C., Nopoulos, P., Magnotta, V., Pierson, R., Ziebell, S., and Ho, B.C. (2011). Progressive brain change in schizophrenia: a prospective longitudinal study of first-episode schizophrenia. Biological psychiatry, 70(7), 672-679. https://doi.org/10.1016/j.biopsych.2011.05.017

Antonopoulou, Z., Konstantakopoulos, G., Tzinieri-Coccosis, M., Sinodinou, C. (2017). Rates of childhood trauma in a sample of university students in Greece: The Greek version of the Early Trauma

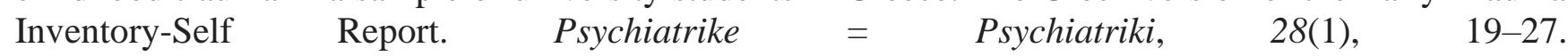
https://doi.org/10.22365/jpsych.2017.281.19

APA (American Psychological Association). (2013). The Diagnostic and Statistical Manual of Mental Disorders(DSM-5). https://doi.org/10.1176/appi.books.9780890425596

Balu, D.T. and Coyle, J.T. (2011). Neuroplasticity signaling pathways linked to the pathophysiology of schizophrenia. Neuroscience and biobehavioral reviews, 35(3), 848-870. https://doi.org/10.1016/j.neubiorev.2010.10.005

Batinic B. (2019). Cognitive Models of Positive and Negative Symptoms of Schizophrenia and Implications for Treatment. Psychiatr Danub. 31(Suppl 2):181-184.

Berger, M., Juster, R. P., Westphal, S., Amminger, G. P., Bogerts, B., Schiltz, K., Bahn, S., Steiner, J., \& Sarnyai, Z. (2018a). Allostatic load is associated with psychotic symptoms and decreases with antipsychotic treatment in patients with schizophrenia and first-episode psychosis. Psychoneuroendocrinology, 90, 35-42. https://doi.org/10.1016/j.psyneuen.2018.02.001

Berger, M., Lavoie, S., McGorry, P.D., Nelson, B., Markulev, C., Yuen, H.P., Schaefer, M., Sarnyai, Z., Amminger, G.P. (2018b). Relationship between allostatic load and clinical outcomes in youth at ultrahigh risk for psychosis in the NEURAPRO study. Schizophr. Res. https://doi.org/10.1016/j.schres.2018.10.002.

Bradley, A.J., and Dinan, T.G. (2010). Review: A systematic review of hypothalamic-pituitary-adrenal axis function in schizophrenia: implications for mortality. Journal of Psychopharmacology, 24(4 suppl), 91-118. https://doi.org/10.1177/1359786810385491

Brown A.S. (2011). The environment and susceptibility to schizophrenia. Progress in neurobiology, 93(1), 23-58. https://doi.org/10.1016/j.pneurobio.2010.09.003

Brown, D.W., Anda, R.F., Tiemeier, H., Felitti, V.J., Edwards, V.J., Croft, J.B., and Giles, W.H. (2009). Adverse childhood experiences and the risk of premature mortality. American journal of preventive medicine, 37(5), 389-396. https://doi.org/10.1016/j.amepre.2009.06.021

Büschlen, J., Berger, G.E., Borgwardt, S.J., Aston, J., Gschwandtner, U., Pflueger, M.O., Kuster, P., Radü, E.W., Stieglitz, R.D. and Riecher-Rössler, A. (2011). Pituitary volume increase during emerging psychosis. Schizophrenia research, 125(1), 41-48. https://doi.org/10.1016/j.schres.2010.09.022

Capilla, J. González-Marqués, A. Carboni-Román, F. Maestú, N. Paúl-Lapedriza. (2007). Desarrollo cognitivo tras un traumatismo craneoencefálico en la infancia. EduPsykhé, 6(2), 171-198. 
Carroll, J. E., Gruenewald, T. L., Taylor, S. E., Janicki-Deverts, D., Matthews, K. A., \& Seeman, T. E. (2013). Childhood abuse, parental warmth, and adult multisystem biological risk in the Coronary Artery Risk Development in Young Adults study. Proceedings of the National Academy of Sciences, 110(42), 17149-17153. https://doi.org/10.1073/pnas.1315458110

Castro, Á., Ibáñez, J., Maté, B., Esteban, J., and Barrada, J.R. (2019). Childhood Sexual Abuse, Sexual Behavior, and Revictimization in Adolescence and Youth: A Mini Review. Frontiers in psychology, 10, 2018. https://doi.org/10.3389/fpsyg.2019.02018

Cerda-Molina, A.L., Borráz-León, J.I., Mayagoitia-Novales, L., and Gaspar Del Río, A.T. (2017). Reactividad del cortisol y salud mental en adultos expuestos a violencia temprana: revisión sistemática [Cortisol reactivity and adult mental health in adults exposed to early violence: a systematic reviewReatividade do cortisol e saúde mental em adultos com exposição precoce à violência: uma revisão sistemática]. Revista panamericana de salud publica = Pan American journal of public health, 41, e171. https://doi.org/10.26633/RPSP.2017.171

Collip, D., Nicolson, N.A., Lardinois, M., Lataster, T., van Os, J., Myin-Germeys, I., and G.R.O.U.P (2011). Daily cortisol, stress reactivity and psychotic experiences in individuals at above average genetic risk for psychosis. Psychological medicine, 41(11), 2305-2315. https://doi.org/10.1017/S0033291711000602

Conrad, C.D., MacMillan, D.D., 2nd, Tsekhanov, S., Wright, RL., Baran, S.E. and Fuchs, R.A. (2004). Influence of chronic corticosterone and glucocorticoid receptor antagonism in the amygdala on fear conditioning. Neurobiology of learning and memory, 81(3), 185-199. https://doi.org/10.1016/j.nlm.2004.01.002

Chu, W.W. and Chu, N.F. (2021). Adverse childhood experiences and development of obesity and diabetes in adulthood-A mini review. Obesity research and clinical practice, 15(2), 101-105. https://doi.org/10.1016/j.orcp.2020.12.010

Danese, A., and McEwen, B.S. (2012). Adverse childhood experiences, allostasis, allostatic load, and

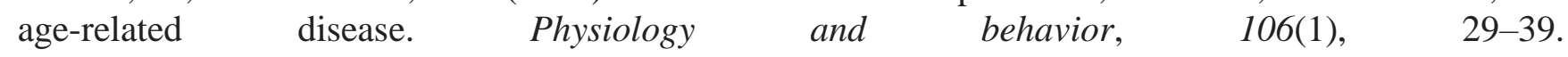
https://doi.org/10.1016/j.physbeh.2011.08.019

Danese, A., Moffitt, T.E., Harrington, H., Milne, B.J., Polanczyk, G., Pariante, C.M., Poulton, R., and Caspi, A. (2009). Adverse childhood experiences and adult risk factors for age-related disease: depression, inflammation, and clustering of metabolic risk markers. Archives of pediatrics and adolescent medicine, 163(12), 1135-1143. https://doi.org/10.1001/archpediatrics.2009.214

De Bellis M.D. (2005). The psychobiology of neglect. Child maltreatment, 10(2), 150-172. https://doi.org/10.1177/1077559505275116

Dennis, M. F., Flood, A.M., Reynolds, V., Araujo, G., Clancy, C.P., Barefoot, J.C., and Beckham, J. C. (2009). Evaluation of lifetime trauma exposure and physical health in women with posttraumatic stress disorder or major depressive disorder. Violence against women, 15(5), 618-627. https://doi.org/10.1177/1077801209331410

Dube, S.R., Fairweather, D., Pearson, W.S., Felitti, V.J., Anda, R.F., and Croft, J.B. (2009). Cumulative childhood stress and autoimmune diseases in adults. Psychosomatic medicine, 71(2), 243-250. https://doi.org/10.1097/PSY.0b013e3181907888

Dwork, A.J., Mancevski, B. and Rosoklija, G. (2007). White matter and cognitive function in schizophrenia. The international journal of neuropsychopharmacology, 10(4), 513-536. https://doi.org/10.1017/S1461145707007638

Edwards, V.J., Holden, G.W., Felitti, V.J., and Anda, R.F. (2003). Relationship between multiple forms of childhood maltreatment and adult mental health in community respondents: results from the adverse childhood experiences study. The American journal of psychiatry, 160(8), 1453-1460. https://doi.org/10.1176/appi.ajp.160.8.1453 
French P, and Morrison A.P. (2004). Early Detection and Cognitive Therapy for People at High Risk of Developing Psychosis: A Treatment Approach. (Ed) England: Chichester, West Sussex. John Wiley and Sons.

Fusar-Poli, P., Deste, G., Smieskova, R., Barlati, S., Yung, A.R., Howes, O., Stieglitz, R.D., Vita, A., McGuire, P. and Borgwardt, S. (2012). Cognitive functioning in prodromal psychosis: a meta-analysis. Archives of general psychiatry, 69(6), 562-571. https://doi.org/10.1001/archgenpsychiatry.2011.1592

Garner, B., Pariante, C.M., Wood, S.J., Velakoulis, D., Phillips, L., Soulsby, B., Brewer, W.J., Smith, D.J., Dazzan, P., Berger, G.E., Yung, A.R., van den Buuse, M., Murray, R., McGorry, P.D., and Pantelis, C. (2005). Pituitary volume predicts future transition to psychosis in individuals at ultra-high risk of $\begin{array}{lllll}\text { developing } & \text { psychosis. } & \text { Biological } & \text { psychiatry, } & \text { 58(5), }\end{array}$ https://doi.org/10.1016/j.biopsych.2005.04.018

Giraldo-Chica, M., Rogers, B.P., Damon, S.M., Landman, B.A., and Woodward, N.D. (2018). PrefrontalThalamic Anatomical Connectivity and Executive Cognitive Function in Schizophrenia. Biological psychiatry, 83(6), 509-517. https://doi.org/10.1016/j.biopsych.2017.09.022

Glantz, L.A. and Lewis, D.A. (2000). Decreased dendritic spine density on prefrontal cortical pyramidal neurons in schizophrenia. Archives of general psychiatry, 57(1), 65-73. https://doi.org/10.1001/archpsyc.57.1.65

Heim, C., Newport, D.J., Heit, S., Graham, Y.P., Wilcox, M., Bonsall, R., Miller, A.H., and Nemeroff, C.B. (2000). Pituitary-adrenal and autonomic responses to stress in women after sexual and physical abuse in childhood. JAMA, 284(5), 592-597. https://doi.org/10.1001/jama.284.5.592

Hoffman, R.E. and McGlashan, T.H. (1997). Synaptic elimination, neurodevelopment, and the mechanism of hallucinated "voices" in schizophrenia. The American journal of psychiatry, 154(12), 1683-1689. https://doi.org/10.1176/ajp.154.12.1683

Holtzman, C.W., Shapiro, D.I., Trotman, H.D. and Walker, E.F. (2012). Stress and the prodromal phase of psychosis. Current pharmaceutical design, 18(4), 527-533. https://doi.org/10.2174/138161212799316280

Juruena M.F. (2014). Early-life stress and HPA axis trigger recurrent adulthood depression. Epilepsy and behavior: $E \& B, 38,148-159$. https://doi.org/10.1016/j.yebeh.2013.10.020

Juul, S.H., Hendrix, C., Robinson, B., Stowe, Z.N., Newport, D.J., Brennan, P.A., and Johnson, K.C. (2016). Maternal early-life trauma and affective parenting style: the mediating role of HPA-axis function. Archives of women's mental health, 19(1), 17-23. https://doi.org/10.1007/s00737-015-0528-x

Kirsch, D.E., Tretyak, V., Radpour, S., Weber, W.A., Nemeroff, C.B., Fromme, K., Strakowski, S.M., and Lippard, E. (2021). Childhood maltreatment, prefrontal-paralimbic gray matter volume, and substance use in young adults and interactions with risk for bipolar disorder. Scientific reports, 11(1), 123. https://doi.org/10.1038/s41598-020-80407-w

Krug, E.G., Mercy, J.A., Dahlberg, L.L., and Zwi, A.B. (2002). The world report on violence and health. Lancet (London, England), 360(9339), 1083-1088. https://doi.org/10.1016/S0140-6736(02)11133-0

Lardinois, M., Lataster, T., Mengelers, R., Van Os, J., and Myin-Germeys, I. (2011). Childhood trauma and increased stress sensitivity in psychosis. Acta psychiatrica Scandinavica, 123(1), 28-35. https://doi.org/10.1111/j.1600-0447.2010.01594.x

Laucht, M., Treutlein, J., Blomeyer, D., Buchmann, A.F., Schmidt, M.H., Esser, G., Jennen-Steinmetz, C., Rietschel, M. and Banaschewski, T. (2013). Interactive effects of corticotropin-releasing hormone receptor 1 gene and childhood adversity on depressive symptoms in young adults: findings from a longitudinal study. European neuropsychopharmacology: the journal of the European College of Neuropsychopharmacology, 23(5), 358-367. https://doi.org/10.1016/j.euroneuro.2012.06.002 
Light, A.E., Holt-Lunstad, J., Porter, C.L., and Light, K.C. (2019). Early life trauma: An exploratory study of effects on OXTR and NR3C1 gene expression and nurturing self-efficacy in mothers of infants. International journal of psychophysiology : official journal of the International Organization of Psychophysiology, 136, 64-72. https://doi.org/10.1016/j.ijpsycho.2018.03.018

Lippard, E., and Nemeroff, C.B. (2020). The Devastating Clinical Consequences of Child Abuse and Neglect: Increased Disease Vulnerability and Poor Treatment Response in Mood Disorders. The American journal of psychiatry, 177(1), 20-36. https://doi.org/10.1176/appi.ajp.2019.19010020

Lupien, S.J., and McEwen, B.S. (1997). The acute effects of corticosteroids on cognition: integration of animal and human model studies. Brain research. Brain research reviews, 24(1), 1-27. https://doi.org/10.1016/s0165-0173(97)00004-0

Martins, C.M.S., de Carvalho Tofoli, S.M., Von Werne Baes, C., and Juruena, M. (2011). Analysis of the occurrence of early life stress in adult psychiatric patients: A systematic review. Psychology and Neuroscience, 4(2), 219-227. http://dx.doi.org/10.3922/j.psns.2011.2.007

Matheson, S.L., Shepherd, A.M., Pinchbeck, R.M., Laurens, K.R., and Carr, V.J. (2013). Childhood adversity in schizophrenia: a systematic meta-analysis. Psychological medicine, 43(2), 225-238. https://doi.org/10.1017/S0033291712000785

Mathews B, Pacella R., Dunne M.P, Simunovic M, Marston C. (2020) Improving measurement of child abuse and neglect: A systematic review and analysis of national prevalence studies. PLoS ONE, 15(1): e0227884. https://doi.org/10.1371/journal.pone.0227884

McEwen B.S. (2006). Protective and damaging effects of stress mediators: central role of the brain. Dialogues in clinical neuroscience, 8(4), 367-381. https://doi.org/10.31887/DCNS.2006.8.4/bmcewen

McGlashan, T.H. and Hoffman, R.E. (2000). Schizophrenia as a disorder of developmentally reduced synaptic connectivity. Archives of general psychiatry, 57(7), 637-648. https://doi.org/10.1001/archpsyc.57.7.637

Meaney, M.J., Aitken, D.H., Viau, V., Sharma, S., and Sarrieau, A. (1989). Neonatal handling alters adrenocortical negative feedback sensitivity and hippocampal type II glucocorticoid receptor binding in the rat. Neuroendocrinology, 50(5), 597-604. https://doi.org/10.1159/000125287

Mesa-Gresa, P. and Moya-Albiol, L. (2011). Neurobiología del maltrato infantil: el ciclo de la violencia. Revista de Neurología, 52(8), 489-503.

Mifsud, K. R., Kennedy, C., Salatino, S., Sharma, E., Price, E. M., Haque, S. N., Gialeli, A., Goss, H. M., Panchenko, P. E., Broxholme, J., Engledow, S., Lockstone, H., Cordero Llana, O., \& Reul, J. (2021). Distinct regulation of hippocampal neuroplasticity and ciliary genes by corticosteroid receptors. Nature communications, 12(1), 4737. https://doi.org/10.1038/s41467-021-24967-z

Mizrahi, R., Addington, J., Rusjan, PM., Suridjan, I., Ng, A., Boileau, I., Pruessner, JC., Remington, G., Houle, S. and Wilson, AA. (2012). Increased stress-induced dopamine release in psychosis. Biological psychiatry, 71(6), 561-567. https://doi.org/10.1016/j.biopsych.2011.10.009

Moghaddam B. (2002). Stress activation of glutamate neurotransmission in the prefrontal cortex: implications for dopamine-associated psychiatric disorders. Biological psychiatry, 51(10), 775-787. https://doi.org/10.1016/s0006-3223(01)01362-2

Mullen, P.E., Martin, J.L., Anderson, J.C., Romans, S.E., and Herbison, G.P. (1996). The long-term impact of the physical, emotional, and sexual abuse of children: a community study. Child abuse and neglect, 20(1), 7-21. https://doi.org/10.1016/0145-2134(95)00112-3

Nemeroff C.B. (2016). Paradise Lost: The Neurobiological and Clinical Consequences of Child Abuse and Neglect. Neuron, 89(5), 892-909. https://doi.org/10.1016/j.neuron.2016.01.019 
Nuechterlein, K.H. and Dawson, M.E. (1984). A heuristic vulnerability/stress model of schizophrenic episodes. Schizophrenia bulletin, 10(2), 300-312. https://doi.org/10.1093/schbul/10.2.300

Openshaw, M., Thompson, L.M., de Pheils, P.B., Mendoza-Flores, M.E., and Humphreys, J. (2015). Childhood trauma is associated with depressive symptoms in Mexico City women. Revista panamericana de salud publica $=$ Pan American journal of public health, 37(4-5), 308-315.

Pantelis, C., Yücel, M., Bora, E., Fornito, A., Testa, R., Brewer, W.J., Velakoulis, D. and Wood, S.J. (2009). Neurobiological markers of illness onset in psychosis and schizophrenia: The search for a moving target. Neuropsychology review, 19(3), 385-398. https://doi.org/10.1007/s11065-009-9114-1

Pavlides, C., Watanabe, Y. and McEwen, B.S. (1993). Effects of glucocorticoids on hippocampal longterm potentiation. Hippocampus, 3(2), 183-192. https://doi.org/10.1002/hipo.450030210

Pechtel, P., Lyons-Ruth, K., Anderson, C. M., and Teicher, M.H. (2014). Sensitive periods of amygdala development: the role of maltreatment in preadolescence. NeuroImage, 97, 236-244. https://doi.org/10.1016/j.neuroimage.2014.04.025

Piotrowski, P., Frydecka, D., Kotowicz, K., Stańczykiewicz, B., Samochowiec, J., Szczygieł, K., and Misiak, B. (2020). A history of childhood trauma and allostatic load in patients with psychotic disorders with respect to stress coping strategies. Psychoneuroendocrinology, 115, 104645. https://doi.org/10.1016/j.psyneuen.2020.104645

Pruessner, M., Iyer, SN., Faridi, K., Joober, R. and Malla, A. K. (2011). Stress and protective factors in individuals at ultra-high risk for psychosis, first episode psychosis and healthy controls. Schizophrenia research, 129(1), 29-35. https://doi.org/10.1016/j.schres.2011.03.022

Rivier, C.L., and Plotsky, P.M. (1986). Mediation by corticotropin releasing factor (CRF) of adenohypophysial hormone secretion. Annual review of physiology, 48, 475-494. https://doi.org/10.1146/annurev.ph.48.030186.002355

Sapolsky R.M. (1985). Glucocorticoid toxicity in the hippocampus: temporal aspects of neuronal vulnerability. Brain research, 359(1-2), 300-305. https://doi.org/10.1016/0006-8993(85)91440-4

Sapolsky, R.M., Uno, H., Rebert, C.S. And Finch, C.E. (1990). Hippocampal damage associated with prolonged glucocorticoid exposure in primates. The Journal of neuroscience : the official journal of the Society for Neuroscience, 10(9), 2897-2902. https://doi.org/10.1523/JNEUROSCI.10-09-02897.1990

Sassarini D.J. (2016). Depression in midlife women. Maturitas, 94, 149-154. https://doi.org/10.1016/j.maturitas.2016.09.004

Schreier, H.M., Enlow, M.B., Ritz, T., Gennings, C., and Wright, R.J. (2015). Childhood abuse is associated with increased hair cortisol levels among urban pregnant women. Journal of epidemiology and community health, 69(12), 1169-1174. https://doi.org/10.1136/jech-2015-205541

Seeman, T. E., McEwen, B. S., Rowe, J. W., \& Singer, B. H. (2001). Allostatic load as a marker of cumulative biological risk: MacArthur studies of successful aging. Proceedings of the National Academy of Sciences, 98(8), 4770-4775. https://doi.org/10.1073/pnas.081072698

Seeman, T. E., Singer, B. H., Rowe, J. W., Horwitz, R. I., \& McEwen, B. S. (1997). Price of adaptationallostatic load and its health consequences: MacArthur studies of successful aging. Archives of internal medicine, 157(19), 2259-2268. doi:10.1001/archinte.1997.0044040011101

Selemon, L.D., Rajkowska, G. and Goldman-Rakic, P.S. (1995). Abnormally high neuronal density in the schizophrenic cortex. A morphometric analysis of prefrontal area 9 and occipital area 17. Archives of general psychiatry, 52(10), 805-820. https://doi.org/10.1001/archpsyc.1995.03950220015005 
Seligowski A.V., Harnett N.G., Merker J.B., Ressler K.J. (2020). Nervous and Endocrine System Dysfunction in Posttraumatic Stress Disorder: An Overview and Consideration of Sex as a Biological Variable, Biological Psychiatry. Cognitive Neuroscience and Neuroimaging, 5(4), 381-391, https://doi.org/10.1016/j.bpsc.2019.12.006

Sideli, L., Mule, A., La Barbera, D. and Murray, R.M. (2012). Do child abuse and maltreatment increase risk of schizophrenia?. Psychiatry investigation, 9(2), 87-99. https://doi.org/10.4306/pi.2012.9.2.87

Šimić, G., Tkalčić, M., Vukić, V., Mulc, D., Španić, E., Šagud, M., Olucha-Bordonau, F. E., Vukšić, M., \& R Hof, P. (2021). Understanding Emotions: Origins and Roles of the Amygdala. Biomolecules, 11(6), 823. https://doi.org/10.3390/biom11060823

Spear L.P. (2003). Neurodevelopment during adolescence. In: Cicchetti D, Walker E (Ed). Neurodevelopmental Mechanisms in Psychopathology (pp. 62-83). Cambridge University Press; New York, NY.

Stein-Behrens, B., Mattson, M.P., Chang, I., Yeh, M. and Sapolsky, R. (1994). Stress exacerbates neuron loss and cytoskeletal pathology in the hippocampus. The Journal of neuroscience : the official journal of the Society for Neuroscience, 14(9), 5373-5380. https://doi.org/10.1523/JNEUROSCI.14-0905373.1994 .

Tessner, KD., Mittal, V. and Walker, E.F. (2011). Longitudinal study of stressful life events and daily stressors among adolescents at high risk for psychotic disorders. Schizophrenia bulletin, 37(2), 432-441. https://doi.org/10.1093/schbul/sbp087

Thara, R., and Kamath, S. (2015). Women and schizophrenia. Indian journal of psychiatry, 57(Suppl 2), S246-S251. https://doi.org/10.4103/0019-5545.161487

Thayer, Z., Barbosa-Leiker, C., McDonell, M., Nelson, L., Buchwald, D., \& Manson, S. (2017). Early life trauma, post-traumatic stress disorder, and allostatic load in a sample of American Indian adults. American journal of human biology: the official journal of the Human Biology Council, 29(3), 10.1002/ajhb.22943. https://doi.org/10.1002/ajhb.22943

Vitriol, V., Cancino, A., Ballesteros, S., Núñez, C., and Navarrete, A. (2017). Depresión y trauma temprano: hacia una caracterización clínica de perfiles de consulta en un servicio de salud secundario. Revista chilena de neuro-psiquiatría, 55(2), 123-134. https://dx.doi.org/10.4067/S071792272017000200007

Vyas, A., Pillai, A.G. and Chattarji, S. (2004). Recovery after chronic stress fails to reverse amygdaloid neuronal hypertrophy and enhanced anxiety-like behavior. Neuroscience, 128(4), 667-673. https://doi.org/10.1016/j.neuroscience.2004.07.013

Vythilingam M, Heim C, Newport J, Miller AH, Anderson E, Bronen R, Brummer M, Staib L, Vermetten E, Charney DS, Nemeroff CB, Bremmer JD. (2002). Childhood trauma associated with smaller hippocampal volume in women with major depression. Am J Psychiatry. Dec; 159(12):2072-80. https://doi:org/10.1176/qppi.ajp.159.12.2071.

Walder, D.J., Walker, E.F. and Lewine, R.J. (2000). Cognitive functioning, cortisol release, and symptom severity in patients with schizophrenia. Biological psychiatry, 48(12), 1121-1132. https://doi.org/10.1016/s0006-3223(00)01052-0

Walker, E. and Bollini, A.M. (2002). Pubertal neurodevelopment and the emergence of psychotic symptoms. Schizophrenia research, 54(1-2), 17-23. https://doi.org/10.1016/s0920-9964(01)00347-4

Walker, E.F. And Diforio, D. (1997). Schizophrenia: a neural diathesis-stress model. Psychological review, 104(4), 667-685. https://doi.org/10.1037/0033-295x.104.4.667 
Walker, E.F., Walder, D.J. and Reynolds, F. (2001). Developmental changes in cortisol secretion in normal and at-risk youth. Development and psychopathology, 13(3), 721-732. https://doi.org/10.1017/s0954579401003169

Wenham, C., Smith, J., Morgan, R., and Gender and COVID-19 Working Group (2020). COVID-19: the gendered impacts of the outbreak. Lancet (London, England), 395(10227), 846-848. https://doi.org/10.1016/S0140-6736(20)30526-2

World Health Organization. (2006). Preventing child maltreatment : a guide to taking action and generating evidence. World Health Organization and International Society for Prevention of Child Abuse and Neglect. World Health Organization.https://apps.who.int/iris/handle/10665/43499

World Health Organization. (2016). Investing in treatment for depression and anxiety leads to fourfold return. World Health Organization. Retrieved from https://www.who.int/es/news/item/13-04-2016investing-in-treatment-for-depression-and-anxiety-leads-to-fourfold-return

World Health Organization. (2018). Eliminating female genital mutilation: An interagency statement. Geneva. Retrieved from http://www. who.int/reproductivehealth/publications/fgm/9789241596442/en/

World Health Organization. (2019). Delivered by women, led by men: a gender and equity analysis of the global health and social workforce. World Health Organization. https://apps.who.int/iris/handle/10665/311322. Licencia: CC BY-NC-SA 3.0 IGO

Yee C.M., Mathis K.I., Lang P.J., Taylor S.E., Sholty G.L., Sun, J.C. and Neuchterlein, K.H. (2007). Stress reactivity and affective modulation during the prodromal, first-episode and chronic phases of schizophrenia. In Translational Research on Neurocognition and Emotion in Schizophrenia. Symp. Int. Congr. Schizophrenia Res., KH Nuechterlein, chair, Colorado Springs, CO. 
Chapter 4 Growth and development of the craneofacial region and the stomatognátic apparatus

Capítulo 4 Crecimiento y desarrollo de la región craneofacial y el aparato estomatognático

TORRE-MARTÍNEZ, Hilda †*, THERIOT-GIRÓN, María de Carmen, CARRILLO-GONZÁLEZ, Roberto and MENDOZA-TIJERINA, Adrian

Universidad Autónoma de Nuevo León, Mexico

ID $1^{\text {st }}$ Author: Hilda, Torre.Martínez / ORC ID: 0000-0002-4147-7310

ID $1^{\text {st }}$ Co-author: María de Carmen, Theriot-Girón

ID $2^{\text {nd }}$ Co-author: Roberto, Carrillo-González

ID $3^{\text {rd }}$ Co-author: Adrian, Mendoza-Tijerina

DOI: $10.35429 / \mathrm{H} .2021 .13 .36 .56$

H. Torre, M, Theriot, R. Carrillo and A. Mendoza

*dratorrem@gmail.com

A. Marroquín, J. Olivares, M. Cruz, L. Cruz. (Coord.) CIERMMI Women in Science TXIII Medicine and Health Sciences. Handbooks-@ECORFAN-México, Querétaro, 2021. 


\begin{abstract}
The purpose of this chapter is to recall the importance of craniofacial growth and development in the human being, that is why concepts and monitoring of this important process are included. It is a compilation of information obtained on the basis of knowledge obtained from the literature as well as from the authors, it can be said to be a systematic review of information or frame of reference. This is a contribution to the academic training of students and a brief journey through time on this topic for dentists in practice and teachers in this area. It is concluded that growth and development in the theoretical aspect is very important to apply in practice the knowledge obtained and remembered in this contribution.
\end{abstract}

\title{
Growth, Development, Cephalometry, Cephalometry
}

\section{Resumen}

El presente capítulo tiene como objetivo recordar la importancia del crecimiento y desarrollo cráneo facial en el ser humano, es por eso que se incluyen conceptos y y seguimiento de este importante proceso. Es una recopilación de información obtenida en base a los conocimientos obtenidos en la literatura como en los de los autores, se puede decir que es una revisión sistemática de información o marco de referencia. Con este se contribuye a la formación académica de los estudiantes y un breve viaje en el tiempo acerca de es te tema para los odontólogos en consulta y los docentes en esta área. Se concluye que el crecimiento y desarrollo en el aspecto teórico es muy importante para aplicar en la práctica los conocimientos obtenidos y recordados en esta aportación.

\section{Crecimiento, Desarrollo, Cefalometría}

\subsection{Introduction}

To practice dentistry it is necessary to have a broad knowledge of craniofacial growth and development. Although dentistry has many specialties, it is important to have the knowledge even when not working with children, since many of the disorders in adults are originated from development.

Most, if not all, dentists have contact with children, so it is important to know how to distinguish normal processes from the effects of abnormal or pathological processes.

Figure 4.1 Skull of a new-born

\section{Cráneo Normal del Recién Nacido}

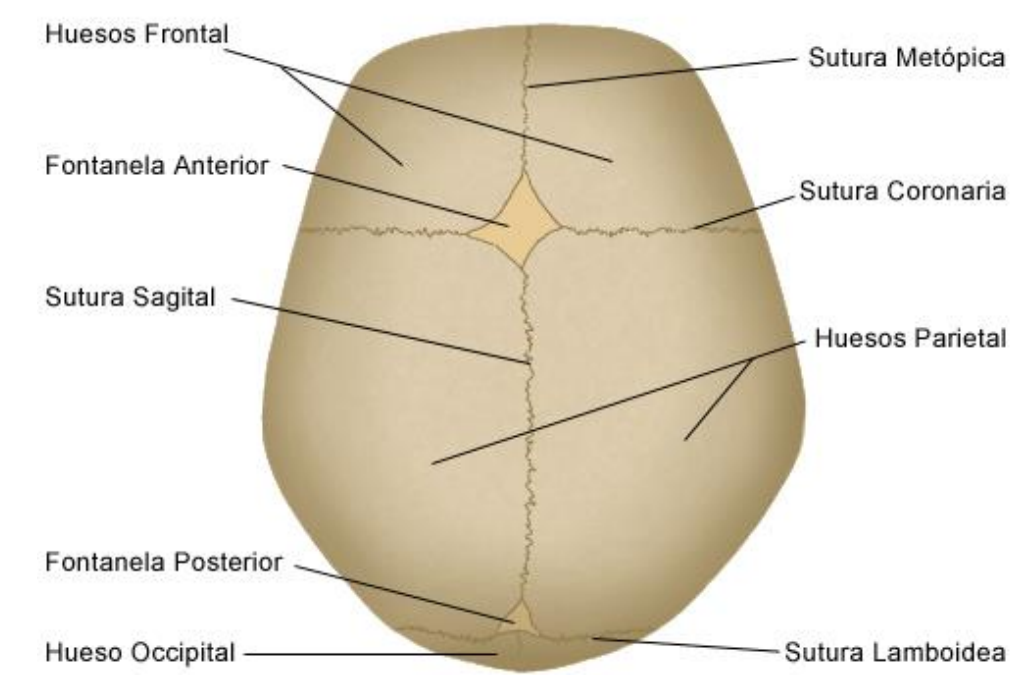

Both orthodontists and pediatric dentists will be able to beneficially manipulate the facial growth of patients when they have the knowledge of the norms of growth and the mechanisms that are related to it. The knowledge of the growth of the craniofacial skeleton is a complex and essential process for diagnosis and treatment in interceptive or preventive orthodontics. (1) 
First of all, we must differentiate the terms growth and development because although they are totally linked they are different terms, growth refers to an increase in size or number, it is an anatomical phenomenon, it is the increase in the dimensions of the body mass (size, height and weight) this is due to hypertrophy and hyperplasia of the constituent tissues of the organism, The basis of this process is the cellular differentiation, sometimes the increase will not be neither in size nor in number but in complexity, then we will be talking about development which is an anatomical phenomenon, it is the change in the physical proportions, quantitative and qualitative changes that take place in the human organism and that bring at the same time an increase in the complexity of the organization and interaction of all the systems. The basis of this process is cellular differentiation, which leads to the maturation of different physical and psychological functions, a quality that gradually leads to the improvement of functional capacity. It also refers to unidirectional changes that occur in a living being from being constituted as a simple cell until death, when referring to complexity we speak of development, growth and development are not independent, but represent a continuity of interactions of processes that cause changes in form and functions of all tissues of the body and includes the increase of the individual's capabilities and adaptations acquired in the process towards maturity. $(1,2,3)$

Craniofacial development and growth derives from a series of morphogenetic processes in intrauterine life and after birth these achieve a functional and structural balance between the hard and soft tissue of the craniofacial region. Since the bones of the craniofacial complex are in constant growth before the action and internal and external circumstances in order to preserve the balance during childhood and adulthood. (1)

\subsection{Growth: patterns, variability and chronology}

When we talk about growth we use the word pattern, which is a scheme that is followed to make a dress, shoes, artificial teeth, etc. Therefore, the pattern of growth refers to the changes that spatial proportions undergo over time, that is, there is a superior organization.

During fetal development by the third month the head represents $50 \%$ of the total body length, the skull is large in relation to the face and represents more than half of the total head, the limbs and trunk are underdeveloped (Figure 4.1). As time goes by, the head decreases to $30 \%$ and the trunk and limbs grow faster. When the moment of birth arrives the legs reach $1 / 3$ of the total length of the body, in the adult represent $1 / 2$ the legs grow more than the arms during the postnatal life, these changes reflect the cephalocaudal gradient of growth, that is to say the increase is from the head to the feet. $(3,4)$

Figure 4.2 Developmental changes of the head from newborn to adult
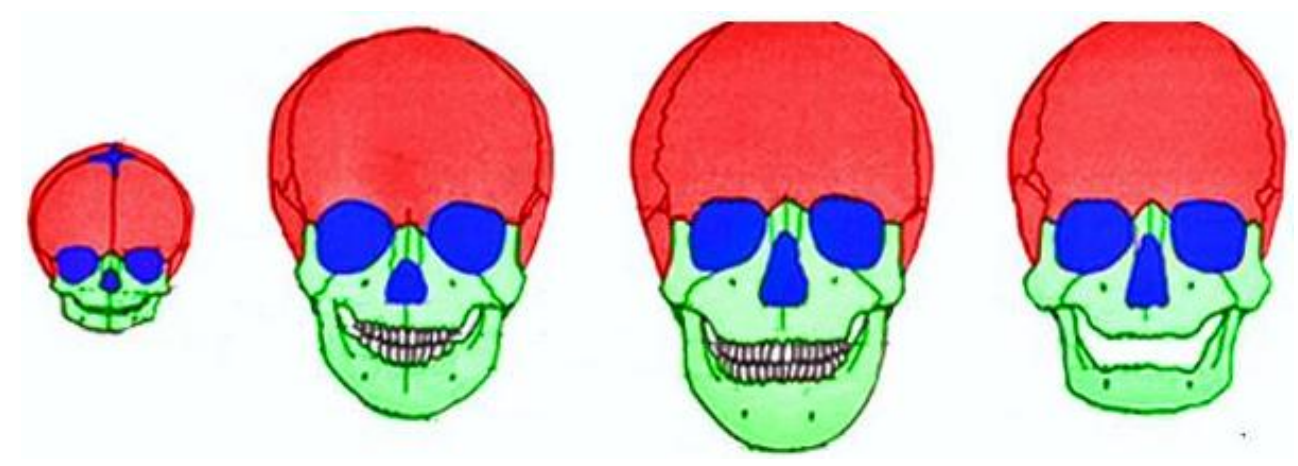

Muscles and bones grow faster than the brain and the central nervous system, which indicates that there are different growth gradients found in different parts of the body, the tissues are different and grow at different rates. With respect to the head and face it can be observed that the changes are very noticeable when comparing the proportions of a newborn with those of an adult, the child has a larger skull (80\% development) than the size of the face (20\% development), later on the facial growth pattern will make the proportions more accentuated in the growth of the face than in the skull.

Growth patterns are predictable because they repeat themselves, similar to a geometric pattern where the only difference lies in the addition of the temporal dimension. A change in the growth pattern will indicate an alteration in the predictable and predictable sequence of changes that can be expected in an individual. (4) 
Variability is a concept to keep in mind when studying growth and development, individuals are not alike in the way they grow, think and do, it is very important to decide whether the individual represents an extreme of normal variation or exceeds normal limits. Therefore, it is better to use the term variability to indicate deviations from a growth pattern and not to classify individuals into normal and abnormal. There are charts and graphs to assess a child's growth and development that were designed in a standardized way, specifically for height and weight, and can be made for any part of the body.

Based on these graphs it can be established if the child is growing normally when it is within the limits of normality of these graphs, if the child's height and/or weight are higher or lower, the professional should consider the possibility of a growth abnormality. (1)

Timing is another important term in growth and development. Variations can affect growth in several ways: normal variation, by influences outside the normal experience (serious illness) and by their effects depending on the time at which they occur. Chronological variations are those in which the same event affects different individuals at different times, with the biological clocks of individuals functioning differently.

In adolescence it is possible to see chronological variations in growth and development more easily. Occasionally some children grow and mature more rapidly, establishing and completing their growth and appear in the charts and graphs in the higher zones, which will be temporary as they will be overtaken by peers. Some other children grow and mature more slowly and fall behind but will suddenly grow up and leave the taller children behind. This growth spurt, which all children tend to have, happens at different times for each child.

In girls, the phenomenon of chronological variation can be observed more easily, since the onset of menstruation, also known as menarche, indicates the onset of sexual maturity, which is accompanied by an acceleration of growth. Girls also show gender differences, with some maturing earlier than others and surpassing the pubertal growth spurt, while late-maturing girls have not begun to grow rapidly. Chronological variation that occurs in many forms contributes to variability. Age is usually measured chronologically with elapsed time in years, but it is also possible to measure it with the series of markers or developmental stages that are used to do so biologically.

A range of \pm 2 years on average is considered normal. Therefore, for girls the onset of the outbreak may be between 9-13 years and for boys between 9-15. The value of this range of values is as in many biological distributions a normal distribution.

It is possible to reduce chronological variability by using developmental age as an expression of an individual's development. When it is possible to do this, a table of sexual development using a biological time scale is used and the pattern is shown to be expressed at chronologically different, but not physiologically different, times. (1)

\subsection{Methods for studying growth}

To perform the study of craniofacial growth and development there are two methods; one that is based on the specific measurement techniques of live animals including humans, without being detrimental and the study subject can be used for other measurements.

The other method of measurement is the one that is performed by manipulating the growth is based on experimentation, the subject on which is experimented most of the time is sacrificed, so many of the experimental studies are performed on animals.

\section{Measurement methods}

\section{Craneometry}

Physical anthropology (called craniometry) began with methods of measuring the skulls of human skeletal remains, especially used to study the skulls of Neanderthal and Cro-Magnon men found in Europe in the 18th and 19th centuries. With this, a great deal of information has been obtained about the extinct beings and to determine something about growth patterns by making comparisons. 
Craniometry allows measurements on dry skulls which are usually quite accurate, the main disadvantage is that the measurements are usually in cross section, even if the skulls or representations are of several individuals they can only be measured once. (1)

\section{Anthropometry}

Anthropometry measures in living individuals various parameters established in studies with dissected skulls, in this case the soft tissue areas that cover the bony points of reference are used. As an example, the length of the skull can be measured from the bridge of the nose to the maximum convexity of the back of the skull. Such a measurement can be performed on a living individual as well as on a dry skull, there will be some differences mainly found with respect to the existence of soft tissues.

With this type of measurement, several measurements can be taken on the same individual at different times at the same points, thus performing longitudinal studies.

Farkas in recent years has conducted very interesting studies on facial proportions and their changes over time. $(1,5)$

\section{Cephalometry}

It is an important measurement technique since, in addition to assessing growth, it supports the study of orthodontic patients. It is based on the exact orientation of the head before performing an X-ray with controlled magnification.

It combines craniometry and anthropometry, measures skeletal bone dimensions, since in the Xray the bone can be seen through the soft tissues that cover it, allowing the individual to be followed over time. Cephalometric studies are carried out by superimposing a digital model or tracing a posterior cephalogram over an anterior one, measuring the changes, observing the locations and the degree of growth.

A drawback of cephalometric radiography is that it gives a two-dimensional image of a threedimensional one even when the head is well positioned. However, this problem can be solved by taking several radiographs in different orientations and using triangulation to calculate oblique distances. (1, $6,7)$

\section{$3 D$ three-dimensional images}

In this super-modern era, measurements are obtained using three-dimensional techniques. Computed axial tomography (CT) allows reconstruction of the skull and face in 3D, and has been used for years in the design, planning and surgical reconstruction of patients with facial deformities. (1)

\section{Hand radiography}

Any part of the body can be used to determine bone age, but in practice the hand and wrist are the most commonly used, because they have several bones and epiphyses in development, which allows tracking the changes that occur through growth. They are the most convenient areas to assess bone maturation, as they are far from the gonads and require less radiation. Radiographs of the left hand and wrist are taken because they are less influenced by external factors, considering the higher proportion of right-handed patients. Although Greulich and Pyle show very little difference between the bone growth of the right and left hand. (8)

\subsection{Stages of growth and development}

In growth and development, the limits between them are not precise and present special characteristics. Growth presents 3 main stages. 
First stage: infancy

Early Childhood: from birth to 3 years of age and the changes observed are:

Eruption of primary teeth and completion of the primary dentition.

The increase in height by more than $40 \%$ in the first year is the largest of all the child's growth.

Increase in height from $50 \mathrm{~cm}$ to $1 \mathrm{~m}$.

Weight gain from 3 to $12 \mathrm{~kg}$.

Second childhood: from 3 to 6 years of age.

This completes the deciduous dentition and initiates the mixed dentition with the eruption of the $1^{\text {st }}$ permanent molar at 6 years of age.

The increase in height and weight is less than in early childhood, being 25 to $30 \mathrm{~cm}$ and 6 to 7 $\mathrm{kg}$, respectively.

25 to $30 \mathrm{~cm}$ and 6 or $7 \mathrm{~kg}$. respectively.

Increased growth in width.

Apparently stationary dental evolution.

Head volume is very large in relation to the overall size.

Third Childhood: in girls it is from 6 to 11 years of age and in boys from 12 or 13 years of age.

The primary dentition is replaced by the permanent dentition, a period known as mixed dentition. Head growth slows down.

Longitudinal increase of the skeleton in relation to transverse growth. $(4,9)$.

Second stage: adolescence

Pre-puberty:

It lasts 2 years and appears first in girls, it is a time of important changes in the organism, from 11 to 13 in women and from 12 to 14 in men.

In men.

Increased growth of the lower extremities.

Increase in height of approximately $7 \mathrm{~cm}$ per year.

Puberty.

From 13 to 15 years of age in females and from 14 to 16 years of age in males.

Maturation of sexual organs and manifestation of sexual characteristics such as menarche and first ejaculation.

From the dental point of view very few changes are observed, although in some processes it is possible to find the budding of the 3 rd molars in our environment. 
Post-puberty: The individual completes its transformation and acquires its definitive shape and proportions and proportions, it goes from 15 to 18 in females and from 16 to 20 in males.

20 in males.

Adolescence is the most important time of growth and development, as the major evolutionary crises of some organs occur.

The major evolutionary crises of some organs take place.

The permanent dentition is established and there is some remaining growth of the jaws.

Second stage: cloudiness. -youth 18 years old until 25 years old

The growth is relative and the individual reaches the definitive height and proportions. The only dental change may be the eruption of the 3rd molars and the remaining growth of the jaws is very reduced.

Adult Age. Between 25 and 60 years of age.

Period of functional balance, growth is complete and the individual reaches his greatest physical, intellectual and genital strength. During all stages the individual undergoes changes in physical body proportions such as that of the head in relation to the total size and of the face in relation to the total volume of the head. $(1,3)$

\subsection{Areas and types of craniofacial growth}

It is important to know: 1. the areas of growth, 2. the type of growth that occurs in that place, 3. and the factors that determine or control such growth.

The facial skull complex can be divided into four regions that grow in different ways:

1. Cranial vault, the bones that cover the external surface of the brain.

2. Base of the skull, the bony floor beneath the brain, which is also the dividing line between the skull and the face.

3. Naso-maxillary complex, consisting of the nose, the maxilla and associated bones.

4. Jaw.

\section{Mechanism of bone growth}

\section{Sites of craniofacial growth and remodeling}

During craniofacial development and growth, it is necessary to take into account how the displacement and translation of the craniofacial complex takes place, since it is influenced by several factors that are of great importance for dentists to know since they act on the stomatognathic system.

During growth there are remodeling functions that are linked to childhood, most of which also last until adulthood. Facial growth is a process that requires close morphogenic interrelationships between hard or soft tissue that grow, change and function. No element is self-sufficient and independent in terms of development; a continuous state of structural and functional equilibrium is fundamental and important in growth. $(1,4,9)$

Bone growth is a cumulative process of resorption, apposition or deposition of bone accompanied by remodeling, resulting in the displacement of bone, as a bone increases in volume, at the same time moving away from other bones in contact with it. This movement is given by the apposition of new bone on one side of the cortex and resorption of the opposite side, producing a real movement of growth that indicates the increase of the dimensions of the whole bone. 
During the enlargement of the craniofacial bones two types of growth movements are seen:

\section{Cortical creep and displacement}

Creep: Creep is the movement of bone that is the result of the combination of deposition of new bone on one side of the cortical lamina and resorption on the opposite side, this happens throughout the growth zone of a bone and is not located in the main growth centers, it produces generalized augmentation, as well as relocation of the points involved. Dragging occurs simultaneously with displacement, but they are different as they are distinct ways of movement of the whole bone as a unit.

Remodeling: During remodeling, the amount of bone deposition is greater in relation to bone resorption, so that regions of a bone gradually increase and the cortical laminae present greater thickness as soon as they are remodeled.

Remodeling is a fundamental part of growth, so that the bone can move, resulting in movement in each bone relocating them from one site to another. Therefore, growth and remodeling are inseparable parts, so the bone must present an external periosteal surface of resorption and apposition which need not be carried out with the same intensity.

The growth activity can be observed that some areas of the different bones grow faster than others, therefore there are areas of greater importance in the growth that are called "growth sites", for example, the condyle is one of these sites, however, growth does not occur only on certain surfaces, All bone surfaces are specially designated growth sites because during growth apposition is greater than resorption and as bone size increases, acting on the expansive force of all the soft tissues surrounding the bone determines the rate of the growth remodeling process that surrounds the bone and displaces it, physiological actions applied on the bone, leading to apposition of new bone on the contact surface. All particular contacts and bone ends have fundamental importance in growth, from these same points the displacement continues and at the same time the places where the remodeling lengthens a particular bone. And in this way continuous regional structural adjustments of all portions of the bone are made in order to achieve proper adaptation for future intrinsic and extrinsic changes during growth. $(3,410)$

The bone surface oriented towards the actual direction of growth receives new bone deposit there is bone apposition, while that which is away from the course of growth is resorbed, and in this way the bone can migrate or displace which is the movement of a whole bone as a unit and simultaneously maintain relationships with neighboring bones in relation to a fixed structure, whereby the individual bones are kept in constant articular union. $(1,3,4)$

\section{Cranial bowl}

The cranial vault is constituted by a series of flat bones that originate directly by intramembranous bone formation without cartilaginous precursors, the growth process is the result of periosteal activity on the surface of these bones. At birth the cranial vault is asymmetrical due to the pressure to which it is subjected during birth, this is corrected with post natal growth, so it changes shape in the first two years of life, when the child is born the bones of the skull are separated by lax intermediate connective tissue (figure 2).

At the moment of birth the skull can be deformed thanks to these spaces called fontanelles, the head is very large and with this deformation the baby can descend through the birth canal. The skull enlarges due to the pressure exerted by the growing brain and its primary function is to protect it. At birth the sutures between the bones are separated by fontanelles, which are membranous spaces in the skull. The growth of the cranial vault is (according to Brodie) concentric.

After birth, there is bone apposition along the fontanelles and the open spaces are rapidly being eliminated, however the bones are still separated by a thin periosteal covered suture which in adulthood fuses, the apposition of newly formed bone at the sutures and the main mechanism of growth of the cranial vault, remodeling and growth occur at the periosteal covered contact zones that exist at the cranial sutures, hence it is sutural development. $(4,11)$ 
Figure 4.3 Skull of the newborn

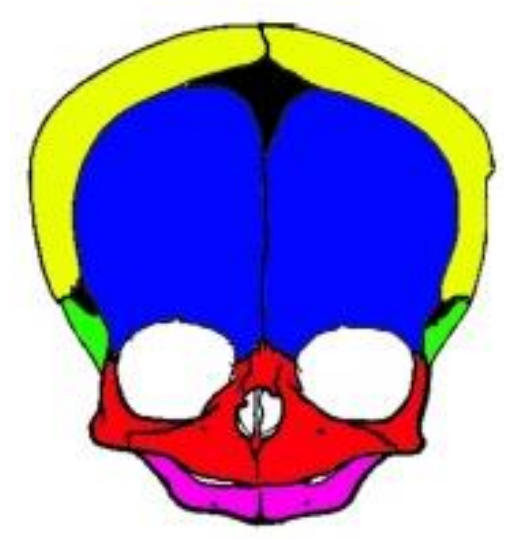

The growth of the cranial vault is determined by environmental factors and in the same way as the previous ones is based on membranous growth centers in the region and simultaneously begins the ossification of the sutures that are found between them, which will be constituted in: growth centers, areas of flexibility and future movement of the cranial vault. Thus, the coronal, sagittal, occipital, metopic, bregmatic, lamboid, pteric and asteric sutures will become potential areas of expansion of the cranial vault during the first years of life, or areas of growth limitation that give rise to cranial malformations due to their premature closure.

\section{Growth in width}

There is apposition on the external surface, and resorption on the internal table, growth of the medial sagittal suture between the parietal bones and of the sagittal suture between the frontal bones (Figure 3 ).

\section{Growth in height}

It is carried out by growth of the cranial sutures: fronto-sphenoidal, parieto-sphenoidal, parietotemporal and parietooccipital, and to a lesser degree by apposition on the external table of the cranial vault.

\section{Growth in length}

It is at the level of the coronary-frontoparietal suture, compensating the increase in length of the skull base and there is little remodeling, mainly adjacent to the suture. $(1,3,4)$

Figure 4.4 Cranial vault width and height growth

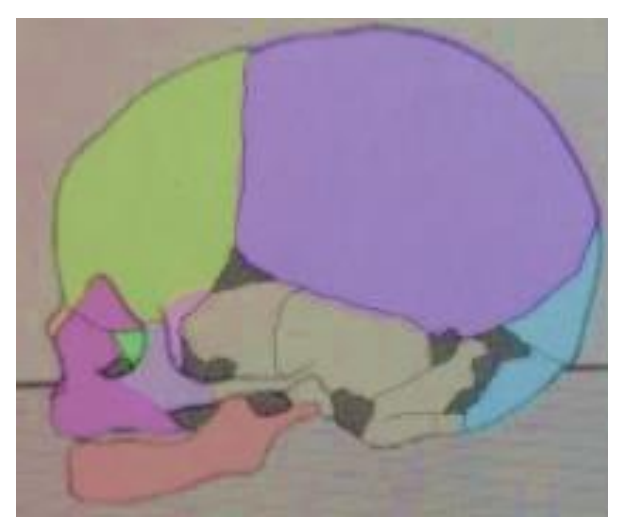

Skull base

\section{Growth of the cranial base (condocranium)}

Linked to the vault, they share the function of protecting the brain, but are also articulated with the spine, the mandibular condyle and the nasomaxillary complex. 
The bones at the base of the skull are formed from cartilage and are transformed into bone by endochondral ossification, which affects the midline structures.

When laterally displaced, suture growth and surface remodeling are more important, the skull base is a midline structure.

At the beginning of intrauterine life the growth centers of the chondrocranium appear, definitively locating the bones: ethmoid, sphenoid and the basilar portion of the occipital. As ossification progresses, bands of cartilage called synchondrosis appear between the ossification centers. The most important are the spheno-occipital synchondrosis between the sphenoid and the occipital, and the intersphenoidal synchondrosis between the two parts of the sphenoid, which ossifies before or immediately after birth. And between the sphenoid and ethmoid the sphenoethmoidal synchondrosis, the area between the two bones is formed by growing cartilage. The synchondrosis has a zone of cellular hyperplasia in the center, with bands of chondrocytes and maturation extending in both directions that will be replaced by bone.

Immobile joints develop between the bones of the skull base, unlike the bones of the extremities which develop extremely mobile joints. The base of the skull resembles a long bone, with the difference that it has multiple synchondroses that are similar to epiphyseal plates. There are immobile joints at the base of the skull, the exception being the mandible. The periosteum-covered sutures at other points that do not contain cartilage are quite different from the cartilaginous synchondroses. (4)

\section{Growth in width of the skull base}

The temporo-sphenoidal and temporo-occipital synchondrosis contribute to the width of the base, in addition to the superficial apposition. Temporo-occipital synchondrosis, in addition to the superficial apposition.

\section{Growth in height of the base of the skull.}

The height of the base is given by the surface apposition.

\section{Growth of the skull base.}

Until early childhood, the spheno-ethmoid synchondrosis plays a fundamental role in the growth in length of the cranial base.

The growth in length of the cranial base, later and up to about 20 years of age, the main the main anteroposterior growth of the skull base is due to the spheno-etmoid synchondrosis.

The skull base is due to the spheno-occipital synchondrosis (Figure 4). Bone apposition processes with their corresponding resorption are also involved.

Figure 4.5 Skull base growth

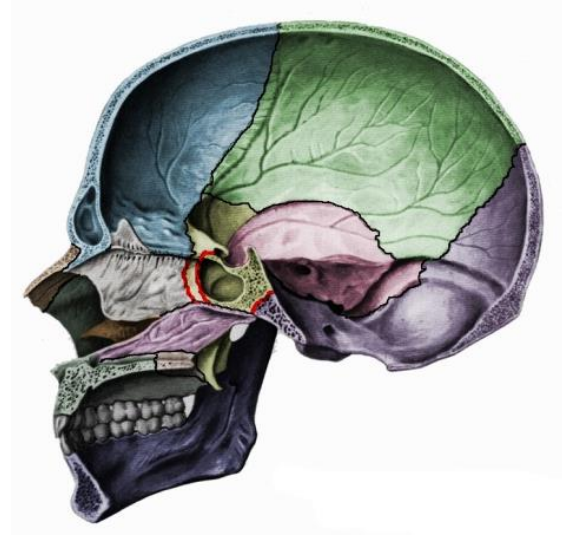




\section{Growth of the facial mass and jaws}

The growth of the face is purely membranous, because of this environmental factors may simply contribute to the development of shape and growth. Because of this developmental process it can be differentiated that the face is small in comparison with the skull due to the lack of development of the paranasal pneumatic sinuses and the reduced size of the bones, this is more evident in the maxillae, but with the appearance of the teeth and the development of the paranasal air cavities the face acquires its infantile features. $(4,11)$

Figure 4.6 Direction of growth of the middle third of the face

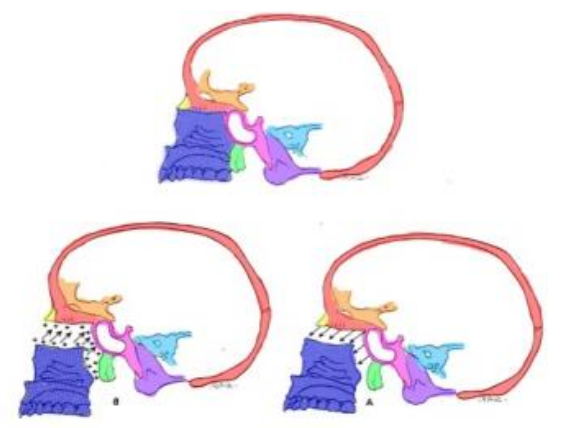

\section{Growth of the nasomaxillary complex}

The maxillae develop from the lateral membranous tissue of the cartilage of the nasal capsule by the end of the sixth week of fetal life.

Nasal capsule at the end of the sixth week of fetal life, where the canine will form.

From this point on, ossification will occur in all directions.

The jaw proper (premaxilla, maxilla and palate) is the result of a highly complex growth pattern with many different components.

Highly complex growth pattern with many different components.

The development of the orbital cavities is virtually complete at birth.

Birth. The nasal cavity is located between the two orbits, and its floor is at the level of the is at the level of the fundus. The alveolar process is only faintly discernible and the palate has a weak transverse curvature. The maxillary body is completely filled with dental development. The paranasal sinuses in sense, are still deficient, although they are a depression in the floor of the nasal floor of the nasal cavity, indicating their future position.

\section{Deep facial growth}

In relation to the cranial base, maxillary growth occurs in an anteroinferior direction, although with great individual variations.

Anteroinferiorly, although with great individual variations. The anterior the anterior growth is mainly the result of displacement of the maxillary bodies (Figure 5). Maxillary bodies (Figure 5). The dimensional increase in the maxilla occurs mainly posteriorly by bony apposition at the tuberosities and their adjacent sutures. The alveolar base is also elongated, creating space for later erupting teeth.

The anterior surface of the maxilla, on the other hand, is stable from the growth point of view, and only shows variations in the remodeling pattern (Figure 6).

Growth point of view, and only presents variations in the remodeling pattern (Figure 6). 
The position of the anterior contour of the zygomatic process is also markedly stable in relation to the maxillary body. (3)

Figure 4.7 Maxillary apposition - AND resorption

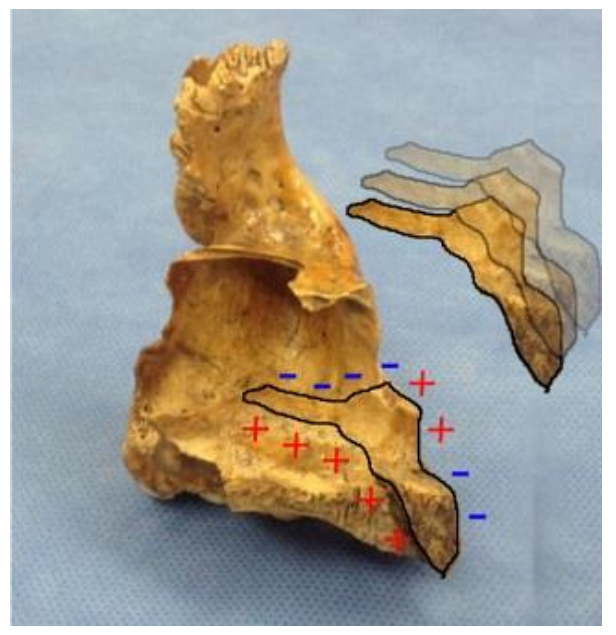

Growth in height of the face

The vertical growth of the midface in relation to the anterior cranial base is the combined result of the downward movement of the maxilla as a whole by displacement and remodeling of the bony surfaces, is the combined result of downward movement of the maxilla as a whole by displacement and remodeling of the bony surfaces. The displacement of the displacement of the maxilla, classified as sutural descent of the bone, generates space for expansion of the nasal cavity and orbits (Figure 4.7).

Figure 4.8 Downward direction of maxillary growth

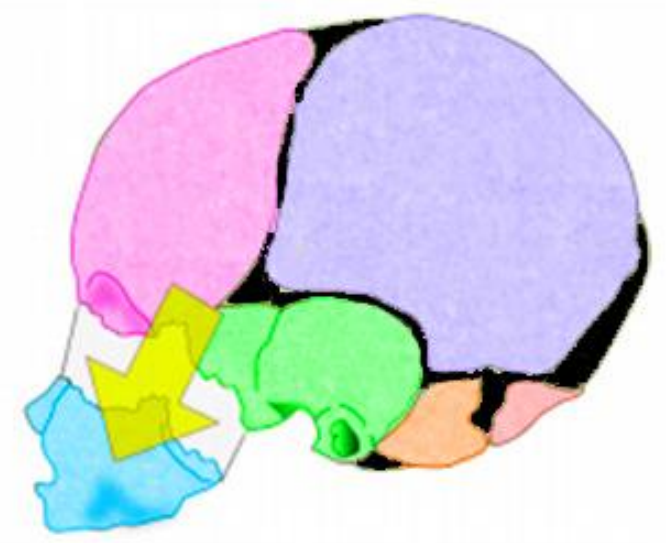

Sicher states that the growth of the nasomaxillary mass is due to 4 pairs of parallel sutures (Fig. 4.8) that join the skull and face and push the nasomaxillary complex forward and downward to adapt its growth with the mandible (Figure 4.8):

1. Frontomaxillary suture.

2. Zygomatic- maxillary suture.

3. Zygomatic-temporal suture.

4. Pterygo-palatal suture. 
Figure 4.9 Sutures joining the skull and face
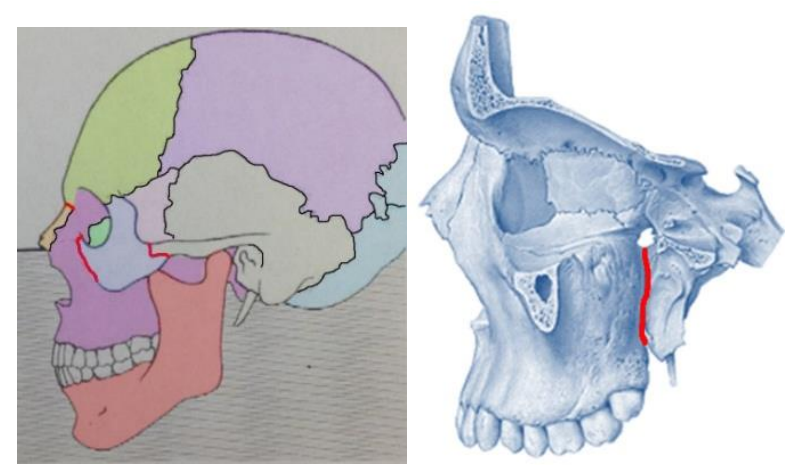

The floor of the nasal cavity and the roof of the palate move vertically relative to the orbits. Relative to the orbits. The growth of the alveolar processes is rapid during tooth eruption and exceeds the descent of the roof of the palate by three during tooth eruption and exceeds the descent of the roof of the palate by three times on three times on average, thus accentuating the curvature of the palate. The magnitude of the vertical growth of the alveolar processes and the curvature of the palate show relative individual variation, due to the adaptive capacity of the alveolar process and the dentition alveolar process and the dentition.

On the other hand, Scott considered that the facial sutures could not drive the nasomaxillary complex in its anterior and downward displacement.

Nasomaxillary complex in its anterior and descending displacement. He reasoned that the cartilaginous nasal septum occupies a strategic position that causes the mid-facial region to the midfacial region to move anteroinferiorly as it increases in size.

Increases in size. As the tissue is more pressure tolerant than the sutures, it appears to have the tissue appears to have the developmental capacity to push expansively downward and forward downward and forward the nasomaxillary complex. $(3,4,13)$

Moss posits that skeletal tissues grow in response to the growth of soft tissues (subcutaneous and submucosal cellular soft tissues (subcutaneous and submucosal cellular tissue, nasal epithelium, buccal epithelium, vessels, nerves, muscles), vessels, nerves, muscles). (12)

\section{Growth in width}

Additional expansion of the nasal cavity occurs by separation of the two maxillary bodies at the medial suture, lateral displacement and of the two maxillary bodies at the medial suture, lateral displacement and bone resorption in the lateral bone resorption in the lateral walls of the cavity. It has been shown that the growth in width of the maxilla at the mid-suture continues until the juvenile stage, between 17 and 18 years of age.

Stage, at approximately 17 to 18 years of age and parallel to the height growth curve. growth curve in height. It has also been shown that the separation of the two bodies is greater posteriorly than bodies is greater posteriorly than anteriorly. $(12,13)$

Jaw growth

Although still separated by a symphysis in the midline at birth, the two halves of the halves of the mandible fuse between the first and second year of life.

Llife. The alveolar processes and the muscular system are poorly developed at this age, so that the shape of the developed at this age, so that the shape of the mandible in the neonate is mainly determined by its arch. 
The shape of the mandible in the neonate is mainly determined by its basal arch. Of all the facial of all the facial bones, the mandibular shows the greatest amount of postnatal growth, as well as the greatest postnatal growth, also the greatest individual variation in its morphology.

\section{Deep jaw growth}

Like the nasomaxillary complex, the mandible grows forward and downward mainly as a result of the displacement of the entire bone. The mandibular symphysis part of the mandibular symphysis contributes little or nothing in length during postnatal growth (Figure 4.10).

Figure 4.10 Growth of the mandible

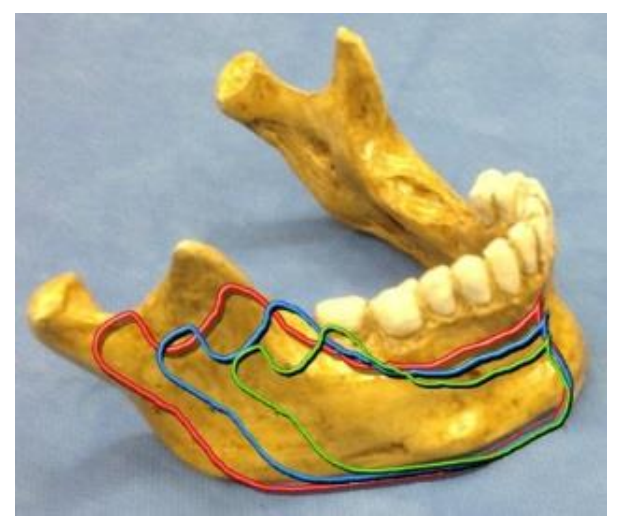

With the growth backward and upward of the condyle, the ramus relocates backward, apposition occurs at the posterior margin of the ramus with simultaneous resorption of the anterior contour, which lengthens the mandibular body.

The direction of growth of the condyle shows great individual variability, the range of growth appears to be greater in individuals with anterior range of growth appears to be greater in individuals with anterior growth of the condyle.

\section{Jaw height growth}

The growth in height allowed by the alveolar process to adjust the downward displacement of the mandibular body is downward displacement of the mandibular body depends on the direction and rate of growth of the direction and rate of growth of the condyle. In relation to the mandibular base, the amount of condylar growth averages $3 \mathrm{~mm}$ during, of condylar growth averages $3 \mathrm{~mm}$ during childhood and up to about $5 \mathrm{~mm}$ during, $5 \mathrm{~mm}$ during the pubertal growth spurt. The lower border of the mandible.

The lower border of the mandible contributes little to the growth in height, what occurs in this area is extensive remodeling (Figure 4.10).

\section{- $\quad$ Growth in width.}

Because of its early fusion, the symphysis has little involvement in postnatal width growth (Vshape). postnatal width growth (V-shape) As both branches have the same diverging V-shape in a vertical $\mathrm{V}$-shape in a vertical section, the same principle of growth will contribute in width during the vertical enlargement of the coronoid processes $(1,4,11)$ 
Figure 4.11 Direction of growth of the lower jaw

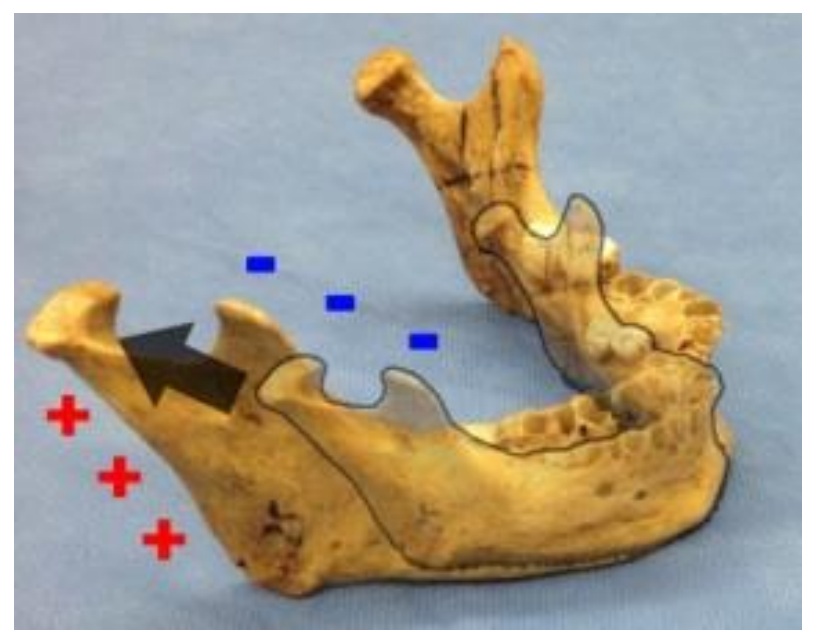

\subsection{Stomatognathic apparatus}

The stomatognathic apparatus (from the Greek $\sigma \tau o ́ \mu \alpha$, mouth; and $\gamma v \alpha \dot{\theta} \theta o \varsigma$, jaws ---- Stoma-oral cavity and Gnatus-jaw) is a morphofunctional unit whose elements correlate with each other organs and tissues to develop the functions of the stomatognathic system which are: eating, speaking, pronouncing, chewing, swallowing, smiling, breathing, kissing or sucking therefore any pathology should be treated in relation to the overall health of the individual not individually (14).

Located in the craniofacial region, in an area bounded approximately by a frontal plane passing through the mastoid processes and two horizontal lines passing, the upper one through the infraorbital ridges and the lower one through the hyoid bone.

Knowledge of the anatomy and physiology of the elements that make up this stomatognathic system, also known as the masticatory apparatus or gnathic system, is the basis for defining the concepts of normality, pathogenesis, treatment and prevention of cervico-craniofacial diseases. This system has become the object of study of dentistry. (14)

The stomatognathic system is the integrated and coordinated morpho-functional unit, constituted by the set of skeletal, muscular, vascular, nervous, glandular and dental structures, organized around the occipito-atloid, atlo-axoid, vertebro-vertebral cervical, temporomandibular, dento-dental in occlusion and dento-alveolar joints, which are organically and functionally linked with the digestive, respiratory, phonological and aesthetic-facial expression systems and with the senses of taste, touch, balance and orientation to develop the functions of sucking, oral digestion (which includes chewing, salivation, tasting and initial degradation of carbohydrates), swallowing, verbal communication (which includes chewing, salivation, tasting and initial degradation of carbohydrates); swallowing, verbal communication (which is integrated, among other actions, by phonological modulation, articulation of sounds, speech, whistling and desire); oral sexuality (which includes smiling, laughing, oral-facial gesticulation, kissing, among other aesthetic-affective manifestations); alternate respiration and vital defense, integrated by coughing, expectoration, sneezing, yawning, sighing, exhalation and vomiting, essential for the survival of the individual. (14)

\subsection{Components of the stomatognatic apparatus}

Lips:

The lips are the entrance to the digestive tract and the anterior opening of the mouth. They have a central muscular portion, made of skeletal muscle, covered on the outside by skin and on the inside by a mucous membrane. 


\section{Salivary glands}

They are the glands annexed to the mouth, formed by two groups main salivary glands such as the parotid, submaxillary and sublingual glands and accessory salivary glands such as the palatine, molar and labial glands, The function of these glands is the secretion of saliva 24 hours a day and varies between 1000 and 1500 milliliters and their functions are to maintain the humidity of the mucosa of the oral cavity to avoid its drying, to moisten the food to facilitate its chewing and swallowing by the dissolution of the substances, which allows to capture the taste of the same $(15,16)$.

\section{Braces}

Frenulum are mucosal folds of fibrous connective tissue, muscle or both, that join two contiguous surfaces, and that in certain situations can cause orthodontic, phonetic, periodontal and prosthetic problems, due to variations in their shape, size and position. According to their location they are classified as: upper labial, lower labial and lingual. $(14,15,16)$.

\section{Teeth}

Del lat. dens, dentis, are hard structures formed of mineralized tissue that begin to develop from embryonic life, and begin to erupt in the first six months of life, articulated in the alveolar processes of the maxillary and mandibular bones through a special type of joint called gonphosis, attached to the bone by the periodontal ligament, involved in the functions of chewing food, digestion and also participates in oral communication. Basically in the tooth two parts can be recognized, the crown, part covered by dental enamel and the root not visible in a healthy mouth. (14)

The deciduous dentition consists of 20 teeth, whose appearance begins at approximately 6 months of age and their replacement by permanent teeth lasts until approximately 12 years of age.

The permanent dentition begins to erupt at approximately 6 years of age and will replace the teeth of the first dentition until adolescence. The permanent dentition consists of 32 teeth. At the age of 16 to 25 years the third molars (called "wisdom teeth or wisdom teeth") can erupt and are frequently retained in the jaws $(14,15,16)$

\section{Gum}

It is a fibromucosa formed by dense connective tissue with a covering of keratinized squamous epithelium that covers the alveolar processes and surrounds the teeth. The gingiva is contiguous with the periodontal ligament and, on the outside, with the mucosal tissues of the oral cavity.

\section{Floor of the mouth}

The floor of the mouth is limited by the lower dental arches, forming an elongated cavity called lingual canal where the tongue rests and we observe on the sides of the lingual frenulum the mouth of the main submaxillary and sublingual glands. $(14,15,16)$

\section{Cheeks}

The cheek, cheeks or cheeks is each of the two prominences in the human face, below the eyes. It is also called the fleshy part of the face, from the cheekbones to below the jaw and next to the lips. $(14,15,16)$

\section{Palate}

The palate is a structure that forms the roof of the oral cavity and separates it from the nostrils: it is covered by masticatory mucosa and is an area of friction whose interaction allows the tongue-palate to articulate sounds $(14,15,16)$. 


\section{Tonsils}

They are part of Waldeyer's lymphatic ring, are masses of lymphatic tissue masses of lymphatic tissue, located in the lateral walls of the isthmus of the fauces (throat).

\section{Oropharynx}

It is an anatomical region located in the most posterior part of the mouth, whose limits are from the soft palate to the hyoid bone and includes the posterior third of the tongue.

\section{Maxilla}

It is the most voluminous bone of the face, is even and forms part of the upper jaw is irregular quadrilateral shape, with two faces, internal and external, four edges and four angles.

\section{Jaw}

It is the only movable bone of the bony head, is odd and horseshoe-shaped and forms part of the temporomandibular joint.

\section{Paranasal sinuses}

They are pneumatic cavities that communicate with the nasal cavities and their function is to lighten the bone, humidify and warm the air and communicate with the nostrils.

\section{Temporomandibular joint}

It is a bicondylar joint formed by the condyle of the temporal bone and the anterior portion of the glenoid cavity of the temporal bone where the condyle of the lower jaw articulates, these surfaces are adapted by means of an articular disc, which, together with the masticatory, supra hyoid and infra hyoid muscles, allow the mandible to perform masticatory movements, such as opening and closing, protrusion, retrusion, and laterality. $(14,15,16)$

\section{Alveolar-dental articulation}

It is the one that takes place between the dental pieces and the alveolar processes of the upper and lower jaw, its greatest importance is that it maintains a relationship of interdependence with the ATM: Any functional or pathological disorder of localization in any of them will be able to alter the integrity of their respective constituent elements. $(14,15,16)$

\section{Muscles}

The muscles involved in the functioning of the stomatognathic apparatus are the following muscle groups: head muscles, masticatory muscles, and muscles of the anterior and lateral neck region;

\section{Vascular system}

Primitive carotid system, internal and external carotid, and subclavian artery. And the jugular system, formed by the internal jugular trunk, tributary trunks to the internal jugular and the venous sinuses of the dura mater.

\section{Nervous system}

Formed by the central and peripheral nervous system and the main nerves are the trigeminal, facial, glossopharyngeal, and greater hypoglossal nerves. 


\section{Lymph nodes}

Lymph nodes are strategically distributed throughout the body and are an important part of the immune system. In the head they are distributed as follows: submental, submaxillary, anterior auricular, posterior auricular, occipital, superficial cervical, deep cervical and finally clavicular lymph nodes. They are accumulations of lymphatic tissue that act as the first line of defense of our organism helping it to recognize and fight microbes and infections. $(14,15,16)$

\subsection{Physiology of the stomatognathic system}

Its main functions are chewing, swallowing and phonation and it should not be forgotten that this system still influences facial expression, aesthetics and stabilization of the mandibular skull (Lee 1992).

During the functions of this system, the jaw assumes different postures and can be at rest, in occlusion or in movement.

\subsection{Mastication}

It is a conditioned, learned and automatic function necessary for the nutrition and digestion processes of the organism. It begins with tooth eruption and during which jaw movements are guided by specialized nerve receptors (proprioceptors) constituting a complex neuromuscular activity.

Chewing is directly influenced by dental occlusion, without which chewing would significantly decrease in efficiency. The maximum intercuspidation is reached about 5000 times a day during normal functions.

When chewing occurs in an alternating bilateral manner it results in the greatest occlusal stability.

When it occurs unilaterally, a compensatory adaptation is necessary through increased masticatory effort, which may lead to joint problems in the future.

The masticatory muscles produce a pressure of up to $200-300 \mathrm{Lb}$. (90-136 kg). The maximum functional masticatory force is 300 to $500 \mathrm{~N}$ in the molar region in an individual with healthy natural dentition.

When there is tooth loss, the periodontal ligament disappears, this leads to the absence of all its functions and perhaps the most important one is proprioception - sense of location, as a regulatory mechanism of the physiological masticatory force protecting the anatomical structures of the maximum anatomical force through the opening and closing reflex. (14)

\section{Masticatory cycle}

Constituted in the mandibular opening processes, then by the mandibular closing and finally by the occlusal phase.

There is a variation in the magnitude of the masticatory force in relation to the consistency of the food. Therefore, in a soft diet the movements are more vertical and there is less lateral displacement, while in a hard diet there is more lateral displacement.

* Factors influencing Functional Peak Masticatory Strength (F.M.M.F):

- $\quad$ Gender and age

- $\quad$ Feeding time

- State of the dentition number and position of teeth.

- Mandibular positions in the sagittal plane.

- Mandibular positions in the horizontal and frontal plane. 
Craniofacial Skeletal Characteristics is the most important one and refers to whether it is brachycephalic (more strength) or dolichocephalic.

Stages of chewing

Incision or prehension

It is performed through the anterior teeth with the contraction of the external pterygoid, infrahyoid and digastric muscles, as well as the levator, temporalis, masseter and internal pterygoid muscles.

Cutting and grinding

It is performed through the marginal ridges and cuspid elevations. During this stage it occurs with a bilateral mandibular movement with repeated cycles so that there is reduction of large pieces into small ones, resulting in an increase in the surface area, which is where the digestive enzymes work most efficiently.

\section{Final movement}

In this stage the most posterior parts are very important, through the occlusal faces of the molar units, which is where the food bolus is formed. This occlusal table helps the softening and transformation into a size conducive to swallowing for it is also necessary the correct lubrication of the food impregnating it with saliva. (14)

\subsection{Deglution}

It is a primary unconditioned reflex that occurs twice a minute. Unconsciously.

According to some authors up to 3 years of age it is accepted as normal that the child keeps the arches separated at the moment of swallowing, between 3 and 5 years of age the masticatory function is perfected and the swallowing function matures. In the adult it is characterized by tongue and lip interposition, the jaw is elevated and the teeth in dental occlusion, slight lip contact and no contraction of facial muscles.

In the functional analysis we must observe the lingual position. The tongue occupies most of the interior space of the mouth and provides an internal shape for the dental arch, therefore any modification in its function or position will be reflected in the shape of the dental arch. If the tongue is placed low or high in the vestibular sector, this will produce different forms of occlusion such as crossbite.

In the clinical examination the tongue should be observed at rest and during swallowing, its size should be analyzed, the presence of scalloping can be suspected of macroglossia. (14)

The size of the pharyngeal tonsils is important in swallowing, since tonsillar hypertrophy produces tongue protrusion.

Swallowing stages:

1. Buccal: Voluntary stage where the food bolus is formed.

2. Pharyngeal: Lasts from 1 to 2 sec. Elevation of the soft palate, closure of the epiglottis. It is characterized by elevation of the pharynx and hyoid and the passage of the alimentary bolus produces peristaltic stimuli.

3. Esophageal: lasts 5 - 8 seconds, a peristaltic wave is produced in the smooth muscles along the esophagus. 


\subsection{Fonation}

The mouth forms the sounding board together with the nostrils, its annexes such as the paranasal sinuses and the pharynx. The stomatognathic system plays an important role especially for the pronunciation of interdental and labiodental phonemes. Intentional phonation is more complicated since it has to be performed on the basis of stabilized and learned pharyngeal and lingual jaw postures. Phonation is characteristic of Homo sapiens, while language is the exclusive capacity of man, through which he is able to communicate. $(14,15)$

There is a strong relationship between dentomaxillofacial anomalies and speech disorders. The most frequent being dyslalia caused by defective lingual frenulum.

\subsection{Breathing}

Normal breathing is through the nostrils. When there is obstruction of the nasal passage, air entry through the oral cavity is resolved, but at the cost of many other side effects: The immediate effects consist of the introduction of dry, dust-laden cold air into the mouth and pharynx. The warming, humidifying and filtering functions of the air entering through the nose are lost, with consequent increased irritation of the pharyngeal mucosa.

The long term effects are more complex and far reaching, from the moment the mouth is opened the tongue descends and loses contact with the upper jaw, which influences the growth of the upper jaw generally leading to maxillary compression, the tension of the muscles varies, producing a series of alterations in the muscular function that affects the posture of the lower jaw and the teeth as well as the postural muscular chain of the individual $(14,15,16)$.

\subsection{Aesthetics}

The current aesthetic canons in our civilization are in accordance with the golden ratio or divine proportion. These principles or "requirements" of beauty are captured unconsciously by our sight. They could be considered as naturally immutable throughout the centuries in our human conception of beauty.

When we talk about aesthetics there must be harmony in the structures that we observe, that is to say a relationship of aesthetic balance without predominance of only one element, so we will talk about facial harmony with symmetry, all this follows under a parameter that has been called golden ratio.

In order to obtain ideal dental esthetics it is necessary to provide a harmonious, pleasant and balanced smile. For this reason it is necessary, in order to treat our patients bioesthetically, to perform an analysis of all the factors involved in the smile in order to properly diagnose the esthetic problem and determine the patient's concerns and expectations. (14)

Failures in dental esthetics can only be avoided if we pay due attention to the determining factors of harmony and proportionality, as well as the incorporation of the patient in the decision making process, under the guidance of the dentist, through the presentation of all the treatment alternatives.

The golden ratio. For many artists it represents the ultimate expression of Beauty, the perfect proportion, perhaps because we ourselves are built in golden proportions.

In the field of dentistry, it has been discovered that the dentition grows, following golden proportions, and so do other facial features, such as the smile with respect to the dental arch, the distance between the eyes and many more. The widths of the four front teeth, from the central incisor to the premolar, are in golden ratio to each other.

The ratio between the width of the smile arch and the width of the 8 central teeth (the ones that can be seen while smiling) is also golden. When the teeth are not together, the lip line divides the lower part of the face according to the golden ratio. The relationship between the distance between the eyes and the width of the eyes is also golden. 
In physiology, a smile is a facial expression formed by flexing the muscles near the ends of the mouth, but also around the eyes. Studies have shown that smiling is a normal reaction to certain stimuli and is not learned, but born with it (14).

Smiling not only changes facial expression, but also causes the brain to produce endorphins that reduce physical and emotional pain and provide a sense of well-being. Smiling can be considered a soft, silent form of laughter Babies begin to laugh around four months of age.

Laughter is a part of human behavior controlled by the brain. It is used as a sign of belonging to a group (indicating acceptance and positive interactions). Laughter is contagious; often laughter itself causes others to laugh. This partly explains the popularity of canned laughter in TV comedy series.

Some medical theories attribute beneficial effects on health and well-being to laughter, since it releases endorphins (14).

\subsection{References}

1. Proffit, W. R., Fields, H. W., \& Ackerman, J. L. (1994). Ortodoncia: teoría y práctica: segunda edición. Mosby/Doyma Libros.

2. Graber, T. M., Vanardsdall, R. L., Frydman, J., \& Sosa Manrique, N. B. (1997). Ortodoncia: principios generales y técnicas.

3. Moyers, R. E., \& LEYT, S. (1992). Manual de ortodoncia.

4. Enlow, D. H.: (2006) Crecimiento craneofacial; 3ra. Edición, México, Editorial Interamericana McGraw-Hill, 2006; 26-29; 35-37.

5. Farkas, L. G., \& Munro, I. R. (Eds.). (1987). Anthropometric facial proportions in medicine. Charles C Thomas Pub Limited.

6. Ricketts, R. M., \& Porter, R. J. (1983). Técnica bioprogresiva de Ricketts.

7. Mc. Namara JA. (1997). Un método cefalométrico. Evaluación. Am. J. Orthod,

8. Greulich WW, Pyle SI. (1959). Radiographic Atlas of Skeletal Development of the Hand and Wrist. 2nd ed... London: Oxford University Press.

9. Canut, J. A.: (2005). Ortodoncia clínica y preventiva; 2da. Edición, Barcelona-España, Editorial Masson S.A., 355-367.1.

10. Pritchard, J. J. (1956). The osteoblast. In the biochemistry and physiology of bone.

11. Lagman, S., \& Sadler, T. W. (2005). Embriología Médica con orientación clínica. Editorial médica panamericana sa 8 va edición, 357.

12. Moss, M. L., \& Salentijn, L. (1969). The primary role of functional matrices in facial growth. American journal of orthodontics, 55(6), 566-577.

13. Scott, J. H. (1959). Further studies on the growth of the human face.

14. Zerón, A. (2003). Cómo conservar sus dientes y encías toda la vida: odontología para pacientes. UNAM.

15. Quiroz Gutiérrez, F. (1962). Anatomía humana. Porrúa México, 264-277.

16. Sinelnikov, R. D., \& Tergas, H. V. (1976). Atlas de anatomía humana: Estudio de los huesos, articulaciones, ligamentos y músculos. 
Chapter 5 Assessment of physical activity, sedentary behaviors and physical fitness in perimenopausal women

Capítulo 5 Valoración de la actividad física, comportamientos sedentarios y aptitud física de mujeres perimenopaúsicas

VILLARREAL-SALAZAR, Angelly del Carmen†, ENRIQUEZ-REYNA, María Cristina*, HERNÁNDEZ-CORTÉS, Perla Lizeth and MEDINA-RODRÍGUEZ, Rosa Elena

Universidad Autónoma de Nuevo León, Facultad de Organización Deportiva

ID $1^{\text {st }}$ Author: Angelly del Carmen, Villarreal-Salazar / ORC ID: 0000-0002-1051-0405, CVU CONACYT ID: 899992

ID $1^{\text {st }}$ Co-author: María Cristina, Enriquez-Reyna / ORC ID: 0000-0002-7720-4269, Researcher ID Thomson: K-8324-2017, CVU CONACYT ID: 300058

ID $2^{\text {nd }}$ Co-author: Perla Lizeth, Hernández-Cortes / ORC ID: 0000-0001-9185-9416, Researcher ID Thomson: A-9682-2019, CVU CONACYT ID: 269697

ID $3^{\text {rd }}$ Co-author: Rosa Elena, Medina-Rodríguez / ORC ID: 0000-0002-5897-3249, Researcher ID Thomson: A-9659-2019, CVU CONACYT ID: 242117

DOI: $10.35429 / \mathrm{H} .2021 .13 .57 .77$

A. Villarreal, M. Enriquez, P. Hernández and R. Medina

* maria.enriquezryn@uanl.edu.mx

A. Marroquín, J. Olivares, M. Cruz, L. Cruz. (Coord.) CIERMMI Women in Science TXIII Medicine and Health Sciences. Handbooks-@ECORFAN-México, Querétaro, 2021. 


\begin{abstract}
Introduction. Promoting active lifestyles to maintain physical functionality in middle-aged women implies field assessments which could sometimes be considered subjective or problematic. The proposal was to analyze physical activity, sedentary behaviors, and physical fitness in perimenopausal women living in the urban area of Monterrey. Methods. An analytical and descriptive study that includes comparative and association aspects with a single measurement. A personal data form was applied, as well as accelerometry with an ActiGraph GT3X+ movement detector, the AMAI Socioeconomic Level Questionnaire, the Sedentary Behavior Questionnaire, and the International Physical Activity Questionnaire (IPAQ)-Long Form. Physical fitness was assessed in relation to strength in the upper limbs (dynamometry) and lower limbs (30 second Sit to Stand Test) in addition to balance (Unipedal Stance Test). Data analysis was performed with the SPPS software, version 21.0; with descriptive and inferential statistics considering a critical value of 0.05 for Cronbach's alpha. Results. According to the IPAQ report, $54.8 \%$ of the participants meet the global recommendations for health, whereas, with accelerometry, the result was $52.4 \%(p>0.05)$. On average, the participants spend more than 850 minutes a day in sedentary activities. No differences were found between the self-report and the objective accelerometry measurement of PA and sedentary behaviors in the participants of this sample. In more than half of the participants, physical fitness is considered as of a low level for all the tests considered. The participants who are housewives presented more PA in their leisure time than those who work $(p<.05)$. Excess weight exerted an effect on overall physical activity and on balance with the eyes open $(p<.05)$. Conclusions. Perimenopausal women usually present excess weight, sedentary behaviors, and low level of physical fitness. In this sample, no differences were found between the self-report of PA and sedentary behaviors in relation to the accelerometry measurement. Promoting active lifestyles and physical assessment in the life stage is advisable to maintain physical functionality prior to old age.
\end{abstract}

\title{
Behavior, Muscular strength, Balance, Health risk, Women health
}

\section{Resumen}

Introducción. La promoción de estilos de vida activos para mantener la funcionalidad física de mujeres de mediana edad implica evaluaciones de campo que en ocasiones pudieran ser consideradas subjetivas o problemáticas. Se propuso analizar la actividad física, los comportamientos sedentarios y la aptitud física de mujeres perimenopaúsicas del área urbana de Monterrey. Métodos. Estudio descriptivo analítico, que incluye aspectos comparativos y de asociación con una sola medición. Se aplicaron cédula de datos personales, acelerometría con sensor de movimiento ActiGraph GT3X+, Cuestionario sobre nivel socioeconómico AMAI, Cuestionario de Comportamiento Sedentario y la versión larga del Cuestionario Internacional de Actividad Física (IPAQ por sus siglas en inglés). Se avaluó la aptitud física al respecto de la fuerza de miembros superiores (dinamometría) e inferiores (prueba de la silla) además del equilibrio (prueba de equilibrio unipodal con ojos abiertos y cerrados). El análisis de datos se realizó con el software SPPS versión 21.0; con estadística descriptiva e inferencial considerando un valor crítico para el alfa de .05. Resultados. De acuerdo con el reporte del IPAQ, el $54.8 \%$ de las participantes cumple con las recomendaciones mundiales para la salud; mientras que con la acelerometría el dato fue del $52.4 \%(p>.05)$. En promedio, las participantes presentan más de 850 minutos al día en actividades sedentarias. No se encontraron diferencias entre el autoreporte y la medición objetiva con acelerometría de la actividad física y los comportamientos sedentarios en las participantes de esta muestra. La aptitud física de más de la mitad de las participantes se considera en nivel bajo para todas las pruebas consideradas. Las participantes que se dedican al hogar presentaron mayor actividad física en el tiempo libre que las que trabajan $(p<.05)$. El exceso de peso afectó la actividad física total y el equilibrio con ojos abiertos $(p<.05)$. Conclusiones. Las mujeres que transitan la perimenopausia presentan habitualmente exceso de peso, comportamientos sedentarios y baja aptitud física. En esta muestra no se encontraron diferencias entre el autoreporte de actividad física y comportamientos sedentarios en relación con la medición con acelerometría. La promoción de estilos de vida activos y la valoración física en esta etapa de la vida resulta aconsejable para el mantenimiento de la funcionalidad física previo a la vejez.

\section{Conducta, Fuerza muscular, Equilibrio postural, Riesgos a la salud, Salud de la mujer}




\subsection{Introduction}

Timely diagnosis of factors that endanger physical functionality and quality of life during the aging process should be initiated in early life stages. Based on the hormonal and physical changes associated with menopause, which manifests itself between the ages of 41 and 55 years old (TorresJiménez \& Torres-Rincón, 2018), women face a rapid decline in their physical condition during the perimenopausal period (Bondarev et al., 2018). Other factors such as socioeconomic level, schooling, social life, and structural changes at the family level might represent a synergy to increase the trend towards physical inactivity. In Mexico, physical inactivity seems to increase with advancing age: $66.7 \%$ of the women aged from 45 to 54 years old's do not engage in PA, whereas from age 55, this percentage rises to $70.5 \%$ (Instituto Nacional de Estadística y Geografía [INEGI], 2018).

The trend towards a reduction in PA and the increase in the number of post-menopause sedentary behaviors have already been reported in other contexts (Cheng et al., 2009; Colpani, Oppermann, \& Spritzer, 2013; $\quad$ Moratalla et al., 2016; Rathnayake, Lenora, Alwis, \& Lekamwasam, 2019). Performing moderate to intense PA supposes better physical functionality and less body pain (Dugan et al., 2018), reason why it could be a positive indicator of quality of life. Given the relationship between PA and fitness, it becomes necessary to promote multidisciplinary work to recognize their influence on individual and social quality of life.

Promoting active lifestyles implies field assessments which could sometimes be considered subjective or problematic. Measuring PA with adequate tools such as accelerometry can impose multiple difficulties and be onerous for epidemiological research studies. On the other hand, measurements with questionnaires have given rise to the development of standardized methods to increase their precision, reason why they have turned into an additional element for knowledge application. The Mexican adults' trend to over-report PA levels has been pointed out (Gutiérrez et al., 2012). In the search to develop the study phenomenon, in recent years PA measurement has expanded to other related characteristics such us: sedentary behaviors; physical fitness; and the benefits, motivations, barriers and social support to physical exercise, only to mention some related themes. Validating the versions of the different questionnaires in relation to objective measurements is a current research topic for most of the contexts. The general theme of this paper is PA behavior in perimenopausal women. Aspects related to measurement in research and to the influence of the personal characteristics on the status of this population group are addressed. The findings from this type of analysis are the basis to design effective strategies for adherence to active lifestyles and for health promotion in general. This paper intends to evaluate the use of questionnaires to assess PA and sedentary behaviors in perimenopausal women. The proposal was to analyze the influence of the personal characteristics on the PA level, sedentary behaviors, and physical fitness in a group of perimenopausal women from an urban community in northeastern Mexico, during the second semester of 2019.

Four specific objectives were established to such end, namely:

1. To describe the differences between the self-report and the objective measurement of compliance with the global recommendations regarding the participants' PA.

2. To compare the sedentary behaviors on weekdays and during the weekend obtained through the participants' self-report and from the accelerometry report.

3. To evaluate the association between the participants' PA, sedentary behaviors, and physical aptitude.

4. To analyze the influence of the personal characteristics on the participants' PA, sedentary behaviors, and physical fitness. 


\subsubsection{Characteristics of perimenopausal women}

Throughout their lives, women go through different growth and development stages related to their reproductive cycle. One of these stages is menopause, which, according to the World Health Organization (1995) "is permanent interruption of menstruation, determined in a retrospective manner after 12 consecutive months of amenorrhea, without any pathologic cause" (as cited in Torres-Jiménez $\&$ Torres-Rincón, 2018). Mexican women experience menopause approximately at the age of 47.6 years old (Vázquez-Martínez et al., 2015).

Perimenopause, or menopausal transition, is the period in which certain physiological changes, such as reduction in the follicle-stimulating hormone levels, indicate that the woman is close to experiencing her last menstruation (Delamater \& Santoro, 2018). For Delamater and Santoro (2018), perimenopause begins with the onset of irregularities in the menstrual cycle and finishes when the woman reaches menopause, or up to one year after this event. According to Mexican Official Standard (Norma Oficial Mexicana, NOM) 035-SSA2-2012, perimenopause encompasses the five years prior to menopause and the year after it (Diario Oficial de la Federación, 2012).

During menopausal transition, the changes in the hormone levels trigger a series of symptoms and alterations in the functioning of the musculoskeletal system, which might represent a risk for the woman's health. Among the symptoms associated with perimenopause are hot flashes, vaginal dryness, sleep disorders, skin atrophy, psychosocial problems, psychiatric symptoms and diseases resulting from prolonged estrogen deprivation, such as osteoporosis and cardiovascular diseases (Delamater \& Santoro, 2018; Thurston et al., 2018).

In relation to the musculoskeletal system, the main changes observed are reduction in bone mineral density and muscle mass loss (Sipilä et al., 2020). Monteleone et al. (2018) indicate that bone mineral density is rapidly reduced during late perimenopause and that its annual losses after menopause vary between $1.8 \%$ and $2.3 \%$ in the spine and from $1 \%$ to $1.4 \%$ in the hip. Muscle mass loss is related to muscle strength condition (Devries \& Phillips, 2015). According to Abdulnour (2016), during menopause women lose a greater proportion of muscle mass and strength when compared to men of similar ages.

\subsubsection{Physical activity and its measurement in research}

PA is any body movement produced by the skeletal muscles which generates an energy expenditure that is higher than that of a rest state (World Health Organization [OMS], 2010). For Pettee-Gabriel, Morrow and Woolsey (2012), PA is a behavior involving human movement, which induces physiological changes such as increased energy expenditure and improvement in physical fitness. As it is a behavior, PA can be performed in different domains: during leisure time, as part of the work or school activity, while performing house chores, and as transportation means (Pettee-Gabriel, Morrow, \& Woolsey, 2012).

Depending on its intensity, PA can be classified as light, moderate and vigorous. Moderate and vigorous intensity PA offers greater benefits for health (Salvo et al., 2018; Warburton \& Bredin, 2017) and, in middle-aged women, it can mitigate the impact of physical decline associated with the aging process, as it helps to maintain an adequate muscle mass level during perimenopause (Juppi et al., 2020). According to the WHO Guidelines on PA and sedentary habits (WHO, 2020), adults aged from 18 to 64 years old should accumulate 150-300 weekly minutes of moderate aerobic PA, 75-150 weekly minutes of vigorous aerobic PA, or a combination of both. In addition, muscle strengthening activities must be performed at least twice a week.

Due to the numerous benefits for health reported by PA, different instruments to measure this behavior in different population groups have been developed over time. The instruments to measure the PA levels can be classified as objective, such as accelerometry, and as subjective, such as self-reported questionnaires (Aparicio-Ugarriza et al., 2015). 
Regarding accelerometry, it is a method that allows measuring body acceleration in the threemovement axis and expressing it as counts per time unit through portable devices called accelerometers, which can be used around the hip or the wrist (Ainsworth et al., 2015). By using cutoff points based on the accelerometer's counts, it is possible to measure the minutes of PA performed based on its intensity: light, moderate, vigorous, or very vigorous (O’Neill et al., 2017). In Mexican adults (Table 5.1), the cutoff points that have been used to estimate the PA level are those proposed by Freedson et al. in 1998 (Salvo et al., 2015).

Table 5.1 Cut-off points for the classification of the intensity of physical activity

\begin{tabular}{|r|l|}
\hline Activity counts & Classification \\
\hline $0-99$ & Sedentary \\
\hline $100-759$ & Very Ligth \\
\hline $760-1951$ & Ligth \\
\hline $1951-5724$ & Moderate \\
\hline $5725-9498$ & Hard \\
\hline 9499 and more & Very hard \\
\hline
\end{tabular}

Source: Freedson, P. S., Melanson, E., \& Sirard, J. (1998). Calibration of the Computer Science and Applications, Inc. accelerometer. Medicine \& Science in Sports \& Exercise, 30(5), 777-781. https://doi.org/10.1097/00005768199805000-00021

Accelerometry offers the advantages of allowing to evaluate with precision and in a minimally invasive manner the PA level throughout days, weeks, or even longer periods of time. Among its limitations is lack of homogeneity in the protocols used to validate the data obtained; AparicioUgarriza et al. (2017) indicate that the accelerometers must be used during seven days for a minimum of 10 hours a day; however, studies have been found in which they were only used for three days at a rate of eight hours a day. In addition, accelerometers do not quantify activities that are not related to walking, such as riding a bicycle or weightlifting (Ainsworth et al., 2015).

On the other hand, among the self-reported questionnaires are the global questionnaires, which are easy to apply and estimate the PA performed in each of their domains by means of simple questions. The International Physical Activity Questionnaire (IPAQ) is an example of a global questionnaire and has two versions: its Long Form, in which the PA patterns are fully and detailly investigated in the four domains; and its Short Form, which only includes seven global questions about PA. In Latin America, Hallal et al. (2010) report that the IPAQ presents high reliability and a moderate validity index when compared to accelerometers; however, they recommend that, in the Latin American population, only the PA during leisure time and during transportation domains from its long version be used to measure the PA levels, since PA modules such as part of the house chores and in the work or school environment overestimate the amount of PA performed.

\subsubsection{Sedentary behaviors and their measurement in research}

Sedentary behavior encompasses the activities that imply an energy expenditure below 1.5 METs, while in a sitting position, reclined or lying down (Magnon et al. 2018) and bears no relation to the PA level, as a person can meet the PA recommendations for their age and, at the same time, be considered as sedentary for spending long periods of time in a sitting position, either due to work, school and recreational reasons or to transportation. It is known that sedentary behavior increases the risk of suffering some non-communicable chronic disease such as obesity, diabetes, metabolic syndrome and cardiovascular diseases, even in the case of individuals who meet the moderate to vigorous PA recommendations (Same et al., 2016). Blümel et al. (2016) report that the prevalence of sedentary behaviors among Latin American women aged from 40 to 59 years old is high and that it is associated with more severe menopausal symptoms and with high anxiety and obesity rates in that population group.

Given the high prevalence of sedentary behavior in contemporary society and its adverse effects on health, its assessment has gained greater relevance. As is the case with the measurement of the PA level, there are subjective and objective methods to estimate sedentary behavior. Among the subjective methods are the printed questionnaires and the interviews (Headley et al., 2018). 
The subjective methods allow identifying different types of sedentary behaviors and the contexts in which they occur, which is not possible with the objective methods. For example, the Sedentary Behavior Questionnaire (SBQ) (Rosenberg et al., 2010) measures the time spent on nine sedentary activities during a given week and weekend, which serves as the basis to ease the design of specific and individualized interventions to reduce sedentary time (Kang \& Rowe, 2015). One of the limitations of the subjective methods is that they depend on the person' ability to accurately record the time spent on sedentary activities, which can be difficult, given that the behavior occurs throughout the day and does not pursue any objective or follow any structure, as is the case with PA (Headley et al., 2018).

It is also possible to estimate sedentary behaviors through accelerometry, which provides more reliable estimates of the total sedentary time in an everyday context when compared to the subjective methods. In addition, it allows identifying patterns, such as the presence of sedentary blocks throughout the day and their average duration (Kang \& Rowe, 2015). One of the inconveniences of using accelerometers is the great diversity in terms of monitoring protocols, which can under- or over-estimate the sedentary behaviors. The cutoff point most frequently used to measure sedentary time is the accumulation of $<100$ counts per minute and, for a day of use to be valid, the accelerometer should have been employed for a minimum of 10 hours (Tudor-Locke, Camhi, \& Troiano, 2012). However, Kang and Rowe (2015) indicate that the cutoff point seems to underestimate sedentary behavior in overweight adults and that using the accelerometer for the minimum time (10 hours) reduces sedentary time by $28 \%$ when compared to situations in which it is used 14 hours a day.

\subsubsection{Assessment of physical fitness in perimenopausal women}

Health-Related Physical Fitness (HRPF) is defined as the ability to perform work, recreational and everyday activities without feeling fatigue (Kaminsky, 2010). The physical abilities that comprise HRPF are as follows: cardiorespiratory resistance, musculoskeletal fitness (which encompasses muscle strength and resistance), weight and body composition, flexibility and balance (Heyward, 2010). Chrismas et al. (2019) mention that the adults who habitually perform moderate to vigorous PA enjoy better physical fitness and present lower morbidity and mortality rates. Strength and balance are of main interest in this paper.

Regarding muscle strength, which is the maximum tension level that any given muscle group can exert (Heyward, 2010), it is known that it presents an inversely proportional relation with metabolic risk and with mortality, regardless of cardiorespiratory resistance. From the third decade of life and until age 85 , a 50\% muscle strength loss is estimated, more pronounced in women, which might be associated with the hormonal changes experienced during menopause, as well as with the reduction in the PA levels at different life events, such as marriage, motherhood, and menopause (Skelton \& Mavroeidi, 2018).

Because of strength loss in the lower limbs, women can experience changes in their balance, which is defined as the ability to maintain the body's gravity center based on support while in a static position, performing voluntary movements or in the face of external unbalancing forces (Heyward, 2010). Changes in balance increase the risk of falls and fractures in older adults. In addition, muscle strength loss is the main limiting factor for the development of the activities of daily living, since it exerts an effect on skills such as climbing stairs and getting up from a chair, as well as on gait speed (Skelton \& Mavroeidi, 2018).

To assess the HRPF physical abilities there are test and field tests available, the latter being the most frequently used in studies involving large sample sizes (Kaminsky, 2010). Among the field tests to assess muscle strength in the upper and lower limbs are the 30 second Sit to Stand Test (30 SST) and manual dynamometry. 30 SST consists in getting up from and sitting on a chair as many times as possible during 30 seconds with the arms crossed against the chest (Bergamin et al., 2015; Pullybank et al., 2020) and, although it is part of the Senior Fit Test battery (Rikli \& Jones, 2001), which assesses physical condition in older adults, has been used to assess physical fitness in middle-aged women (MoratallaCecilia et al., 2016; Pullybank et al., 2020). Regarding manual dynamometry, it is a test that assesses the forearm muscles' static strength (Kaminsky, 2010) and consists in exerting as much pressure as possible on a manual dynamometer while the elbow is kept flexed at $90^{\circ}$ to ensure maximum force application (Bergamin et al., 2015). To interpret this test, Wang et al. (2018) established different cutoff points based on gender and age for the population aged from 18 to 65 years old. 
To assess balance, Heyward (2010) proposes the statistic balance tests on one leg in their two modalities: with the eyes open and with the eyes closed. In both tests, the participant must maintain their balance with unipedal support during a maximum of 45 seconds while keeping the arms crossed against the chest; the test ends when the participant changes the arms' posture, moves their supporting foot or opens the eyes in the eyes-closed modality. This test has been applied in populations aged from 18 to 90 years old and includes different cutoff points by gender and age (Springer et al., 2007).

In addition to standardizing procedures among the evaluators, the assessment with physical tests requires considering appropriate cutoff points for the study population. This aspect represents an opportunity area in most of the populations, as many tests used in research have generated cutoff points considering gender and age; however, we must now acknowledge the major influence of body composition and even of anthropometry regarding the trunk's and legs' size on the physical performance results. Hence the need to develop cutoff points considering race and, when possible, it is even recommended to work on the development of specific cutoff points for each context.

\subsection{Methodology}

According to the quantitative approach and considering the objectives pointed out in the previous section, the study design is descriptive, comparative, correlational, analytical, and cross-sectional (HernándezSampieri, Fernández and Baptista, 2014). The study population corresponds to women belonging to several social groups from a community in the urban area of northeastern Mexico. Women aged from 45 to 59 years old who were able to walk without the assistance of another person were included, as well as those without any medical contraindication for physical exercise and who accepted to voluntarily participate in the study. The participants excluded were those who stated suffering from any acute disease during the previous week, as well those who indicated having a history of acute myocardial infarction, use of pacemaker, surgery, or fractures in the past three months. To avoid risks during the assessment of balance, it was decided to exclude those participants who stated suffering from any neuromuscular disease with use of medications that can alter habitual physical performance. The data of the participants who did not finish the physical tests were removed.

A formula was used to assess the difference of two proportions in an infinite population based on a value of $60 \%$ of physical inactivity reported in the literature. Based on the above, a necessary sample of 95 participants was considered. The proportional cluster sampling technique was employed to attain a more homogeneous representation of the study universe.

\subsubsection{Characteristics of the group of perimenopausal women}

A personal data form was used to collect personal information, namely: age, occupation, marital status; and the socioeconomic characteristics were surveyed with the Socioeconomic Level Questionnaire elaborated by AMAI (Asociación Mexicana de Agencias de Inteligencia de Mercado y Opinión, 2018). This questionnaire assesses six variables associated with the usual income in Mexican households: schooling level of the head of the house, number of full bathrooms in the house, number of cars in the household, Internet connection in the home, number of working family members aged over 14 years old, and number of bedrooms in the house. These variables are studied through six questions that yield a score from zero to 300 points, to later classify the socioeconomic level in one out seven possible levels. The socioeconomic levels proposed by AMAI are as follows: A/B (205 points or more) $=$ High level; $\mathrm{C}+(166-204$ points $)=$ Mid-high $\quad$ level; $\quad \mathrm{C}(136-165$ points $)=$ Typical mid-level; $\quad \mathrm{C}-(112-$ 135 points $)=$ Emerging mid-level; D+ (90-111 points $)=$ Typical low level; D (48-89 points $)=$ Extreme low level; E (0-47 points) = Very extreme low level. The questionnaire was validated by AMAI with data from the 2016 National Income and Expense Survey (Encuesta Nacional de Ingreso $y$ Gasto, ENIGH).

Weight and height were measured to estimate the Body Mass Index (BMI). A SECA stadiometer and an OMRON HBF-514c scale were used. The individuals with BMI values between 18 and $25 \mathrm{~kg} / \mathrm{m}^{2}$ were classified as with normal weight, overweight corresponded to BMI values between 25 and $29 \mathrm{~kg} / \mathrm{m}^{2}$ and obesity was considered for BMI values over $30 \mathrm{~kg} / \mathrm{m}^{2}$ (Governor's Office Secretariat, 2018). The recommendations set forth in the manual by Lohman, Roche and Martorell (1998) were followed for these measurements. 


\subsubsection{Physical activity self-report}

It was initially measured with the International Physical Activity Questionnaire-Long Form, which was designed to assess PA in adults aged from 18 to 69 years old, distinguishing four domains from overall PA, namely: PA at work, due to active transportation, at home, and during leisure time (International Physical Activity Questionnaire Group, no date). The version in Spanish has been validated by Caravali et al. (2016). It was designed in 1998 by a group of experts in Geneva and its long version was validated to monitor PA levels in adults aged between 18 and 65 years old (Craig et al., 2003); and the IPAQ group recommendations were followed for its assessment. The METs/minutes/week used in the activities from each domain of the questionnaire were calculated; subsequently, the total METs/minutes/week were added up. To classify the PA level between low and acceptable, the cutoff point recommended by the authors was used: 3,000 METs.

\subsubsection{Physical activity with accelerometry}

PA was quantified by means of ActiGraph ${ }^{\mathrm{TM}}{ }_{\text {wGT3X }}$ accelerometers (Actigraph, Pensacola, Florida, USA), which measure body acceleration in the three movement axis and express it as counts per time unit; with the use of cutoff points based on the accelerometer's counts, it is possible to measure the amount of PA performed based on its intensity: light, moderate, vigorous or very vigorous, as well as the number of steps walked (O'Neill et al., 2017). The Actigraph GT3X accelerometers have been validated to quantify PA in adults aged from 40 to 55 years old (O'Neill et al., 2017; Santos-Lozano et al., 2013). In Mexico, they have been used to assess PA level in adults aged between 20 and 65 years old (Salvo et al., 2015). Caravali et al. (2016) mention that the triaxial accelerometers such as those used in this study provide a more accurate estimate than their uniaxial counterparts.

The cutoff points used to measure PA intensity were those proposed by Freedson et al. (1998), which have been validated to measure moderate to vigorous PA in postmenopausal women (Diniz et al., 2017). The protocol used to validate the data was that described by Salvo et al. (2015), and the ActiLife v6.8.2 software (Actigraph, Pensacola, Florida, USA) was used. The variables that were considered to estimate the amount of PA performed are the following: daily average of moderate to vigorous PA (DAMVPA) expressed in minutes, and time devoted to light PA per day and per week. The criterion to verify if the participants met the moderate to vigorous PA (MVPA) recommendation for their age was multiplying the DAMVPA variable by 7 - the number of days in a week (Braun et al., 2016); if the participants accumulated $\geq 150$ minutes of MVPA, they were considered active; otherwise, they were considered as inactive (WHO, 2020).

\subsubsection{Sedentary behavior self-report}

The instrument applied to measure this variable was the Sedentary Behavior Questionnaire (Rosenberg et al., 2010), which, by means of the self-report, quantifies the time spent to perform 11 sedentary activities (watching television, eating in a sitting position, resting in a lying position, playing videogames or with the cell phone, talking over the phone or with other people while seated, reading in a sitting position, playing some musical instrument, making handicrafts or craftwork, remaining in a sitting position while traveling or driving a car, bus or subway formation) during weekdays (from Monday to Friday) and, separately, the weekend activities. The total time in minutes of each aspect is reported to estimate sedentary behavior. The version in Spanish of this questionnaire has been validated by Munguía et al. (2013). To complement the information from the PA and sedentary behavior self-reports, accelerometry was applied in a percentage of the total sample $(n=42,50 \%)$.

\subsubsection{Sedentary behaviors with accelerometry}

They are also quantified with ActiGraph $^{\mathrm{TM}}{ }_{\mathrm{wGT}} 3 \mathrm{X}$ accelerometers (Actigraph, Pensacola, Florida, USA), which measure body acceleration in the three-movement axis and express it as counts per time unit. The following criteria were applied to assess sedentary behaviors by means of accelerometry: the accelerometer was used around the hip for seven days; the epoch used to integrate the data lasted 60 seconds; the days on which the participants accumulated a minimum use time of 10 hours were considered as valid, and only data from the participants who attained four valid days during weekdays and on one weekend day were included (Healy et al., 2011; Schlaff et al., 2017). 
The cutoff point used to distinguish between sedentary activity and light PA was that proposed by Freedson et al. (1998). The data were validated using the ActiLife v6.8.2 software (Actigraph, Pensacola, Florida, USA).

To measure this variable, the minutes accumulated in average sedentary blocks per day, per weekday and per weekend day were considered (Schlaff et al., 2017). A sedentary block was defined as any period $\geq 30$ minutes with $\geq 80 \%$ of minutes $<100$ counts per minute with not more than 5 consecutive minutes with $\geq 100$ counts per minute (Tudor-Locke, Camhi, \& Troiano, 2012). The sedentary blocks per day variable is reported based on the daily average of sedentary minutes as a function of the time of accelerometer use; while the variables of sedentary blocks on weekdays (average of the sedentary blocks per day accumulated from Monday to Friday) and during the weekend (average of the sedentary blocks per day accumulated on Saturday and Sunday), are reported according to the recommendation by Schlaff et al. (2017).

\subsubsection{Assessment of physical fitness: strength and balance}

Strength in the upper and lower limbs and two balance tests were considered to measure physical fitness.

\section{Strength in the upper limbs}

As an indicator of the strength in the upper limbs, the hand grip test with a TAKEI digital dynamometer was used to assess the forearm muscles' strength. Rathnayake et al. (2019) mention that, in women, muscle mass loss starts during the fourth decade of life and that muscle strength suffers a $21 \%$ reduction between ages 25 and 55. Savva et al. (2018) state that the hand grip test presents an intraclass correlation coefficient of 0.94 to assess hand grip strength in adults aged from 18 to 59 years old with subacromial impingement syndrome. The test was applied in both hands and in duplicate with a minimum rest interval of two minutes between measurements; the highest value of the four attempts was considered to represent this variable (Table 5.2).

Table 5.2 Reference values for hand grip strength test in women aged 40 to 59 years

\begin{tabular}{|l|c|c|c|c|}
\hline \multicolumn{1}{|c|}{ Variable } & $\mathbf{4 0 - 4 4}$ & $\mathbf{4 5 - 4 9}$ & $\mathbf{5 0 - 5 4}$ & $\mathbf{5 5 - 5 9}$ \\
\hline Dominant hand & $29.9 \pm 6.2$ & $28.8 \pm 7.2$ & $28.2 \pm 6.3$ & $25.1 \pm 6.2$ \\
\hline Non dominant hand & $28.9 \pm 6.4$ & $27.4 \pm 7.0$ & $26.5 \pm 6.5$ & $23.6 \pm 6.4$ \\
\hline
\end{tabular}

\footnotetext{
Source: Wang, Y. C., Bohannon, R. W., Li, X., Sindhu, B., \& Kapellusch, J. (2018). Hand-Grip Strength: Normative Reference Values and Equations for Individuals 18 to 85 Years of Age Residing in the United States. The Journal of Orthopaedic and Sports Physical therapy, 48(9), 685-693. https://doi:10.2519/jospt.2018.7851
}

\section{Strength in the lower limbs}

The 30 second Sit to Stand Test was applied: the participant is asked to get up from and sit on a chair for 30 seconds and the number of repetitions is counted. It is part of the battery included in the Senior Fitness Test, which was developed by Rikli and Jones (2001). The tests from the Senior Fitness Test present intraclass correlation coefficients from 0.8 to 0.98 , and some of them have been validated in relation to the recognized gold standard (Langhammer \& Stanghelle, 2015). Acosta et al. (2018) mention that the tests are safe, adaptable, and feasible for clinical populations, such as perimenopausal women. For normality, the cutoff point of 13 repetitions was applied, based on the publication by MoratallaCecilia et al., 2016.

\section{Balance}

The Unipedal Stance Test was applied, which is used to assess static balance and, according to Heyward (2010), validity of this test has been proven due to its relationship with gait, risk of falls and performance in the activities of daily living in older adults. Its intraclass correlation coefficient is 0.74 if performed with the eyes closed and 0.91 if conducted with the eyes open; and it provides a reliable measure of static balance in adults and adolescents (Heyward, 2010). To perform the test, the person to be evaluated is placed on an orthostatic position using only one leg, with the eyes open and then closed. 
The test is scored based on the seconds that the person can maintain balance on the dominant leg; the assessment lasts a maximum of 45 minutes. To assess this variable, the scalar value of the time per participant in the two versions of the test (eyes open and eyes closed) will be considered. Additionally, with the results, performance will be classified as of acceptable or low level according to cutoff points recommended by the author of this test: Eyes open, 42.1 seconds for $40-49$ years old and 40.9 seconds for 50-59 years old; Eyes closed, 13.5 seconds for 40-49 years old and 7.9 seconds for 50-59 years old.

\section{Procedures}

This project was registered at the Research Coordination Office of the Facultad de Organización Deportiva at the Universidad Autónoma de Nuevo León and has been approved by the authorities of the institutions involved, adhering to the ethical criteria for research with human beings (Health Secretariat, 1987). To publicize the project, information posters were used, and word-of-mouth invitations were made among renowned leaders of the social groups. Participation was made effective with prior scheduling. In the first appointment, the informed consent was signed, the personal data form was filled out, physical condition was assessed, the schedule was defined, and the accelerometer was handed in. A tutorial about using and taking care of the accelerometer during measurements was handed in, as well as ancillary questionnaires to the project. A new appointment was scheduled to return the accelerometer with the promise of delivering the interpretation of the physical condition assessment's results and customized recommendations as a retribution for collaborating with the project. With this, participation in the study was ended.

\section{Data analysis}

The SPSS software, version 21.0, was used for data analysis. The scalar variables are described with central tendency and dispersion measures, as well as the data distribution test. The categorical variables are presented as frequencies and percentages. Inferential statistics for the comparison of the qualitative variables was performed with the Chi-square test. To compare the results of the continuous variables obtained under different conditions, the ttests for related samples or the Mann-Whitney $U$ test were performed. Kruskal-Wallis tests were used in variables with more than two levels. The association between variables was reviewed with a Spearman's or Pearson's correlation matrix according to data distribution. Statistical significance level was considered with $p$-value $<0.05$.

\subsection{Results}

\subsubsection{Characteristics of the group of perimenopausal women}

A total of 109 women answered the invitation in the scheduled collection period. Eight of them did not meet some inclusion criterion and another one had to be excluded. Taking into consideration the exclusion criteria, the data of 16 participants $(14.67 \%)$ were discarded for not having undergone the strength in the upper limbs test. The reasons pointed out for not accepting performance of this test included difficulty or discomfort exerting hand grip $(n=10,62.5 \%)$ and history of surgery $(n=6,37.5 \%)$. The results presented are those of the 84 participants who concluded their participation in the study. Table 5.3 includes the description of the scalar variables and data distribution. 
Table 5.3 Descriptive characteristics of participants who are going through perimenopause

\begin{tabular}{|l|r|r|r|r|r|r|}
\hline Variable & \multicolumn{1}{c}{ Mean } & \multicolumn{1}{c|}{ Median } & \multicolumn{1}{c|}{ SD } & \multicolumn{1}{c|}{ Mín } & \multicolumn{1}{c|}{ Max } & K-SL \\
\hline Age, years & 49.39 & 49.00 & 4.51 & 40.00 & 59.00 & $* *$ \\
\hline Weigth, kg. & 71.46 & 70.30 & 13.97 & 42.50 & 119.40 & \\
\hline Heigth, cm. & 156.66 & 156.00 & 5.54 & 145.00 & 175.00 & \\
\hline BMI, Kg/m ${ }^{2}$ & 29.23 & 28.20 & 5.39 & 19.10 & 49.06 & \\
\hline AMAI+ points & 181.92 & 181.00 & 44.35 & 45.00 & 294.00 & \\
\hline SBBW, hrs. & 899.11 & 862.50 & 367.64 & 250.00 & 2200.00 & \\
\hline SBWD, hrs. & 875.00 & 875.00 & 375.39 & 125.00 & 1875.00 & \\
\hline PA++, METs & 4381.90 & 3567.57 & 3197.85 & 297.00 & 15240.51 & $*$ \\
\hline Work & 498.32 & 0.00 & 1080.73 & 0.00 & 4590.00 & $* *$ \\
\hline Transportation & 593.08 & 346.50 & 710.75 & 0.00 & 2772.00 & $* *$ \\
\hline Home & 1752.98 & 1417.36 & 1406.46 & 0.00 & 5460.00 & $* *$ \\
\hline Free time & 1537.37 & 959.92 & 2106.97 & 0.00 & 12960.00 & $* *$ \\
\hline Physical tests & & & & & & \\
\hline UBS, rep. & 17.10 & 17.00 & 3.75 & 9.00 & 27.00 & \\
\hline LBS, kg. & 23.80 & 23.45 & 4.51 & 13.10 & 32.80 & \\
\hline USTOE, s & 22.66 & 19.00 & 15.41 & 1.12 & 46.00 & $* *$ \\
\hline USTCE, s & 4.91 & 4.17 & 2.78 & 1.00 & 13.00 & $* *$ \\
\hline
\end{tabular}

Note BMI = Body mass index; SBBW = Sedentary Behavior Between Weekdays; SBWD = Sedentary Behaviors Weekend Days; PA = Physical Activity; METs = energy expenditury units; UBS = Upper body strength; LBS = Lower body strength, USTEO = Unipedal stance test with open eyes; USTCE = Unipedal stance test with closed eyes; $K$-SL $=$ Kolmogorov-Smirnov with Lilliefors' correction. ${ }^{*} p<.05 ; * * p<.01$. +AMAI Level $=$ Socioeconomic status questionnaire AMAI. ++Total physical activity and dimensions in METs. $n=84$.

\section{Source: Sedentary Behavior Questionnaire, International Physical Activity Questionnaire Long form, and physical} tests' report

The sociodemographic variables considered include the following: occupation, socioeconomic level, marital status, schooling, and Body Mass Index. Table 5.4 presents the participants' distribution regarding these categories.

Table 5.4 Distribution of the participants regarding sociodemographic variables

\begin{tabular}{|c|c|c|}
\hline Variables & $\boldsymbol{n}$ & $(\%)$ \\
\hline \multicolumn{3}{|l|}{ Ocupation } \\
\hline Home & 56 & 66.7 \\
\hline Work & 28 & 33.3 \\
\hline \multicolumn{3}{|l|}{ Socioeconomic level } \\
\hline$A / B$ & 24 & 28.6 \\
\hline$C$ & 30 & 35.7 \\
\hline$C+$ & 19 & 22.6 \\
\hline$C-$ & 9 & 10.7 \\
\hline$D+$ & 2 & 2.4 \\
\hline \multicolumn{3}{|l|}{ Marital status } \\
\hline Single & 2 & 2.4 \\
\hline Married/Free union & 74 & 88.1 \\
\hline Divorced & 7 & 8.3 \\
\hline Widow & 1 & 1.2 \\
\hline \multicolumn{3}{|l|}{ Scholarity } \\
\hline Master's degree/speciality & 5 & 6 \\
\hline Bachelor's Degree & 27 & 32.1 \\
\hline Hight school & 27 & 32.1 \\
\hline Middle school & 21 & 25 \\
\hline Elementary & 4 & 4.8 \\
\hline \multicolumn{3}{|l|}{ Body mass index } \\
\hline Normal weight & 16 & 19 \\
\hline Overweight & 33 & 39.3 \\
\hline Obesity & 35 & 41.7 \\
\hline
\end{tabular}

Source: Personal data card. $n=84$ 
To continue describing the participants, Graphic 5.1 summarizes the meaning of the strength and balance assessment of the study sample. Low values were found in more than half of the participants for all the physical tests.

Graphic 5.1 Summary of results of the evaluation of strength and balance in perimenopausal women ( $n$ $=84)$

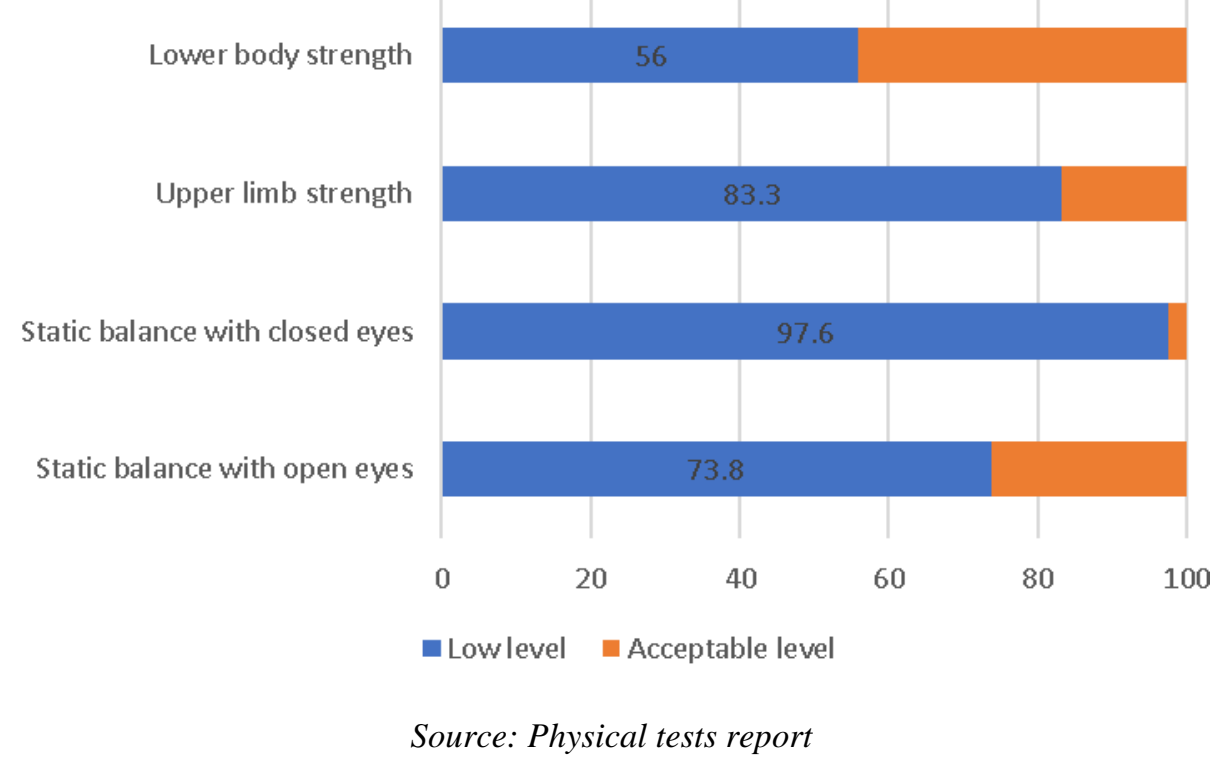

\subsubsection{Physical activity}

When reviewing the differences regarding the scalar variables between the percentage of the total sample subjected to accelerometry and the participants not subjected to such measurement, significant data were only found in relation to the balance test with the eyes closed $(p=0.042)$. In this test, the participants who did undergo the accelerometry measurement presented lower average values (4.30 vs $5.53, t=-$ $2.064, D o F=82$ ). Table 5.5 describes the results obtained with accelerometry.

Table 5.5 Report of physical activity of a proportion of participating perimenopausal women with accelerometry

\begin{tabular}{|c|c|c|c|c|c|c|}
\hline Variable & Mean & Median & SD & Mín & $\operatorname{Max}$ & $K S-L$ \\
\hline MVPA/week & 191.82 & 161.85 & 141.11 & 29.17 & 784.00 & * \\
\hline Ligth activity/day & 239.22 & 241.94 & 46.36 & 127.42 & 322.43 & \\
\hline Ligth activity/week & 1674.56 & 1693.58 & 324.49 & 891.92 & 2257.00 & \\
\hline
\end{tabular}

Source: Accelerometry report

The difference between the self-report and the accelerometry measurement regarding compliance with the PA recommendations for health was reviewed in the percentage of the sample who underwent the two assessments $(n=42,50 \%)$. According to the PA self-report obtained through the IPAQ, 54.8\% of the participants meet the global recommendations for health, which require at least 150 minutes of moderate to vigorous PA per week, whereas with accelerometry, the percentage was $52.4 \%$. Hence the absence of statistically significant differences between the measurements $(p>0.05)$.

\subsubsection{Sedentary behaviors}

From the questionnaire applied, the specific description of each of the sedentary behaviors considered by the instrument is presented. The data are presented according to weekdays and to weekend days (Table 5.6). 
Table 5.6 Descriptive analysis of self-reported sedentary behavior

\begin{tabular}{|l|r|r|r|r|}
\hline \multicolumn{1}{|c|}{ Behavior } & \multicolumn{2}{cc}{ Weekdays } & \multicolumn{2}{c|}{ Weekend } \\
& Mean & \multicolumn{1}{c|}{ SD } & \multicolumn{1}{c|}{ Mean } & \multicolumn{1}{c|}{ SD } \\
\hline 1. Watching TV & 117.89 & 84.02 & 126.98 & 77.27 \\
\hline 2. Eat sitting & 55.26 & 37.73 & 78.36 & 51.96 \\
\hline 3. Rest lying & 80.79 & 91.19 & 98.53 & 86.70 \\
\hline 4.Sitting playing computer & 43.68 & 50.25 & 46.29 & 52.36 \\
\hline 5. Listening music & 15.79 & 36.68 & 16.03 & 33.70 \\
\hline 6. Sitting and talking on the phone & 32.11 & 40.73 & 33.10 & 40.40 \\
\hline 7.Sitting with office work & 97.37 & 126.97 & 30.26 & 61.91 \\
\hline 8. Sitting reading & 35.26 & 38.5 & 31.81 & 45.57 \\
\hline 9.Playing a musical instrument & 8.95 & 31.03 & 1.03 & 7.88 \\
\hline 10.Doing artwork or crafts & 30.53 & 53.63 & 15.78 & 39.38 \\
\hline 11.Sitting for transportation & 62.63 & 60.54 & 64.91 & 70.55 \\
\hline
\end{tabular}

Source: Sedentary Behavior Questionnaire $n=58$.

Graphic 5.2 shows the average sedentary behaviors by type and regarding the weekend and those reported during the week.

\section{Graphic 5.2}

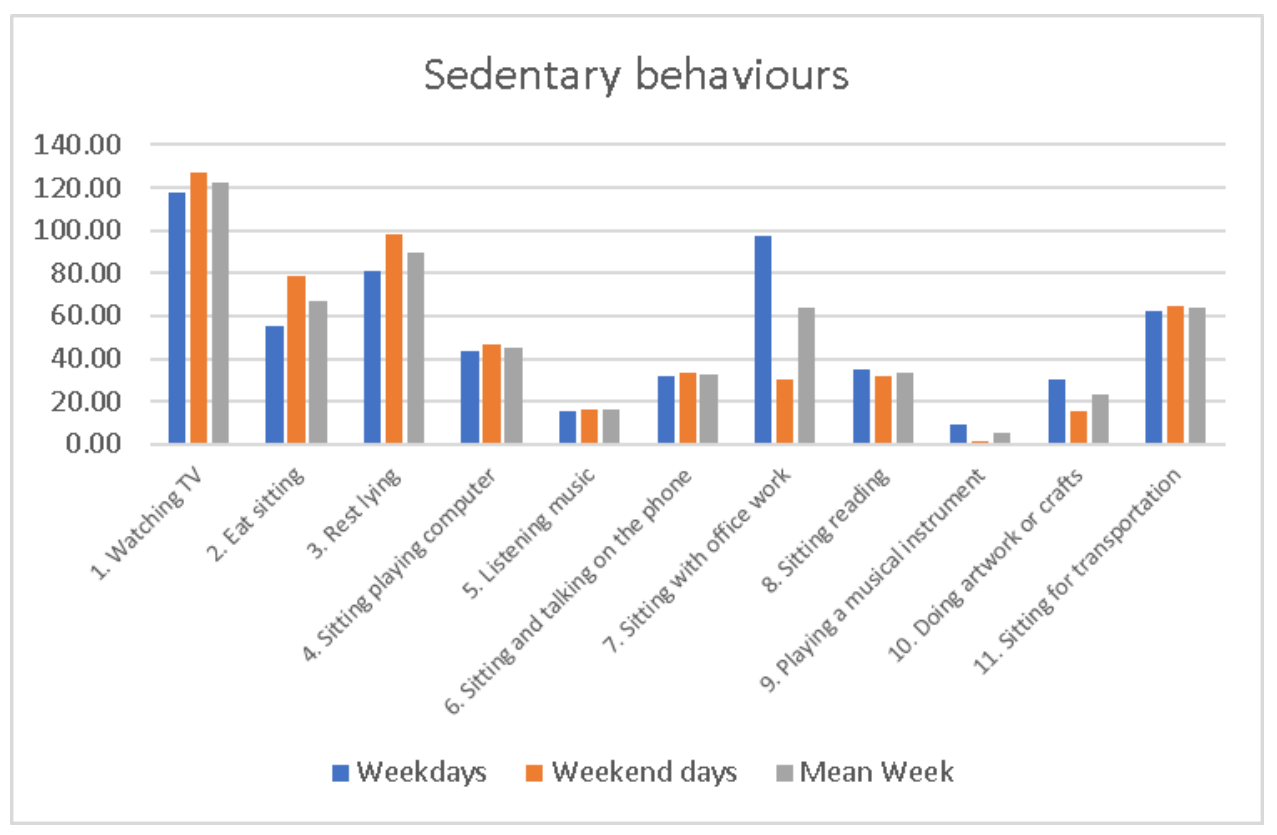

The description of the sedentary behaviors measured with accelerometry by blocks is presented in Table 5.7. As can be seen, on average, more than 850 minutes a day is classified within the sedentary level, which suggests the so-called sedentary lifestyle.

Table 5.7 Sedentary behaviors of a proportion of participating perimenopausal women with accelerometry

\begin{tabular}{|c|c|c|c|c|c|c|}
\hline Variable & Mean & Median & $S D$ & Min & $\operatorname{Max}$ & $K S-L$ \\
\hline Sedentary blocks/day & 876.18 & 869.90 & 96.09 & 705.50 & 1119.70 & $*$ \\
\hline Sedentary blocks/BW & 893.17 & 874.00 & 132.78 & 646.75 & 1311.20 & \\
\hline Sedentary blocks/WD & 891.57 & 859.75 & 207.95 & 179.00 & 1245.50 & \\
\hline
\end{tabular}

\section{Source: Accelerometry report}

The data regarding the sedentary behaviors on weekdays and during the weekend obtained through the participants' self-report and from the accelerometry report did not present differences (Table 5.8). 
Table 5.8 Comparison of sedentary behaviors evaluated with self-report and accelerometry

\begin{tabular}{|c|c|c|c|c|c|c|c|c|}
\hline & \multirow[b]{2}{*}{ Mean } & \multicolumn{6}{|c|}{ CI $95 \%$} & \multirow[b]{2}{*}{$p$} \\
\hline & & SD & Error & Lower & Higher & $t$ & $g l$ & \\
\hline SBW, $\min -\mathrm{SBBW}$ & 6.83 & 387.38 & 59.77 & -113.89 & 127.54 & .114 & 41 & .910 \\
\hline SWD, min - SBWD & 4.86 & 384.61 & 59.35 & -114.99 & 124.71 & .082 & 41 & .935 \\
\hline
\end{tabular}

Source: Accelerometry report, Sedentary behaviors questionnaire.

\subsubsection{Physical activity, sedentary behaviors, and physical fitness}

Considering that the self-report and accelerometry data did not present statistically significant differences, the assessment of the association between the participants' PA, sedentary behaviors and physical fitness was reviewed in the entire sample (Table 3.4.1). A direct association was found between PA and strength in the upper limbs $(r=0.358, p<0.01)$. The weekday sedentary behaviors were positively associated with the weekend behaviors $(r=0.614, p<0.01)$; likewise, the two balance tests showed an association $(r=350, p<0.01)$. PA was not associated with the sedentary behaviors on weekdays or during the weekend $(p>0.05)$.

Table 5.9 Spearman association matrix between physical activity, sedentary behaviors, and physical fitness

\begin{tabular}{|c|c|c|c|c|c|c|c|c|}
\hline & Mean & SD & 2 & 3 & 4 & 5 & 6 & 7 \\
\hline 1. PA, METs & 4381.90 & 3197.85 & -.174 & -.020 & .215 & $.358^{* *}$ & .145 & -.007 \\
\hline 2. SBBW, min & 899.11 & 367.64 & - & $.614^{* *} \mathrm{~T}$ & -.126 & .038 & .059 & -.034 \\
\hline 3. SBWD, $\min$ & 875.00 & 375.39 & & - & -.132 & .009 & -.067 & -.009 \\
\hline 4. UBS, kg & 23.80 & 4.51 & & & - & .100 & -.065 & -.175 \\
\hline 5. LBS, rep & 14.67 & 5.12 & & & & - & .099 & -.009 \\
\hline 6. USTOE, s & 22.66 & 15.41 & & & & & - & $.350^{* *}$ \\
\hline 7. USTCE, s & 4.91 & 2.78 & & & & & & - \\
\hline
\end{tabular}

Source: Accelerometry report and Physical test report.

Being a housewife or having a job implied differences regarding the PA during leisure time domain $(p<0.05)$, with higher energy expenditure for the participants who devoted themselves to house chores (46.52 vs 34.46). Marital status generated differences in relation to the weekday sedentary behaviors with greater range for the women who were divorced, single, married or in consensual unions and, finally, widows $(p<0.05)$.

Socioeconomic level and schooling showed to exert an influence on strength in the lower limbs with a lower difference range for the participants belonging to the $\mathrm{C}+$ level $(p<0.05)$. The Body Mass Index categories exerted an effect on the energy expenditure related to overall PA and the balance test with the eyes open: the greater the index, the lower the range recorded $(p<0.05)$.

\subsection{Discussion}

This paper analyzed the influence of the personal characteristics on the PA level, as well as on the sedentary behaviors, considering measurements through the self-report with questionnaires and the objective accelerometry assessment. In addition, the association with physical fitness was reviewed, which yielded important results for the epidemiological research of different professionals from the multidisciplinary health team, among which medical staff, PA or sports professionals, nutritionists, psychologists and nurses should be considered. 
The presence of excess weight in most of the participants is in accordance with other women's reports during this life stage (Abdulnour et al., 2012; Aguilera-Barreiro et al., 2013; Darbandi, Najafi, Pasdar, \& Rezaeian, 2020; Rossi et al., 2018; Villaverde-Gutiérrez et al., 2015). Excess weight affects women's physical fitness and cardiovascular health (Acosta-Manzano et al., 2018; Gregorio-Arenas et al., 2016); consequently, the high levels in this parameter might be a determining factor that exerts a negative influence on the physical performance of the participants in this sample. Although the association between PA and strength in the upper limbs has been mainly reported in the aged population, there are reports such as those by Bondarev et al. (2018) and by Leblanc et al. (2015) corroborating that this relationship is present in younger age groups.

At an appropriate level, strength and balance can mark a difference in case of falls or other types of accidents. According to the literature, these two skills can be trained (Chalapud-Narváez \& EscobarAlmario, 2017; Otero, Esain, González-Suárez, \& Gil, 2017; Vaca-García et al., 2017) and do not necessarily depend on age (Vaca-García et al., 2017). Measuring physical fitness with field tests would be an advisable assessment for consideration within the family consultation activities for everyday review and timely detection of health risks. This justifies the promotion of lifestyles that allow recovery and/or maintenance of these skills during perimenopause or climacteric (Nolting et al., 2019).

In 2020, the percentage distribution by age group in Nuevo León allowed identifying that $39.2 \%$ of the state's population is aged between 30 and 59 years old, with an equivalent proportion between men and women (INEGI, 2020). At the social level, maintaining families and/or paid work are an expected constant for the subjects belonging to this age group. The importance of assessing physical fitness for timely detection of health risk factors in stages prior to old age lies not only on protecting the individual as such, but also due to the social repercussions that early disability might present.

The fact that no differences were found between the questionnaires' reports and those obtained by means of accelerometry represents a very useful finding for researching PA behavior in women with similar characteristics to those of this sample. Consequently, the long version of the IPAQ questionnaire and the Sedentary Behavior Questionnaire turn out to be appropriate and advisable to assess these variables in women aged over 45 years old and less than 60 years old, with mid socioeconomic level and complete high school or higher education. It is worth noting that the sample's characteristics regarding schooling correspond to the average of 10.6 years reported for the state, which is slightly above the national mean of 9.7 years (INEGI, 2020).

The difficulty finding participants willing to use accelerometry equipment for a period of seven to nine days, coupled to the "inconvenience" that is for the woman to be evaluated regarding her physical fitness, might be limiting the generation of this type of evidence. The participants of this project faced the need to use a piece of equipment that measures PA level even on the days they knew that their PA was insufficient; the most problematic measurement was that of the two weekend days that was required. Although this is a small sample, it turns out to be representative of the study population; in addition, as can be seen, the sample presents the main distinctive sociodemographic characteristics of this age group at the state level.

In general, the limitations of this project are circumscribed to those inherent to the cross-sectional design and to the lack of laboratory physical tests to assess physical fitness; the findings must be limited to people with similar characteristics as those of this sample. The use of specific cutoff points for women belonging to this age group in this context constitutes an additional research need related to the study theme. Future studies might consider longitudinal analyses to observe the changes in these variables over time. Measuring physical fitness with field tests is considered an appropriate technique for epidemiological studies; this is convenient because it turns out to be economical and accessible, even in the clinical-assistance scope; it is necessary to work on the development of cutoff points adapted to the population characteristics of the context.

\subsection{Conclusions}

Regarding PA level, sedentary behaviors, and physical fitness in perimenopausal women, it is concluded that little more than half of the participants (54.8\%) meet the PA recommendations for health; nevertheless, the amount of sedentary time per day is high. 
No differences were found between the self-report and the objective accelerometry measurement of PA and sedentary behaviors in the participants of this sample. In the physical fitness tests applied, performance was low in more than half of the participants.

Excess weight exerts an influence on the total amount of activity, as well as on performance on the unipedal stance test with the eyes open. House chores exert an effect on the PA performed during leisure time. Based on the findings, future study lines can be targeted to the promotion and reinforcement of health-promoting behaviors, as well as to the design of interventions that maintain and/or improve the status of muscle strength and balance during this stage, as it is advisable to maintain physical functionality in old age and, with this, prevent functional limitations and motor disability.

\subsection{Acknowledgments}

To the Consejo Nacional de Ciencia y Tecnología for the support for the authors' graduate studies; and to the Support Program for Science and Technology of the Universidad Autónoma de Nuevo León for financing.

\subsection{References}

Aguilera-Barreiro, M. D. L. A., Rivera-Márquez, J. A., Trujillo-Arriaga, H. M., Ruiz-Acosta, J. M., \& Rodríguez-García, M. E. (2013). Impacto de los factores de riesgo en osteoporosis sobre la densidad mineral ósea en mujeres perimenopaúsicas de la Ciudad de Querétaro, México. Archivos Latinoamericanos de Nutrición, 63(1), 21-28.

Abdulnour, J., Doucet, É., Brochu, M., Lavoie, J. M., Strychar, I., Rabasa-Lhoret, R., \& Prud'homme, D. (2012). The effect of the menopausal transition on body composition and cardiometabolic risk factors: A Montreal-Ottawa New Emerging Team group study. Menopause, 19(7), 760-767. https://doi.org/10.1097/gme.0b013e318240f6f3

Acosta-Manzano, P., Segura-Jiménez, V., Coll-Risco, I., Borges-Cosic, M., Castro-Piñeiro, J., Delgado-Fernández, M., \& Aparicio, V. A. (2018). Association of sedentary time and physical fitness with ideal cardiovascular health in perimenopausal women: The FLAMENCO project. Maturitas, 120(1), 53-60. https://doi.org/10.1016/j.maturitas.2018.11.015

Ainsworth, B., Cahalin, L., Buman, M., \& Ross, R. (2015). The current state of physical activity assessment tools. Progress in Cardiovascular Diseases, 57(4), 387-395. https://doi.org/10.1016/j.pcad.2014.10.005

Aparicio-Ugarriza, R., Mielgo-Ayuso, J., Benito, P. J., Pedrero-Chamizo, R., Ara, I., González-Gross, M., \& EXERNET Study Group (2015). Physical activity assessment in the general population; instrumental methods and new technologies. Nutricion Hospitalaria, 31 Suppl 3, 219-226. https://doi.org/10.3305/nh.2015.31.sup3.8769

Asociación Mexicana de Agencias de Inteligencia de Mercado y Opinión (2018). Nivel Socioeconómico AMAI 2018. Nota metodológica. Niveles socioeconómicos AMAI sitio web: http://www.amai.org/nse/wp-content/uploads/2018/04/Nota-Metodolo\%CC\%81 gico-NSE-2018v3.pdf

Bergamin, M., Gobbo, S., Bullo, V., Zanotto, T., Vendramin, B., Duregon, F., Cugusi, L., Camozzi, V., Zaccaria, M., Neunhaeuserer, D., \& Ermolao, A. (2015). Effects of a Pilates exercise program on muscle strength, postural control, and body composition: results from a pilot study in a group of postmenopausal women. Age (Dordrecht, Netherlands), 37(6), 118. https://doi.org/10.1007/s11357-015$9852-3$

Blümel, J. E., Fica, J., Chedraui, P., Mezones-Holgún, E., Zuñiga, M. C., Witis, S., Vallejo, M.S., Tserotas, K., Sánchez, H., Onatra, W., Ojeda, E., Mostajo, D., Monterrosa, A., Lima, S., Martino, M., Hernández-Bueno, J.A., Gómez, G., Espinoza, M.T., Flores, D., Calle, A., ... Aedo, S. (2016). Sedentary lifestyle in middle-aged women is associated with severe menopausal symptoms and obesity. Menopause, 23(5), 488-493. https://doi.org/10.1097/GME.0000000000000575 
Bondarev, D., Laakkonen, E. K., Finni, T., Kokko, K., Kujala, U. M., Aukee, P., Kovanen, V., \& Sipilä, S. (2018). Physical performance in relation to menopause status and physical activity. Menopause, 25(12), 1432-1441. https://doi.org/10.1097/GME.0000000000001137

Braun, S. I., Kim, Y., Jetton, A. E., Kang, M., \& Morgan, D. W. (2017). Sedentary Behavior, Physical Activity, and Bone Health in Postmenopausal Women. Journal of Aging and Physical Activity, 25(2), 173-181. https://doi.org/10.1123/japa.2016-0046

Caravali-Meza, N. Y. \& Armendáriz-Anguiano, A. L. (2016). Validación del Cuestionario de Actividad Física del IPAQ en Adultos Mexicanos con Diabetes Tipo 2. Validity of the IPAQ among Mexican adults with type 2 diabetes. Journal of Negative and No Positive Results,1(3), 93-99. https://doi.org/10.19230/jonnpr.2016.1.3.1015

Chalapud-Narváez, L. M., \& Escobar-Almario, A. (2017). Actividad física para mejorar fuerza y equilibrio en el adulto mayor. Universidad y Salud, 19(1), 94-101. https://doi.org/10.22267/rus.171901.73

Cheng, M. H., Wang, S. J., Yang, F. Y., Wang, P. H., \& Fuh, J. L. (2009). Menopause and physical performance - A community-based cross-sectional study. Menopause, 16(5), 892-896. https://doi.org/10.1097/gme.0b013e3181a0e091

Chrismas, B., Majed, L., \& Kneffel, Z. (2019). Physical fitness and physical self-concept of male and female young adults in Qatar. PloS ONE, 14(10), e0223359. https://doi.org/10.1371/journal.pone.0223359

Colpani, V., Oppermann, K., \& Spritzer, P.M. (2013). Association between habitual physical activity and lower cardiovascular risk in premenopausal, perimenopausal, and postmenopausal women: A population-based study. Menopause, 20 (5), 525-531. http://doi.org/10.1097/GME.0b013e318271b388

Craig, C. L., Marshall, A. L., Sjöström, M., Bauman, A. E., Booth, M. L., Ainsworth, B. E., ... \& Oja, P. (2003). International physical activity questionnaire: 12 -country reliability and validity. Medicine \& $\begin{array}{lllll}\text { Science in } \quad \text { Sports } & \text { Exercise, } & 35(8), & 1381-1395 .\end{array}$ https://doi.org/10.1249/01.MSS.0000078924.61453.FB

Darbandi, M., Najafi, F., Pasdar, Y., \& Rezaeian, S. (2020). Structural equation model analysis for the evaluation of factors associated with overweight and obesity in menopausal women in RaNCD cohort study. Menopause, 27(2), 208-215. https://dx.doi.org/10.1097/GME.0000000000001452

Delamater, L., \& Santoro, N. (2018). Management of the Perimenopause. Clinical obstetrics and gynecology, 61(3), 419-432. https://doi.org/10.1097/GRF.0000000000000389

Devries, M. C., \& Phillips, S. M. (2015). Supplemental protein in support of muscle mass and health: advantage whey. Journal of Food Science, 80(Suppl 1), A8-A15. https://doi.org/10.1111/17503841.12802

Diario Oficial de la Federación. (2012). Norma Oficial Mexicana NOM-035-SSA2-2012 para la prevención y control de enfermedades en la perimenopausia y la postmenopausia de la mujer. Criterios para brindar atención médica. http://dof.gob.mx/nota_detalle.php?codigo=5284235\&fecha=07/01/2013.

Diniz, T. A., Rossi, F. E., Rosa, C. S., Mota, J., \& Freitas-Junior, I. F. (2017). Moderate-to-Vigorous Physical Activity Among Postmenopausal Women: Discrepancies in Accelerometry-Based CutPoints. Journal of Aging and Physical Activity, 25(1), 20-26. https://doi.org/10.1123/japa.2015-0193

Dugan, S. A., Gabriel, K. P., Lange-Maia, B. S., \& Karvonen-Gutierrez, C. (2018). Physical Activity and Physical Function: Moving and Aging. Obstetrics and Gynecology Clinics of North America, 45(4), 723-736. https://doi.org/10.1016/j.ogc.2018.07.009 
Freedson, P. S., Melanson, E., \& Sirard, J. (1998). Calibration of the Computer Science and Applications, Inc. accelerometer. Medicine \& Science in Sports \& Exercise, 30(5), 777-781. https://doi.org/10.1097/00005768-199805000-00021

Gregorio-Arenas, E., Ruiz-Cabello, P., Camiletti-Moirón, D., Moratalla-Cecilia, N., Aranda, P., LópezJurado, M., Llopis, J., \& Aparicio, V. (2016). The associations between physical fitness and cardiometabolic risk and body-size phenotypes in perimenopausal women. Maturitas, 92, 162-167. https://doi.org/10.1016/j.maturitas.2016.08.008

Gutiérrez, J. P., Rivera-Dommarco, J., Shamah-Levy, T., Villalpando-Hernández, S., Franco, A., Cuevas-Nasu, L., Romero-Martínez, M., \& Hernández-Ávila, M. (2013). Encuesta Nacional de Salud y Nutrición 2012. Resultados nacionales. 2a. ed. Cuernavaca, México: Instituto Nacional de Salud Pública

(MX). https://ensanut.insp.mx/encuestas/ensanut2012/doctos/informes/ENSANUT2012ResultadosNacionale s2Ed.pdf

Hallal, P. C., Gomez, L. F., Parra, D. C., Lobelo, F., Mosquera, J., Florindo, A. A., Reis, R. S., Pratt, M., \& Sarmiento, O. L. (2010). Lessons learned after 10 years of IPAQ use in Brazil and Colombia. Journal of Physical Activity \& Health, 7(Suppl 2), 259-264. https://doi.org/10.1123/jpah.7.s2.s259

Headley, S., Hutchinson, J., Wooley, S., Dempsey, K., Phan, K., Spicer, G., Janssen, X., Laguilles, J., $\&$ Matthews, T. (2018). Subjective and objective assessment of sedentary behavior among college employees. BMC Public Health, 18(1), 768. https://doi.org/10.1186/s12889-018-5630-3

Healy, G. N., Matthews, C. E., Dunstan, D. W., Winkler, E. A., \& Owen, N. (2011). Sedentary time and cardio-metabolic biomarkers in US adults: NHANES 2003-06. European Heart Journal, 32(5), 590-597. https://doi.org/10.1093/eurheartj/ehq451

Hernández-Sampieri, R., Fernández, C., \& Baptista, P. (2014). Metodología de la investigación. $6^{\text {a }}$ ed. Editorial Mc Graw Hill Interamericana.

Heyward, V. (2010). Advanced Fitness Assessment and Exercise Prescription. 6a Ed. Editorial Human Kinetics.

Instituto Nacional de Estadística y Geografía. (2018). Mujeres y hombres en México 2018. Centro de Documentación del Instituto Nacional de las Mujeres sitio web: http://cedoc.inmujeres.gob.mx/documentos_download/MHM_2018.pdf

Instituto Nacional de Estadística y Geografía. (2020). Censo de población y vivienda 2020. Presentación de resultados Nuevo León.

International Physical Activity Questionnarie Group. (s. f.). Cuestionario Internacional de Actividad Física: Formato largo autoadministrado de los últimos 7 días. International Physical Activity sitio web: https://sites.google.com/site/theipaq/.

Juppi, H. K., Sipilä, S., Cronin, N. J., Karvinen, S., Karppinen, J. E., Tammelin, T. H., Aukee, P., Kovanen, V., Kujala, U. M., \& Laakkonen, E. K. (2020). Role of Menopausal Transition and Physical Activity in Loss of Lean and Muscle Mass: A Follow-Up Study in Middle-Aged Finnish Women. Journal of Clinical Medicine, 9(5), 1588. https://doi.org/10.3390/jcm9051588

Kaminsky, L. (2010). ACSM's Health Related Physical Fitness Assessment Manual. 3a Ed. Editorial Lippincott Williams \& Wilkins

Kang, M. \& Rowe, D. (2015). Issues and Challenges in Sedentary Behavior Measurement. Measurement in Physical Education and Exercise Science, 19(3), 105-115. http://dx.doi.org/10.1080/1091367X.2015.1055566

Langhammer, B., \& Stanghelle, J. K. (2015). The Senior Fitness Test. Journal of Physiotherapy, 61(3), 163. https://doi.org/10.1016/j.jphys.2015.04.001 
Leblanc, A., Taylor, B. A., Thompson, P. D., Capizzi, J. A., Clarkson, P. M., White, C. M., \& Pescatello, L. S. (2015). Relationships between physical activity and muscular strength among healthy adults across the lifespan. Springerplus, 4(1), 1-10. https://doi.org/10.1186/s40064-015-1357-0

Lohman, T. G., Roche, A. F., \& Martorell, R. (1988). Anthropometric standardization reference manual (Vol. 177). Editorial Human kinetics books.

Magnon, V., Dutheil, F., \& Auxiette, C. (2018). Sedentariness: A Need for a Definition. Frontiers in Public Health, 6, 55-58. https://doi.org/10.3389/fpubh.2018.00372

Monteleone, P., Mascagni, G., Giannini, A., Genazzani, A. R., \& Simoncini, T. (2018). Symptoms of menopause - Global prevalence, physiology, and implications. Nature Reviews Endocrinology, 14(4), 199-215. https://doi.org/10.1038/nrendo.2017.180

Moratalla-Cecilia, N., Soriano-Maldonado, A., Ruiz-Cabello, P., Fernández, M. M., Gregorio-Arenas, E., Aranda, P., \& Aparicio, V. A. (2016). Association of physical fitness with health-related quality of life in early postmenopause. Quality of Life Research, 25(10), 2675-2681. https://doi.org/10.1007/s11136-016-1294-6

Munguia-Izquierdo, D., Segura-Jimenez, V., Camiletti-Moiron, D., Alvarez-Gallardo, I. C., EstevezLopez, F., Romero, A., Chillon, P., Carbonell-Baeza, A., Ortega, F.B., Ruiz, J.R., \& DelgadoFernandez, M. (2013). Spanish adaptation and psychometric properties of the Sedentary Behaviour Questionnaire for fibromyalgia patients: the al-Ándalus study. Clinical and Experimental Rheumatology, 31(6), 22-23.

Nolting, M., Ñañez, M., Pérez, B. L., Belgrado, M. A., Campostrini, B., Cremonte, A. E., ... \& Ugarteche, C. (2019). Estado actual del tratamiento en climaterio. Revista de la Federación Centroamericana de Obstetricia y Ginecología, 21(4).

O'Neill, B., McDonough, S. M., Wilson, J. J., Bradbury, I., Hayes, K., Kirk, A., Kent, L., Cosgrove, D., Bradley, J. M., \& Tully, M. A. (2017). Comparing accelerometer, pedometer and a questionnaire for measuring physical activity in bronchiectasis: a validity and feasibility study? Respiratory Research, 18(1), 16. https://doi.org/10.1186/s12931-016-0497-2

Organización Mundial de la Salud (2010). Recomendaciones mundiales sobre actividad física para la salud. Organización Mundial de la Salud sitio web: https://apps.who.int/iris/bitstream/handle/10665/44441/9789243599977_spa.pdf;jsessionid=6DEBA5 92B56103E2B6DBCEC2EF136005? sequence=1

Organización Mundial de la Salud. (2020). Directrices de la OMS sobre actividad física y hábitos sedentarios: un vistazo. Organización Mundial de la Salud sitio web: https://apps.who.int/iris/bitstream/handle/10665/337004/9789240014817-spa.pdf

Otero, M., Esain, I., González-Suarez, Á. M., \& Gil, S. M. (2017). The effectiveness of a basic exercise intervention to improve strength and balance in women with osteoporosis. Clinical Interventions in Aging, 12, 505. https://doi.org/10.2147/CIA.S127233

Pette-Gabriel, K., Morrow, J. \& Woolsey, A. (2012). Framework for physical activity as a complex and multidimensional behavior. Journal of Physical Activity and Health, 9, 11-18. https://doi. org/10.1123/jpah.9. s1. s1

Pullyblank, K., Strogatz, D., Folta, S. C., Paul, L., Nelson, M. E., Graham, M., Marshall, G. A., Eldridge, G., Parry, S. A., Mebust, S., \& Seguin, R. A. (2020). Effects of the Strong Hearts, Healthy Communities Intervention on Functional Fitness of Rural Women. Journal of Rural Health, 36(1), 104110. https://doi.org/10.1111/jrh.12361.

Rathnayake, N., Alwis, G., Lenora, J., \& Lekamwasam, S. (2019). Cutoff values for the determination of sarcopenia and the prevalence of the condition in middle-aged women: A study from Sri Lanka. Ceylon Medical Journal, 64(1), 9. https://doi.org/10.4038/cmj.v64i1.8834 
Rikli \& Jones (2001). Senior Fitness Test Manual.2a ed. Editorial Human Kinetics.

Rosenberg, D. E., Norman, G. J., Patrick, K., Caifas, K. J., \& Sallis, J. F. (2010). Reliability and validity of the Sedentary Behavior Questionnaire (SBQ) for adults. Journal of Physical Activity and Health, 7(6), 697-705. https://doi.org/ 10.1123/jpah.7.6.697

Rossi, M., Janjetic, M., Ferreyra, M., Garaicoechea, A., Matioli, M., Vásquez, F., \& Torresani, M. (2018). Relación entre estado nutricional, consumo de alimentos no nutritivos y percepción de estrés en mujeres perimenopaúsicas. Revista Chilena de Nutrición, 45(2), 105-111.

Salvo, D., Cantoral, A., Medina, C., \& Jáuregui, A. (2018). Importancia de la actividad física en la prevención y control de la obesidad y comorbilidades asociadas. En Rivera, J., Colchero M. , Fuentes M., González de Cosío, T., Aguilar A., Hernández, G. \& Barquera S. (eds.). La obesidad en México. Estado de la política pública y recomendaciones para su prevención y control (pp. 157-168). Cuernavaca: Instituto Nacional de Salud Pública.

Salvo, D., Villa, U., Rivera, J., Sarmiento, O., Reis, R., \& Pratt, M. (2015). Accelerometer-based physical activity levels among Mexican adults and their relationship with sociodemographic characteristics and BMI: a cross-sectional study. International Journal of Behavioral Nutrition and Physical Activity, 12(79). https://doi.org/10.1186/s12966-015-0243-z.

Same, R. V., Feldman, D. I., Shah, N., Martin, S. S., Al Rifai, M., Blaha, M. J., Graham, G., \& Ahmed, H. M. (2016). Relationship Between Sedentary Behavior and Cardiovascular Risk. Current Cardiology Reports, 18(1), 6. https://doi.org/10.1007/s11886-015-0678-5

Santos-Lozano, A., Santín-Medeiros, F., Cardon, G., Torres-Luque, G., Bailón, R., Bergmeir, C., Ruiz, J. R., Lucia, A., \& Garatachea, N. (2013). Actigraph GT3X: validation and determination of physical activity intensity cut points. International Journal of Sports Medicine,34(11), 975-982. https://doi.org/10.1055/s-0033-1337945

Savva, C., Mougiaris, P., Xadjimichael, C., Karagiannis, C., \& Efstathiou, M. (2018). Test-Retest Reliability of Handgrip Strength as an Outcome Measure in Patients with Symptoms of Shoulder Impingement Syndrome. Journal of Manipulative and Physiological Therapeutics, 41(3), 252-257. https://doi.org/10.1016/j.jmpt.2017.09.005

Schlaff, R. A., Baruth, M., Boggs, A., \& Hutto, B. (2017). Patterns of Sedentary Behavior in Older Adults. American Journal of Health Behavior, 41(4), 411-418. https://doi.org/10.5993/AJHB.41.4.5

Secretaría de Gobernación. (2018). NORMA Oficial Mexicana NOM-008-SSA3-2017, Para el tratamiento integral del sobrepeso y la obesidad. Gobierno de México. http://www.dof.gob.mx/nota_detalle.php?codigo=5523105\&fecha $=18 / 05 / 2018$

Secretaría de Salud. (1987). Reglamento de la Ley General de Salud en Materia de Investigación para la Salud. Secretaria de Salud sitio

http://www.salud.gob.mx/unidades/cdi/nom/compi/rlgsmis.html

Sipilä, S., Törmäkangas, T., Sillanpää, E., Aukee, P., Kujala, U. M., Kovanen, V., \& Laakkonen, E. K. (2020). Muscle and bone mass in middle-aged women: role of menopausal status and physical activity. Journal of Cachexia, Sarcopenia and Muscle, 11(3), 698-709. https://doi.org/10.1002/jcsm.12547

Skelton, D. A., \& Mavroeidi, A. (2018). How do muscle and bone strengthening and balance activities (MBSBA) vary across the life course, and are there particular ages where MBSBA are most important? Journal of Frailty, Sarcopenia and Falls, 3(2), 74-84. https://doi.org/10.22540/JFSF-03-074

Springer, B. A., Marin, R., Cyhan, T., Roberts, H., \& Gill, N. W. (2007). Normative values for the unipedal stance test with eyes open and closed. Journal of Geriatric Physical Therapy, 30(1), 8-15. https://doi.org/10.1519/00139143-200704000-00003 
Thurston, R. C., Karvonen-Gutierrez, C. A., Derby, C. A., El Khoudary, S. R., Kravitz, H. M., \& Manson, J. A. E. (2018). Menopause versus chronologic aging: Their roles in women's health. Menopause, 25(8), 849-854. https://doi.org/10.1097/GME.0000000000001143

Torres-Jiménez, A. P., \& Torres-Rincón, J. M. (2018). Climaterio y menopausia Climacteric and menopause. Universidad Autonoma de Mexico, 61, 8. Medigraphic sitio web: https://www.medigraphic.com/pdfs/facmed/un-2018/un182j.pdf.

Tudor-Locke, C., Camhi, S. M., \& Troiano, R. P. (2012). A catalog of rules, variables, and definitions applied to accelerometer data in the National Health and Nutrition Examination Survey, 2003-2006. Preventing Chronic Disease, 9, E113. https://doi.org/10.5888/pcd9.110332

Vaca García, M. R., Gómez Nicolalde, R. V., Cosme Arias, F. D., Mena Pila, F. M., Yandún Yalamá, S. V., \& Realpe Zambrano, Z. E. (2017). Estudio comparativo de las capacidades físicas del adulto mayor: rango etario vs actividad física. Revista Cubana de Investigaciones Biomédicas, 36(1), 1-11. http://scielo.sld.cu/scielo.php?script=sci_arttext\&pid=S0864-03002017000100013

Vázquez-Martínez, J. E., Morfin Martín, J., \& Motta-Martínez, E. (2010). Estudio del climaterio y la menopausia. Colegio Mexicano de Especialistas En Ginecología y Obstetricia, A.C., 235-256. Colegio Mexicano de Especialistas en Ginecología y Obstetricia sitio web: http://www.comego.org.mx/GPC_TextoCompleto/10-Estudio del climaterio y la menopausia.pdf

Villaverde Gutiérrez, C., Ramírez Rodrigo, J., Olmedo Alguacil, M. M., Sánchez Caravaca, M. A., Argente del Castillo Lechuga, M. J., \& Ruiz Villaverde, A. (2015). Overweight obesity and cardiovascular risk in menopausal transition. Nutrición Hospitalaria, 32(4), 16031608. https://dx.doi.org/10.3305/nh.2015.32.4.9380

Wang, Y. C., Bohannon, R. W., Li, X., Sindhu, B., \& Kapellusch, J. (2018). Hand-Grip Strength: Normative Reference Values and Equations for Individuals 18 to 85 Years of Age Residing in the United States. The Journal of Orthopedic and Sports Physical Therapy, 48(9), 685-693. https://doi.org/10.2519/jospt.2018.7851.

Warburton, D. E. R., \& Bredin, S. S. D. (2017). Health benefits of physical activity: a systematic review of current systematic reviews. Current Opinion in Cardiology, 32(5), 541-556. https://doi.org/10.1097/HCO.0000000000000437 
Chapter 6 Pro-inflammatory cytokines: leptin and visfatin associated to obesity in young university students

Capítulo 6 Citocinas pro-inflamatorias: leptina y visfatina asociadas a obesidad en jóvenes universitarios

DÍAZ-BURKE, Yolanda†*, GONZÁLEZ-SANDOVAL, Claudia Elena, UVALLE-NAVARRO, Rosario Lizette and MEDEROS-TORRES, Claudia Verónica

Universidad de Guadalajara, Centro Universitario de Ciencias Exactas e Ingenierías, Pharmacobiology Department, Biochemistry Laboratory. Mexico.

ID $1^{\text {st }}$ Author: Yolanda, Díaz-Burke / ORC ID: 0000-0001-5142-1495, CVU CONACYT ID: 272319

ID $1^{\text {st }}$ Co-author: Claudia Elena, González-Sandoval / ORC ID: 0000-0001-8479-0828, CVU CONACYT ID: 44588

ID $2^{\text {nd }}$ Co-author: Rosario Lizette, Uvalle-Navarro / ORC ID: 0000-0002-3566-2579, CVU CONACYT ID: 660368

ID $3^{\text {rd }}$ Co-author: Claudia Verónica, Mederos-Torres / ORC ID: 0000-0002-6259-8904, CVU CONACYT ID: 663067

DOI: $10.35429 / \mathrm{H} .2021 .13 .78 .88$

Y. Díaz, C. González, R. Uvalle and C. Mederos

*yolanda.diaz@academicos.udg.mx

A. Marroquín, J. Olivares, M. Cruz, L. Cruz. (Coord.) CIERMMI Women in Science TXIII Medicine and Health Sciences. Handbooks-@ECORFAN-México, Querétaro, 2021. 


\begin{abstract}
Obesity has been associated with the development of important degenerative diseases such as hypertension, metabolic syndrome, diabetes mellitus (DM), cardiovascular disease (CVD), cancer, among others. And is also described that the disease severity of infections illnesses such as coronavirus, influenza, parainfluenza, and rhinovirus in increased. Besides, in 2009 was recognized as a risk factor during the pandemic of influenza H1N1 Currently there are several studies which suggest that some adipocytokines as leptin, resistin, plasminogen activator inhibitor-1 (PAI-1), adiponectin, visfatina among others have mediators affects in cardiovascular system.
\end{abstract}

Some authors had shown plasmatic levels of leptin seem to be one of the best biological markers of obesity, and hyperleptinemia is closely related with several metabolic risk factors on insulin resistance in DM Some studies reveals that visfatin have mimetic affects with insulin in muscle stimulation and in glucose transport in adipocyte, also inhibit glucose production in liver. The objective of this work was to describe the association between leptin and visfatina in the development of obesity in a young population to identify the possible risk factor or as a protective factor of this adipocytokines with obesity.

Methodology. Cross-sectional study. The present study was carried out in the facilities of the Centro Universitario de Ciencias Exactas e Ingenierías of the Universidad de Guadalajara. We recruit 171 young students $(57.6 \%$ female, $42.4 \%$ male) with the following characteristics: age between 18- 25 years old, fasting of 8 to 10 hours to take the blood sample.

The results shows that BMI is higher in male and triglycerides also. On the other hand, leptin levels and total cholesterol are higher in women. The group with hyperleptinemia has higher values of BMI, total cholesterol, triglycerides, LDL and visfatina comparing with the group with normal leptin levels.

We observed that hyperleptinemia is a risk factor for the development of obesity with OR 5.86 $(\mathrm{p}=0.01)$, in the other hand, visfatina acts as a protector factor with OR $0.2901(0.02)$.

Conclusion. Therapeutic intervention in early stages previous the beginning of the metabolic complications could have a favorable cost-benefit. However, the incorporation of markers such as the size of the particle of LDL, insulin resistance index, adipocytokines pro inflammatory as leptin and visfatin could improve the current predictive capacity.

\title{
Obesity, Leptin, Leptin, Visfatin, Young people, Proinflammatory
}

\section{Resumen}

La obesidad se ha asociado al desarrollo de importantes enfermedades degenerativas como la hipertensión, el síndrome metabólico, la diabetes mellitus (DM), las enfermedades cardiovasculares (ECV) y el cáncer, entre otras. Y también se describe que la gravedad de las enfermedades infecciosas como el coronavirus, la gripe, la parainfluenza y el rinovirus en aumentada. Además, en 2009 se reconoció como un factor de riesgo durante la pandemia de gripe H1N1 Actualmente hay varios estudios que sugieren que algunas adipocitoquinas como la leptina, la resistina, el inhibidor del activador del plasminógeno-1 (PAI-1), la adiponectina, la visfatina entre otros tienen efectos mediadores en el sistema cardiovascular.

Algunos autores han demostrado que los niveles plasmáticos de leptina parecen ser uno de los mejores marcadores biológicos de la obesidad, y que la hiperleptinemia está estrechamente relacionada con varios factores de riesgo metabólico en la resistencia a la insulina en la DM. Algunos estudios revelan que la visfatina tiene efectos miméticos con la insulina en la estimulación muscular y en el transporte de glucosa en el adipocito, además de inhibir la producción de glucosa en el hígado.

El objetivo de este trabajo fue describir la asociación entre la leptina y la visfatina en el desarrollo de la obesidad en una población joven para identificar el posible factor de riesgo o como factor protector de esta adipocitoquina con la obesidad. 
Metodología. Estudio transversal. El presente estudio se realizó en las instalaciones del Centro Universitario de Ciencias Exactas e Ingenierías de la Universidad de Guadalajara. Reclutamos a 171 jóvenes estudiantes (57.6\% mujeres, $42.4 \%$ hombres) con las siguientes características: edad entre 1825 años, ayuno de 8 a 10 horas para tomar la muestra de sangre.

Los resultados muestran que el IMC es mayor en los hombres y también los triglicéridos. Por otro lado, los niveles de leptina y el colesterol total son mayores en las mujeres. El grupo con hiperleptinemia tiene valores más altos de IMC, colesterol total, triglicéridos, LDL y visfatina en comparación con el grupo con niveles normales de leptina. Observamos que la hiperleptinemia es un factor de riesgo para el desarrollo de la obesidad con OR 5,86 ( $\mathrm{p}=0,01)$, en cambio, la visfatina actúa como factor protector con OR 0,2901 (0,02).

Conclusión. La intervención terapéutica en estadios tempranos previos al inicio de las complicaciones metabólicas podría tener un coste-beneficio favorable. Sin embargo, la incorporación de marcadores como el tamaño de la partícula de LDL, índice de resistencia a la insulina, adipocitoquinas pro inflamatorias como la leptina y la visfatina podría mejorar la capacidad predictiva actual.

\section{Obesidad, Leptina, Visfatina, Jóvenes, Proinflamatorio}

\subsection{Introduction}

At present, obesity is considered by the World Health Organization to be one of the most serious health problems in the world. (OMS) and other organizations as a worldwide epidemic. (Collaboration NCDRF, 2016) It is a disorder characterized by a disproportionate increase in body weight in relation to height mainly due to fat accumulation. Several factors influence the development of this disease: genetic, environmental and behavioral are the main ones (Bray et al, 2018). Usually the criterion used for diagnosis is the body mass index. (IMC), where a value between $25-29.9 \mathrm{Kg} / \mathrm{m}^{2}$ as overweight and a value equal to or greater than $30 \mathrm{Kg} / \mathrm{m}^{2}$ as obesity. (Rangel-Huerta et al, 2019)

Epidemiologically, obesity has undergone a significant increase in recent decades. According to data from the OMS, has tripled in prevalence since 1975. As of 2016, 1.9 billion (39\% of the world's population) adults were estimated to be overweight, of which about 650 million are obese. (WHO, 2018). In Mexico, the prevalence of overweight and obesity reported in the National Nutrition Survey 2018 was $76.8 \%$ in women and $73 \%$ in men. Likewise in young university population values of $32.7 \%$ have been reported. (INSP 2018; González et al, 2014)

It has been associated with the development of important chronic degenerative diseases such as: hypertension, metabolic syndrome, diabetes mellitus (DM), cardiovascular diseases (CVD), cancer among others. (Williams et al, 2015) And it has been described to be associated with increased severity of infectious diseases such as coronavirus, influenza, para influenza and rhinovirus.

In addition, in 2009 it was recognized as an independent risk factor in the pandemic caused by the influenza A, H1N1 variant (Kwok et al, 2020). (Kwok et al, 2020) On the other hand, in the current COVID19 pandemic, several studies have shown that the risk of severe disease is increased in the presence of obesity, as well as the rate of hospitalization and a negative outcome. (Druncker D.J., 2021)

The relationship between obesity and these various pathologies has been described mainly due to the increase in adipose tissue, since this is associated with an increase in metabolic activity, which leads to inflammation, greater risk of thrombosis and alterations in carbohydrate metabolism. Its metabolic products, called adipokines, play an important role in energy homeostasis, carbohydrate and lipid metabolism, intake control, thermogenesis, cell viability, reproduction, immunity, neuroendocrine function, and the structure and function of the cardiovascular system. (Choe et al, 2016)

Currently, several studies suggest that the levels of some adipocytokines such as leptin, resistin, plasminogen activator inhibitor-1 (PAI-1), adiponectin, visfatin, among others, mediate cardiovascular effects due to their effects on the body. These constitute a family of hormones with important actions in the cardiovascular system. (García-Torres et al, 2011). 


\section{Obesity and inflammation}

The first evidence of obesity-related inflammation arose from a report of elevated TNF $\alpha$ in adipose tissue in obesity. Since then, numerous studies have consistently demonstrated increased inflammation in adipose tissue in obese animals and humans. Although inflammation in people with obesity has been described as occurring in a variety of tissues, there is evidence that most of it occurs in adipose tissue (Wu \& Ballantyne, 2020).

The mechanisms that explain the relationship between obesity and inflammation remain poorly understood; however, obesity has been considered a chronic low-grade inflammatory state that provides a direct relationship with various pathologies such as metabolic syndrome and cardiovascular disease. The final common pathway is atherosclerosis, causing generalized vascular disease, leading to arterial hypertension, coronary artery disease and peripheral vascular disease. (Aprahamian et al, 2011).

It has now been demonstrated that adipose tissue actively participates in immune and inflammatory processes. When excess fat is present, an "inflammatory environment" is created with the release of adipocytokines such as leptin, visfatin and resistin (Fig. 6.1), which are also believed to contribute to the development of insulin resistance. Furthermore, adipocytokines, especially leptin, activate endothelial cells and the accumulation of macrophages in adipose tissue, which release proinflammatory molecules, including TNF- $\alpha$, thus perpetuating the inflammatory state described in obesity. (Hugo \& Ben, 2016).

Figure 6.1 Inflammation in adipose tissue

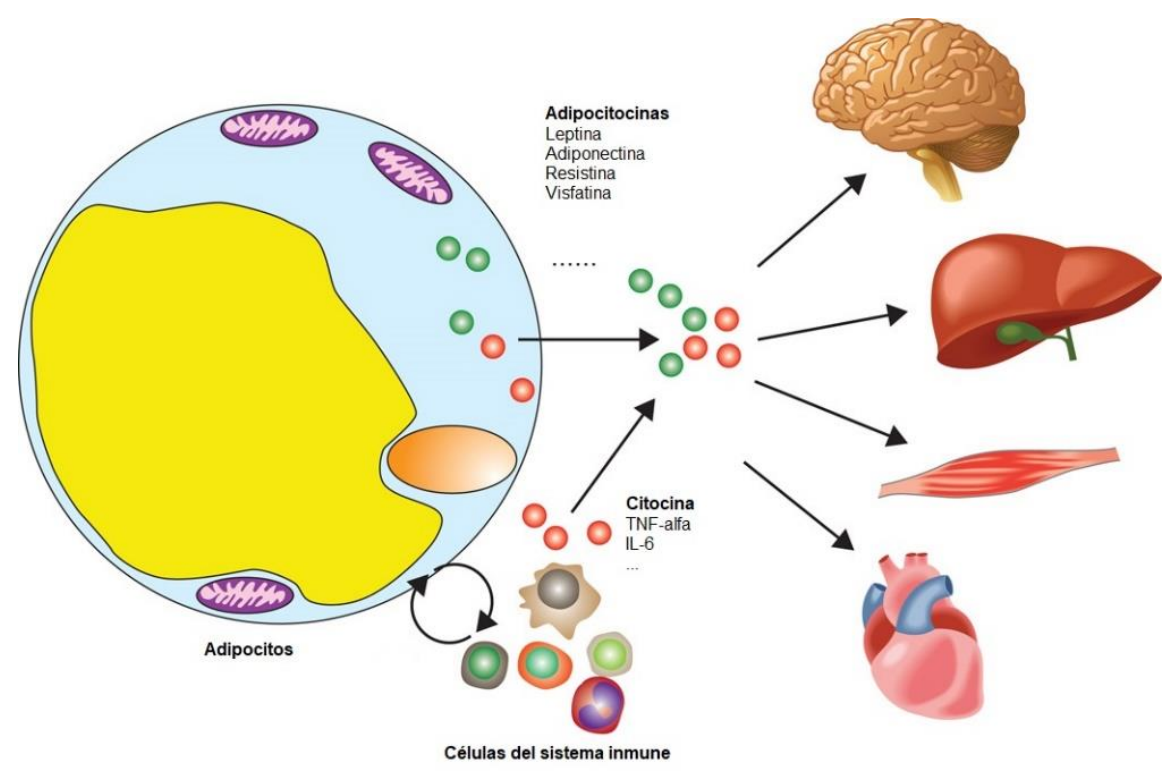

Adipocytes in a state of inflammation characterized by obesity modify cytokine release levels and their actions are generally altered. Adipocytokines are also sent to remote organs to regulate energy metabolism.

Source: Cao H. (2014)

The adipocyte as an endocrine tissue

An indisputable protagonist in the pathophysiological process of obesity is the adipose tissue and, in particular, the adipocyte, an extremely active cell whose physiological role involves, in addition to general metabolic regulation, cell growth, immune response, thermogenesis, and reproductive and cardiovascular functions. (Nava Santana et al, 2013). Recently, white adipose tissue (WAT) has been recognized not only as an energy reservoir, but also as an important secretory organ of numerous bioactive molecules identified as important chemical messengers with local and systemic actions called adipokines. The mechanism of action of these molecules involves a great diversity of receptors and intracellular signaling cascades that act in a variety of cells -including the adipocyte- through welldefined autocrine signals and in many neighboring cells inhabiting the same adipose tissue, establishing very complex paracrine communications and participating in energy homeostasis to maintain the body metabolism in an adequate balance. (Martinez-Sanchez, 2020) 
Alterations in the adipocyte induced by overeating and sedentary lifestyle and aggravated by all the factors related to increased metabolic and cardiovascular risk, are the starting point for a cascade of events leading to metabolic imbalance. In addition, the inflammatory response indicated in $\mathrm{TAB}$ produces a chronic situation at the systemic level that eventually leads to insulin resistance, atherosclerosis and alterations typical of MS. (Nava Santana et al, 2013).

\section{Leptin}

It is a hormone secreted by adipose tissue that plays an important role in the control of energy homeostasis, through binding to its ligand LepR which is mainly expressed in the hypothalamus. (Seoane-Collazo et al.2020) Blood leptin levels $(3.9 \mathrm{ng} / \mathrm{mL})$ reflect the amount of energy stored in adipose tissue and has been correlated with the degree of obesity. (Perez-Perez et al, 2020)

Studies have shown that plasma leptin levels appear to be one of the best biomarkers of obesity, and that hyperleptinemia is closely associated with several metabolic risk factors related to IR in DM. (Martinez-Sanchez, 2020)

There is a significant relationship between insulin and leptin, but it is not immediate. The molecule leptin has a role in the development of IR and is postulated as a link between obesity and DM. Obesity is an established risk factor for the development of DM2, affecting individuals who show signs of IR and hyperinsulinemia, although the mechanism by which DM and obesity are associated is not clear, it is argued that leptin could play a key role in this mechanism. (Seoane-Collazo et al, 2020).

Recent evidence suggests that leptin and insulin, in addition to their critical role in the regulation of energy homeostasis, may also play an important role in the hypothalamic control of glucose metabolism, with leptin being a regulator of glucose homeostasis, independently of its effects on food intake. Hyperleptinemia is common in obesity and reflects increased adiposity and leptin resistance. Notably, the renal actions of leptin may play an important role in the pathogenesis of obesity-related hypertension and MS. In addition, the lipotoxic effect of leptin resistance may cause IR and $\beta$-cell dysfunction increasing the risk of type 2 DM. (Mendez et al, 2009)

\section{Visfatina}

It is an adipocytokine secreted by adipocytes, macrophages and inflamed endothelial tissue, and is elevated in obesity, insulin resistance and DM2. This cytokine acts as a proinflammatory mediator, with the ability to induce MT1 metalloproteinase in human monocytes and endothelial cells, and therefore plays an important role in the pathogenesis of vascular inflammation produced in obesity and type 2 diabetes. (Landencho et al, 2019).

Also known as pre-B cell colony enhancing factor, it is highly expressed in visceral fat and was originally isolated as a secreted factor that upregulates interleukin 7 (IL-7) and the stem cell responsible for promoting the growth of B cell precursors. It has been postulated to play an important role in innate immunity. However, the biological activity of visfatin is still poorly understood. It is secreted by activated lymphocytes, monocytes and neutrophils. It stimulates the expression of Interleukin 6 (IL-6) and interleukin 8 (IL-8) in amniotic cells, and prolongs neutrophil survival in clinical sepsis. (Sheta et al, 2012)

Visfatin has been reported to exert insulin mimetic effects on stimulated muscle and adipocyte glucose transport and inhibit hepatocyte glucose production. It was also found to bind to and activate the insulin receptor, causing phosphorylation and activation of the signaling molecule pathway. However, visfatin and insulin do not compete for binding to insulin receptors, indicating that the two proteins are recognized in different regions of the receptor. It could be that it also plays a role in glucose homeostasis and the pathogenesis of DM. (Sheta et al, 2012) 
High visfatin levels are also correlated with an increased risk of adverse cardiac events in patients with myocardial infarction and it has been observed that in addition in weight loss after bariatric surgery the levels decrease. Landencho et al, 2019). The role of this adipocytokine with respect to obesity has been entirely conclusive, as contradictory results have been found. Sheta et al in 2012 found that visfatin expression in visceral fat in obese subjects and visfatin concentrations in plasma correlated closely with the amount of visceral fat, better than subcutaneous fat. On the other hand, other work has found an inverse association between circulating visfatin levels and obesity. One study found that visfatin levels were negatively related to visceral fat tissue and triglycerides. And positively to HDL cholesterol. (Wang et al, 2007, Sheta et al, 2012)

Due to the increase of obesity in recent years and the not very encouraging prognosis of its acceleration, identifying the pathogenesis of this disease and the possible role of inflammation through the evaluation of proinflammatory adipocytokines will allow a better understanding of the pathogenesis and disorders related to this disease. Therefore, the aim of this work was to describe the association between leptin and visfatin with obesity in a young population in order to identify the possible role as a risk factor or protective factor of these in obesity.

\subsection{Materials and methods}

The work carried out was an analytical cross-sectional study.

The study was carried out in the facilities of the University Center of Exact Sciences and Engineering of the University of Guadalajara. An invitation was made to the general population of the university center and a total of 171 young people were obtained with the following characteristics: 18 25 years old, not under treatment for obesity, not taking corticoids and who presented themselves with a fasting period of 8 - 10 hours to obtain the blood sample.

Those who complied with the inclusion requirements were summoned to the laboratory in the morning and there they filled out their clinical history. Subsequently, anthropometric measurements (weight and height) were taken to calculate the body mass index (BMI), for classification into people with and without obesity. A blood sample was then obtained to determine biochemical parameters.

The parameters obtained were obtained as follows:

- $\quad$ Body Mass Index. The formula Weight $(\mathrm{kg}) /$ Height $\left(\mathrm{m}^{2}\right)$ was used to calculate the BMI. A Tanita $30 \mathrm{~A}$ scale was used to obtain the weight and its scalimeter was used for the height.

Determination of adipocytokines: Serum determination was performed using a sandwich ELISA technique in a Magpix Luminex kit with a Pre-Diabetes Kit. Human Assay de BioRad@.

For the identification of obesity and NON-obesity, the points established by the World Health Organization were taken into account. $18-29.9 \mathrm{Kg} / \mathrm{m} 2$ and as obesity for those with a BMI greater than $30 \mathrm{Kg} / \mathrm{m}^{2}$. (WHO, 2018)

For the separation into people with normal and elevated leptin, the cut-off points used were normal leptin, normal leptin, elevated leptin and elevated leptin. 0- $3.9 \mathrm{ng} / \mathrm{mL}$ and hyperleptinemia > 3.9 $\mathrm{ng} / \mathrm{mL}$. And for normal visfatin $0-1.48 \mathrm{ng} / \mathrm{mL}$ and elevated visfatin was considered when it was greater than $1.48 \mathrm{ng} / \mathrm{mL}$. (Wang et al, 2007)

In addition, biochemical parameters were analyzed for a better description of the population such as glucose and lipid profile composed of: Cholesterol, triglycerides, HDL and LDL. It was performed from a blood sample in a dry chemistry equipment. Fujifilm Drichem N500imx ®; total cholesterol, HDL and triglycerides. And using the Friedewald formula, VLDL and LDL were calculated.

Statistical analysis. Descriptive statistics were performed, presenting the results as mean and standard deviation in the case of quantitative variables. As well as frequencies in the case of qualitative variables. The association between variables was carried out by means of a Chi-squared test for the calculation of Odds Ratio. A value $p<0.05$ fue considerado como significativo. We used the Excel package and the program Graph Pad version 5 for the development of the analysis. 
Ethical aspects. This study is in accordance with the General Health Law of the United Mexican States regarding research, which according to Art. 17 of the research regulations considers minimum risk research, and each volunteer signed an informed consent form. The privacy of each individual is protected and he/she has the right to withdraw at any time from the study. The work also has the approval of a bioethics committee of the work center.

\subsection{Results}

A total of 171 young people who met the inclusion criteria were recruited. They ranged in age from 18 25 years with a mean of 20.6. Of these $57.6 \%(n=98)$ were female and $42.4 \%(n=73)$ were male. Table 6.1 below shows the descriptive results of the population compared by gender.

Table 6.1 Descriptive results of the population separated by gender

\begin{tabular}{|l|r|r|r|}
\hline Parameter & General $\mathbf{n = 1 7 1}$ & \multicolumn{1}{c|}{ Women $\mathbf{n = 9 8}$} & \multicolumn{1}{c|}{ Men $\mathbf{n = 7 3}$} \\
\hline Age & $20.6 \pm 1.66$ & $20.32 \pm 1.38$ & $21.00 \pm 1.91$ \\
\hline IMC $\left(\mathrm{Kg} / \mathrm{m}^{2}\right)$ & $25.8 \pm 6$ & $24.05 \pm 4.98$ & $28.11 \pm 6.48$ \\
\hline Glucose $(\mathrm{mg} / \mathrm{dL})$ & $85 \pm 8.31$ & $84.61 \pm 7.92$ & $85.55 \pm 8.82$ \\
\hline Total Cholesterol $(\mathrm{mg} / \mathrm{dL})$ & $168.1 \pm 35.09$ & $172.35 \pm 35.22$ & $162.34 \pm 34.30$ \\
\hline Triglycerides $(\mathrm{mg} / \mathrm{dL})$ & $98.84 \pm 52.27$ & $88.40 \pm 47.50$ & $112.90 \pm 55.36$ \\
\hline HDL $(\mathrm{mg} / \mathrm{dL})$ & $46.88 \pm 12.57$ & $51.78 \pm 12.55$ & $40.30 \pm 9.18$ \\
\hline LDL $(\mathrm{mg} / \mathrm{dL})$ & $101.7 \pm 29.19$ & $94.79 \pm 78.91$ & $99.02 \pm 27.99$ \\
\hline Leptin $(\mathrm{ng} / \mathrm{mL})$ & $2.49 \pm 2.08$ & $3.13 \pm 1.96$ & $1.63 \pm 1.94$ \\
\hline Visfatina $(\mathrm{ng} / \mathrm{dL})$ & $1.23 \pm 0.42$ & $1.29 \pm 0.34$ & $1.11 \pm 0.45$ \\
\hline HDL: High Density cholesterol (for its acronym in English), LDL: low density cholesterol. \\
\hline
\end{tabular}

The data show that men have the highest BMI, as well as triglycerides. On the other hand, leptin and total cholesterol values are higher in women than in men.

Subsequently, we proceeded to stratify the data according to leptin levels in hyperleptinemia and normal leptin. The results can be seen in Table 6.2.

Table 6.2 Biochemical parameters stratified according to leptin value

\begin{tabular}{|l|r|r|r|}
\hline \multicolumn{1}{|c}{ Parameter } & \multicolumn{1}{c}{ Hyperleptinemia } & \multicolumn{1}{c|}{ Normal leptin } & \multicolumn{1}{c|}{ Value p } \\
\hline Age & $20.48 \pm 1.40$ & $20.64 \pm 1.71$ & 0.8306 \\
\hline IMC & $30.54 \pm 6.80$ & $24.73 \pm 5.28$ & $0.0000 *$ \\
\hline Glucose $(\mathrm{mg} / \mathrm{dL})$ & $83.71 \pm 7.64$ & $85.30 \pm 8.44$ & 0.3362 \\
\hline Total Cholesterol $(\mathrm{mg} / \mathrm{dL})$ & $177.74 \pm 44.78$ & $165.94 \pm 32.36$ & 0.0900 \\
\hline Triglycerides $(\mathrm{mg} / \mathrm{dL})$ & $105.17 \pm 46.71$ & $97.47 \pm 53.45$ & 0.4665 \\
\hline HDL $(\mathrm{mg} / \mathrm{dL})$ & $46.94 \pm 13.93$ & $46.86 \pm 12.30$ & 0.9773 \\
\hline LDL $(\mathrm{mg} / \mathrm{dL})$ & $110.43 \pm 38.23$ & $99.77 \pm 26.55$ & 0.0653 \\
\hline Leptin $(\mathrm{ng} / \mathrm{mL})$ & $5.87 \pm 2.22$ & $1.74 \pm 1.06$ & $0.0000 *$ \\
\hline Visfatina $(\mathrm{ng} / \mathrm{mL})$ & $1.27 \pm 0.46$ & $1.22 \pm 0.42$ & 0.6590 \\
\hline HDL: High Density cholesterol, LDL: low density cholesterol. *statistically significant \\
\hline
\end{tabular}

We observed that the group with hyperleptinemia had higher BMI, cholesterol, triglycerides, LDL and visfatin values compared to the group with normal leptin values.

Finally, we proceeded to perform the association between leptin and visfatin with obesity and the results we found are reported in Table 6.3.

Table 6.3 Association of leptin and visfatin with obesity

\begin{tabular}{|l|r|r|r|}
\hline \multicolumn{1}{|c}{ Parameter } & \multicolumn{1}{c}{ OR } & \multicolumn{1}{c|}{ Value p } & \multicolumn{1}{c|}{ IC } \\
\hline Leptin & 5.866 & $0.001 *$ & $2.552-13.50$ \\
\hline Visfatina & 0.2901 & $0.0201 *$ & $0.0963-0.8737$ \\
\hline OR: Odds Ratio, IC: Intervalo de Confianza. $\mathrm{p}<0.05$ Considerado como significativo \\
\hline
\end{tabular}

It is observed that hyperleptinemia is a risk factor for the development of obesity with an OR of $5.86(\mathrm{p}=0.01)$, while visfatin acts as a protective factor with an OR of $0.2901(\mathrm{p}=0.02)$. 


\subsection{Discussion}

The health significance of body fat has been constantly modified according to changes in the living conditions and expectations of each population group. As may be the role of abdominal obesity as a direct contributor to metabolic and cardiovascular risk is not yet systematically incorporated into the classical assessment of cardiometabolic risk. On the one hand, the cut-off points for waist circumference in different races are controversial. (Rosales, 2012)

Structural changes in adipose tissue lead to the release by adipocytes of cytokines called adipocytokines, as well as the mobilization and activation of leukocyte subpopulations, which can also release various mediators, helping to establish the inflammatory process and impair insulin sensitivity locally. In turn, these molecules manage to reach the systemic circulation, where they damage other organs such as the liver and skeletal muscle, causing damage to macronutrient metabolism, leading to the development of metabolic diseases such as metabolic syndrome, which in turn increases the possibility of triggering chronic degenerative diseases. (Vega-Robledo et al, 2019)

It is now fully demonstrated that adipose tissue, which includes adipocytes, macrophages, fibroblasts and other cell types, is a source of numerous molecules with different action profiles. Some adipokines such as leptin and adiponectin are preferentially produced by adipocytes, while others of an inflammatory nature, such as TNF $\alpha$ and IL-6 involved in inflammation and IR phenomena, are predominantly secreted by macrophages. (Vega-Robledo et al, 2019)

In our study we found an association between leptin and obesity with an OR of 5.86, establishing it as a risk factor for the development of this pathology. On the other hand, visfatin, in our study, was found to be a protective factor with an OR of 0.29 ..

The association with leptin has been reported in other studies and its role in the development of obesity is known; however, the mechanism by which it exerts its function is still under investigation. With respect to what was reported in our work, we can identify that elevated leptin levels have a negative role in health, since we found an increase in BMI, triglycerides and cholesterol.

In relation to the present study regarding the role of visfatin, there is great controversy due to the diversity of results that have been obtained, such as a study carried out in young adult patients with obesity, an association can be applied between the blood concentration of visfatin in patients without metabolic syndrome and with increased visceral adipose tissue, compared to those without metabolic syndrome and with normal visceral adipose tissue, a relationship that could not be observed in persons with the presence of metabolic syndrome. The authors concluded that the increase of resistin in patients with increased visceral adipose tissue without metabolic disease could indicate in some way that these individuals may present metabolic alterations in the future, since resistin has been shown to promote the production of inflammatory cytokines and has been pointed out as a marker of metabolic disease. (Rodríguez- López, 2015)

However, other researchers have not observed a relationship between metabolic markers and the levels of this adipocytokine, and it has even been found to be decreased in people with obesity. AlSuhaimi et al, 2013; Cao H. et al, 2014; De Luis et al, 2010; Carvalho et al, 2014. Similarly, in other research with obese children, no correlation of visfatin levels with weight reduction, response to physical activity, body fat content or insulin resistance indices was found. (Martos-Moreno et al, 2013) On the other hand, in a similar study in obese children, serum resistin levels were related to central obesity and insulin resistance. (Sypniewska, 2015) This could be due to the stage of life being developed by the study participants, as well as gender.

With all that has been pointed out, it could be said that the excessive accumulation of body fat has a high impact on the health of obese individuals, negatively affecting their physical condition, vitality and, in general, their quality of life and thus their health. These alterations can be avoided to try to contain the obesity epidemic and prevent the increase of the negative consequences associated with obesity, since it has been predicted that if the trends of the increase of this condition continue as they have after the beginning of the century, the world will not meet the global objective to stop this epidemic. (Vázquez et $a l, 2013)$ Prevention must be effective to achieve restoration of homeostasis (cardiovascular and metabolic). (Collaboration NCDRF, 2016) 


\subsection{Conclusions}

As a research group, we concluded that it is essential to have prospective studies that report on the predictive nature of the pathogenesis of obesity as soon as possible. In this case, therapeutic intervention in the early stages prior to the onset of metabolic complications could have a favorable cost-benefit ratio. Likewise, the incorporation of markers such as LDL particle size, insulin resistance index, proinflammatory adipocytokines such as leptin and visfatin may improve the current predictive capacity.

On the other hand, obesity not only leads to problems such as cardiometabolic diseases, but also influences the immune system in many ways. Obesity causes chronic low-grade activation of the immune system. When someone with this pre-existing condition is confronted with infectious processes, this could lead to a hyperactivation of the immune system, but in a detrimental way that does not fight the infection.

The situation currently being experienced with the COVID-19 pandemic has made us aware of the complex interactions of obesity with infectious diseases and the gaps in our understanding of how chronic health conditions affect our immune responses to acute infection. Finally, we are observing the rise of infections among young adults creates a "reservoir of disease" that eventually "spills over into the rest of society," one that has not yet achieved herd immunity, and portends a broader increase in cases. Fortunately, the chance of dying from COVID-19 remains very small for people under the age of 50, but this age group can become severely ill or suffer long-term symptoms after initial infection. People with underlying conditions, such as obesity and heart disease, are also more likely to become seriously ill.

\subsection{Acknowledgments}

To the Programa de Apoyo a Cuerpos Académicos (PIFI 2018-2020), academic secretariat of CUCEI, with the program "Tamizaje para evaluar el control metabólico en una población joven aparentemente saludable" of the CA 156 Fisiología y Toxicología, which funded this project. Dr. Yolanda Díaz Burke was in charge of this project.

\subsection{References}

Al-Suhaimi, E. A., \& Shehzad, A. (2013). Leptin, resistin and visfatin: the missing link between endocrine metabolic disorders and immunity. European journal of medical research, 18(1), 12. https://doi.org/10.1186/2047-783X-18-12

Aprahamian, T. R., \& Sam, F. (2011). Adiponectin in cardiovascular inflammation and obesity. International journal of inflammation, 2011, 376909. https://doi.org/10.4061/2011/376909

Bray, G. A., Heisel, W. E., Afshin, A., Jensen, M. D., Dietz, W. H., Long, M., Kushner, R. F., Daniels, S. R., Wadden, T. A., Tsai, A. G., Hu, F. B., Jakicic, J. M., Ryan, D. H., Wolfe, B. M., \& Inge, T. H. (2018). The Science of Obesity Management: An Endocrine Society Scientific Statement. Endocrine reviews, 39(2), 79-132. https://doi.org/10.1210/er.2017-00253

Cao H. (2014). Adipocytokines in obesity and metabolic disease. The Journal of endocrinology, 220(2), T47-T59. https://doi.org/10.1530/JOE-13-0339

Carvalho A, Rocha D, McIntyre R, Mesquita L, Kohler C, Hyphantis T, Sales P, Machado-Vieira RBerk M. (2014) Adipokines as emerging depression biomarkers: a systematic review and meta-analysis. J Psychiatr Res, 59: 28-37. doi: 10.1016/j.jpsychires.2014.08.002.

Choe, S. S., Huh, J. Y., Hwang, I. J., Kim, J. I., \& Kim, J. B. (2016). Adipose Tissue Remodeling: Its Role in Energy Metabolism and Metabolic Disorders. Frontiers in endocrinology, 7, 30. https://doi.org/10.3389/fendo.2016.00030

Drucker D. J. (2021). Diabetes, obesity, metabolism, and SARS-CoV-2 infection: the end of the beginning. Cell metabolism, 33(3), 479-498. https://doi.org/10.1016/j.cmet.2021.01.016 
Instituto Nacional de Salud Pública (INSP). (2018) "Encuesta Nacional de Salud y Nutrición 2018". Disponible en https://ensanut.insp.mx/encuestas/ensanut2018/doctos/informes/ Consulado el 23 de agosto de 2021. Instituto Nacional de Salud Pública (INSP), "Encuesta Nacional de Salud y Nutrición

García-Torres D, Castellanos-González M, Cedeño-Morales R, Benet-Rodríguez M, Ramírez-Arteaga I. (2011). Tejido adiposo como glándula endocrina. Implicaciones fisiopatológicas.. Revista Finlay Disponible en: http://www.revfinlay.sld.cu/index.php/finlay/article/view/39

González Sandoval, Claudia Elena et al . Prevalencia de obesidad y perfil lipídico alterado en jóvenes universitarios. Nutr. Hosp., Madrid , v. 29, n. 2, p. 315-321, feb. 2014 . Disponible en http://scielo.isciii.es/scielo.php?script=sci_arttext\&pid=S0212-16112014000200010\&lng=es\&nrm=iso https://dx.doi.org/10.3305/nh.2014.29.2.7054.

Hugo, E. R., y Ben-Jonathan, N. (2016). . Endocrine Disruptors, Adipokines and he Metabolic Syndrome. Adipokines, 228.

Kwok, S., Adam, S., Ho, J. H., Iqbal, Z., Turkington, P., Razvi, S., Le Roux, C. W., Soran, H., \& Syed, A. A. (2020). Obesity: A critical risk factor in the COVID-19 pandemic. Clinical obesity, 10(6), e12403. https://doi.org/10.1111/cob.12403

Landecho, M. F., Tuero, C., Valentí, V., Bilbao, I., de la Higuera, M., \& Frühbeck, G. (2019). Relevance of Leptin and Other Adipokines in Obesity-Associated Cardiovascular Risk. Nutrients, 11(11), 2664. https://doi.org/10.3390/nu11112664

Luis, D. A. De, González Sagrado, M., Conde, R., Aller, R., \& Izaola, O.. (2010). Resistin levels and inflammatory markers in patients with morbid obesity. Nutrición Hospitalaria, 25(4), 630-634.

Martínez-Sánchez N. (2020). There and Back Again: Leptin Actions in White Adipose Tissue. International journal of molecular sciences, 21(17), 6039. https://doi.org/10.3390/ijms21176039

Martos-Moreno G, Kopchick J, Argente J. (2013) Adipokines in healthy and obese children. An Pediatr (Barc) 2013; 78: 189.e181-189.e115.

Méndez, C., Montero, Y., \& Alvarado, S. (2009). Niveles de leptina sérica como indicador del control metabólico en pacientes con diabetes mellitus tipo 2. Salus, 13(3), 30-36.

Nava-Santana, C. A., de Jesús Guerra-Soto, A., Mendoza-Vázquez, G., Flores-Chávez, A., \& Nava, A. (2013). Las adipocinas como mediadoras en la inflamación y el sistema inmune. El Residente, 8(3), 97 105.

NCD Risk Factor Collaboration (NCD-RisC) (2017). Worldwide trends in body-mass index, underweight, overweight, and obesity from 1975 to 2016: a pooled analysis of 2416 population-based measurement studies in 128.9 million children, adolescents, and adults. Lancet (London, England), 390(10113), 2627-2642. https://doi.org/10.1016/S0140-6736(17)32129-3

Pérez-Pérez, A., Sánchez-Jiménez, F., Vilariño-García, T., \& Sánchez-Margalet, V. (2020). Role of Leptin in Inflammation and Vice Versa. International journal of molecular sciences, 21(16), 5887. https://doi.org/10.3390/ijms21165887

Rangel-Huerta, O. D., Pastor-Villaescusa, B., \& Gil, A. (2019). Are we close to defining a metabolomic signature of human obesity? A systematic review of metabolomics studies. Metabolomics : Official journal of the Metabolomic Society, 15(6), 93. https://doi.org/10.1007/s11306-019-1553-y

Rodríguez-López C. (2015) Relación de adipocitocinas y subpoblaciones linfocitarias en pacientes con síndrome metabólico con y sin obesidad visceral. [Tesis de Maestría]. México, D.F.: Universidad Autónoma Metropolitana unidad Xochimilco; 2015.

Rosales Ricardo, Y. (2012). Antropometría en el diagnóstico de pacientes obesos: una revisión. Nutrición Hospitalaria, 27(6), 18031809. https://dx.doi.org/10.3305/nh.2012.27.6.6044 
Seoane-Collazo, P., Martínez-Sánchez, N., Milbank, E., \& Contreras, C. (2020). Incendiary Leptin. Nutrients, 12(2), 472. https://doi.org/10.3390/nu12020472

Sheta, Y. S., Elgohary, E. S. A., \& Sharaf, S. (2012). Visfatin Between Fact and Fiction; A Marker af Obesity or a New Player in the Pathogenesis of Type 2 Diabetes Mellitus. Journal of Asian Scientific Research, 2(12), 949.

Sypniewska G. (2015) Laboratory assessment of cardiometabolic risk in overweight and obese children. Clin Biochem. 48: 370:376.

Vásquez F, Diaz E, Lera L, Vásquez L, Anziani A, Leyton B, Burrows R. (2013) Evaluación longitudinal de la composición corporal por diferentes métodos como producto de una intervención integral para tratar la obesidad en escolares chilenos. Nutr Hosp. 28: 148-154.

Vega-Robledo, Gloria Bertha, \& Rico-Rosillo, María Guadalupe. (2019). Tejido adiposo: función inmune y alteraciones inducidas por obesidad. Revista alergia México, 66(3), 340-353. Epub 19 de febrero de 2020.https://doi.org/10.29262/ram.v66i3.589

Wang P, Van Greevenbrock MM, Bouwman FG, Van der Kallen CJ, Smit E, et al. (2007). The circulating PBEF/NAMPT/Visfatin level is associated with beneficial blood lipid. Pflugers Arch. 454:971-6.

Williams, E. P., Mesidor, M., Winters, K., Dubbert, P. M., \& Wyatt, S. B. (2015). Overweight and obesity: prevalence, consequences, and causes of a growing public health problem. Current obesity reports, 4(3), 363-370.

World Health Organization (WHO) (2018). Global status report on noncommunicable diseases. Geneva: World Health Organization; 2018.

Wu, H., \& Ballantyne, C. M. (2020). Metabolic Inflammation and Insulin Resistance in Obesity. Circulation research, 126(11), 1549-1564. https://doi.org/10.1161/CIRCRESAHA.119.315896 
Chapter 7 Presence of neuroglobin in the substantia nigra in a murine model of parkinson's disease: an immunohistochemical study

Capítulo 7 Presencia de neuroglobina en la sustancia negra en un modelo murino de enfermedad de Parkinson: un estudio inmunohistoquímico

ENRÍQUEZ-MEJIA, María Guadalupe $\dagger$, VIEYRA-REYES, Patricia*, RAMOS-BERUMEN, Diana Carolina and TRUJILLO-CONDES, Virgilio Eduardo

Universidad Autónoma del Estado de México, Mexico.

ID $1^{\text {st }}$ Author: María Guadalupe, Enríquez-Mejia / ORC ID: 0000-0003-1826-092X, CVU CONACYT ID: 481212

ID $1^{\text {st }}$ Co-author: Patricia, Vieyra-Reyes / ORC ID: 0000-0003-1762-3936, CVU CONACYT ID: 132206

ID $2^{\text {nd }}$ Co-author: Diana Carolina, Ramos-Berumen / ORC ID: 0000-0003-4311-7842

ID $3^{\text {rd }}$ Co-author: Virgilio Eduardo, Trujillo-Condes / ORC ID: 0000-0003-1982-0028, CVU CONACYT ID: 385417

DOI: $10.35429 / \mathrm{H} .2021 .13 .89 .99$ 


\begin{abstract}
Neuroglobin (NGB) is a protein with antioxidant and antiapoptotic activity against conditions such as oxidative stress, oxygen / glucose deprivation and neuronal apoptosis. Its presence has been documented in different brain areas including the midbrain, a site of key importance for global motor control by the presence of dopaminergic neurons in the substantia nigra located inside and whose progressive loss culminates in the most common neurodegenerative movement disorder, Parkinson's disease (PD). PD is a condition characterized by motor disturbances such as resting tremor, muscle rigidity, bradykinesia and deterioration gait and balance. There are few studies that inquire about the role of this protein in this disease, including its expression in the substantia nigra. The present study evaluated the presence of NGB in a murine model of PD induced by 6-OHDA injury using immunohistochemistry. The results show a significant difference of NGB aggregates in the substantia nigra in compared to controls $(p=0.003)$ These findings provide the first in vivo experimental evidence of an adaptive NGB response in a model of PD, supporting its probable neuroprotective action in the main area involved in the pathophysiology of this disease.
\end{abstract}

\title{
Neuroglobin, Substantia nigra, Neurodegeneration, Immunohistochemistry
}

\section{Resumen}

La neuroglobina (NGB) es una proteína con actividad antioxidante y antiapoptótica frente a condiciones como el estrés oxidativo, la privación de oxígeno / glucosa y la apoptosis neuronal. Se ha documentado su presencia en diferentes áreas cerebrales, incluyendo el mesencéfalo, un sitio de importancia clave para el control motor global por la presencia de neuronas dopaminérgicas en la sustancia negra ubicada en su interior y cuya pérdida progresiva culmina en el trastorno neurodegenerativo del movimiento más común, la enfermedad de Parkinson (EP). La EP es una enfermedad caracterizada por alteraciones motoras como temblor en reposo, rigidez muscular, bradicinesia y deterioro de la marcha y el equilibrio. Hay pocos estudios que indaguen sobre el papel de esta proteína en esta enfermedad, incluyendo su expresión en la sustancia negra. El presente estudio evaluó la presencia de NGB en un modelo murino de EP inducido por lesión de 6-OHDA utilizando inmunohistoquímica. Los resultados muestran una diferencia significativa de agregados de NGB en la sustancia negra en comparación con los controles $(p=0.003$ ). Estos hallazgos proporcionan la primera evidencia experimental in vivo de una respuesta adaptativa de NGB en un modelo de EP, apoyando su probable acción neuroprotectora en la principal área involucrada en la fisiopatología de esta enfermedad.

\section{Neuroglobina, Substancia nigra, Neurodegeneración, Inmunohistoquímica}

\subsection{Introduction}

Neuroglobin (NGB) is a member of the globin superfamily and its presence in neurons of the central (CNS) and peripheral (SNP) nervous system was demonstrated in 2000 (Burmester, Weich, Reinhardt, \& Hankeln, 2000), becoming a paradigm for current molecular biology, since its discovery has been shown to have an essential function in vertebrates as a neuroprotector.

NGB is described as a particularly conserved protein; in mice and humans it differs only by $6 \%$ in amino acid positions and, substitution rates are three to four times lower than those of vertebrate hemoglobin and myoglobin (Pesce et al., 2003), disclosing that its function does not allow great changes in its sequence.

NGB is a 150 - 160 amino acid long hemoprotein with a molecular mass of $17 \mathrm{kDa}$ (Qiu \& Chen, 2014) placed in a monomeric structure similar to myoglobin and $\alpha$ and $\beta$ chains of hemoglobin, however, its iron atom is hexacoordinated, so the binding of the ligand to the center of the metal requires the dissociation of the distal His (E7) 64-Fe bond (Ascenzi et al., 2016); for this reason, its affinity for oxygen measured by the p50 value, that is, the oxygen pressure required to saturate $50 \%$ of the protein binding sites, is similar to that of myoglobin (Pesce et al., 2002). In addition, NGB has high stability, and its melting temperature is $100^{\circ} \mathrm{C}$ (Hamdane et al., 2005). 
The intrinsic affinity of this globin for low molecular weight diatomic gases is like other globins, but the relatively low level of its expression in brain neurons limits its potential to function as an oxygen reservoir, especially during periods of acute ischemia. In vitro studies suggest that the neuroprotective role of NGB is due to its ability to uptake reactive oxygen species (ROS) and nitrogen (RNS), however, other studies have proposed that NGB is part of a signaling chain that transmits the redox state of the cell to protect it against oxidative stress and inhibit its apoptosis (Hua, Antao, Corbett, \& Witting, 2010).

The antioxidant properties of NGB are related to its affinity for nitric oxide (NO) (Brunori et al., 2005; Lee, McClintock, Santore, Budinger, \& Chandel, 2002) and it has been shown to act as a scavenger of ROS and RNS in different animal models under hypoxic conditions (Liu et al., 2015; Qiu \& Chen, 2014), in which exist a low oxygen level and an excess of reactive species. NGB also has interactions with proteins related to antioxidants such as Cyt c (Mitochondrial electronic transporter) (Fago, Hundahl, Malte, \& Weber, 2004).

Human studies have correlated NGB genetic polymorphisms with susceptibility to neurodegeneration. One of these studies showed that decreased NGB expression in the elderly is associated with an increased risk of Alzheimer's disease (AD) (Baez et al., 2016). In another preclinical study using transgenic mice, it was found that the intracerebral ventricular injection of NGB decreased the formation of $\mathrm{A} \beta$ peptides, the mitochondrial dysfunction, apoptosis, and neuronal death (Chen et al., 2012).

Other studies suggested that the neuroprotective effects of NGB involve the inhibition of caspase3 and 9, activation of the PI3K / Akt pathway (Baez et al., 2016), and removal of protein aggregates (Lechauve et al., 2009); Another actions of NGB involved mitochondrial mechanisms related to apoptosome assembly through a redox reaction with Cyt c. Therefore, NGB can be considered as a potential target to decrease neuronal damage, and its upward expression after brain injury probably reflects endogenous neuroprotective mechanisms (Baez et al., 2016).

In the CNS of mice and humans, NGB is predominantly expressed in neurons. Although the evidence suggests mRNA and protein expression in neurons from different brain regions, NGB expression is different at regional and cellular level (Fago et al., 2004). For example, NGB is highly expressed in the hypothalamus, particularly in the anterior and lateral hypothalamic area (mammillary region), paraventricular nucleus, and arcuate nucleus; in dorsomedial hypothalamic nucleus and preoptic area; laterodorsal and pontine tegmental nucleus and anterior medial basomedial and posterodorsal tonsil nucleus, as well as in midbrain (Schneuer et al., 2012).

NGB has been also found in different regions including cortex, thalamus, cerebellum, hippocampus, and hypothalamus (Van Leuven, Van Dam, Moens, De Deyn, \& Dewilde, 2013). These areas are important in sensation processing, memory and learning, and are often affected in hypoxic and ischemic shock, and traumatic injuries (Burmester \& Hankeln, 2004).

On particular interest is that the presence of NGB in the midbrain. The midbrain is a key development component of appropriate goal-directed behaviors, which is due to calculations based on the integration of different aspects of motivation and cognition to develop and execute appropriate action plans. Midbrain dopaminergic neurons play a central role in these behaviors, including reward, cognition, and motor control; the latter being fundamental the role of neurons belonging to the substantia nigra (SN) (Haber, 2014). Although the substantia nigra was first recognized in 1786 with the description of the distribution of brain neuromelanin, it was linked to the motor system much later because of its association with Parkinson's disease (PD). Collectively, the work of several researchers demonstrated that cells of the substantia nigra contained dopamine (a catecholaminergic neurotransmitter that participates in the regulation of various functions such as motor behavior, emotion and affectivity) and that these cells were dopamine depleted in Parkinson's disease (Haber, 2014).

Parkinson's disease (PD) is a chronic neurodegenerative disorder characterized by motor disturbances that include slow voluntary movements, resting tremor, muscle stiffness, impaired gait and balance (Stacy, 2009). This disorder affects up to 3\% of the population over 60 years old (Tysnes \& Storstein, 2017); Furthermore, in Mexico a prevalence of 40-50 cases per 100,000 inhabitants / year has been estimated. 
It has been calculated that Parkinson's disease currently affects 4.1-4.6 million people over 50 years of age around the globe, calculating that by the year 2030 this number will be doubled, which entails a public health problem(Tysnes \& Storstein, 2017). This progressive neurodegenerative disorder is mainly caused by the loss of dopaminergic cells in the substantia nigra (SN) (Hornykiewicz, 2006). However, it has been widely accepted that the early stages of this pathology are related to brain stem problems, followed later by $\alpha$-synuclein deposition in the cerebral cortex (Braak et al., 2003; McCann, Cartwright, \& Halliday, 2016). $\alpha$-synuclein is a presynaptic protein that can be soluble in the cytosol or bound to cell membranes. It has been linked to synaptic plasticity and intraneuronal vesicular transport, as well as to the release and reuptake of dopamine (Apostolova et al., 2010). Likewise, it has been hypothesized that it could fulfill the function of a molecular chaperone collaborating in the folding and unfolding of synaptic proteins called SNARE (receptors for soluble binding proteins of NSF (sensitive factor to N-ethylmaleimide), which would be fundamental for neurotransmitter release, vesicle recycling, and synapse integrity. Mutations in $\alpha$-synuclein caused by oxidative stress, nitrite aggregates, the presence of heavy metals and toxins increase its intracellular concentration and aggregates in a fibrillar way in the soma of vulnerable neurons, forming inclusions called Lewy bodies. Lewy bodies lead to neuronal dysfunction occurring in PD, favoring increased vulnerability to oxidative stress and ultimately to the appearance of apoptosis (Demey I \& Allegri R, 2008). In advanced stages of PD, a selective loss of dopaminergic neurons from the substantia nigra pars compacta of the ventral midbrain (German, Manaye, Smith, Woodward, \& Saper, 1989; German, Manaye, Sonsalla, \& Brooks, 1992). Neurodegeneration is accompanied by the loss of neuromelanin neurons leading to depigmentation of the area (Fedorow et al., 2005; Gibb \& Lees, 1991). The loss of nigral dopamine neurons leads dopamine depletion in the striatum and generates a wide range of motor dysfunctions (Bellucci et al., 2016). PD is also associated with non-motor and non-dopaminergic symptoms extended beyond the nigrostriatal dopaminergic pathway and often occur years or even decades before clinical diagnosis (Bellucci et al., 2016).

According to Kleinknecht et al. (Kleinknecht et al., 2016), human NGB showed a protective effect against $\alpha$-synuclein aggregates in yeast and mammalian cells. NGB expression reduced the number of cells with $\alpha$-synuclein aggregates almost twice compared to the controls, as well as the number of aggregates per cell. When performing lactate dehydrogenase (LDH) measurements to determine whether there was an effect of NGB on cell toxicity (the release of LDH in the cell culture medium is an indicator of damage to the plasma membrane and is used as a marker of cytotoxicity), Kleinknecht et al., found LDH levels were similar for all cells in the test; indicating that NGB acts as a suppressor of $\alpha$-synuclein aggregation without causing significant cytotoxicity (Kleinknecht et al., 2016).

Until now, although the neuroprotective properties of NGB have been proven under different pathological conditions, only in vitro investigations have been carried out in PD. Our study represents the first in vivo report of the presence of NGB in the main damaged area in this disease. For this purpose, a murine model of lesion with 6-OHDA in the substantia nigra was used using stereotaxic surgery and the presence of NGB in brain sections was subsequently investigated by immunohistochemistry. We hypothesized that an increase of NGB in the substantia nigra indicates a response to cell damage.

The following sections detail the methodology for the induction of the experimental model of Parkinson's disease through the lesion of the dopaminergic neurons of the substantia nigra with 6-OHDA using stereotaxic surgery and the subsequent processing of brain tissue as well as detection of the presence of NGB by immunohistochemistry, the results are detailed exposing the representative images and the accumulated count to finally expose our conclusions.

\subsection{Methodology}

\subsubsection{Ethical implications}

Experiments followed the principles and procedures outlined by the National Institutes of Health; the guide for the care and use of laboratory animals and the local IRB of the Universidad Autónoma del Estado de México. The study observed Mexican standard NOM-062-ZOO-1999, regarding technical specifications for the production, care and use of laboratory animals. 


\subsubsection{Murine model of Parkinson's disease}

Eight male Wistar rats, weighing 200-300 g, were used for the study. The animals were kept under standardized conditions in 12:12 light / dark cycles, controlled room temperature $\left(22 \pm 2^{\circ} \mathrm{C}\right)$, and food and water ad libitum.

Surgery was performed under anesthesia using a cocktail of $90 \mathrm{mg} / \mathrm{kg}$ of ketamine (Pisa, Mexico) and $10 \mathrm{mg} / \mathrm{kg}$ of xylazine (Pisa, Mexico) administered by intraperitoneal injection (27-gauge needle and $1 \mathrm{cc}$ syringe). Additional anesthesia was supplemented as necessary during the surgical precedures.

The lesion with 6-OHDA was performed according to Jáidar et al. (Dunnett \& Iversen, 1980). Briefly, $20 \mu \mathrm{l}$ of 6-hydroxydopamine (6-OHDA) (Sigma, $4 \mu \mathrm{g} / \mu \mathrm{l}$ in $0.9 \% \mathrm{NaCl}, 0.5 \%$ C6H8O6) were injected into the right substantia nigra $(2 \mu \mathrm{l} / \mathrm{min})$ according to the following stereotaxic coordinates: anteroposterior, 3.9; lateral, 1.8; ventral, $6.7 \mathrm{~mm}$ (Figure 7.1). One week after injection, rats were treated with amphetamine (4 mg / kg i.p.) and ipsilateral turns were counted for 90 minutes with an automatic apparatus (device). Animals that showed $>500$ ipsilateral turns were used for the experiments that were performed 15 days after injury (Figure 7.2). This rotational score corresponds to> $97 \%$ of SN dopaminergic cell injury (Dunnett \& Iversen, 1980; Grant \& Clarke, 2002). Controls were injected with vehicle only (sham op).

Figure 7.1 Stereotaxic surgery for induction of murine model of Parkinson's disease

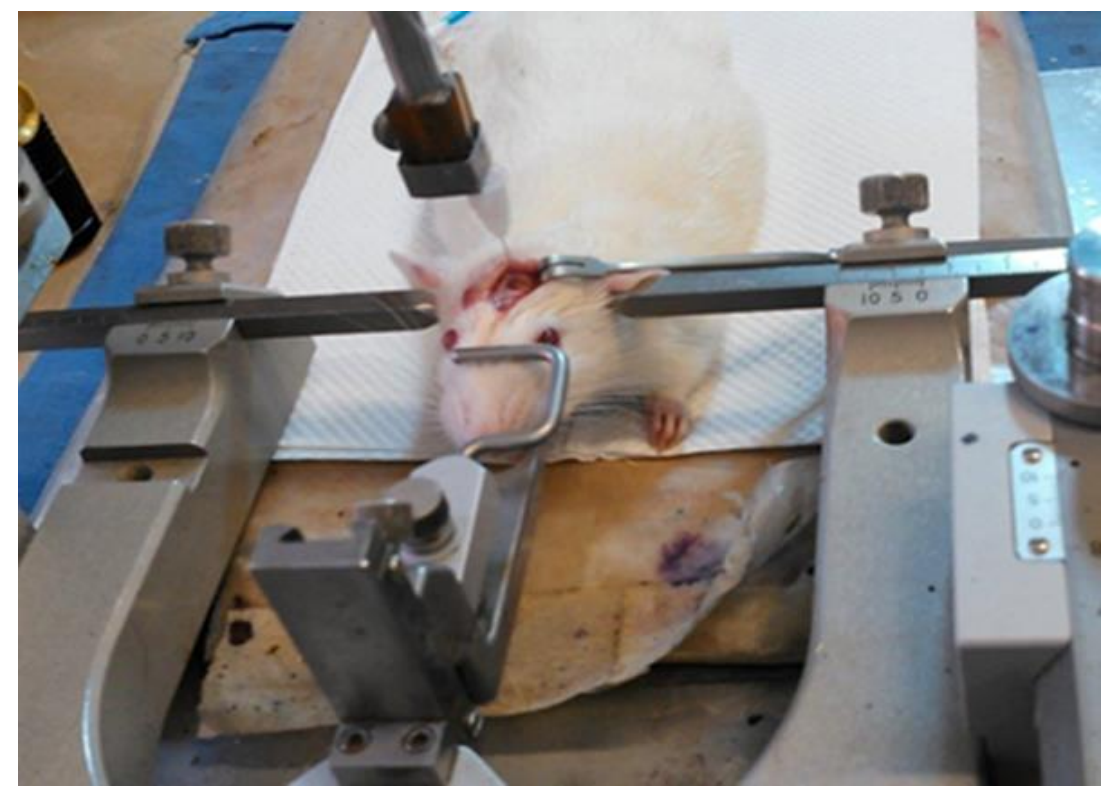

Figure 7.2 Automatic lap counter for turning test

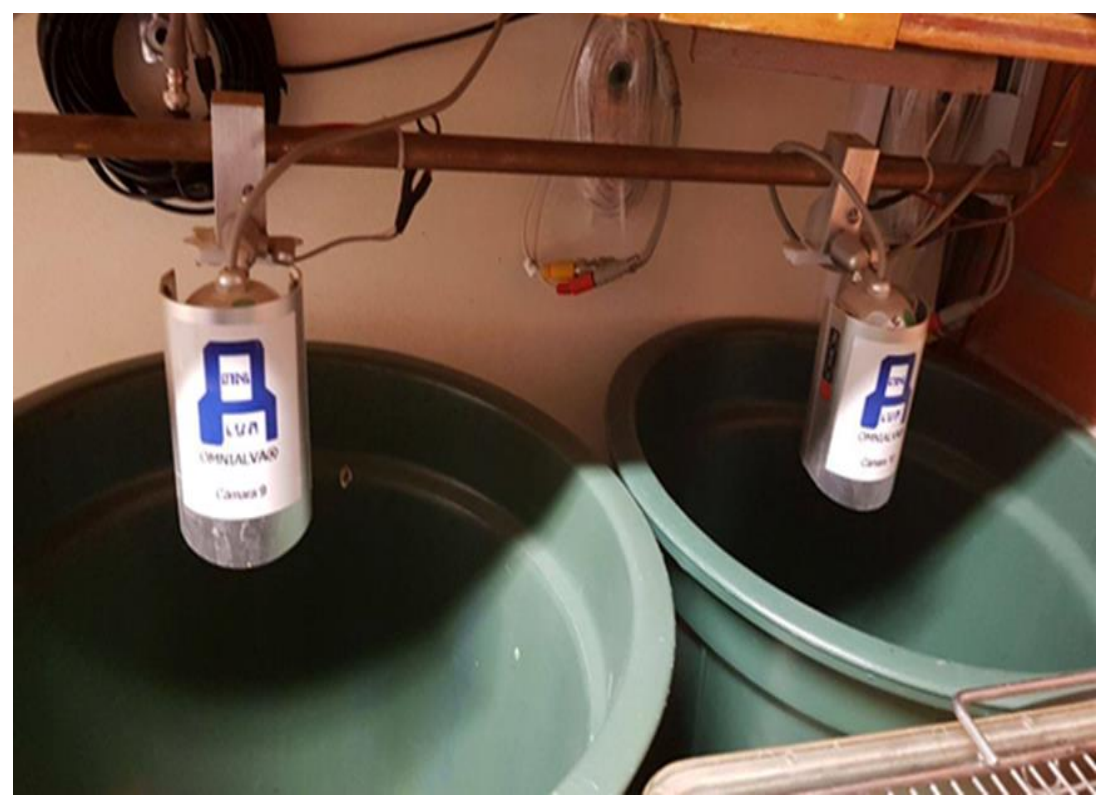




\subsubsection{Obtaining samples}

\section{Euthanasia}

$2 \mathrm{~mL}$ of sodium pentobarbital (Pfizer anesthetic) was administered intramuscularly and after the absence of vital signs, perfusion was carried out.

\section{Perfusion}

After euthanasia, the abdominal cavity was opened, followed by clamping of the vena cava and abdominal aorta. A cannula was introduced intracardially directed to the ascending aorta, fixed with a pressure clamp, and the cardiac atria were cut. $200 \mathrm{~mL}$ of phosphate buffer were perfused, followed by $250 \mathrm{~mL}$ of $4 \%$ paraformaldehyde. Once the perfusion was completed, the head was removed using a guillotine and the brain extruded.

After removing the brain from the bone cavity, it was placed in a vial containing $20 \mathrm{~mL}$ of $10 \%$ sucrose solution for 24 hours, and then replaced by $20 \%$ sucrose for a further period of 24 hours. The next 24 hours, the brain was maintained with sucrose at $30 \%$. Subsequently, a coronal cut was made at the level of the midbrain (Figure 7.3) and coronal slices of $40 \mu \mathrm{m}$ were made using cryostat (820 jung histocut microtome, Leica, USA).

Figure 7.3 Brain section at ventral midbrain level, showing the lesion in substantia nigra (black arrow)

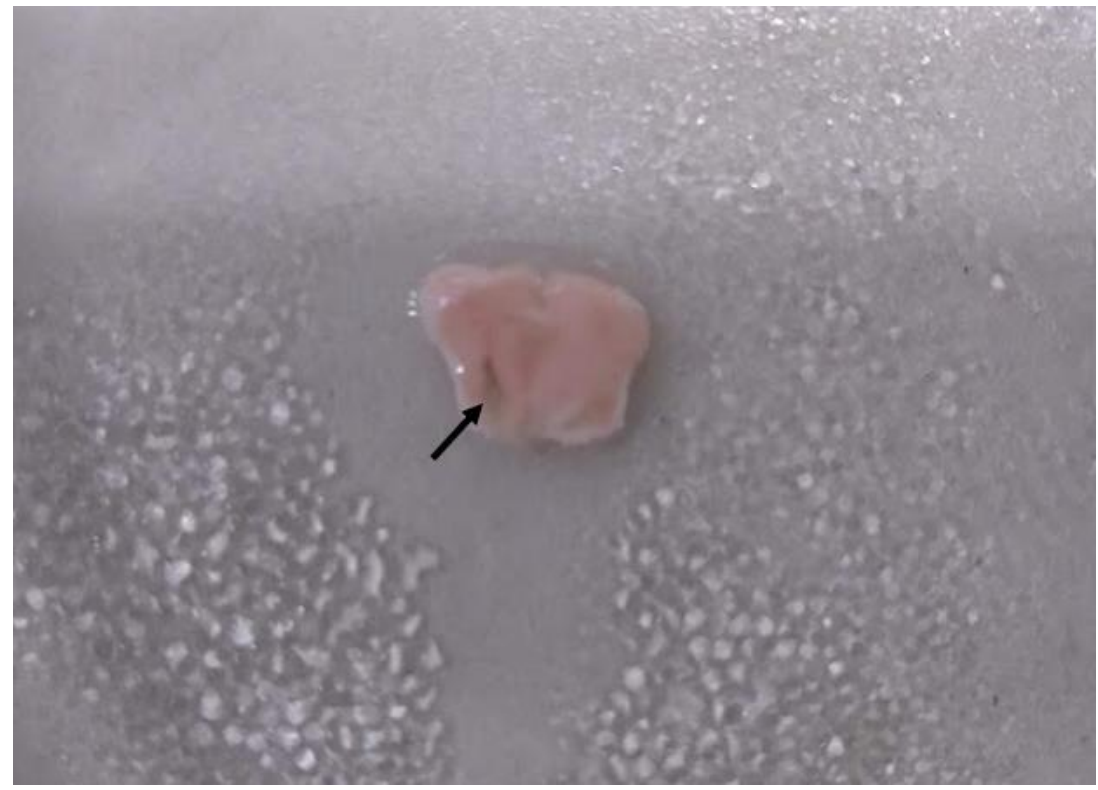

\subsubsection{Immunohistochemistry}

Midbrain slices (anteroposterior, 3.9; lateral, 1.8; ventral, $6.7 \mathrm{~mm}$ ) were washed three times in PBS pH 7.0, and then were immersed in $0.28 \%$ of periodic acid solution for 1 minute at room temperature Next, they were immediately washed again and then incubated in antigen retriever for 30 minutes at $60^{\circ} \mathrm{C}$ and maintained at room temperature. The slices were washed again and placed in a blocking solution (PBS Triton $0.01 \%+$ Bovine Serum Albumin 2.5\%). At the end of the previous step, the sections were incubated in a 1: 500 solution of primary antineuroglobin antibody (Sigma) in blocking solution for 24 hours at $4^{\circ} \mathrm{C}$, then they were washed 3 times with PBS pH 7.0 and were placed in a solution 1,500 biotinylated secondary antibody 2 hours at room temperature. The washes were repeated, and the slices were immersed in Complex AB (Streptovidin-Peroxidase) for $45 \mathrm{~min}$ at room temperature, the washes were repeated once more and finally submerge the sections in developing solution for 5 minutes. For microscopic observation, the sections were mounted on slides, allowed to dry at room temperature, and synthetic resin was placed on them to seal the coverslip. 


\subsubsection{Neuroglobin quantification}

Counts of NGB aggregates were identified with a brown color precipitate using a 100X objective in a brightfield microscope in a standardized area of $0.031 \mathrm{~mm}^{2}$. The counts were made for triplicate in each of the areas to be evaluated in the sections for each animal. 18 fields were analyzed overall. The data were then analyzed in (SPSS $®)$ Statistics. An exploratory / descriptive study of the counts was carried out, which included measures of central tendency, dispersion, and a normality test. The Independent Samples $t$ test was used to compare means. The measured variable was the density of brown NGB aggregates per unit area $\left(0.031 \mathrm{~mm}^{2}\right)$. Statistical differences were accepted when $\mathrm{p}<0.05$.

\subsection{Results}

A reconstruction of the sections of the area was performed with Bregma coordinates $-6.00 \mathrm{~mm}$ and interaural $2.96 \mathrm{~mm}$, according to Paxinos (Figure 7.4). Photographs were taken with $4 \mathrm{X}$ objective for reconstruction and $40 \mathrm{X}$ for cell/aggregates counting using a bright field microscope, later the reconstruction was performed using the Image Composite Editor program. In figure 7.5 the specific marking can be seen as small brown marks corresponding to NGB, evaluated in the substantia nigra on the left side, in the control and the injured, respectively.

Figure 7.4 Reconstruction of substantia nigra sections (blue box)

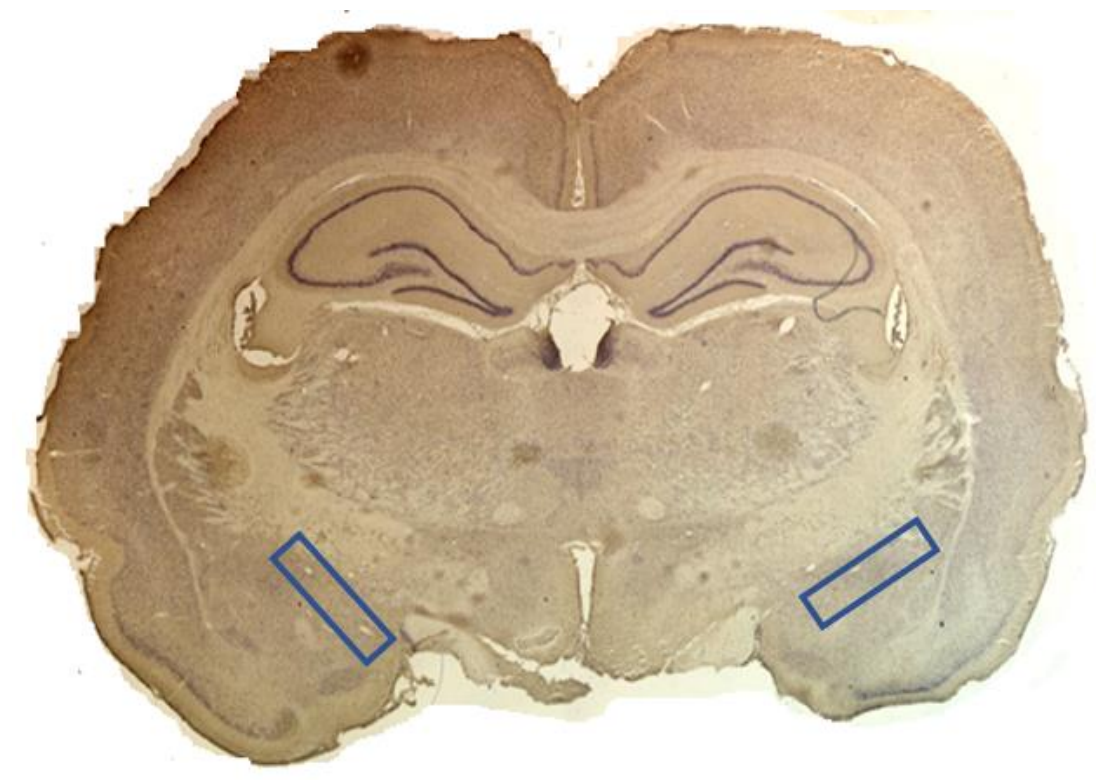

Figure 7.5 Immunohistochemistry of neuroglobin in substantia nigra of murine model of Parkinson's disease. Points correspond to NGB aggregates. a. Sham. b. Parkinson Disease

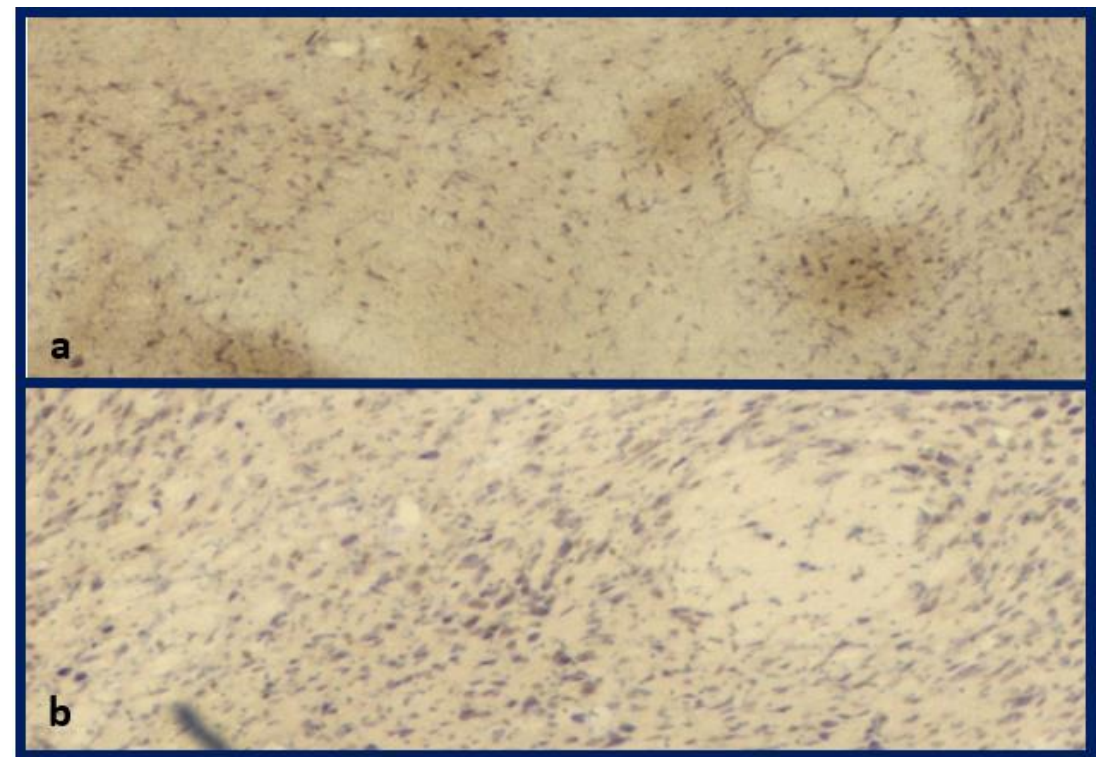


According to statistical study, we found a greater presence of NGB when the 6-OHDA lesion is present $(\bar{X}=25.22 \pm 2.005) v s$. control $(\bar{X}=17 \pm 1.179)$, according to the density of NGB aggregates found in the target area $\left(0.031 \mathrm{~mm}^{2}\right)$ in the triplicate counts that were carried out $(\mathrm{t}(16)=-3.535 \mathrm{p}<$ 0.003) (Graphic 7.1).

Graphic 7.1 Comparison of means of NGB aggregates density. The average number of aggregates in a standardized area of $0.031 \mathrm{~mm}^{2}$ are shown. Parkinson's disease $(\overline{\mathrm{X}}=25.22 \pm 2.005)$ vs sham $(\bar{X}=17 \pm 1.179)(\mathrm{t}(16)=-3.535 \mathrm{p}<0.003)$

Sham $\square$ Parkinson's Disease
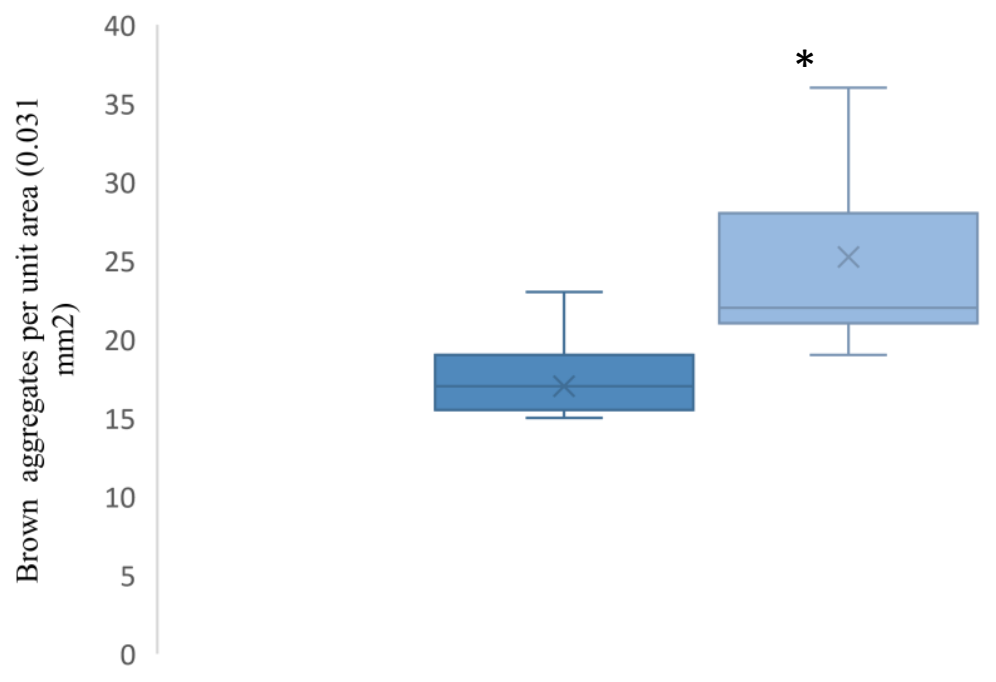

\subsection{Discussion}

NGB has a wide presence in the central nervous system, which has been demonstrated in previous studies. According to Wistub (Wystub et al., 2003), this protein is present in the cortex, thalamus, hippocampus, and hypothalamus, among other areas. However, there are few studies that showed NGB presence in neurodegenerative diseases. In a report where its presence was evaluated in affected areas in Huntington's disease, (striatum, thalamus and cortex) it was found a greater presence of the protein in striatum where the disease is evident, however, NGB had a lesser expression in thalamus and cortex, despite the striatum being the main area affected in the disease (Cardinale et al., 2018). In our study, we found the presence of NGB in the substantia nigra in control subjects (sham op), in an area where it had not been previously described (Fig. 5) however, its presence was much lower than in the experimental subject $(\bar{X}=25.22 \pm$ 2.005 vs $\bar{X}=17 \pm 1.179, \mathrm{t}(16)=-3.535 \mathrm{p}<0.003)$. Due to the great epidemiological importance of Parkinson's disease, analyzing the presence of a protein with proven neuroprotective functions is of relevance and interest. Overall, our study shows the first report of NGB presence in the substantia nigra and a statistically significant increase of the protein when the lesion was present. corresponding to the main area affected in PD due to the loss of dopaminergic neurons. We suggest that an increase in NGB in this midbrain area could indicate a upregulation dependent on damage and neurodegeneration.

\subsection{Acknowledgments}

Funding to carry out this research is acknowledged to Apoyo a Proyectos de Investigación en Nutrición (APIN) del Instituto de Salud y Nutrición Kellogg, Kellogg Company S de R.L. de C.V. Code 4843 / 2019E. As well as Proyectos de Investigación Científica para la Consolidación de Grupos de Investigación y Estudios Avanzados UAEM 2019. Code 4758 / 2019CIF.

\subsection{Conclusions}

The increase in life expectancy at a global level brings with it a progressive increase in the incidence of degenerative diseases such as Parkinson's disease, whose pathophysiology is far from being clarified. The study of proteins with neuroprotective functions, like NGB, can play a relevant role. The present study shows upregulation of the protein when progressive and irreversible death of dopaminergic neurons in substantia nigra occurs. 
More studies are needed on NGB in Parkinson's disease, not only in the substantia nigra but in other affected areas such as the motor cortex and the striatum, it is also important to determine in future studies the cell type that expresses the protein, as well as its subcellular location in order to clarify its role in this condition.

\subsection{References}

Apostolova, L. G., Beyer, M., Green, A. E., Hwang, K. S., Morra, J. H., Chou, Y. Y., . . Thompson, P. M. (2010). Hippocampal, caudate, and ventricular changes in Parkinson's disease with and without dementia. Mov Disord, 25(6), 687-695. doi:10.1002/mds.22799

Ascenzi, P., di Masi, A., Leboffe, L., Fiocchetti, M., Nuzzo, M. T., Brunori, M., \& Marino, M. (2016). Neuroglobin: From structure to function in health and disease. Mol Aspects Med, 52, 1-48. doi:10.1016/j.mam.2016.10.004

Baez, E., Echeverria, V., Cabezas, R., Avila-Rodriguez, M., Garcia-Segura, L. M., \& Barreto, G. E. (2016). Protection by Neuroglobin Expression in Brain Pathologies. Front Neurol, 7, 146. doi:10.3389/fneur.2016.00146

Bellucci, A., Mercuri, N. B., Venneri, A., Faustini, G., Longhena, F., Pizzi, M., . . Spano, P. (2016). Review: Parkinson's disease: from synaptic loss to connectome dysfunction. Neuropathol Appl Neurobiol, 42(1), 77-94. doi:10.1111/nan.12297

Braak, H., Del Tredici, K., Rub, U., de Vos, R. A., Jansen Steur, E. N., \& Braak, E. (2003). Staging of brain pathology related to sporadic Parkinson's disease. Neurobiol Aging, 24(2), 197-211.

Brunori, M., Giuffre, A., Nienhaus, K., Nienhaus, G. U., Scandurra, F. M., \& Vallone, B. (2005). Neuroglobin, nitric oxide, and oxygen: functional pathways and conformational changes. Proc Natl Acad Sci U S A, 102(24), 8483-8488. doi:10.1073/pnas.0408766102

Burmester, T., \& Hankeln, T. (2004). Neuroglobin: a respiratory protein of the nervous system. News Physiol Sci, 19, 110-113. doi:10.1152/nips.01513.2003

Burmester, T., Weich, B., Reinhardt, S., \& Hankeln, T. (2000). A vertebrate globin expressed in the brain. Nature, 407(6803), 520-523. doi:10.1038/35035093

Cardinale, A., Fusco, F. R., Paldino, E., Giampa, C., Marino, M., Nuzzo, M. T., . . Melone, M. A. B. (2018). Localization of neuroglobin in the brain of R6/2 mouse model of Huntington's disease. Neurol Sci, 39(2), 275-285. doi:10.1007/s10072-017-3168-2

Chen, L. M., Xiong, Y. S., Kong, F. L., Qu, M., Wang, Q., Chen, X. Q., . . . Zhu, L. Q. (2012). Neuroglobin attenuates Alzheimer-like tau hyperphosphorylation by activating Akt signaling. $J$ Neurochem, 120(1), 157-164. doi:10.1111/j.1471-4159.2011.07275.x

Demey I, \& Allegri R. (2008). Demencia en la enfermedad de parkinson y demencia por cuerpos de lewy. Revista Neurológica Argentina, 33.

Dunnett, S. B., \& Iversen, S. D. (1980). Regulatory impairments following selective kainic acid lesions of the neostriatum. Behav Brain Res, 1(6), 497-506. doi:10.1016/0166-4328(80)90004-2

Fago, A., Hundahl, C., Malte, H., \& Weber, R. E. (2004). Functional properties of neuroglobin and cytoglobin. Insights into the ancestral physiological roles of globins. IUBMB Life, 56(11-12), 689-696. doi:10.1080/15216540500037299

Fedorow, H., Tribl, F., Halliday, G., Gerlach, M., Riederer, P., \& Double, K. L. (2005). Neuromelanin in human dopamine neurons: comparison with peripheral melanins and relevance to Parkinson's disease. Prog Neurobiol, 75(2), 109-124. doi:10.1016/j.pneurobio.2005.02.001 
German, D. C., Manaye, K., Smith, W. K., Woodward, D. J., \& Saper, C. B. (1989). Midbrain dopaminergic cell loss in Parkinson's disease: computer visualization. Ann Neurol, 26(4), 507-514. doi:10.1002/ana.410260403

German, D. C., Manaye, K. F., Sonsalla, P. K., \& Brooks, B. A. (1992). Midbrain dopaminergic cell loss in Parkinson's disease and MPTP-induced parkinsonism: sparing of calbindin-D28k-containing cells. Ann N Y Acad Sci, 648, 42-62.

Gibb, W. R., \& Lees, A. J. (1991). Anatomy, pigmentation, ventral and dorsal subpopulations of the substantia nigra, and differential cell death in Parkinson's disease. J Neurol Neurosurg Psychiatry, 54(5), 388-396.

Grant, R. J., \& Clarke, P. B. (2002). Susceptibility of ascending dopamine projections to 6hydroxydopamine in rats: effect of hypothermia. Neuroscience, 115(4), 1281-1294. doi:10.1016/s03064522(02)00385-8

Haber, S. N. (2014). The place of dopamine in the cortico-basal ganglia circuit. Neuroscience, 282, 248257. doi:10.1016/j.neuroscience.2014.10.008

Hamdane, D., Kiger, L., Dewilde, S., Uzan, J., Burmester, T., Hankeln, T., . . Marden, M. C. (2005). Hyperthermal stability of neuroglobin and cytoglobin. FEBS J, 272(8), 2076-2084. doi:10.1111/j.17424658.2005.04635.x

Hornykiewicz, O. (2006). The discovery of dopamine deficiency in the parkinsonian brain. $J$ Neural Transm Suppl(70), 9-15.

Hua, S., Antao, S. T., Corbett, A., \& Witting, P. K. (2010). The significance of neuroglobin in the brain. Curr Med Chem, 17(2), 160-172.

Kleinknecht, A., Popova, B., Lazaro, D. F., Pinho, R., Valerius, O., Outeiro, T. F., \& Braus, G. H. (2016). C-Terminal Tyrosine Residue Modifications Modulate the Protective Phosphorylation of Serine 129 of alpha-Synuclein in a Yeast Model of Parkinson's Disease. PLoS Genet, 12(6), e1006098. doi:10.1371/journal.pgen.1006098

Lechauve, C., Rezaei, H., Celier, C., Kiger, L., Corral-Debrinski, M., Noinville, S., . . Marden, M. C. (2009). Neuroglobin and prion cellular localization: investigation of a potential interaction. J Mol Biol, 388(5), 968-977. doi:10.1016/j.jmb.2009.03.047

Lee, V. Y., McClintock, D. S., Santore, M. T., Budinger, G. R., \& Chandel, N. S. (2002). Hypoxia sensitizes cells to nitric oxide-induced apoptosis. J Biol Chem, 277(18), 16067-16074. doi:10.1074/jbc.M111177200

Liu, Z. F., Zhang, X., Qiao, Y. X., Xu, W. Q., Ma, C. T., Gu, H. L., . . Chen, Y. G. (2015). Neuroglobin protects cardiomyocytes against apoptosis and cardiac hypertrophy induced by isoproterenol in rats. Int J Clin Exp Med, 8(4), 5351-5360.

McCann, H., Cartwright, H., \& Halliday, G. M. (2016). Neuropathology of alpha-synuclein propagation and braak hypothesis. Mov Disord, 31(2), 152-160. doi:10.1002/mds.26421

Pesce, A., Bolognesi, M., Bocedi, A., Ascenzi, P., Dewilde, S., Moens, L., . . Burmester, T. (2002). Neuroglobin and cytoglobin. Fresh blood for the vertebrate globin family. EMBO Rep, 3(12), 1146-1151. doi:10.1093/embo-reports/kvf248

Pesce, A., Dewilde, S., Nardini, M., Moens, L., Ascenzi, P., Hankeln, T., . . Bolognesi, M. (2003). Human brain neuroglobin structure reveals a distinct mode of controlling oxygen affinity. Structure, 11(9), 1087-1095. doi:10.1016/s0969-2126(03)00166-7

Qiu, X. Y., \& Chen, X. Q. (2014). Neuroglobin - recent developments. Biomol Concepts, 5(3), 195-208. doi:10.1515/bmc-2014-0011 
Schneuer, M., Flachsbarth, S., Czech-Damal, N. U., Folkow, L. P., Siebert, U., \& Burmester, T. (2012). Neuroglobin of seals and whales: evidence for a divergent role in the diving brain. Neuroscience, 223, 35-44. doi:10.1016/j.neuroscience.2012.07.052

Stacy, M. (2009). Medical treatment of Parkinson disease. Neurol Clin, 27(3), 605-631, v. doi:10.1016/j.ncl.2009.04.009

Tysnes, O. B., \& Storstein, A. (2017). Epidemiology of Parkinson's disease. J Neural Transm (Vienna), 124(8), 901-905. doi:10.1007/s00702-017-1686-y

Van Leuven, W., Van Dam, D., Moens, L., De Deyn, P. P., \& Dewilde, S. (2013). A behavioural study of neuroglobin-overexpressing mice under normoxic and hypoxic conditions. Biochim Biophys Acta, 1834(9), 1764-1771. doi:10.1016/j.bbapap.2013.04.015

Wystub, S., Laufs, T., Schmidt, M., Burmester, T., Maas, U., Saaler-Reinhardt, S., . . Reuss, S. (2003). Localization of neuroglobin protein in the mouse brain. Neurosci Lett, 346(1-2), 114-116. doi:10.1016/s0304-3940(03)00563-9 
Chapter 8 Prevalence of ectopic eruption and intercanine distance in children aged 6 to 12 years. Cycle 2019-2020

Capítulo 8 Prevalencia de erupción ectópica y distancia intercanina en niños de 6 a12 años. Ciclo 2019-2020

MARTÍNEZ-ORTIZ, Rosa María†*, TAVIZON-GARCÍA, Jesús Andrés, CARLOS-SÁNCHEZ, María Dolores and CORDERO-CELIBEE, Monserrat

Universidad Autónoma de Zacatecas, Unidad Académica de Odontología. México.

ID $1^{\text {st }}$ Author: Rosa María, Martínez Ortiz / ORC ID: 0000-0001-7811-169X

ID $1^{\text {st }}$ Co-author: Jesús Andrés, Tavizón-García / ORC ID: 0000-0003-2417-2571

ID $2^{\text {nd }}$ Co-author: María Dolores, Carlos-Sánchez / ORC ID: 0000-0001-8012-270X

ID $3^{\text {rd }}$ Co-author: Monserrat, Cordero-Celibee

DOI: $10.35429 /$ H.2021.13.100.106

R. Martínez, J. Tavizon, M, Carlos and M. Cordero

* rosamartinez@uaz.edu.com

A. Marroquín, J. Olivares, M. Cruz, L. Cruz. (Coord.) CIERMMI Women in Science TXIII Medicine and Health Sciences. Handbooks-@ECORFAN-México, Querétaro, 2021. 


\begin{abstract}
The development of permanent teeth and their eruption is of utmost clinical importance, it is also useful in anthropology, demography, forensic medicine and paleontology studies. When the eruption sequence and the mechanisms are not adequate, it causes an ectopic eruption that must be detected in time in order to avoid damage to the occlusion that affects the aesthetics, function, self-esteem and quality of life of the child. Objective: To identify the prevalence of ectopic eruption and intercanine distance in children aged 6 to 12 years. Methodology: An epidemiological, cross-sectional, descriptive study was carried out in order to clinically detect this eruption anomaly. The selection of the sample was 77 children who met the selection criteria, during the 2019-2020 school year. In a rural primary school in a municipality of Zacatecas, the intercanine distance measurements were subsequently carried out with the help of a Vernier, after calibration and informed consent, the information was processed through the statistical program SPSS V 24 and Excel. Results: The prevalence of ectopic eruption was 22\%, the female gender the most frequent age was 7 years. The average upper intercanine distance was $26.76 \mathrm{~mm} *$ - and in the lower jaw it was $33.4 \mathrm{~mm}+$ _ : the tooth that presented the most frequent ectopic eruption was No. 22, the least frequent was 32 and 15 . It was observed a decrease in the intercanine distance $26.7 \mathrm{~mm}$. In children with multiple ectopic eruption, the intercanine distance decreased, the lower lateral incisors were detected between the teeth with the highest prevalence of ectopic eruption. Conclusions: It is necessary to intervene in the early stages in order to avoid the installation of malocclusion and costly, long and more difficult orthodontic treatments. Prevention is better than cure.
\end{abstract}

\title{
Ectopic eruption, Intercanine distance, Children
}

\section{Resumen}

El Desarrollo de los dientes permanentes y su erupción es de suma importancia clínica, además es útil en los estudios de antropología, demografía, medicina forense y paleontología. Cuando la secuencia de erupción y los mecanismos no son adecuados ocasiona una erupción ectópica que se debe detectar a tiempo con la finalidad de evitar daños en la oclusión que afecten la estética, función, la autoestima y la calidad de vida del niño. Objetivo: Identificar cuál es la prevalencia de erupción ectópica y distancia intercanina en niños de 6 a 12 años. Metodología: Se realizó un estudio epidemiológico, transversal, descriptivo con la finalidad, detectar clínicamente esta anomalía de erupción. La selección de la muestra fue 77 niños que cumplían con los criterios de selección, durante el ciclo escolar 2019-2020. En una escuela rural primaria de un municipio de Zacatecas, posteriormente se realizó las mediciones la distancia intercanina con la ayuda de un Vernier, previa calibración y consentimiento informado, se procesó la información a través del programa estadístico SPSS V 24 y Excel. Resultados: La prevalencia de erupción ectópica fue $22 \%$, el género femenino la edad más frecuente fue el de 7 años. El promedio de distancia intercanina superior fue de $26.76 \mathrm{~mm}^{*}$ - y en el maxilar inferior fue de $33.4 \mathrm{~mm}+$ _: el diente que presentó más frecuente la erupción ectópica fue el No. 22, el de menor frecuencia el 32 y el 15. Se observó disminución en la distancia intercanina $26.7 \mathrm{~mm}$. En niños con erupción ectópica múltiple la distancia intercanina disminuyó, se detectaron entre los dientes con mayor prevalencia de erupción ectópica los dientes incisivos laterales inferiores. Conclusiones: Es necesario intervenir en etapas tempranas con la finalidad de evitar la instalación de maloclusión y tratamientos ortodóncicos costosos, largos y más difíciles. Prevenir es mejor que curar.

\section{Erupción ectópica, Distancia intercanina, Niños}

\subsection{Introduction}

Ectopic eruption is defined as a congenital anomaly in the situation or position of an organ, it is very common to observe permanent dentition with dental organs outside the dental arch, but rarely the reason is sought. Ectopic eruption of a tooth within the oral cavity is common but elsewhere it is rare. Ectopic teeth at the level of the maxillary sinus infraorbital region are a rare entity. Ectopic eruption may be associated with developmental disturbances, pathologic processes or iatrogenic. The etiology of an ectopic tooth is not always known. (Moreno Garcia C. Serrano Gil H., 2007) Etiology (causal factors) 
The incidence of ectopic eruption is $15.70 \%$, its timely diagnosis is essential to plan a timely and effective treatment and thus avoid damage to the occlusion and costly orthodontic treatments. Arid, J, (2019). The teeth that have a predilection for erupting ectopically are the permanent third molars, followed by the maxillary canines and first molars constituting 0.8 to $2.8 \%$. Mercuri reports $65.8 \%$ incidence in females and 33.2\% males. Nikiforuk, (2018). Marañón-Vásquez GA, (2019). A study was conducted at the Catholic University of Cuenca Ecuador, 2018-2019. In 300 panoramic radiographs of children 6 to 9 years of age attended. The greater ectopic eruption presents a greater tendency in children 6 years of age. (Heraz C, J, 2020). A clinical case is reported of a male patient aged 11 years, with ectopic eruption of a central incisor, with coronary anomaly and root dilaceration. The presence of a supernumerary tooth above the ectopic central incisor was observed. (Muiño, et al 2018).

This eruption disorder presents a multifactorial etiology; Larger than normal size of all primary and permanent teeth. Larger than normal size of first and permanent molars and deciduous second molars.Smaller than normal size of the maxilla.Incorrect balance between growth and eruption forces if growth of the maxilla in the region of the tuberosity, which is what provides space for the development and positioning of the permanent molars, does not occur before or during the eruption of the permanent molars, the eruption force will be directed mesially, being blocked by the roots of the second primary molar. Growth may occur in the distal maxilla at a later date, but if the eruption force of the previously deviated first permanent molar is very intense, it will be blocked despite the space available.

This will occur in the majority of cases in which the concavity that has produced the resorption on the distal aspect of the deciduous second molar is large. However, if the force of the mesial direction of eruption is of low intensity, it can happen that the bone growth manages to counteract this force and thus, the first permanent molar corrects its position and erupts in its correct position, constituting a reversible ectopic eruption. Abnormal eruption angle of the first permanent molar, so that in comparison with a normal eruption, the forward movement of the crown of the first permanent molar is much greater than the downward movement. (Gallegos López L. G.) .

\subsubsection{Mechanism of dental eruption}

There are several theories on the development of tooth eruption; 4 eruption mechanisms which include the formation and growth of the root part of the tooth, bone growth, vascular and hydrostatic pressure of the connective part of the tooth (Gallardo, Mourelle, \& García, 2016). It has been mentioned that the emergence of the tooth will not only depend on the action of the periodontal ligament since this is implicit but not the main one, it will be accompanied by hydrostatic pressure of the tissues, accompanied by the action of fibroblasts (Berkowitz \& Holland, 2016). Three fundamental parts should be known during this mechanism: the present space granted by the follicle at the time of eruption, the pressure exerted by the apical root membrane thanks to its innervation, and the adaptation of the periodontal ligament to such eruptive process. In spite of this, the conclusions of all the transactional studies carried out in humans show that this mechanism has not been fully understood, so many authors over time have proposed different variables involved in the mechanism, among which we have: As explained by Marks and Schroeder in their 1996 article entitled "tooth eruption: theories and facts" in which they refer to variables such as speed, three-dimensional position of the piece and root length.

In 1992, the book "Essentials of oral histology and embryology" suggests a factor totally different from the others, the pressure exerted by the pulp, vascularization and especially the cells that participate in the formation of the bone tissue around the tooth. Bath-Balogh and Fehrenbach in their book in 2006 refer to the presence of a temporal ligament, contractile collagen and hormonal signs. Koch and Paulsen in 2009 add genetic and local factors, especially the population and its development. Berkowitz suggests the presence of two systems involved in the mechanism, the hydrostatic pressure at the vascular level around the tooth and the activity of periodontal fibroblasts.

However, there is no proven theory with sufficient experimental evidence that can explain in detail the origin of the eruption force, since, in order to do so, a study should be carried out at the molecular level separating the piece from the membrane and the bone. $(\mathrm{Kj}$, s. f.) Another of the theories proposed by Dr. Cobas mentions the participation of the periodontal ligament in the eruption mechanism, calling it a "hammock" in charge of extending from side to side of the dental piece and exerting impulsion movements to produce dental eruption, in turn agreeing with Berkowitz with the vascular theory. (MADURO J. S.G. (20219). 


\subsection{Description of the Method}

\subsubsection{Analysis based on demand curve regression}

It is a transactional, descriptive, observational study, in a convenience sample according to the inclusion criteria 77 children from 6 to 12 years of age from an elementary school in Milpillas and Gutiérrez Municipalities of the State of Zacatecas. an intraoral exploration was performed, occlusion and intercanine distance were assessed. Prior informed consent of the parents was obtained. A univariate and logistic regression analysis was performed with the SPSS V. 24. Excel V. 2016 statistical package. The students were clinically examined according to the safety standards as per the OMS: Mouth cover, diagnostic package. Vernier, millimeter ruler. Research instrument, gloves, Abatelenguas. In order to carry out this study, formal communication was established with the directors of the elementary schools, by means of an official letter. Attendance lists were requested for groups from 1st to 6th grade and all were invited to participate in order to include them in the study. Subsequently, talks were held with parents in which the objective of the study was explained.

With the help of the millimeter ruler to determine the space there is and if it is likely that due to lack of space there could be an ectopic eruption. An average measurement of between 20 to $38 \mathrm{~mm}$ was found. Depending on the age. The following tables show the results obtained from the research: Prevalence by gender male with $49 \%$ and Female with $51 \%$. Prevalence of ectopic eruption $22 \%$. Average age of 8 years.

\subsection{Results}

Table 8.1 Teeth in ectopic eruption

\begin{tabular}{|r|r|r|r|r|r|}
\hline \multicolumn{7}{|c|}{ Teeth in Ectopic Eruption } \\
\hline \multirow{3}{*}{ Valid } & Frequency & Percentage & Valid percentage & Cumulative percentage \\
\cline { 2 - 6 } & $11,21,31,41$ & 1 & 1.3 & 1.3 & 1.3 \\
\cline { 2 - 6 } & 12,22 & 1 & 1.3 & 1.3 & 2.5 \\
\cline { 2 - 6 } & $12,22,32,42$ & 1 & 1.3 & 1.3 & 3.8 \\
\cline { 2 - 6 } & 13,23 & 1 & 1.3 & 1.3 & 5.1 \\
\cline { 2 - 6 } & 15 & 1 & 1.3 & 1.3 & 6.3 \\
\cline { 2 - 6 } & $15,13,23$ & 1 & 1.3 & 1.3 & 7.6 \\
\cline { 2 - 6 } & 21 & 1 & 1.3 & 1.3 & 8.9 \\
\cline { 2 - 6 } & 22 & 1 & 1.3 & 1.3 & 10.1 \\
\cline { 2 - 6 } & 31 & 1 & 1.3 & 1.3 & 13.4 \\
\cline { 2 - 6 } & 31,41 & 2 & 2.5 & 2.5 & 16.5 \\
\cline { 2 - 6 } & 32 & 2 & 2.5 & 2.5 & 17.7 \\
\cline { 2 - 6 } & 32,42 & 1 & 1.3 & 1.3 & 20.3 \\
\cline { 2 - 6 } & 33 & 1 & 1.3 & 1.3 & 21.5 \\
\cline { 2 - 6 } & 41 & 1 & 1.3 & 1.3 & 22.8 \\
\hline & 42 & 1 & 1.3 & 1.3 & 24.1 \\
\hline
\end{tabular}

Source: Own elaboration with the results of the research conducted 
Figure 1 Different eruption patterns found.

\section{Various patterns of ectopic eruption.}

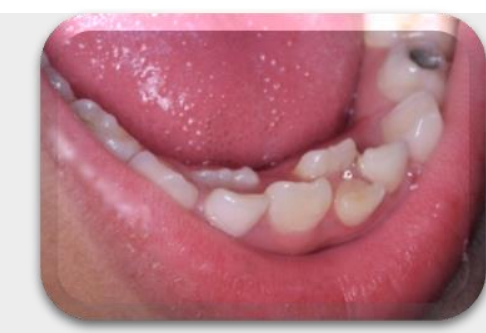

LOWER ECTOPIC

ERUPTION.

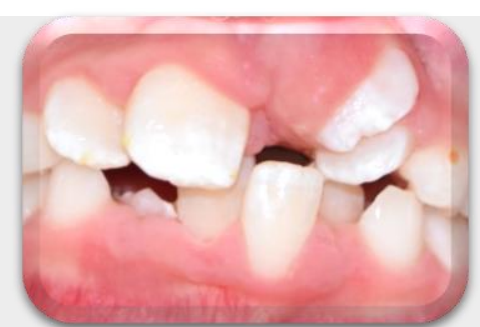

PALATOVERSION NO. 12.

*Multiple ectopic eruption.

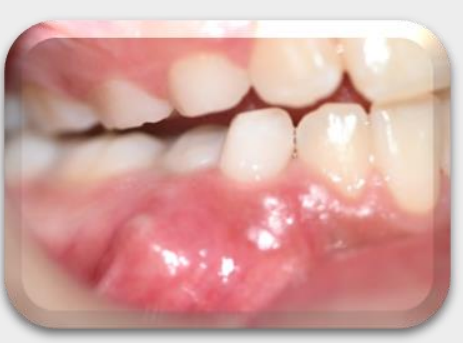

VESTIBULAR ERUPTION OF

THE LOWER PREMOLAR.

Source: Children examined during the research conducted

Table 8.2 Intercanal distance in children with ectopic eruption

\begin{tabular}{|c|c|c|c|c|c|}
\hline \multicolumn{6}{|c|}{ Inter-annual distance Superior } \\
\hline & & Frequency & Percentage & Valid percentage & $\begin{array}{l}\text { Cumulative } \\
\text { percentage }\end{array}$ \\
\hline \multirow[t]{14}{*}{ Valid } & & 7 & 8.9 & 8.9 & 8.9 \\
\hline & 28 & 1 & 1.3 & 1.3 & 10.1 \\
\hline & 31 & 1 & 1.3 & 1.3 & 11.4 \\
\hline & 32 & 4 & 5.1 & 5.1 & 16.5 \\
\hline & 33 & 9 & 11.4 & 11.4 & 27.8 \\
\hline & 34 & 11 & 13.9 & 13.9 & 41.8 \\
\hline & 35 & 20 & 25.3 & 25.3 & 67.1 \\
\hline & 36 & 6 & 7.6 & 7.6 & 74.7 \\
\hline & 37 & 2 & 2.5 & 2.5 & 77.2 \\
\hline & 38 & 12 & 15.2 & 15.2 & 92.4 \\
\hline & 39 & 2 & 2.5 & 2.5 & 94.9 \\
\hline & 40 & 2 & 2.5 & 2.5 & 97.5 \\
\hline & 42 & 1 & 1.3 & 1.3 & 98.7 \\
\hline & $\mathrm{S}$ & 1 & 12 & 1.3 & 100.0 \\
\hline
\end{tabular}

Source: Own authorship of children reviewed in the research

\subsection{Discussion}

The normal pattern of dental eruption is variable in the permanent dentition, with greater changes being observed in the chronology than in the sequence. Ectopic eruption of the upper permanent canine is frequently observed due to the persistence of the temporary second molar, since the adequate use of the drift space (or Nance free space) and the adequate mesialization of the molar depend on it. An alteration facilitates the loss of the length of the arch, producing a malocclusion, according to Fux-Noy, Avia (2019). 
The chronological development of the upper canine is associated with the permanent upper second premolar, although it has a slightly higher fraction with respect to the Nolla stages. The second premolar erupts first before the canine and a high percentage of the population presents a sequence according to the norm: first premolar, second premolar, upper canine. The main alteration in the normal eruption sequence in the support area is the prolonged presence of the temporary second molar.

Currently there are several sequences of eruption of the lateral sectors in the upper arch, the most common being the sequence of first premolar, second premolar, canine. This eruption sequence often results in the presence of elevated canines, which, being the last to erupt, lack space, making it difficult for them to be located properly.

After the third molars, the canines are the teeth that present the greatest number of anomalies in their eruption, since they collect all the space problems that may exist in the dental arch. (Gonzáles Lema Daniel). Ectopic eruption in centrals and laterals there are no epidemiological studies, only clinical cases that document and propose treatments. (Ismail M, 2020).

\subsection{Acknowledgments}

To the educational authorities as well as to the children examined for allowing us to examine them during school hours, in addition to the parents who signed the informed consent form.

\subsection{Conclusions}

Knowing the eruption sequence and the eruption mechanism of the teeth is fundamental to achieve an adequate diagnosis of ectopic eruption. It is necessary to increase the size of the sample in several schools once the pertinent sanitary conditions are met, to use panoramic radiographs in order to know the eruption patterns in posterior teeth, to channel with the orthodontist for rapid and timely intervention and thus avoid skeletal malocclusion in children.

\subsection{References}

CiftcI V, Uguz HN, Ozcan M. (2019). Laser-assisted management of ectopic eruption of permanent incisors. Niger J. Clin Pract. 22:276-80.

Hsiao CC, Boynton JR. (2016). Etiology, Classification and Management of Ectopic Eruption of Permanent First Molars. The Journal of the Michigan Dental Association. Jan;98(1):26-30.

Mubeen S, Seehra J. Failure of Eruption of First Permanent Molar Teeth: A Diagnostic Challenge. (2018). Journal of Orthodontics;45(2):129-134. doi:10.1080/14653125.2018.1462902.

Fux-noy, Avia (2019). Distal Migration and Ectopic Eruption of the Mandibular First Premolar: A Case Report. Journal of Clinical Pediatric Dentistry, 43(5), 364-366. doi:10.17796/1053-4625-43.5.12.

Ismail, M.Q., Lauridsen, E., Andreasen, (2020). O. et al. Ectopic eruption of the second premolar: an analysis of four different treatment approaches. Eur Arch Paediatr Dent 21,119-127. https://doi.org/10.1007/s40368-019-00459-z.

Marañón-Vásquez GA, Matsumoto MAN, Feres MFN, Ferreira JTL, Consolaro A, Romano FL. (2019). Early Treatment of Failure of Eruption of a Permanent Molar. J Dent Child (Chic). 15;86(3):150-153. PMID: 31645256.

Arid, J, Xavier, TA, da Silva, RAB, et al. RANKL (2019) .is associated with persistent primary teeth and delayed permanent tooth emergence. Int $J$ Paediatr Dent. 29: 294- 300. https://doi.org/10.1111/ipd.12467.

Heraz Chávez, Jessica, Magaly Jiménez Romero, Luz Dominga Mamani Cahuata, y Sively Mercado Mamani. (2020). Erupción ectópica de los primeros molares permanentes del maxilar superior.

Moncayo Mero, J. P. (2020-10). Recuperado a partir de http://repositorio.ug.edu.ec/handle/redug/49750 
Maduro Jácome, $\quad$ S. $\quad$ G... (2021-03). Tesis. Recuperado a partir de http://repositorio.ug.edu.ec/handle/redug/52070. 


\section{Chapter 9 Anxiety in medical students, during a COVID-19 pandemic}

\section{Capítulo 9 Ansiedad en estudiantes de medicina, durante pandemia COVID-19}

CACERES-MATTA, Sandra V. $\dagger^{*}$, ZÁRATE-DEPRAECT, Nikell E., FLORES-FLORES, Paula and BUSTILLOS-TERRAZAS, Nora A.

Universidad del Sinú. School of Medicine, Mexico.

Universidad Autónoma de Sinaloa. School of Medicine, Mexico.

Universidad Autónoma de Sinaloa. School of Nutrition and Gastronomy, Mexico.

ID $1^{\text {st }}$ Author: Sandra V., Caceres-Matta / ORC ID: 0000-0001-8277-607X

ID $1^{\text {st }}$ Co-author: Nikell E., Zárate-Depraect / ORC ID: 0000-0002-3087-3959

ID $2^{\text {nd }}$ Co-author: Paula, Flores-Flores / ORC ID: 0000-0003-2929-2134

ID $3^{\text {rd }}$ Co-author: Nora A., Bustillos-Terrazas / ORC ID: 0000-0002-1558-6855

DOI: $10.35429 /$ H.2021.13.107.112

S. Caceres, N. Zárate, P. Flores and N. Bustillos

*senibaza@hotmail.com

A. Marroquín, J. Olivares, M. Cruz, L. Cruz. (Coord.) CIERMMI Women in Science TXIII Medicine and Health Sciences. Handbooks-@ECORFAN-México, Querétaro, 2021. 


\begin{abstract}
Know the presence of anxiety in medical students from a private university in Colombia, during the COVID-19 pandemic. Non-experimental, quantitative, exploratory cross-sectional study; applied the DASS-21 scale. Cronbach's alpha of the total scale was 0.79 . Descriptive analysis was carried out in statistical package spss v21, data collection was by google forms during the month of December 2020, with prior informed consent. The convenience sample consisted of 115 students from the medical school of a private university in the city of Cartagena, Colombia. Of this, 60 were women and 55 men. 80 students were anxious (medium, moderate, severe, and very severe). Very severe and severe anxiety was more frequently expressed in women. It is concluded that during the COVID-19 pandemic, 80 of 115 medical students from a private university in Cartagena Colombia presented anxiety.
\end{abstract}

\title{
Anxiety, Students, Medicine
}

\section{Resumen}

Conocer la presencia de ansiedad en estudiantes de medicina de una universidad privada de Colombia, durante la pandemia COVID-19. Estudio no experimental, cuantitativo, exploratorio de corte transversal; aplicó la escala DASS-21. El alpha de Cronbach de la escala total, fue de 0 .79. Se realizó análisis descriptivo en paquete estadístico spss v21, la recolección de datos fue por Google forms durante el mes de diciembre del 2020, bajo previo consentimiento informado. La muestra por conveniencia se conformó por 115 estudiantes de la facultad de medicina, de una Universidad privada de la ciudad de Cartagena Colombia. De ello, 60 fueron mujeres y 55 hombres. 80 estudiantes resultaron con ansiedad (media, moderada, severa y muy severa). La ansiedad muy severa y severa se expresó con más frecuencia en mujeres. Se concluye que durante la pandemia COVID-19, 80 de 115 estudiantes de medicina de una universidad privada de Cartagena Colombia presentaron ansiedad.

\section{Ansiedad, Estudiantes, Medicina}

\subsection{Introduction}

The year 2020 and so far in 2021 has been difficult for the general population due to the pandemic of the new coronavirus in all its variants. This virus is considered highly contagious, causing rapid, severe and sometimes fatal infections. This has had a negative impact on the mental health of all people, forcing social isolation, fear, loneliness and uncertainty to prevail in some people, and in the educational context to migrate from face-to-face to virtual education. As a result, it altered the psychological well-being of many students and generated anxiety in them.

In Asian countries, the school population was one of the most affected, provoking anxiety in them, generated by the uncertainty of family income and that in turn required technological equipment for their educational activities (Sigüenza \& Vílchez, 2021). Isolation measures included the promotion of education through virtual platforms (Saravia, Cazorla \& Cedillo, 2020). At Changzhi University, out of 7143 medical students, 24.9\% had anxiety due to the pandemic (Garcia-Espinosa, Ortiz-Jiménez, Botello-Hernández, Hernández-Díaz, Góngor-Rivera, \& Gecen, 2021).

Garcia-Espinosa, et al. (2021), also reported that, out of 530 medical students in Saudi Arabia, $38.11 \%$ reported being emotionally tired and $56.22 \%$ acknowledged a decrease in their academic ability during this pandemic. Finally, they state that the predisposing factors: being female, knowing someone with symptomatology and being a non-clinical semester student, generated moderate-severe anxiety in $61.3 \%$ of 348 medical students.

At the same time, varying levels of anxiety were found in medical students at the National University of San Agustín, who are single, live alone and spend a lot of time listening to news about COVID-19. (Chambilla, 2021). Similarly, in students with anxiety in the health area in the Lambayeque region, having repetitive thoughts about becoming infected or infecting family members are influential as triggering factors (Zafra, 2021). (Zafra, 2021) 
Likewise, in contemporary society, anxiety is common among young people, affecting their emotional and mental well-being (Ali \& Cerkez, 2020). Medical students in Mexico believe that having been infected with COVID-19 or having a family member infected with COVID-19 or being the cause of death generated depression in them. (Yusvisaret, Palmer, Medina \& López, 2021).

Today, within the university educational environment, the fulfilment of theoretical and practical skills is demanded as if continuing in the face-to-face context (prior to the COVID-19 pandemic). The pandemic has forced virtual education to take both students and teachers by surprise in order for them to appropriate the teaching and learning strategies that this modality implies. Therefore, the academic environment is different from the traditional one, making information and communication technologies the main and indispensable tools.

Therefore, the concern of educational institutions to offer optimal teaching requires visualising the entire educational context, which is why it is important to detect manifestations that hinder students' learning. In this regard, the psychological well-being of medical students is important and some of them may show anxiety, i.e. agitation and restlessness in their mood, which can disrupt learning. This is a behavioural disorder considered to be a prevalent illness worldwide (Sousaa, Santiago \& Micó, 2020).

In relation to the above, the academic load that university students take each semester can affect the mental health of students in some way (Trunce, Villarroel, Arntz, Muñoz \& Werner, 2020). It is well known that anxiety increases as the university student tends to procrastinate (Araoz \& Uchasara, Altamirano, 2020). The medical student is subjected to a demanding, demanding and socially constrained work environment, which can sometimes be hostile and promote greater vulnerability to developing psychological disorders such as anxiety.

Before the pandemic, it was already known that about $20 \%$ of medical students show traits of anxiety and depression in the psychological profile for entry to this career. (Alvarez, 2020). In the first years of medical school, more anxious students have been observed (Caicedo, Díaz \& Vidal, 2020) and even with depression and suicidal behaviours; with more prevalence in the last grades of the professional career. (Cosme, 2020) Also, during the medical internship year, anxious men score higher than women (Huarcaya, 2020).

Because the pandemic has brought about higher levels of mood distress, this study expects to find that at least $30 \%$ of the students surveyed suffer from anxiety, either at a severe or very severe level.

\subsection{Method}

The aim of this study was to determine the presence of anxiety in medical students at a private university in Colombia during the COVID-19 pandemic.

It was carried out under a non-experimental, quantitative, exploratory and cross-sectional methodology; the anxiety scale DASS-21 (Antúnez, 2012) was applied, which deals with how they felt during the past week and includes: moods, signs of nervousness, desire to live, desire to do activities, etc. Cronbach's alpha of the total scale was 0.79 . Descriptive analysis was carried out using the statistical package spss v21, and the scale was applied using the google forms platform during the month of December 2020, with prior informed consent. The convenience sample consisted of 115 medical students from a private university in the city of Cartagena, Colombia.

\subsection{Results and discussion}

Of the 115 students who participated in this study, according to the gender variable, 60 were female and 55 were male. As can be seen in Table 1, the number of students can be seen in relation to the level of anxiety they manifested. In this sense, 80 students were found to have anxiety (medium, moderate, severe and very severe).

Very severe anxiety was expressed by 30 students, predominantly by 18 females. Severe anxiety was also more frequent in females, while moderate and medium anxiety predominated in males. 
Table 9.1 Anxiety levels in medical students in Colombia

\begin{tabular}{|l|r|r|}
\hline \multicolumn{1}{|c|}{ Range } & Total & \multicolumn{1}{c|}{ Gender } \\
\hline Normal & 35 & $\begin{array}{r}20 \text { women } \\
15 \text { men }\end{array}$ \\
\hline Medium & 9 & $\begin{array}{r}4 \text { women } \\
6 \text { men }\end{array}$ \\
\hline Moderate & 19 & $\begin{array}{r}5 \text { women } \\
14 \text { men }\end{array}$ \\
\hline Severe & 22 & $\begin{array}{r}13 \text { women } \\
8 \text { men }\end{array}$ \\
\hline Very severe & 30 & $\begin{array}{r}18 \text { women } \\
12 \text { men }\end{array}$ \\
\hline
\end{tabular}

Source: Own elaboration, 2020

With the above, we agree with authors such as Sigüenza and Vílchez (2021), in assuring that during COVID isolation, anxious students did show up, as they perceived a greater academic load, affecting their mental and emotional well-being (Ali \& Cerkez, 2020; Trunce, Villarroel, Arntz, Muñoz \& Werner, 2020).

Likewise, it has been shown internationally that university students, especially in the area of health, tend to manifest anxious symptoms (Apaza \& Gonza, 2020). According to Solernou and Solernou (2020), one in five university students suffers from anxiety disorder, and he refers to the fact that this could become an epidemic. High percentages of anxiety were found in medical students (Ruvalcaba, González \& Jiménez, 2021), which reinforces the result found in this study.

Furthermore, it is in agreement with several studies stating that anxiety is more frequent in women than in men (López, Moreno \& Sánchez, 2020; Quesada, Gutiérrez, Gutiérrez, Nouni, \& Carratalá, 2021; Luna, Urquiza, Figuerola, Carreño \& Meneses, 2020. And also with Luna, et al., 2020; Caicedo, Díaz and Vidal, 2020, who state that women who study medicine have more anxiety than men.

Although the causal factors of anxiety were not addressed in this study, however, it was considered relevant to investigate the current literature on them and the following was found:

- When the student is in the evaluation period, anxiety is more evident. (Nolasco, 2020).

- $\quad$ Living alone, having less than 5 hours for recreation, lack of time to eat, sleeping less than 5 hours, requiring more than 90 minutes to travel to the university. (Pinilla, López, Moreno \& Sánchez, 2020).

- The level of anxiety increases as a function of curricular development, and among its main sources are academic, psychosocial and economic aspects (Luna, Urquiza, Figuerola, Carreño, \& Meneses, 2020; Puig, Ricaño, Quiroz \& Puig (2021).

- $\quad$ Sleep disturbances are associated with anxiety, poor performance of daily bodily tasks, depressive disorders, memory problems, academic and motivational problems, suicidal thoughts, obesity and cardiac morbidity. (Ramon, Cahuich \& Lopez 2020)

\subsection{Conclusion and recommendations}

- Anxiety was manifested in 80 out of 115 medical students at a private university in Colombia during the COVID-19 pandemic.

- It predominated in women.

The implementation of promotion and prevention strategies for anxiety control is recommended, such as: family and social support, sleeping 6 to 8 hours a day, allowing time for recreation and physical activity every day.

- $\quad$ Students are encouraged to recognise stressors and self-manage their own learning. 
- Early diagnosis is requested in order to monitor and control the student who suffers from it and thus promote their emotional wellbeing, which has an impact on their learning and warn that it may evolve into depression, stress or Burnout syndrome, among others.

The fear of catching the disease and infecting a family member can theoretically be considered a factor that generates anxiety in university students.

We agree with Piñer, Gómez-Roso and López (2021) in mentioning that clinical rotations in the training of doctors during the COVID-19 pandemic are possible and necessary, as long as they are carried out appropriately with safety measures.

\subsection{References}

UAntúnez, Z. y Vinet, E. V. (2012). Escala de depresión, ansiedad y estrés (DASS-21): validación de la versión abreviada en estudiantes universitarios chilenos. Terapia psicológica. 30(3). 49-55. https://scielo.conicyt.cl/pdf/terpsicol/v30n3/art05.pdf

Ali, Ahmed, S. y Cerkez, Y. (2020). El impacto de la ansiedad, la depresión y el estrés en la estabilidad emocional entre los estudiantes universitarios desde el punto de vista educativo. Propósitos y Representaciones. 8(3). 1-9. http://dx.doi.org/10.20511/pyr2020.v8n3.520

Alvarez, A. M. (2020). Perfil psicológico en estudiantes de medicina en universidad del cusco/psychological profile in medicine students at university in cusco. Situa. 23(1). 118. https://doi.org/10.51343/si.v23i1.191

Apaza Ramirez, B. R., y Gonza Chunga, C. E. (2020). Relación entre religiosidad y ansiedad en estudiantes de una universidad privada de Lima Este. [Tesis para Profesional de Psicólogo(a), en la Universidad Peruana Unión]. Repositorio de Tesis Universidad Peruana Unión. https://repositorio.upeu.edu.pe/handle/20.500.12840/3076

Araoz, E. G. E., y Uchasara, H. J. M. (2020). Procrastinación académica y ansiedad en estudiantes universitarios de Madre de Dios, Perú. Apuntes Universitarios, 10(4), 322-337. https://doi.org/10.17162/au.v10i4.517

Chambilla Rodriguez, C. A. (2021). Factores asociados y nivel de ansiedad frente a COVID-19 en estudiantes del sexto año de la facultad de medicina de la Universidad Nacional de San Agustín, mayo 2021

Caicedo, N. K., Díaz, L. P., \& Vidal, V. L. (2020). Niveles de ansiedad y depresión en estudiantes de ciencias de la salud que usan dispositivos móviles [Tesis Doctoral, Universidad Santiago de Cali]. Repositorio Universidad Santiago de Cali. https://repository.usc.edu.co/handle/20.500.12421/5045

Cosme, J. A. et al (2020). Depresión, ansiedad y conducta suicida en la formación médica en una universidad en México. Revista Investigación en Educación Médica, 9(35), 65-74. https://doi.org/10.22201/facmed.20075057e.2020.35.20224

Luna, D. et al. (2020). Predictores académicos y sociodemográficos de ansiedad y bienestar psicológico en estudiantes mexicanos de medicina. Estudio transversal. Gaceta Médica de México. 156. 40-46. http://dx.doi.org/10.24875/GMM.19005143

Lagunes, Á. A. et al. (2020). Prevalencia de depresión, ansiedad y estrés académico entre estudiantes de medicina, durante distintos periodos de estrés. Atención Familiar, 27(4), 165-171. http://dx.doi.org/10.22201/fm.14058871p.2020.4.76891

Pinilla, L. M. et al. (2020). Prevalencia y factores de riesgo de Ansiedad en estudiantes de medicina de la Fundación Universitaria Juan N. Corpas. Un estudio de corte transversal. Revista Cuarzo, 26(1), $22-$ 27. https://revistas.juanncorpas.edu.co/index.php/cuarzo/article/view/493/439 
Puig-Lagunes, Á. A. et al. (2021). Sintomatología de ansiedad y burnout al término de la licenciatura de médico cirujano. Revista de la Facultad de Ciencias Médicas de Córdoba, 78(1), 25-28. http://dx.doi.org/10.31053/1853.0605.v78.n1.28447

Garcia-Espinosa, P., Ortiz-Jiménez, X., Botello-Hernández, E., Hernández-Díaz, A., GóngoraRivera, F., \& Gecen Investigators. (2021). Covid-19, impacto psicosocial en estudiantes de medicina. Salud Pública de México, 63(3 May-Jun), 330-331.

Gutiérrez, I. et al. (2021). Depresión, ansiedad y salud autopercibida en estudiantes de Medicina: un estudio transversal. Revista Española de Educación Médica, 2(2), 21-31. doi: 10.6018/edumed.470371

Piñel Pérez, C. S., Gómez-Roso Jareño, M. J., \& López Galián, J. J. (2021). Percepción y ansiedad de los estudiantes de Medicina en su rotación clínica en Obstetricia durante la pandemia por COVID-19.

Ramón, L. A. et al. (2020). Calidad de sueño, somnolencia diurna y ansiedad en estudiantes de la carrera de médico cirujano en una universidad privada del norte de México PsicoSophia, 2(1), 12-19, http://psicosophia.um.edu.mx/ojs/index.php/psicosophia/article/view/13/10

Ruvalcaba, K. A. et al. (2021). Depresión y ansiedad en estudiantes de Medicina durante el confinamiento por la pandemia de COVID-19. Investigación edn educación médica, 10(39), 1-8. https://doi.org/10.22201/fm.20075057e.2021.39.21342

Saravia-Bartha, M. M. et al. (2020). Nivel de ansiedad de estudiantes de medicina de primer año de una universidad privada del Perú en tiempos de covid-19. Revista Facultad de Medicina Humana, 20(4), 568-573. DOI 10.25176/RFMH.v20i4.3198

Sigüenza, W. G. y Vílchez, J. L. (2021). Aumento de los niveles de ansiedad en estudiantes universitarios durante la época de pandemia de la COVID-19. Revista Cubana de Medicina Militar. 50(1). 1-14. http://www.revmedmilitar.sld.cu/index.php/mil/article/view/931/731

Solernou, A. J. y Solernou, I.A. (2020, 26-30 de octubre). Factores socio-familiares, académicos, ansiedad y depresión, en estudiantes de medicina. Fundamentación de exploración necesaria. En Primera $\begin{array}{llll}\text { Jornada Virtual de Psiquiatría. } & \end{array}$ http://jvirtualpsiquiatria2020.sld.cu/index.php/jvpsq/2020/paper/view/112

Sousaa, J. et al. (2020). Ansiedad comparada entre estudiantes de medicina y estudiantes de otros grados en el Área de la Salud en Coimbra. Educación médica, 20, 130-134. https://doi.org/10.1016/j.edumed.2020.04.001

Trunce, S. T. et al. (2020). Niveles de depresión, ansiedad, estrés y su relación con el rendimiento académico en estudiantes universitarios. Investigación en educación médica, 9(36), 8-16. https://doi.org/10.22201/fm.20075057e.2020.36.20229

Yusvisaret Palmer, Lourdes, Palmer Morales, Sefnar, Medina Ramirez, Ma. Concepción Rosa, \& López Palmer, Daniel Alexis. (2021). Prevalencia de depresión durante la COVID-19 en estudiantes de medicina de una universidad privada mexicana. MEDISAN, 25(3), 637-646. Epub 07 de junio de 2021. Recuperado en 10 de agosto de 2021, de http://scielo.sld.cu/scielo.php?script=sci_arttext\&pid=S1029$30192021000300637 \& \operatorname{lng}=\mathrm{es} \&$ tlng=es.

Zafra Rodas, J. J. (2021). Prevalencia de ansiedad y depresión en internos de ciencias de la salud de la región Lambayeque durante pandemia por COVID-19, 2020-2021. 


\section{Chapter 10 Overwiev of general plant toxicology uses and adverse effects}

Capítulo 10 Generalidades de la toxicología forense usos y efectos adversos de las plantas

GONZÁLEZ-GARCÍA, Arcelia’, HERNÁNDEZ-SALAS, Claudia', MARTÍNEZ-ORTIZ, Rosa María" and GONZÁLEZ-MARTÍNEZ, Lilia'

'Universidad Autónoma de Zacatecas, Academic Unit of Chemical Sciences, Mexico.

"Universidad Autónoma de Zacatecas, Academic Unit of Dentistry, Mexico.

ID $1^{\text {st }}$ Author: Arcelia, González-García / ORC ID: 0000-0003-0674-1072

ID $1^{\text {st }}$ Co-author: Claudia, Hernández-Salas / ORC ID: 0000-0001-7492-1310)

ID $2^{\text {nd }}$ Co-author: Rosa María, Martínez-Ortiz / ORC ID: 0000-0001-7811-169X)

ID $3^{\text {rd }}$ Co-author: Lilia, González-Martínez / ORC ID: 0000-0002-3679-0070)

DOI: $10.35429 /$ H.2021.13.113.130

A. González, C. Hernández, R. Martínez and L. González

* Arcelia.gonzalez@uaz.edu.mx

A. Marroquín, J. Olivares, M. Cruz, L. Cruz. (Coord.) CIERMMI Women in Science TXIII Medicine and Health Sciences. Handbooks-@ECORFAN-México, Querétaro, 2021. 


\begin{abstract}
That is why this work aims to know the generalities and the toxic substances include those of the organic and inorganic type. Hence, those of the organic type can be ethanol, most of the medicines and poisons of both animal and vegetable and pharmacological origin. Regarding inorganics, we can consider heavy metals, as well as caustic toxins such as sodium hydroxide. Chemical exposure today in the social environment can be very aggressive in extremely low doses. Speaking of any chemical it can be toxic if it is consumed, ingested or absorbed in excess. This can be through food, water, air, or other sources. Therefore, individuals can respond to toxic chemicals in different ways since some are often more sensitive to a specific chemical and can be excessively dangerous. Toxicological effect when supplying plants such as castor, caper flower and giant in male wistar spraley rats.
\end{abstract}

\title{
Toxicology, Uses of plants, Adverse effects
}

\section{Resumen}

Dentro de las sustancias tóxicas se incluyen las del tipo orgánico e inorgánico. De ahí que las del tipo orgánico pueden ser el etanol, la mayor parte de los medicamentos y venenos tanto de origen animal como vegetales y farmacológicos. Respecto de los inorgánicos, podemos considerar los metales pesados, así como también los tóxicos cáusticos como el hidróxido de sodio. La exposición de los químicos hoy en día en el entorno social puede ser muy agresiva en dosis extremadamente bajas. Hablando de cualquier químico puede ser toxico si es consumido, ingerido o se absorbe en exceso. Ésta puede ser a través de la comida, agua, aire u otras fuentes. Por ende, los individuos pueden responder a los químicos tóxicos de diferentes maneras puesto que algunos suelen ser más sensibles a un químico especifico pudiendo ser excesivamente peligrosos. Es por ello que en este trabajo se pretende conocer las generalidades y el efecto toxicológico al suministrar plantas como son la higuerilla, flor de alcaparra y gigante en ratas wistar spraley macho.

\section{Toxicología, Usos de plantas, Efectos adversos}

\subsection{Introduction}

Nowadays the body responds when exposed to toxic substances, so it is important to ask ourselves what is toxic exposure and what is toxicology?

Toxicology is defined as "The science that deals with the study of poisons (toxins) and their effects", as Paracelsus says everything in excess is poison according to the dose. A poison "is more restrictive and should be reserved for substances that in any dose are harmful to the living organism; furthermore, any substance is toxic when it causes harmful health and/or lethal effects in very small doses either by "iatrogenic" poisoning, accidental suicide or in a planned manner when administered to a living organism" (Hodgson and Smart, 2008; Penningroth, 2010). The origins are remote, according to the Ebers Papyrus (1500) BC toxicology deals with the study of the adverse effects of xenobiotics (from the Greek, "xeno" (foreign) biotic (life) meaning compound foreign to life) of chemical agents that damage the organism.

Such a definition suggests that toxicology is an applied science; therefore, its study has a direct impact on society. In the words of "Gallo \& Dull": as medicine toxicology is both science and art, so that the role of the toxicologist is important in everyday life.

Today the toxicologist's involvement in different disciplinary areas of work ranges from environmental protection to the production of safe medicines with minimal side effects, the field of action in general is wide. He can be involved in the study of the toxic effects of chemical agents on man, in forensic science, the investigation of the role of chemical toxicants in the "safe" drug industry, agrochemicals, toxicants in legal cases as is the case in forensic toxicology whose main function is to identify, study and describe the doses, nature, incidence, severity, reversibility and mechanisms of toxic effects. In addition, it can also intervene in another area such as ecotoxicology which refers to toxic effects of chemical compounds in ecosystems and regulation of chemicals that are toxic, as well as the potential effects of toxic chemical agents in "everyday use" (Hodgson et al., 1998). 
It is also important to mention that toxicology as well as biochemistry, medicinal chemistry, pharmacology and applied biology are directly related to medicine for clinical diagnosis, treatment of poisoning and toxic effects of drugs, insecticides, herbicides, fungicides, etc., as high doses have a harmful impact on the organism and side effects are of great significance nowadays. Molecular biology, pharmacology, chemistry and forensic medicine are fundamental to toxicology, so much so that the progress of toxicology is directly related to the development of new methods in these sciences.

Thus, one of the branches of toxicology that is relevant to this research is forensic toxicology. In forensic toxicology, chemistry provides analytical methods for the study of toxicants and their metabolites, residue analysis and metabolism of toxicants. Biochemistry provides methods for the investigation of the metabolism and mechanism of action of toxicants, while molecular genetic biology, pharmacology and forensic medicine contribute methods for the investigation of the role of genes and gene expression in toxicity (Hodgson and Smart, 2008).

Hence, toxicants can be classified by their origin, physical state, target organ, chemical composition and mechanism of action. First, a toxicant is any physical radiation or chemical agent that, when in contact with a foreign agent or when absorbed by a living organism, can produce a direct or indirect adverse effect on it (Guitart, 2008).

In terms of their origin, they can be mineral, botanical or synthetic. By their physical state: liquid toxicants, dusty toxic solids, gaseous toxicants and volatile toxicants. As far as white organ solvents are concerned, there are hepatotoxic and nephrotoxic solvents. Then, according to their chemical composition, there are aromatic amines and halogenated hydrocarbons, and according to their mechanism of action, there are sulphhydryl inhibitors, cholinesterase inhibitors and metahaemoglobinaemia.

On the other hand, caustic poisons are those that cause destructive alterations by direct action on the skin and mucous membranes. Some are used for domestic use in sanitary cleaners and drains. Hence, the main ones are strong acids and alkalis. Therefore, acids include sulphuric acid, hydrochloric acid, nitric acid, oxalic acid, acetic acid, etc. With regard to alkalis, potassium hydroxide, sodium carbonate, etc. stand out.

In addition, within toxicology it is also important to mention biomarkers. There are three types: biomarkers of exposure of the organism to the toxic substance, biomarkers of the organism's response to the exposure, biomarkers of the organism's susceptibility to the chemical. These effects are properly included in toxicology, whereas endogenous generation of high levels of metabolic intermediates due to diseases or metabolic defects are not, and the effects on the organism may be similar (Smarth and Hodgson, 2008).

After mentioning the generalities of toxicology, another element to consider is toxic exposure. When one comes into contact with a toxicant one is said to be exposed to the chemical. In this regard, acute toxicity is often investigated in experimental animals such as rats. They are exposed to a toxic substance which is a chemical that can injure or kill a person, animal or plant: it is a poison. So the toxic effect is a fatal parameter, death.

Plants are known to be fundamental in the development of modern medicine. They are also essential to life by producing oxygen, regulating the water cycle and being the basis of food chains, nutrients, vitamins and industrial raw materials. They could even be part of the solution to future energy shortages by using plant residues to produce alcohol, thus moving from the petrochemical to the phytochemical era (Duke, 1985). However, many of these species are disappearing due to deforestation and the destruction of ecosystems in the environment. The need to live in harmony with nature is not only derived from moral or ethical convictions, but is based on the most elementary sense of survival.

Their preventive or curative action is due to chemical substances that have a physiological effect on the organism. These substances are known as active ingredients and are generally the product of the secondary metabolism of plants. Active ingredients have medicinal, preventive, health-enhancing and wellness-enhancing properties. Some act as antibiotics or antiseptics, others are sedatives or analgesics, they work as stimulants on the nervous system, or have neuromuscular or muscular activity, among other effects. The study of substances of natural origin that have medicinal properties is known as pharmacognosy, and the effect these substances have on the organism is studied in pharmacology. 
Phytochemistry makes it possible to detect and subsequently identify the active principles responsible for the properties attributed to plants. Chemists determine the presence or absence of the major groups of active substances, such as alkaloids, glycosides, quinones, etc., and proceed to their chemical isolation and characterisation. They then prepare extracts to test their physiological activity, and from the promising extracts they separate and purify the substances that constitute them (Domínguez 1976). The compounds are identified according to their physical and chemical properties, and their structure and configuration are studied.

Sources of reference on general aspects of phytochemistry include the works of Dominguez (1976) and Valencia (1995). The large-scale development of synthetic products, with characteristics similar to those of nature, was reflected in the decline in the use of herbal medicine for some decades. However, with the resurgence of various diseases, increasing incidence of cancer and the emergence of AIDS, the search for new substances was considered urgent (Huerta 1997).

Although the development - up to the commercial level - of new drugs from plants is very costly, and so are the programmes for synthesis of new active ingredients, many drugs are and will continue to be developed from plants traditionally used as medicines. Although the digestive properties of papaya have been known for centuries, it was not until the 1980s, when chymopapain was approved by the US Food and Drug Administration (FDA) to cure back problems, that the use of Lobelia pills to control smoking, long used by Native Americans, began: The use of pure active ingredients, isolated from the plant or synthesised, has the advantage of facilitating dosage and administration; however, it is sometimes less effective than the plant or its parts, as the interaction with other components of the plant enhances the therapeutic effects, which mobilises the absorption of the active substance.

It is necessary to emphasise that chemical synthesis has not been a great success for a natural compound, its properties and its behaviour in the human organism (Sarukhán, 1996). That end (Duke 1985). The higuerilla plant is characterised by its hardiness and adaptability to diverse topographical and climatological conditions, it commonly grows in arid regions with sandy soils and is known by the rural population as a weed without economic significance. However, due to the specific characteristics of its oil, it has emerged as a promising crop that generates high quality raw material for various industries worldwide (Franco, 1999).

In recent years, research into oilseeds and especially the higuerilla plant has undergone significant development in countries such as Brazil and Colombia, in which the public and private sectors have taken part, focusing efforts on developing varieties with specific characteristics for some areas, with better agronomic yields, offering the market certified seed, which guarantees production and product quality, as well as other possibilities of linking its cultivation with other production systems. Potential use of higuerilla by-products in animal feed. Uses of the leaves and stems. The leaves and stems of the higuerilla plant, although not suitable for consumption due to their toxic content of ricin and ricin, have a wide variety of uses, from the manufacture of paper or papyrus for handicraft purposes in Mexico (Escoto García, 2010). In addition to plants, they are essential for life by producing oxygen, regulating the water cycle and being the basis of food chains, nutrients, vitamins and industrial raw materials.

\subsection{Description of the method}

In this work, a series of actions were undertaken in a cross-sectional and longitudinal study. In addition, a quantitative and qualitative analysis was carried out. To this end, seven groups of animals were subjected to experimentation; in this case, wistar spraley rats plus a control, giving a total of eight groups. Each of the groups consisted of four rats placed in a cage, which were numbered from 1 to 4 . All the rats were male, with an average weight of 160 to $200 \mathrm{~g} / \mathrm{kg}$, which later reached a weight of $320 \mathrm{~g} / \mathrm{kg}$ during the time of the experiment. They were administered orally for two months with three types of toxic substances: higuerilla, gigante and caper flower, in order to determine their effect on organs such as the stomach, kidney and liver.

The extracts of these plants were used, all in $500 \mathrm{ml}$ of water. This was done in the following way: 
Figure 10.1 Plant and dose administered by Group

\begin{tabular}{|l|l|}
\hline Group & Plant and dose administered per group \\
\hline Group 1 & Caper flower $10 \mathrm{ml}$ \\
\hline Group 2 & Caper flower $15 \mathrm{ml}$ \\
\hline Group 3 & Higuerilla $10 \mathrm{ml}$ \\
\hline Group 4 & Giant $10 \mathrm{ml}$ \\
\hline Group 5 & Caper Flower $10 \mathrm{ml}$ \\
\hline Group 6 & Caper flower $20 \mathrm{ml}$ \\
\hline Group 7 & Caper flower $30 \mathrm{ml}$ \\
\hline
\end{tabular}

Source: Own research

First, the initial weight of the animals was recorded before the substances of interest were administered to each of the experimental groups, including the control group. After that, a dose containing the substance of interest was given orally to each of the groups and they were weighed again every week. After two months ( 8 weeks), the animals were sacrificed. An analysis was then made to see the variation in the weight of each of the above-mentioned organs as a function of the dose for each of the exposed animals, before and after the toxic substances were administered.

In this way, during the eight weeks, the effect of toxic herbs such as higuerilla, gigante and caperflower on the organs of these species was studied. They were also visualised daily in order to keep a record of their weight as well as their weight loss, depletion, clinical signs and symptoms of toxicity.

\subsection{Analysis from demand curve regression}

\subsection{Results}

During the eight weeks of experimentation, there was an increase in weights. Depressed weights were observed due to toxic effects of giant, figwort and caperflower.

In this context in acute toxicity studies, the mean dose is referred to as the mean lethal dose or LD50, it is important to mention that the mean lethal dose is a statistical dose, not an actual dose. It is derived from the acute toxicity studies mentioned above, where half of the test animals die and half survive.

When reporting the LD50, both the species of the test animals and the route of exposure should be noted, because both are determining factors in determining the LD50. For example, the LD50 for the giant in rats exposed by the route of oral ingestion is reported as follows: LD50 oral, rat. It is very important to mention that separate toxicity tests should be performed for each of the 4 routes of exposure, for which human exposure to chemical agents is expected: ingestion, inhalation, and/or dermal absorption (Penningroth, 2010). A chronic toxicity test in small mammals can cover the entire lifespan of the adult of the test species, two years in mice and two and a half years in rats. Carcinogenicity tests of a chemical agent (potential carcinogen) are chronic toxicity tests, designed for the entire adult life of the test animals. The above exposures manifest themselves in a wide variety of ways, including certain diseases such as cancer, peptic ulcers and reproductive effects, to name but a few. In addition, xenobiotics can have diverse effects at different doses (Smarth and Hodgson, 2008). Subchronic toxicity, as opposed to exposure time in acute toxicity testing, involves repeated doses of the chemical being tested, usually administered over a period of approximately 60 days.

Likewise, when a foreign substance enters the organism, biotransformation plays an important role in reducing or increasing possible toxic effects, so that, just as harmful substances are deactivated, or deprived of their harmfulness, less toxic compounds can be transformed into harmful ones, which are then eliminated after a detoxifying process (Repetto, 2009). The activity of the different metabolic pathways determines the effective concentration of the active metabolism. The use of the leaves and stems of the higuerilla plant, although not suitable for consumption due to its toxic ricinine content, has a wide variety of uses such as the manufacture of handmade paper or papyrus, and the feeding of worms produced in Mexico (Escoto García.2010). Gigante, other common names guayacán, palo blanco, tabaco cimarrón, tabacón, virginio Name: the giant plant. 
Other common names guayacán, palo blanco, tabaco cimarrón, tabacón, virginio. Scientific name: Nicotiana glauca Graham Family: SOLANACEAE low-branching shrub growing up to $6 \mathrm{~m}$ tall, with grey-green or bluish-green stem and foliage, yellow flowers, with more or less cylindrical calyx and corolla.

As the data obtained were analysed, it would be expected that, by providing the same substance in an experimental group, the increase or decrease in the weight of each of the internal organs would be in a similar proportion, however, there was variability in the results. We know that each organism is different and will react differently to the supply of these substances.

The data obtained are shown below. We will start with a comparison of the weights of the different study groups.

Graphic 10.1 Initial weight of the working groups

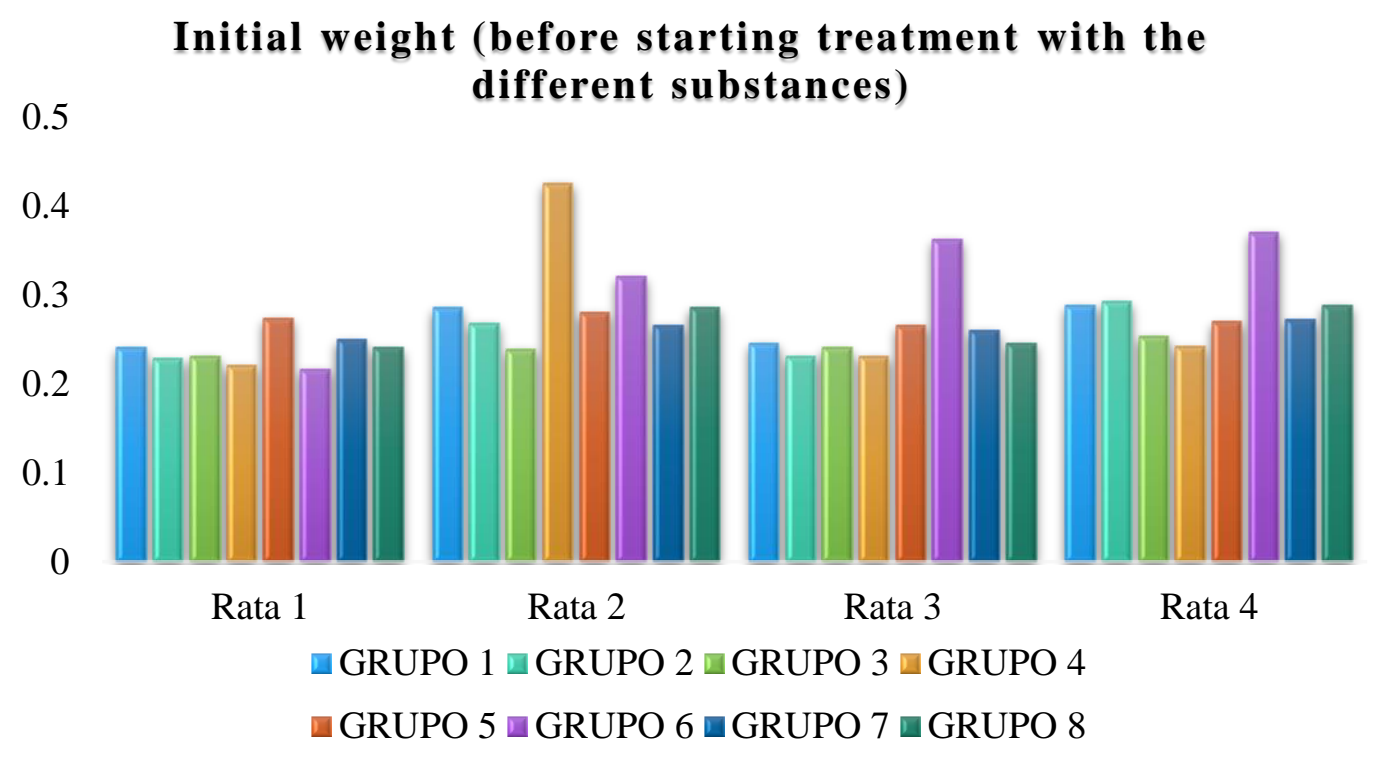

Source: Own research

This analysis, before starting treatment with the different substances, shows that the weights of the rats vary slightly, with the exception of group 6 , where three of them have a higher weight than the rest. In group 4, one of them. The most frequently repeated value is $0.240 \mathrm{~kg} / \mathrm{weight}$.

However, if we look at graphic 10.2, which shows the final weight, the variations found are in groups 6 and 7, where the weight increased when caper flower was given in doses of 20 and $30 \mathrm{ml}$. However, the value that is most frequently found in the sample is $0.246 \mathrm{~kg} / \mathrm{weight}$, so its modification was not significant, except for the cases mentioned above. 
Graphic 10.2 Final weight of the working groups

\section{FINAL WEIGHT (AFTER SUPPLYING THE SUBSTANCE)}

0.5

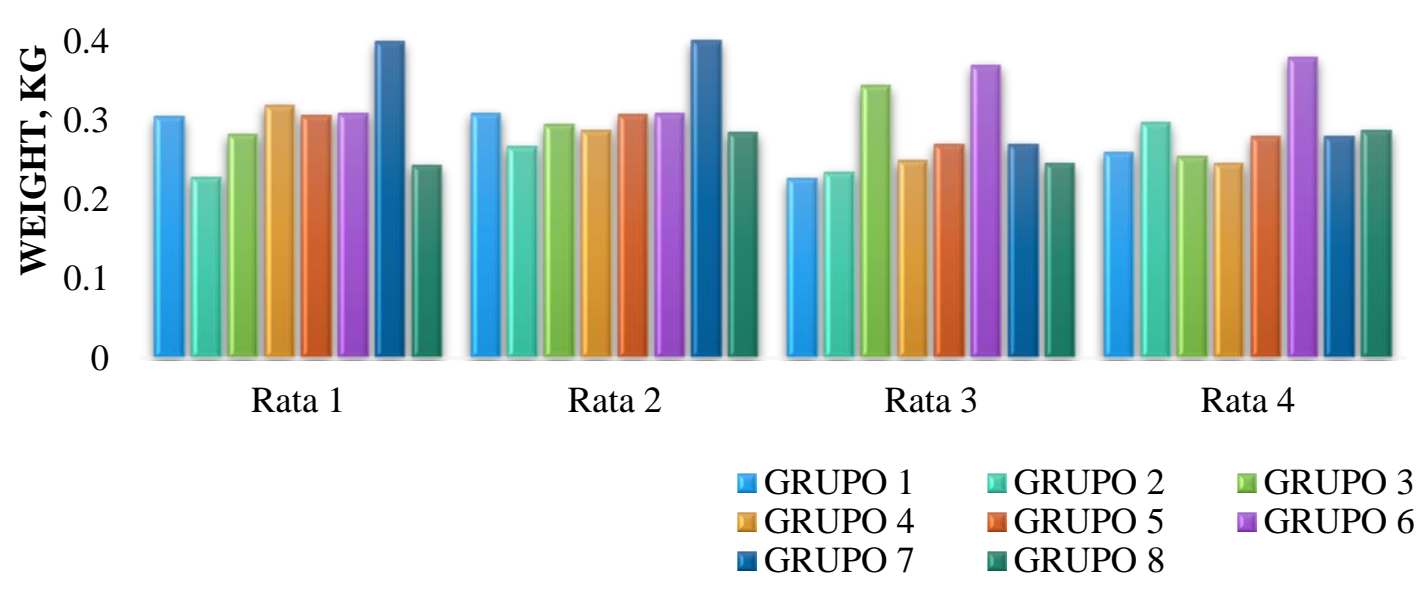

Source: Own research.

It is important to mention that group 8 as a control is only supplied with distilled water and in the graph below we compare group 1 (caper flower, $10 \mathrm{ml}$ ) and group 8 in order to observe the changes in weight after the time of experimentation in the supply of the substances. In the latter group the possible variations in weight are almost imperceptible, of a few decimal places. Therefore, a constant weight is maintained.

Graphic 10.3 Comparison of the initial weight between groups 1 and 8

\section{GROUP 1 Vs GROUP 8}

$$
0.35
$$
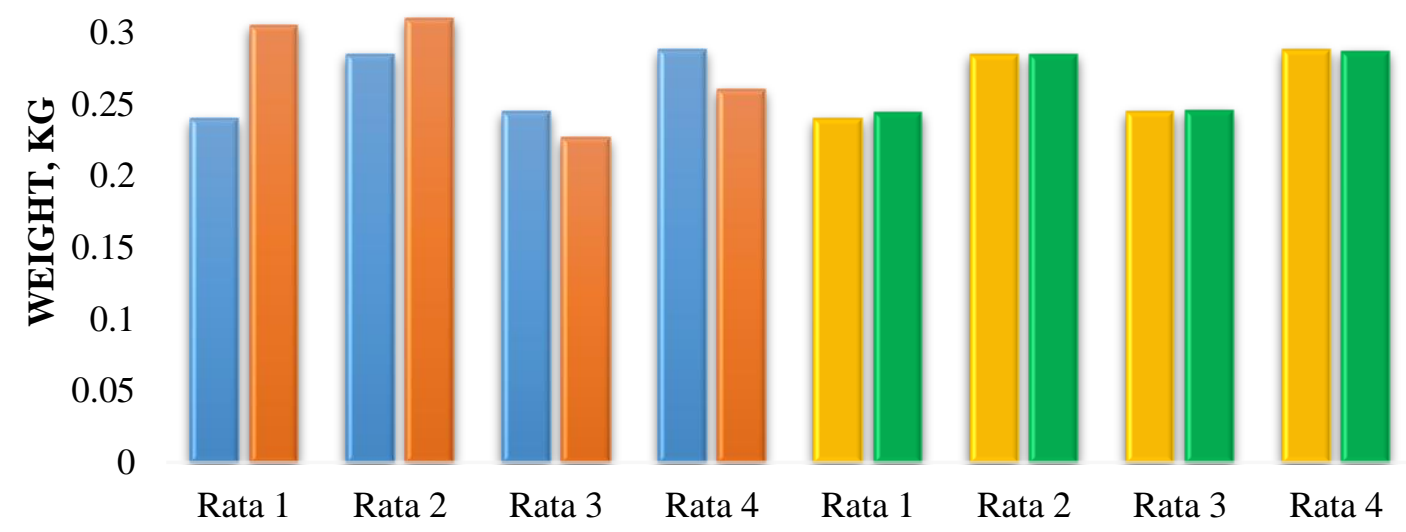

口Peso inicial $\square$ Peso después de 2 meses

Source: Own research

Liver

When examining the results concerning liver weight, in group 1 and 2 where caper flower was administered in doses of 10 and $15 \mathrm{ml}$ respectively, the liver had a considerable decrease in weight. This could be attributed to their heterogeneity and the effect of the doses on the species, environmental factors, differences in the organisms, as well as the effects of the toxicity of the active ingredients in each of the rats. Some toxicants cause symptoms within seconds, while others cause symptoms only after several hours, days or even years. Others do so by causing obvious symptoms before they have caused damage to vital organs, such as the kidneys or liver, sometimes permanently. 
Graphic 10.4 Liver analysis, group 1

\section{GROUP 1, LIVER ANALYSIS}

$$
0.35
$$
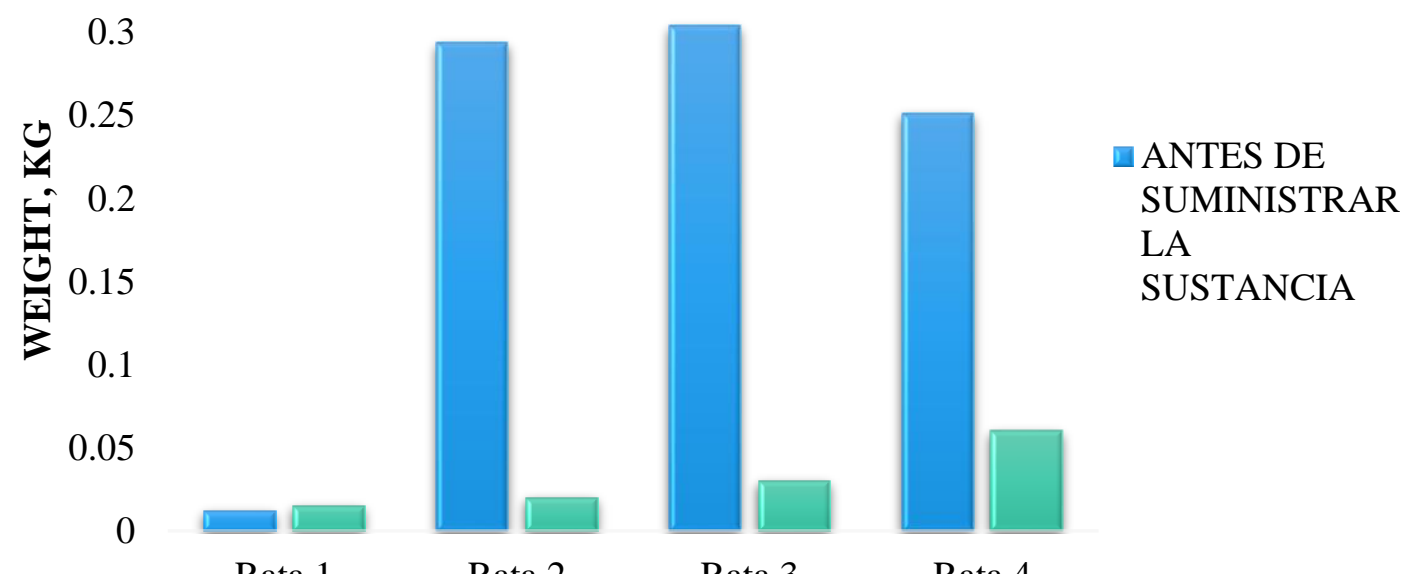

Rata 1

Rata 2

Rata 3

Rata 4

Source: Own research

Graphic 10.5 Liver analysis, group 2

\section{GROUP 2. LIVER ANALYSIS}

0.3

0.2

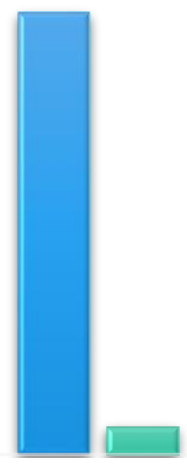

Rata 3

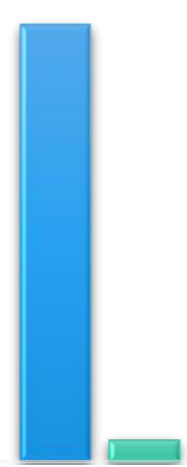

Rata 4
- ANTES DE SUMINISTRAR

LA SUSTANCIA

口 DESPUÉS DE SUMINISTRAR

LA SUSTANCIA

Source: Own research.

For group 3 the substance supplied was $10 \mathrm{ml}$ of higuerilla and in this group the liver weight was not affected to a great extent, but in group 4 where the giant was used, the weight of the liver increased notoriously. 
Graphic 10.6 Liver analysis, group 3

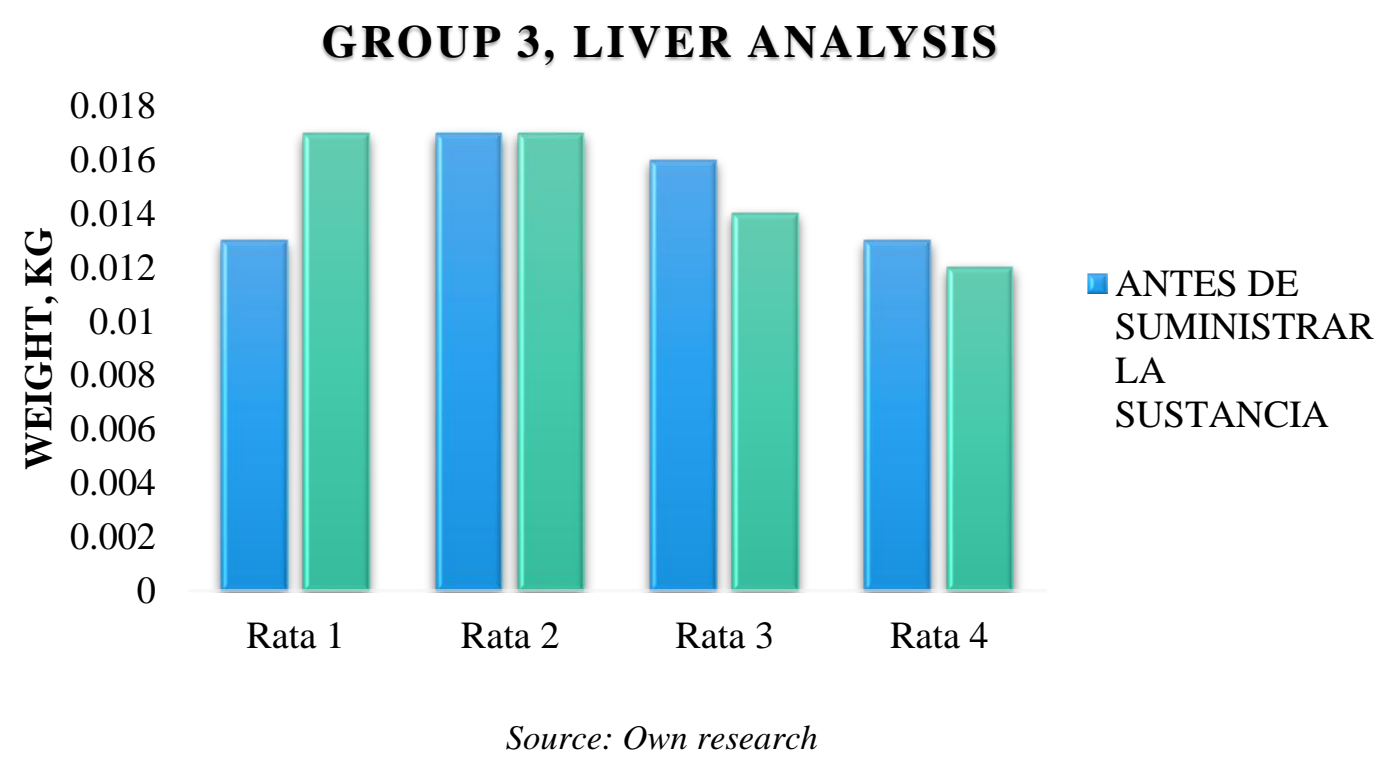

Graphic 10.7 Liver analysis, group 4

\section{GROUP 4, LIVER ANALYSIS}

0.025

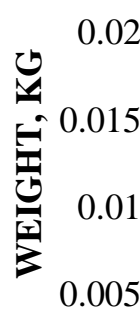

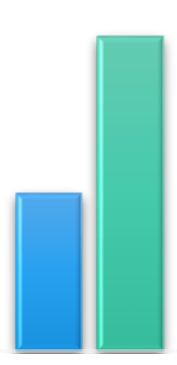

Rata 1

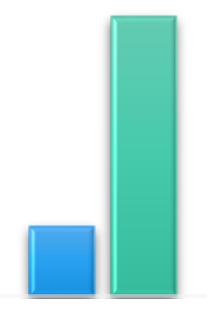

Rata 2

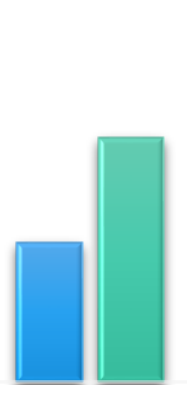

Rata 3

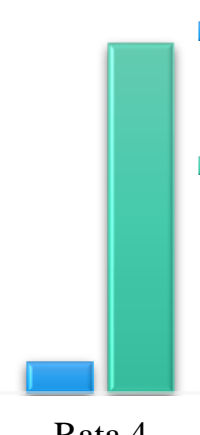

Rata 4
- ANTES DE

SUMINISTRAR LA

SUSTANCIA

口 DESPUÉS DE

SUMINISTRAR LA

SUSTANCIA

Source: Own research.

In group 5 again $10 \mathrm{ml}$ of caper flower was used. It is observed that there is a considerable decrease in two of their species after administering the substance.

Graphic 10.8 Liver analysis, group 5

\section{GROUP 5, LIVER ANALYSIS}

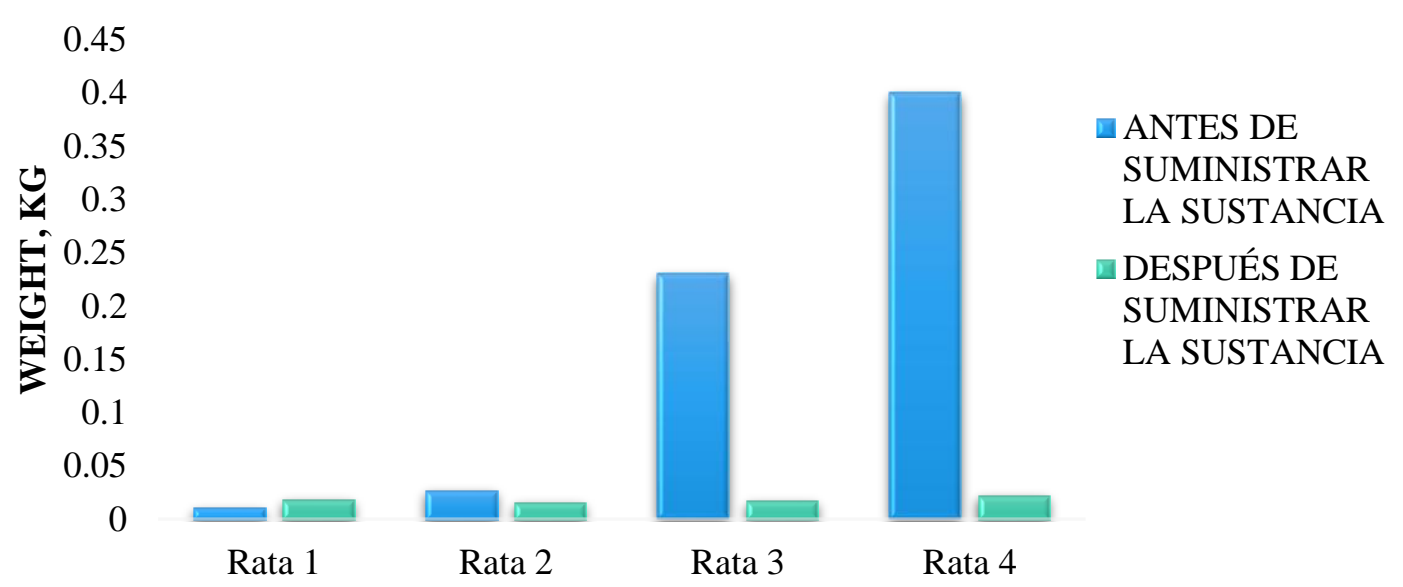

Source: Own research 
For group 6 (20 ml caper flower) the weight is higher in three of the species, with number 2 showing a considerably different weight before and after the supply of the substance. While in number 1 there is no considerable change.

Graphic 10.9 Liver analysis, group 6

\section{GROUP 6, LIVER ANALYSIS}

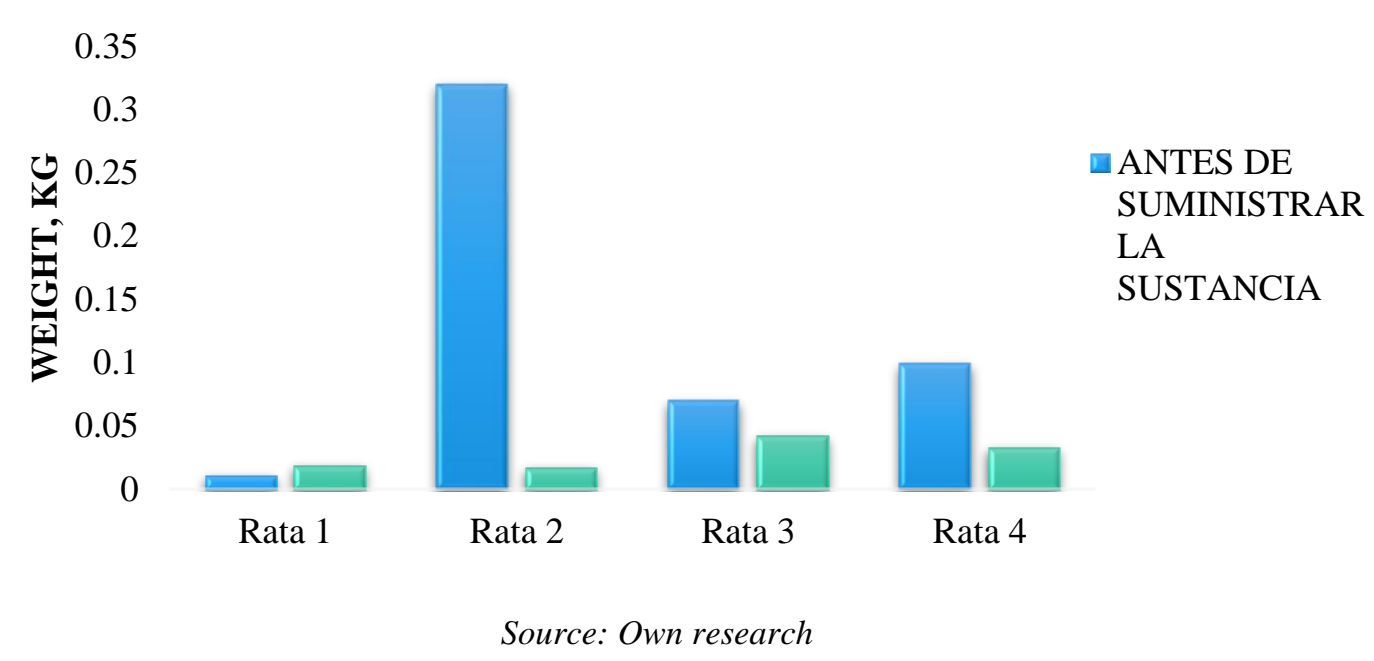

As for group 7 ( $30 \mathrm{ml}$ caper flower), also in this group the species marked as number 2 shows a significant difference, as the weight of its liver decreased considerably, unlike the other 3 , where it was very similar.

Graphic 10.10 Liver analysis, group 7

\section{GROUP 7, LIVER ANALYSIS}

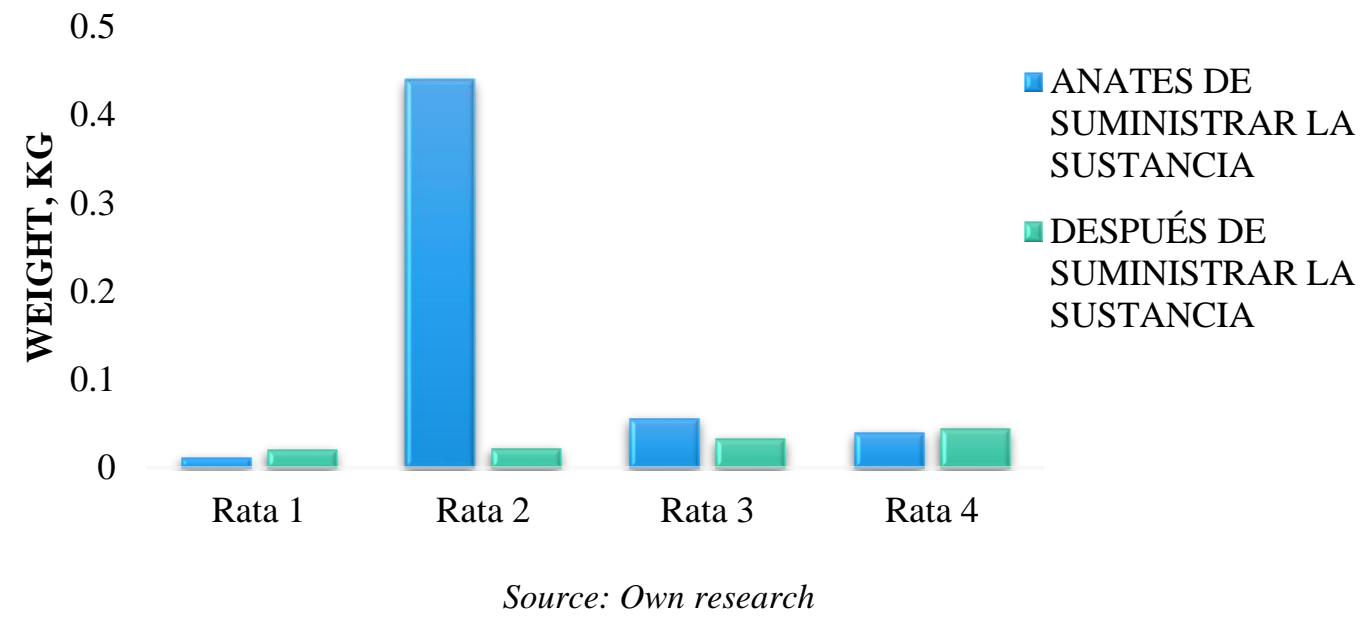

This was not the case in group 8, which was supplied with distilled water. Here three of the rats decreased their weight considerably while one increased it by 5 percentage units. A surprising aspect of metabolism is that the system itself alters the chemicals to allow their efficient elimination from the body. 
Graphic 10.11 Liver analysis, group 8

\section{GROUP 8, LIVER ANALYSIS}

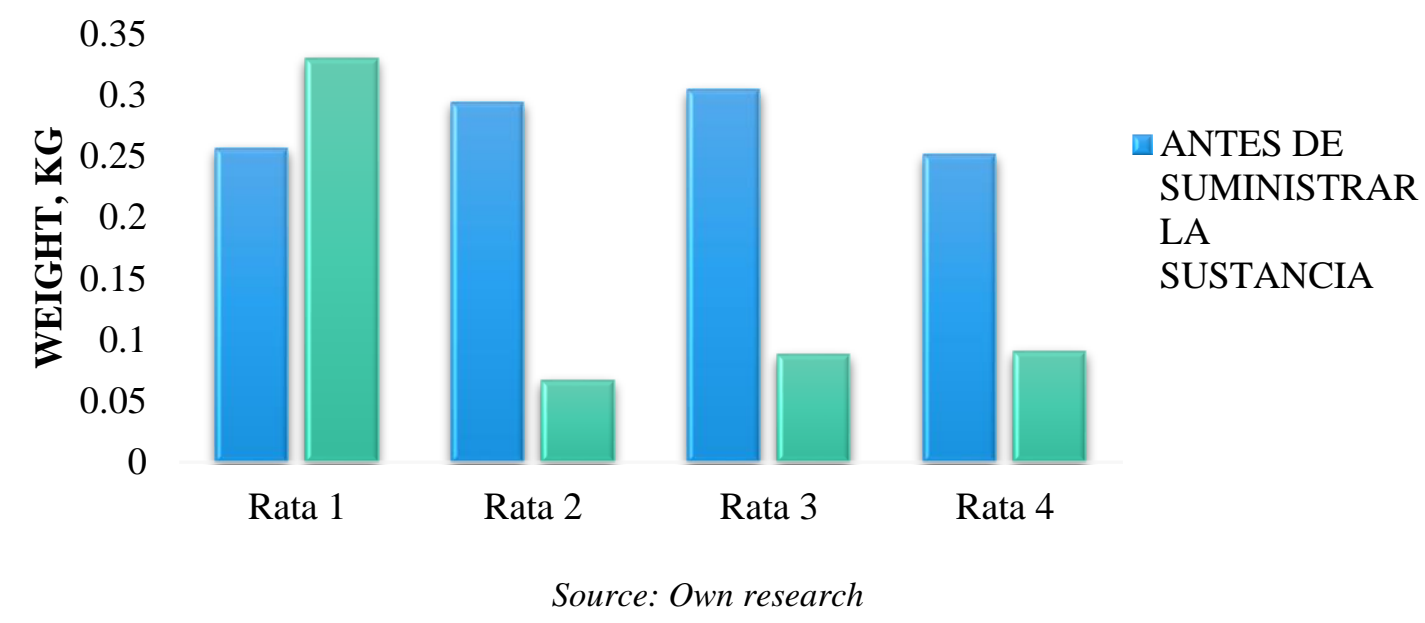

\section{Kidney}

Free radical formation increases as a consequence of the toxicity of a wide range of xenobiotics. A large number of chemical compounds, in order to exert their toxic action, require metabolic activation to reactive intermediates that can generate free radicals (Plant, 2003). Caustic or irritant substances injure the mucous membranes of the mouth, throat, gastrointestinal tract and lungs, causing pain, coughing, vomiting and shortness of breath. When observing the results obtained in the kidney, again when caper flower was administered (group 1 and 5 with $10 \mathrm{ml}$ ) one or two rats increased in size, likewise in group 2 with $15 \mathrm{ml}$ of caper flower the same tendency was observed. The rest of the species in these groups do not.

Graphic 10.12 Kidney analysis, group 1

\section{GROUP 1, KIDNEY ANALYSIS}

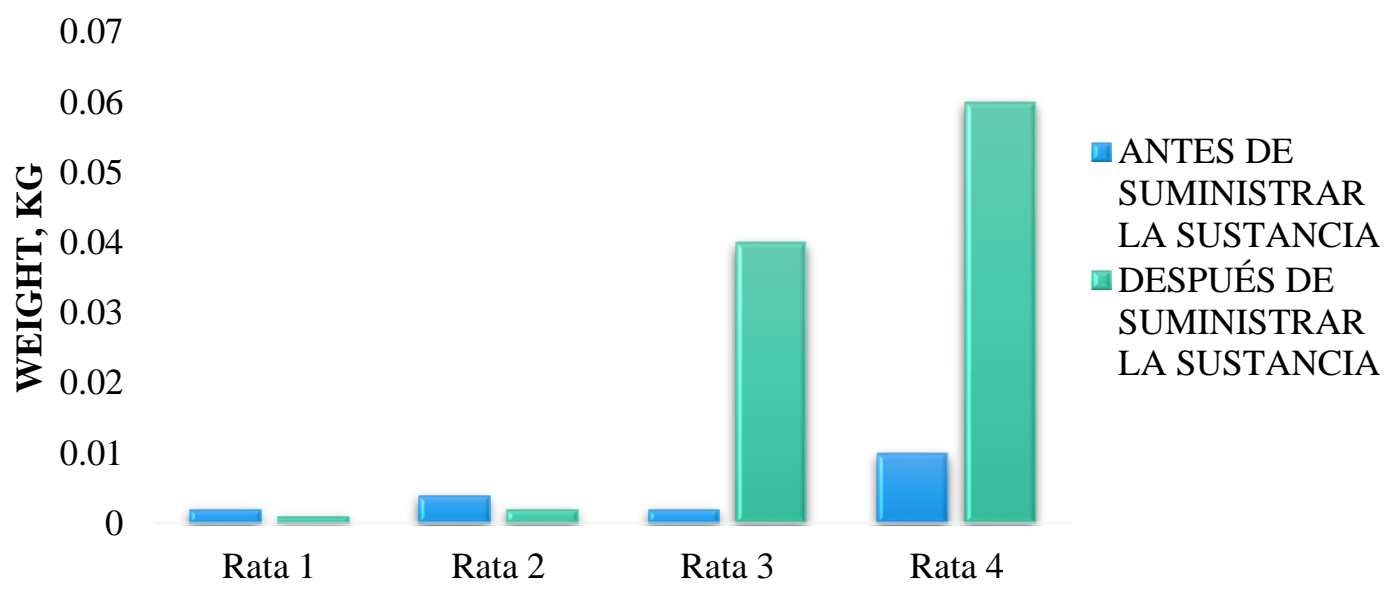

Source: Own research 
Graphic 10.13 Kidney analysis, group 2

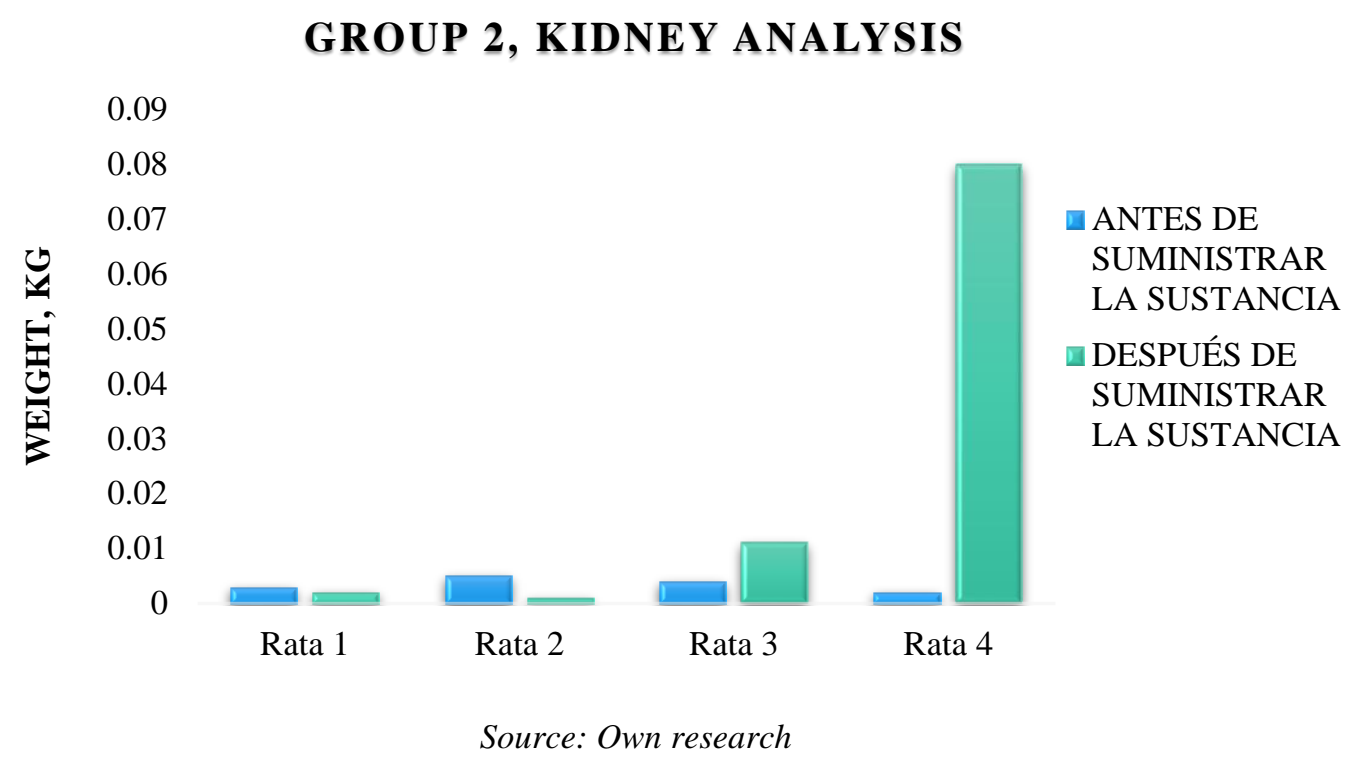

For group 3, a decrease is observed when treated with higuerilla, while in the group that was supplied with giant fig (group 4), a slight increase is observed in 3 of the species.

Graphic 10.14 Kidney analysis, group 3

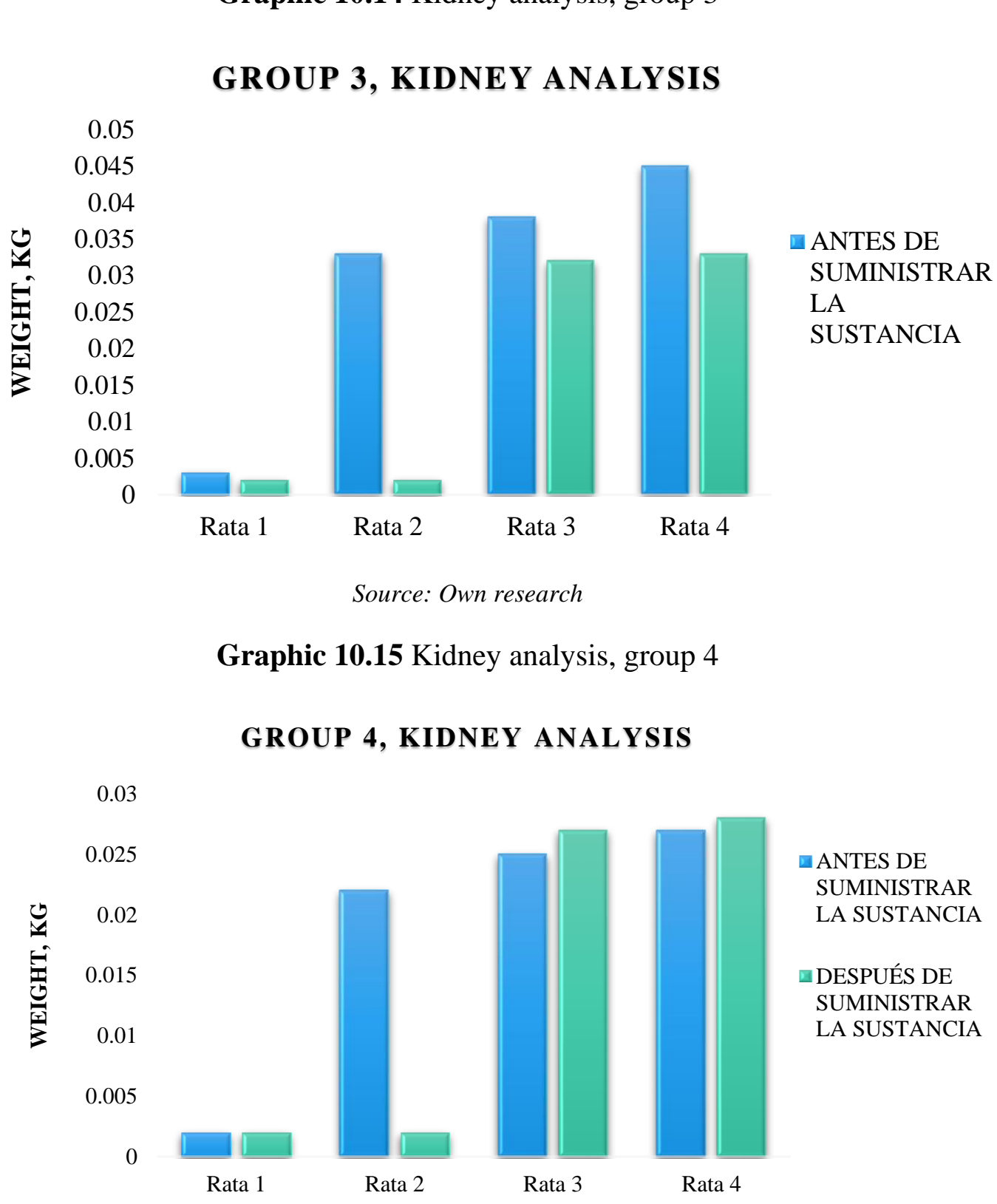

Source: Own research 
In groups 6 and 7, on the other hand, the decrease is notorious.

Graphic 10.16 Kidney analysis, group 5

\section{GROUP 5, KIDNEY ANALYSIS}

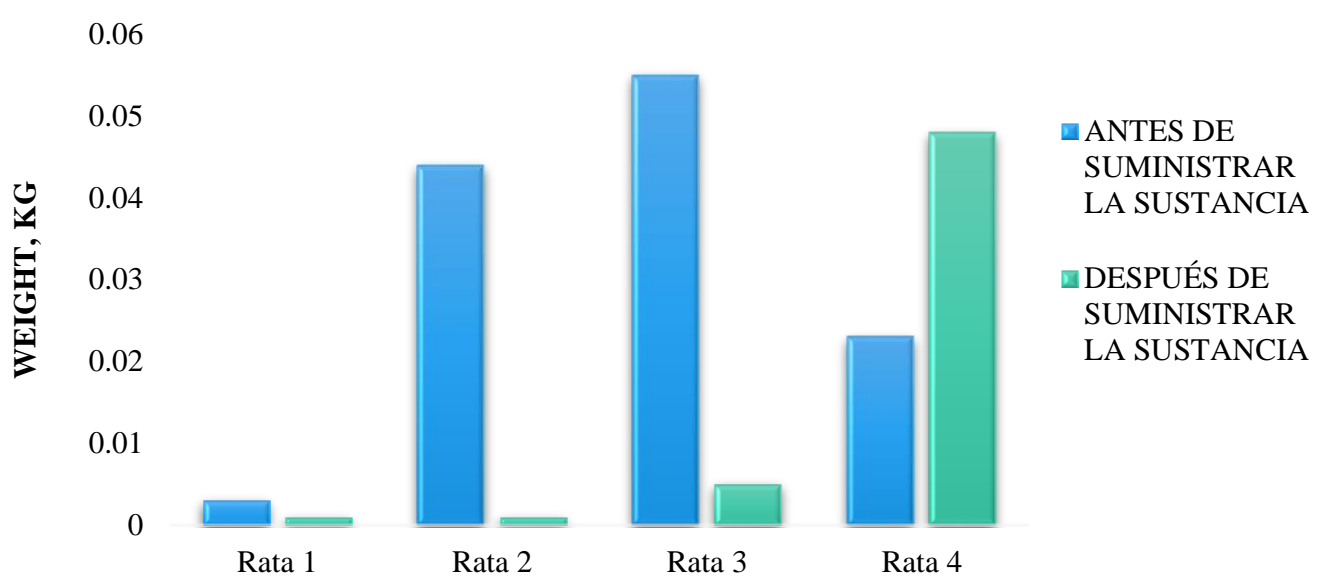

Source: Own research

Graphic 10.17 Kidney analysis, group 6

\section{GROUP 6, KIDNEY ANALYSIS}
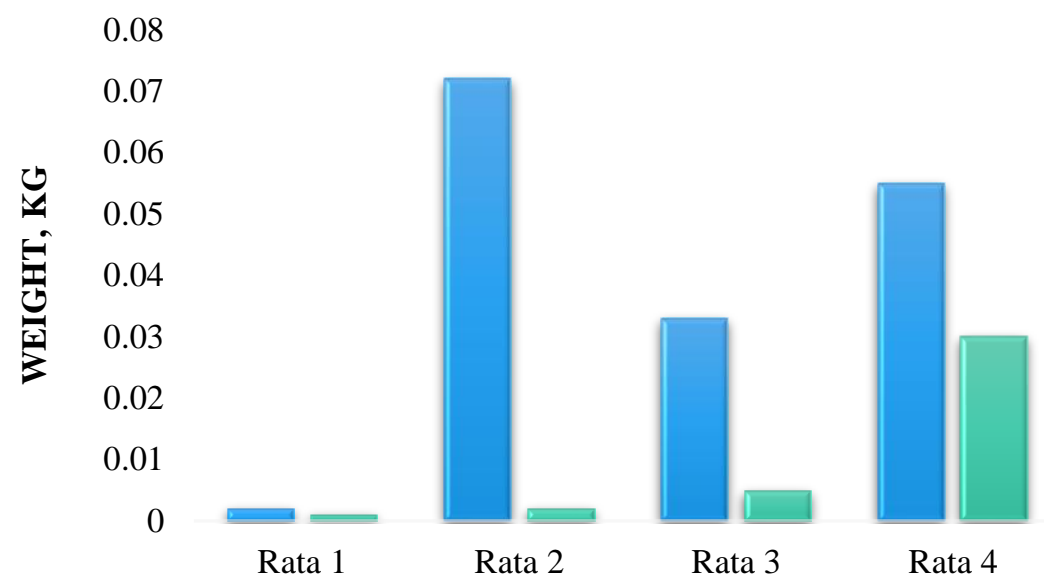

- ANTES DE

SUMINISTRAR

LA SUSTANCIA

- DESPUÉS DE

SUMINISTRAR

LA SUSTANCIA

Source: Own research

Graphic 10.18 Kidney analysis, group 7

\section{GROUP 7, KIDNEY ANALYSIS}
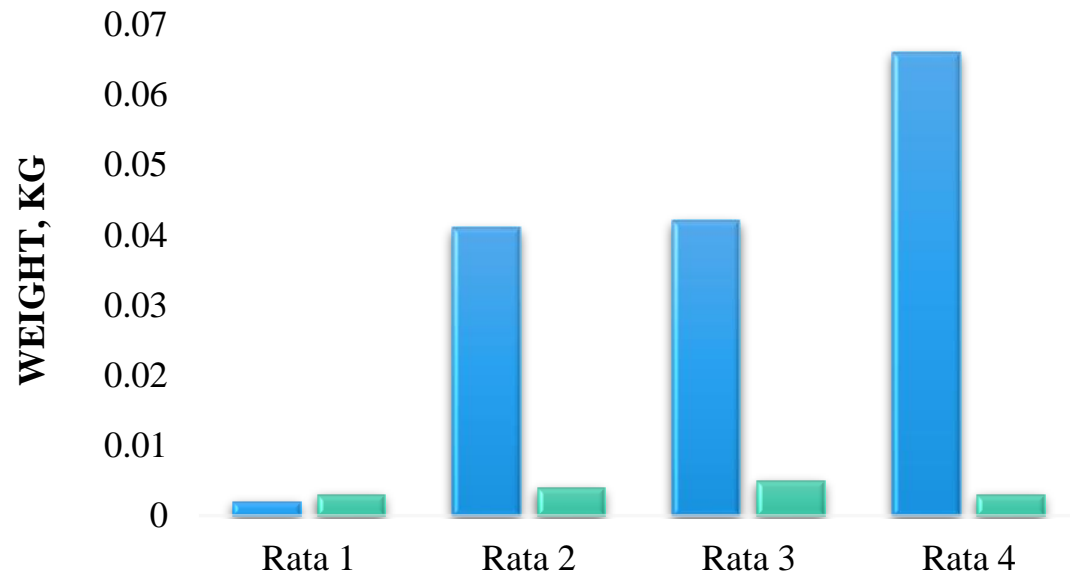
$\square$ ANTES DE
SUMINISTRA
R LA
SUSTANCIA
SUMINISTRA
R LA
SUSTANCIA

\section{Rata 3}

Rata 4

Source: Own research 
Graphic 10.19 Kidney analysis, group 8

\section{GROUP 8, KIDNEY ANALYSIS}

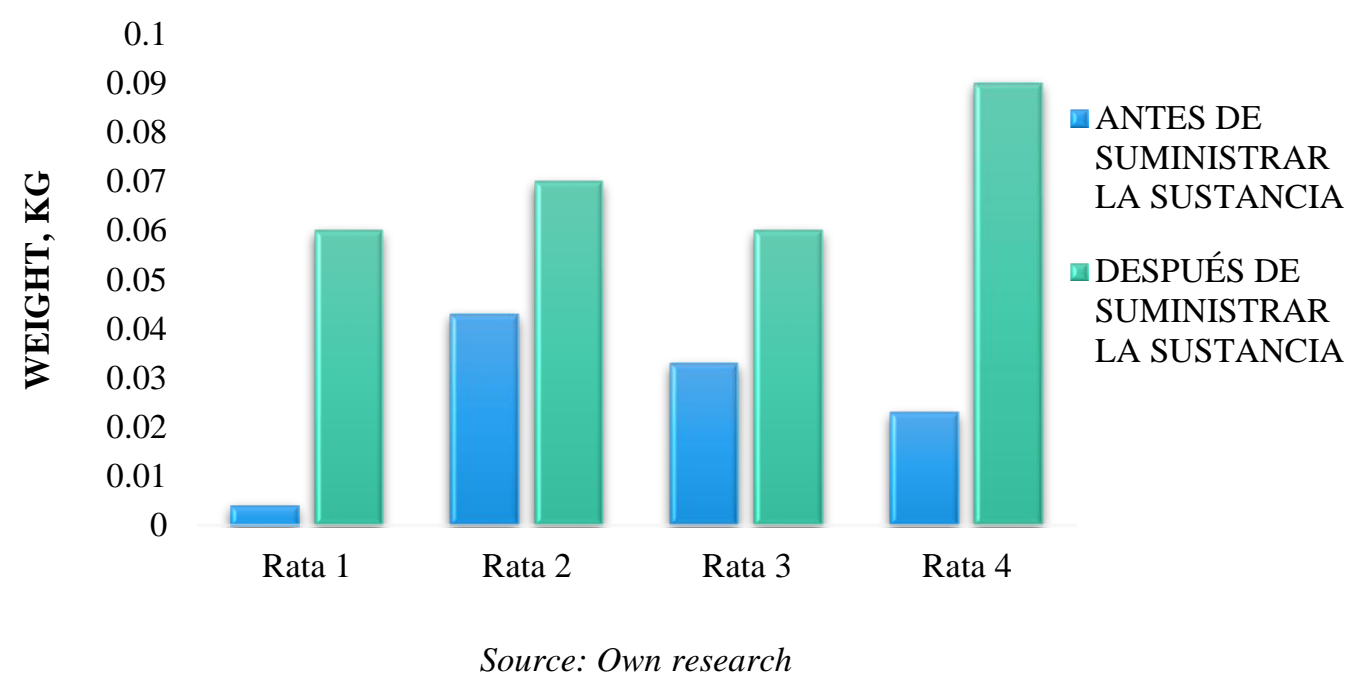

However, for the group treated with distilled water alone (group 8) the kidney size increased considerably.

\section{Stomach}

A striking aspect of metabolism is that the system itself alters chemicals to allow their efficient elimination from the body, it can also produce numerous chemical species that may be toxic to the cell (bioactivation). These species can be divided into two general categories, reactive intermediates formed from the metabolism of a chemical agent (e.g., large chemical structures with reactive groups) and small chemically reactive species released during metabolism (e.g., small mono- or diatomic species) (Smart and Hodgson).

When the different working substances were tested, the effects on the stomach were as follows:

In groups 1, 2, 5, 6 and 7, although caper flower was administered in all cases, only groups 1, 2 and 6 showed increases in the weight of the caper flower. For the block corresponding to group 5, the increase was not so pronounced. However, in group 7 there was a decrease in only two species, while in the remaining ones the weight remained constant.

Graphic 10.20 Stomach analysis, group 1

\section{GROUP 1, STOMACH ANALYSIS}

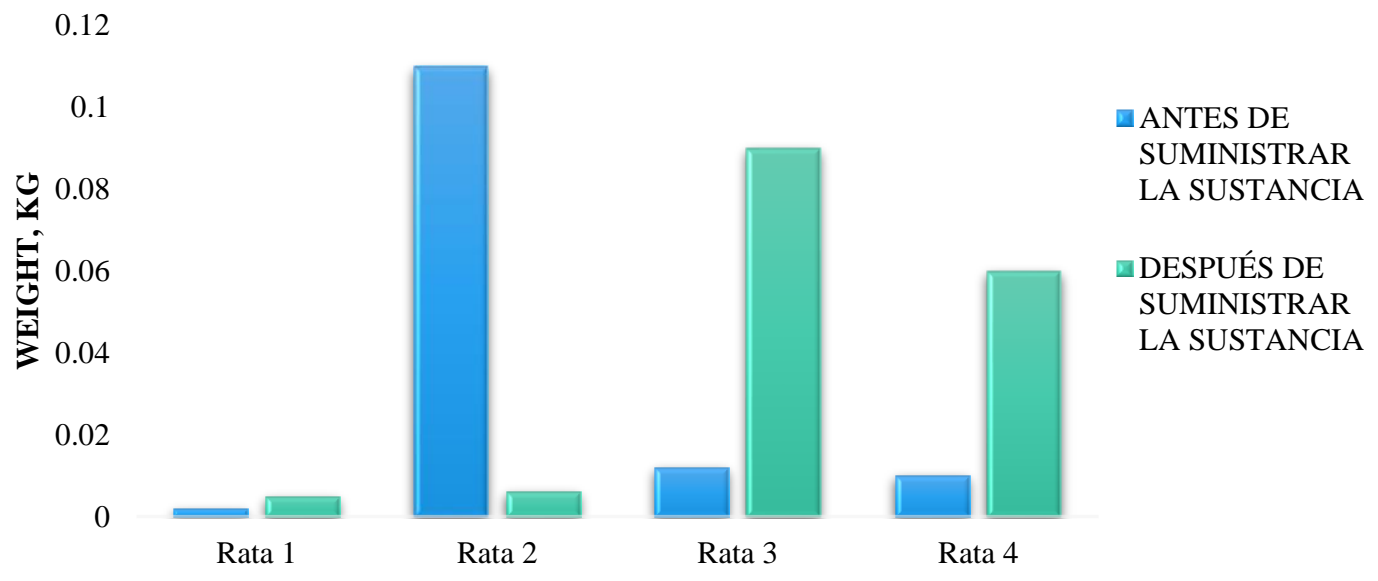

Source: Own research 
Graphic 10.21 Stomach analysis, group 2

GROUP 2, STOMACH ANALYSIS

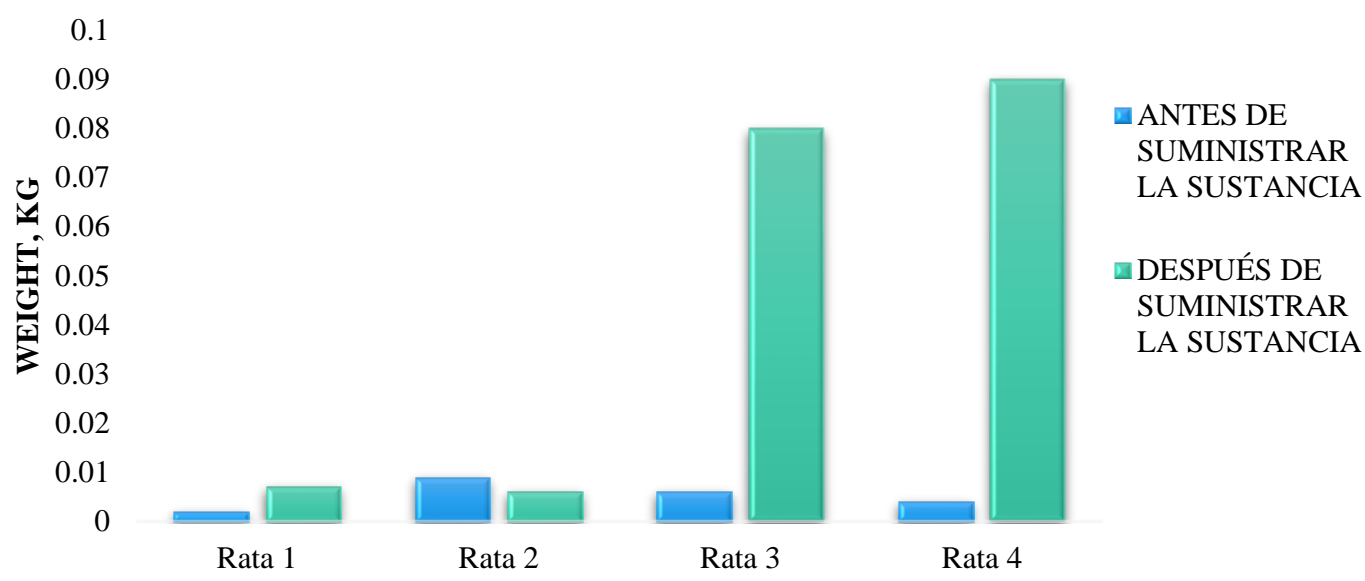

Source: Own research

Graphic 10.22 Stomach analysis, group 3

\section{GROUP 3, STOMACH ANALYSIS}

0.08

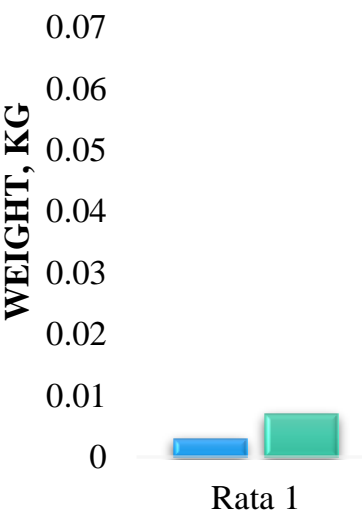

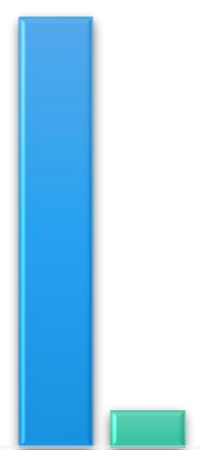

Rata 2

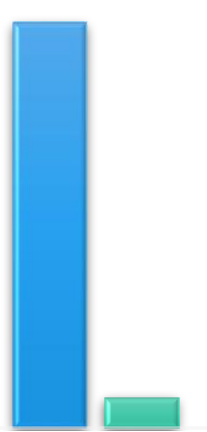

Rata 3

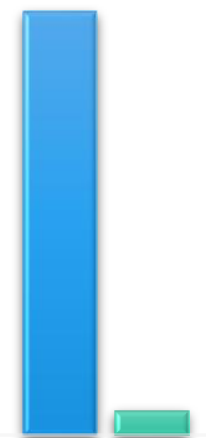

Rata 4
口 ANTES DE

SUMINISTRAR

LA SUSTANCIA

DESPUÉS DE

SUMINISTRAR

LA SUSTANCIA

Source: Own research

Graphic 10.23 Stomach analysis, group 4

\section{GROUP 4, STOMACH ANALYSIS}

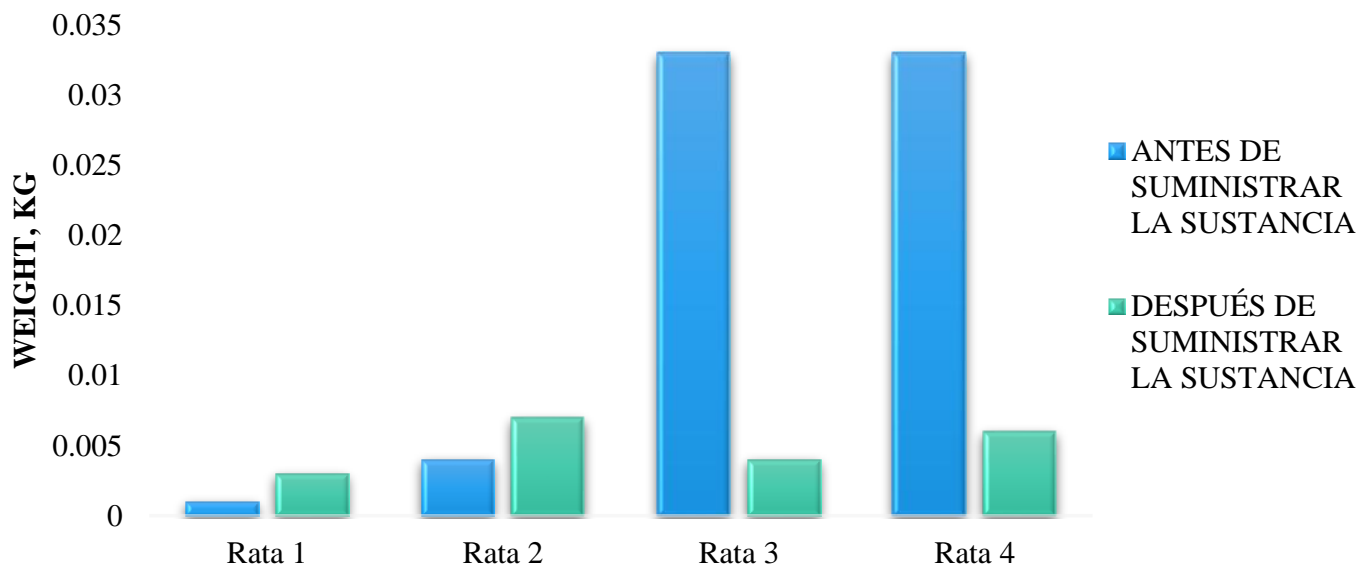

Source: Own research

In the case of groups 3 and 4, the decrease is very noticeable. 
Graphic 10.24 Stomach analysis, group 5

\section{GROUP 5, STOMACH ANALYSIS}

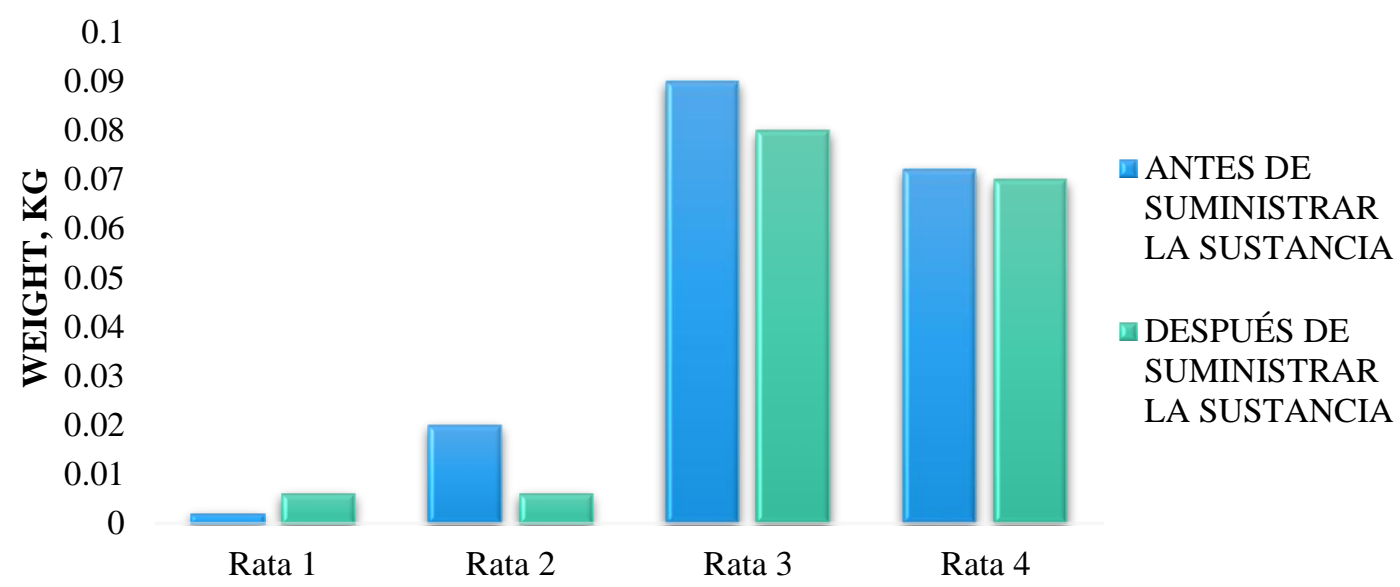

Source: Own research

Graphic 10.25 Stomach analysis, group 6

\section{GROUP 6, STOMACH ANALYSIS}

0.12

0.1

0.08
0.06
0.006

0.02

0

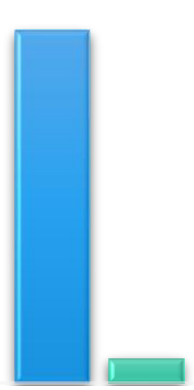

Rata 2

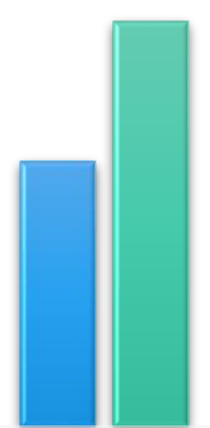

Rata 3

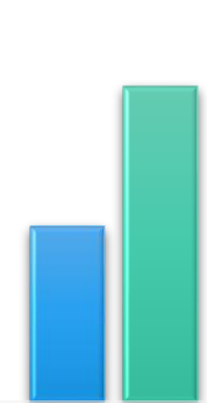

Rata 4
ANTES DE

SUMINISTRAR

LA SUSTANCIA

■DESPUÉS DE

SUMINISTRAR

LA SUSTANCIA

Source: Own research

Graphic 10.26 Stomach analysis, group 7

\section{GROUP 7, STOMACH ANALYSIS}

0.6

0.5

0.4
0.3
0.0 .3

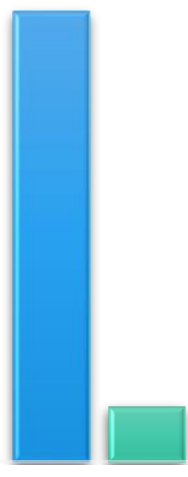

Rata 3
ANTES DE

SUMINISTRAR

LA SUSTANCIA

匹 DESPUÉS DE

SUMINISTRAR

LA SUSTANCIA

0.1

Rata 1
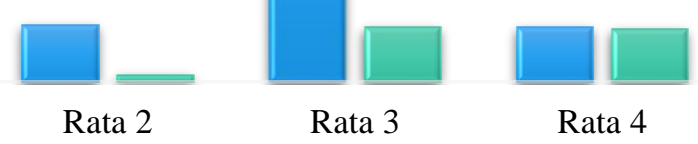

Rata 4

Source: Own research 
Graphic 10.27 Stomach analysis, group 8

\section{GROUP 8, STOMACH ANALYSIS}

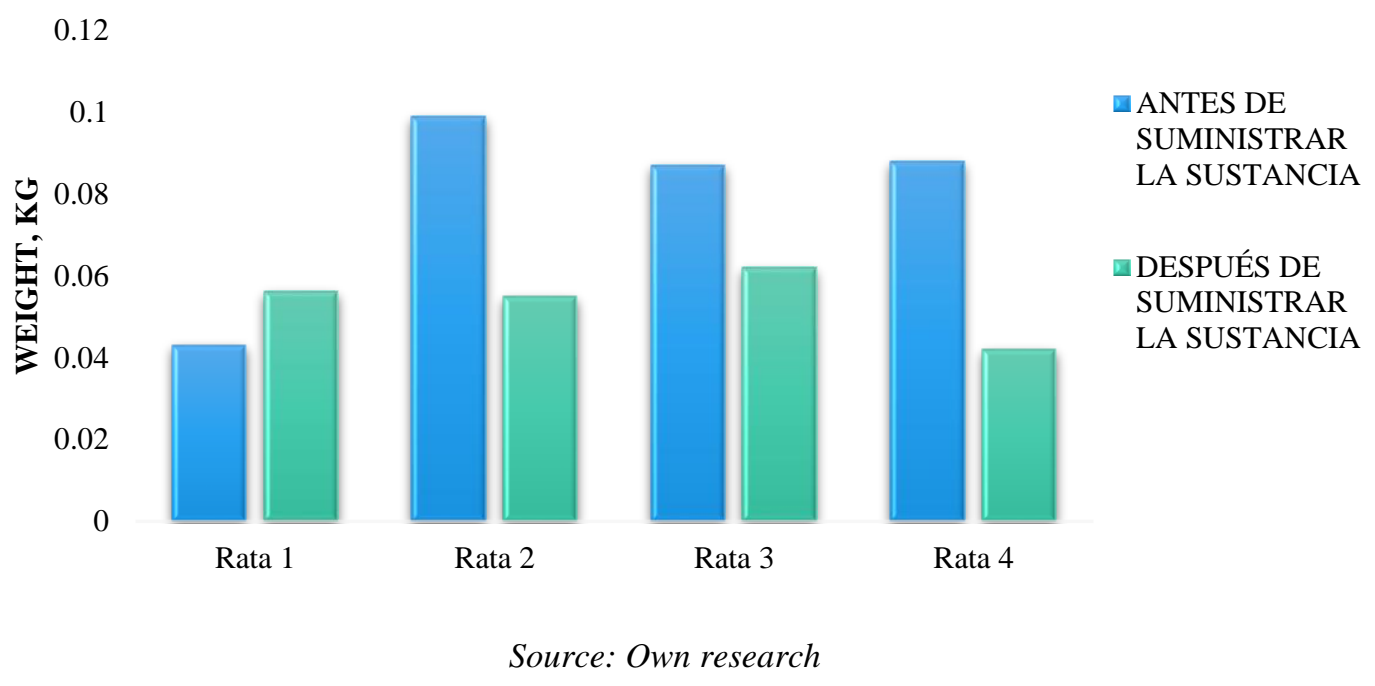

For the species in the distilled water supply group, the size of the distilled water decreases to almost half of its normal size in 3 of the rats. In one of them there is a slight increase.

\subsection{Acknowledgements}

To the authors, the anonymous reviewers and the editor for their valuable suggestions to improve the document, as well as the informants of the participation, authorities of the Academic Unit of Chemical Sciences Area of Health Sciences of the Universidad Autónoma Zacatecas.

\subsection{Conclusions}

It is important to mention that when a foreign substance enters the body, biotransformation plays an important role in reducing or increasing possible toxic effects. Particularly in this study, variability in results was observed when different poisonous plants were fed to the same working group. This could be attributed to the difference in organisms and thus the reaction to each toxic substance would also be different, so that the system would be altered, producing some effect on the increase or decrease in the weight of the different organs analysed. It is important to mention that these plants in our case could be harmful to these organisms, however, at some point they could be a promising option for cultivation due to the type of soil and environmental conditions, generating a benefit by being included in the market for use in various economic sectors.

\subsection{References}

Anderssona, E. F; Eversona, T. \& Everson, C. S. (2012). Management of oil producing Jatropha curcas silvopastoral systems: Risk of herbivory by indigenous goats and competition with planted pastures. School of Life Sciences.

El uso de las plantas medicinales en las comunidades maya-chontales de Nacajuca, Tabasco, México. Polibotánica, Magaña AMA. 2012. Etnobotánica de las plantas medicinales en los huertos familiares de Tabasco, En Mariaca R. El huerto familiar del sureste de México. Ed. Secretaría de Recursos Naturales y Protección Ambiental del Estado de Tabasco y El Colegio de la Frontera Sur, México.

Ethnologue: Languages of the World, Nineteenth edition. Dallas, Texas, USA. López A. 1984a. Textos de medicina náhuatl. UNAM, México DF, México. López A. 1984b. Cuerpo humano e ideología. Las concepciones de los antiguos nahuas. Ed. Instituto de Investigaciones Antropológicas, UNAM, México DF, México. López A. 1996. 
La cosmovisión mesoamericana. En Lombardo S, Nalda E. Temas mesoamericanos, INAH/CONACULTA, México, Lot A, Chiang F. 1986. Manual de herbario. Consejo Nacional Flora de México. México DF, México. Lozoya X. 1984. Bibliografía básica sobre herbolaria medicinal en México. Secretaría de desarrollo urbano y ecología, México DF.

La vegetación de la laguna de las ilusiones. Ed. Universidad Juárez Autónoma de Tabasco, Villahermosa, Tabasco, México. Magaña AMA. 1995. Catálogo de nombres vulgares y científicos de plantas de Tabasco. Ed. Universidad Juárez Autónoma de Tabasco, Villahermosa, Tabasco, México. Magaña AMA. 2010. Vegetación y flora del municipio de Paraíso.

Lans CA. 2006. Ethnomedicines used in Trinidad and Tobago for urinary problems and diabetes mellitus. J Ethnobiol Ethnomed 2:45. León H, Vásquez MA. 2003. Plantas útiles de San Juan Cacahuatepec, Costa de Oaxaca, México. Ed. Dirección General de Culturas Populares e Indígenas, México DF, México. Lewis MP, Gary FS, Charles DF. 2016.

Lot A, Chiang F. 1986. Manual de herbario. Consejo Nacional Flora de México. México DF, México. Lozoya X. 1984. Bibliografía básica sobre herbolaria medicinal en México. Secretaría de desarrollo urbano y ecología, México DF.

Luna LM, González AR, de la Cruz I. 2006. Transmisión del conocimiento herbolario entre los zoques de Rayón, Chiapas, En Aramoni D, Lee TA, Lisbona M. Presencia zoque. Una aproximación multidisciplinaria. Ed. Universidad de Ciencias y Artes de Chiapas, México.

Madsen W, 1955. Hot and Cold in the Universe of San Francisco Tecospa, Valley. J Am Folk 68: 123 139. Magaña AMA. 1988.

Manual de agroforesteria. Proyecto manejo sostenible de recursos naturales. ISBN: 978-99953-65-00San Lorenzo, Paraguay. Córdoba, O. J. (2012). Comportamiento eco fisiológico.

University of KwaZulu-Natal. Scottsville, Pietermaritzburg. South África. Cavalcante, F. S. (2004). A Importancia da Mamona para a agricultura familiar no estado da Paraíba. Revista electrónica de ciencias, 27. Chávez, D. (2007). 


\section{[Title in Times New Roman and Bold Type No. 14 in English and Spanish]}

Last Name (IN CAPITAL LETTERS), First Name of 1st Author $\dagger^{*}$, Last Name (IN CAPITAL LETTERS), First Name of 1st Co-Author, Last Name (IN CAPITAL LETTERS), First Name of 2nd CoAuthor and Last Name (IN CAPITAL LETTERS), First Name of 3rd Co-Author.

Author's Institution of Affiliation including dependency (in Times New Roman No.10 and Italics)

\section{$\underline{\text { International Identification of Science - Technology and Innovation }}$}

$1^{\text {st }}$ Author ID: (ORC ID - Researcher ID Thomson, arXiv Author ID - PubMed Author ID - Open ID) and CVU $1^{\text {st }}$ Author: (Scholar-PNPC or SNI-CONACYT) (No.10 Times New Roman)

$1^{\text {st }}$ Co-author ID: (ORC ID - Researcher ID Thomson, arXiv Author ID - PubMed Author ID - Open ID) and CVU $1^{\text {st }}$ Coauthor: (Grantee-PNPC or SNI-CONACYT) (No.10 Times New Roman)

$2^{\text {nd }}$ Co-author ID: (ORC ID - Researcher ID Thomson, arXiv Author ID - PubMed Author ID - Open ID) and CVU $2^{\text {nd }}$ Coauthor: (Scholar-PNPC or SNI-CONACYT) (No.10 Times New Roman)

$3^{\text {rd }}$ Co-author ID: (ORC ID - Researcher ID Thomson, arXiv Author ID - PubMed Author ID - Open ID) and CVU $3^{\text {rd }}$ Coauthor: (Grantee-PNPC or SNI-CONACYT) (No.10 Times New Roman)

(Indicate Date of Submission: Month, Day, Year); Accepted (Indicate Date of Acceptance: Exclusive Use by ECORFAN)

Citation: First letter (IN CAPITAL LETTERS) of the Name of the 1st Author. Last Name, First Letter (IN CAPITAL LETTERS) of the 1st Co-author's Name. Last name, first letter (IN CAPITAL LETTERS) of the 2nd Co-author's name. Last Name, First Letter (IN CAPITAL LETTERS) of the Name of the 3rd Co-author. Last name

Institutional Mail [Times New Roman No.10].

First letter (IN CAPITAL LETTERS) of the Name Editors. Surname (eds.) Title of the Handbook [Times New Roman No.10], Selected Topics of the corresponding area @ECORFAN-Filial, Year. 


\section{Abstract}

Text written in Times New Roman No.12, single spaced, in English.

Indicate (3-5) keywords in Times New Roman and Bold No.12.

\section{Introduction}

Text written in Times New Roman No.12, single spaced.

Explanation of the topic in general and explain why it is important.

What is its added value with respect to other techniques?

Focus clearly on each of its characteristics.

Clearly explain the problem to be solved and the central hypothesis.

Explanation of the sections of the Chapter.

Development of Sections and Sections of the Chapter with subsequent numbering.

[Title in Times New Roman No.12, single space and Bold].

Development of Chapters in Times New Roman No.12, single space.

\section{Inclusion of Graphs, Figures and Tables-Editables}

In the content of the Chapter, all graphs, tables and figures must be editable in formats that allow modifying size, type and number of letters, for editing purposes, these must be in high quality, not pixelated and must be noticeable even if the image is reduced to scale.

[Indicating the title in the upper part with Times New Roman No.12 and Bold, indicating the font in the lower part centered with Times New Roman No. 10].

Table 1.1 Title

\begin{tabular}{|l|l|r|}
\hline \multicolumn{1}{|c|}{ Variable } & \multicolumn{1}{c|}{ Description } & Value \\
\hline $\mathrm{P}_{1}$ & Partition 1 & 481.00 \\
\hline $\mathrm{P}_{2}$ & Partition 2 & 487.00 \\
\hline $\mathrm{P}_{3}$ & Partition 3 & 484.00 \\
\hline $\mathrm{P}_{4}$ & Partition 4 & 483.50 \\
\hline $\mathrm{P}_{5}$ & Partition 5 & 484.00 \\
\hline $\mathrm{P}_{6}$ & Partition 6 & 490.79 \\
\hline $\mathrm{P}_{7}$ & Partition 7 & 491.61 \\
\hline
\end{tabular}

Source:

(They should not be images, everything should be editable) 
Figure 1.1 Title

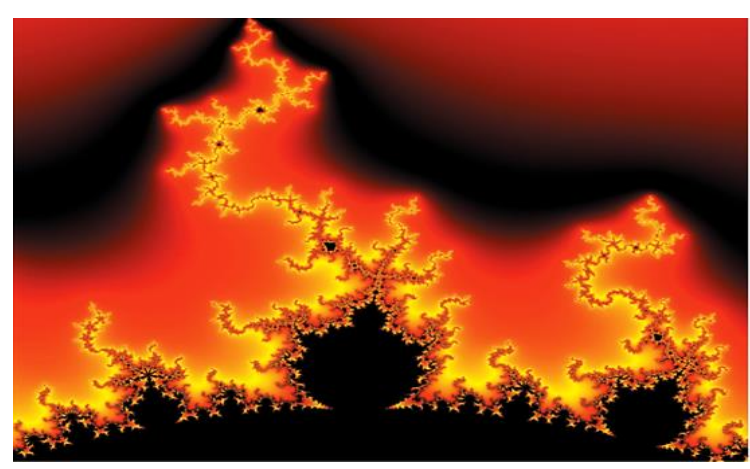

Source:

(They should not be images, everything should be editable)

Graphic 1.1 Title

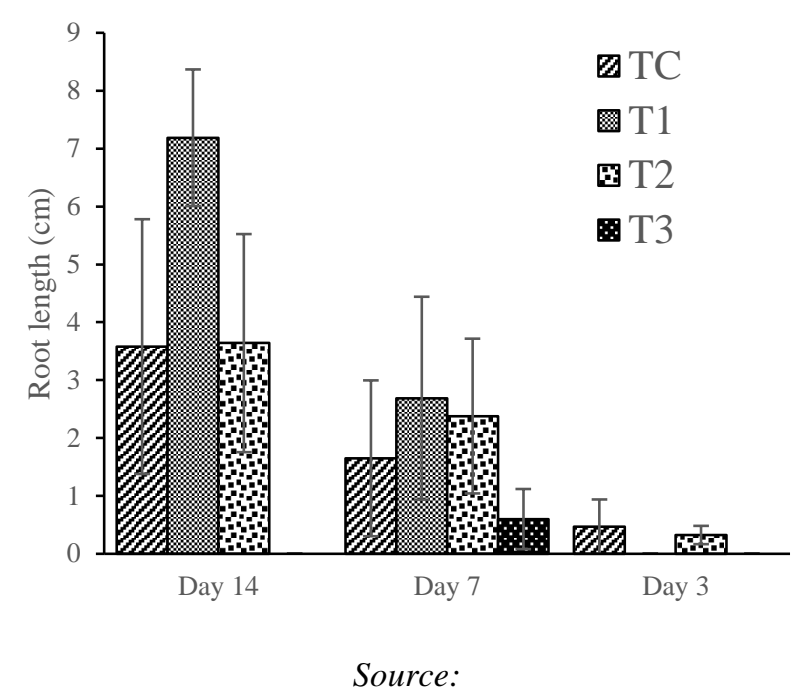

(They should not be images, everything should be editable)

Each Chapter should be presented separately in 3 Folders: a) Figures, b) Graphs and c) Tables in .JPG format, indicating the number in Bold and the sequential Title.

For the use of Equations, indicate as follows:

$\int_{\lim ^{-1}}^{\lim ^{1}}=\int \frac{\lim ^{1}}{\lim ^{-1}}=\left[\frac{1(-1)}{\lim }\right]^{2}=\frac{(0)^{2}}{\lim }=\sqrt{\lim }=0=0 \rightarrow \propto$

They should be editable and with numbering aligned on the far right.

\section{Methodology to be developed}

Give the meaning of the variables in linear wording and it is important to compare the criteria used.

\section{Results}

The results should be per section of the Chapter.

\section{Annexes}

Tables and appropriate sources. 


\section{Acknowledgements}

Indicate if they were financed by any Institution, University or Company.

\section{Conclusions}

Clearly explain the results obtained and the possibilities for improvement.

\section{References}

Use the APA system. They should not be numbered or bulleted, however, if numbering is necessary, it will be because there is a reference or mention in some part of the Chapter.

\section{Technical Data Sheet}

Each Chapter should be presented in a Word document (.docx):

Name of the Handbook

Title of the Chapter

Abstract

Keywords

Sections of the Chapter, e.g:

1. Introduction

2. Description of the method

3. Analysis based on demand curve regression

4. Results

5. Acknowledgement

6. Conclusions

7. References

Name of Author(s)

Correspondence E-mail to Author

References

\section{Intellectual Property Requirements for its edition:}

- Author's and co-authors' autographic signature in blue colour of the originality form.

- Author's and co-authors' autgraphic signature in blue colour of the author and co-authors' acceptance form. 


\section{Reservation to the Editorial Policy}

ECORFAN Handbooks reserves the right to make any editorial changes required to bring the Scientific Work into compliance with the ECORFAN Handbooks Editorial Policy. Once the Scientific Work has been accepted in its final version, ECORFAN Handbooks will send the author the proofs for review. ECORFAN ${ }^{\circledR}$ will only accept the correction of errata and errors or omissions arising from the editing process of the journal, reserving in its entirety the rights of authorship and dissemination of content. Deletions, substitutions or additions that alter the formation of the Scientific Work will not be accepted.

\section{Code of Ethics - Good Practices and Statement of Solution to Editorial Conflicts}

Declaration of Originality and unpublished character of the Scientific Work, of Authorship, on the obtaining of data and interpretation of results, Acknowledgements, Conflict of interests, Assignment of rights and distribution.

The Management of ECORFAN-Mexico, S.C. claims to the Authors of the Scientific Work that its content must be original, unpublished and of Scientific, Technological and Innovation content in order to submit it for evaluation.

The Authors signing the Scientific Work must be the same who have contributed to its conception, realization and development, as well as to the obtaining of the data, the interpretation of the results, its writing and revision. The Corresponding Author of the proposed Scientific Work should fill in the following form.

\section{Title of the Scientific Work:}

- The submission of a Scientific Paper to ECORFAN Handbooks implies the author's commitment not to submit it simultaneously to the consideration of other serial publications. To do so, he/she must complete the Originality Form for his/her Scientific Paper, unless it is rejected by the Referee Committee, it may be withdrawn.

- $\quad$ None of the data presented in this Scientific Work has been plagiarized or invented. The original data are clearly distinguishable from those already published. And we are aware of the PLAGSCAN test, if a positive plagiarism level is detected, we will not proceed to refereeing.

- The references on which the information contained in the Scientific Work is based are cited, as well as theories and data from other previously published Scientific Works.

- The authors sign the Authorization Form for their Scientific Work to be disseminated by the means that ECORFAN-Mexico, S.C. in its Holding Mexico considers pertinent for the dissemination and diffusion of their Scientific Work, ceding their Scientific Work Rights.

- Consent has been obtained from those who have provided unpublished data obtained through verbal or written communication, and such communication and authorship are properly identified.

- The Author and Co-Authors signing this work have participated in its planning, design and execution, as well as in the interpretation of the results. Likewise, they critically reviewed the work, approved its final version and agree with its publication.

- $\quad$ No signature responsible for the work has been omitted and the criteria for Scientific Authorship have been met.

The results of this Scientific Work have been interpreted objectively. Any results contrary to the views of the signatories are stated and discussed in the Scientific Work 


\section{Copyright and Access}

The publication of this Scientific Work implies the assignment of the copyright to ECORFAN-Mexico, S.C. in its Holding Mexico for its ECORFAN Handbooks, which reserves the right to distribute on the Web the published version of the Scientific Work and the availability of the Scientific Work in this format implies for its Authors the compliance with the provisions of the Law of Science and Technology of the United Mexican States, regarding the obligation to allow access to the results of Scientific Research.

Title of the Scientific Work:

\begin{tabular}{|l|c|}
\hline \multicolumn{1}{|c|}{ Name and surname(s) of Contact Author and Co-authors } & Signature \\
\hline 1. & \\
\hline 2. & \\
\hline 3. & \\
\hline 4. & \\
\hline
\end{tabular}

\section{Principles of Ethics and Editorial Conflict Resolution Statement}

\section{Editor's Responsibilities}

The Editor undertakes to guarantee the confidentiality of the evaluation process, and may not reveal the identity of the Authors to the Referees, nor may he/she reveal the identity of the Referees at any time.

The Editor assumes the responsibility of duly informing the Author of the stage of the editorial process in which the submitted text is, as well as of the resolutions of the Double Blind Arbitration.

The Editor must evaluate manuscripts and their intellectual content without distinction of race, gender, sexual orientation, religious beliefs, ethnic origin, nationality, or political philosophy of the Authors.

The Editor and its editorial staff of ECORFAN® Holdings will not disclose any information about the submitted Scientific Work to anyone other than the corresponding Author.

The Editor must make fair and impartial decisions and ensure a fair peer review process.

\section{Responsibilities of the Editorial Board}

The description of the peer review process is made known by the Editorial Board so that the Authors are aware of the evaluation criteria and will always be ready to justify any controversy in the evaluation process. In case of Plagiarism Detection to the Scientific Work, the Committee notifies the Authors for Violation of the Right of Scientific, Technological and Innovation Authorship.

\section{Responsibilities of the Referee Committee}

The Referees undertake to notify any unethical conduct on the part of the Authors and to point out any information that may be a reason to reject the publication of the Scientific Work. In addition, they must undertake to keep confidential the information related to the Scientific Work they evaluate.

Any manuscript received for refereeing must be treated as a confidential document, not to be shown or discussed with other experts, except with the permission of the Editor.

Referees should conduct themselves in an objective manner; any personal criticism of the Author is inappropriate.

Referees should express their views clearly and with valid arguments that contribute to the Scientific, Technological and Innovation achievements of the Author.

Referees should not evaluate manuscripts in which they have conflicts of interest and which have been notified to the Editor before submitting the Scientific Work for evaluation. 


\section{Responsibilities of Authors}

Authors must guarantee that their Scientific Works are the product of their original work and that the data have been obtained in an ethical manner.

Authors must guarantee that they have not been previously published or that they are not being considered in another serial publication.

Authors must strictly follow the rules for the publication of Scientific Works defined by the Editorial Board.

Authors should consider that plagiarism in all its forms constitutes unethical editorial conduct and is unacceptable; consequently, any manuscript that incurs in plagiarism will be eliminated and will not be considered for publication.

Authors should cite publications that have been influential in the nature of the Scientific Work submitted for refereeing.

\section{Information Services}

\section{Indexing - Bases and Repositories}

RESEARCH GATE (Germany)

MENDELEY (Bibliographic Reference Manager)

GOOGLE SCHOLAR (Citation Indexes-Google)

REDIB (Ibero-American Network of Innovation and Scientific Knowledge- CSIC)

\section{Editorial Services}

Citation Identification and H Index

Originality and Authorization Format Management

Handbooks Testing with PLAGSCAN

Evaluation of Scientific Work

Issuance of Referee Certificate

Scientific Work Editing

Web Layout

Indexing and Repository

Publication of Scientific Work

Scientific Work Certificate

Invoicing for Publishing Services

\section{Editorial Policy and Administration}

143 - 50 Itzopan, Ecatepec de Morelos - Mexico. Tel: +52 1556159 2296, +52 1551260 0355, +52 1 556034 9181; E-mail: contact@ecorfan.org www.ecorfan.org 


\section{ECORFAN®}

Editor in Chief

VARGAS-DELGADO, Oscar. PhD

Executive Director

RAMOS-ESCAMILLA, María. PhD

Editorial Director

PERALTA-CASTRO, Enrique. MsC

Web Designer

ESCAMILLA-BOUCHAN, Imelda. PhD

Web Diagrammer

LUNA-SOTO, Vladimir. PhD

Editorial Assistant

TREJO-RAMOS, Iván. BsC

Translator

DÍAZ-OCAMPO, Javier. BsC

Philologist

RAMOS-ARANCIBIA, Alejandra. BsC

\section{Advertising and Sponsorship}

(ECORFAN® - Mexico - Bolivia - Spain - Ecuador - Cameroon - Colombia - El Salvador - Guatemala - Nicaragua - Peru - Paraguay - Democratic Republic of The Congo - Taiwan), sponsorships@ecorfan.org

\section{Site Licenses}

03-2010-032610094200-01-For printed material, 03-2010-031613323600-01-For electronic material, 03-2010-032610105200-01-For photographic material, 03-2010-032610115700-14-For Compilation of Data, 04 -2010-031613323600-01-For its Web page, 19502-For Ibero-American and Caribbean Indexing, 20-281 HB9-For Latin American Indexing in the Social Sciences and Humanities, 671-For Indexing in Electronic Scientific Journals in Spain and Latin America, 7045008-For dissemination and publication in the Ministry of Education and Culture-Spain, 25409-For its repository in the University Library-Madrid, 16258-For its indexing in Dialnet, 20589-For Indexing in the Directory in the countries of Iberoamerica and the Caribbean, 15048-For the international registration of Congresses and Colloquia. financingprograms@ecorfan.org

\section{Management Offices}

143 - 50 Itzopan, Ecatepec de Morelos - Mexico.

21 Santa Lucia, CP-5220. Libertadores -Sucre - Bolivia.

38 Matacerquillas, CP-28411. Moralzarzal -Madrid-Spain.

18 Marcial Romero, CP-241550. Avenue, Salinas I - Santa Elena-Ecuador.

1047 Avenida La Raza - Santa Ana, Cusco-Peru.

Boulevard de la Liberté, Immeuble Kassap, CP-5963.Akwa- Douala-Cameroon.

Avenida Suroeste, San Sebastian - León-Nicaragua.

31 Kinshasa 6593- Republique Démocratique du Congo.

Avenida San Quentin, R 1-17 Miralvalle - San Salvador-El Salvador.

16 kilometers, U.S. highway, Terra Alta house, D7 Mixco Zone 1-Guatemala.

105 Alberdi Rivarola Capitán, CP-2060. Luque City- Paraguay.

69 Street YongHe District, Zhongxin. Taipei-Taiwan.

43 Street \# 30 -90 B. El Triunfo CP.50001. Bogotá-Colombia. 
